SANDIA REPORT

SAND94-2320 • UC-814

Unlimited Release

Printed June 1996

Yucca Mountain Site Characterization Project

\title{
Bench-Scale Experimental Determination of the Thermal Diffusivity of Crushed Tuff
}

E. E. Ryder, R. E. Finley, J. T. George, C. K. Ho,

R. S. Longenbaugh, J. R. Connolly

\section{Prepared by \\ Sandia National Laboratories \\ Albuquerque, New Mexico 87185 and Livermore, California 94550 for the United States Department of Energy under Contract DE-AC04-94AL85000

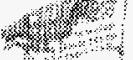 \\ Approved for public release; distribution is unlimited.}

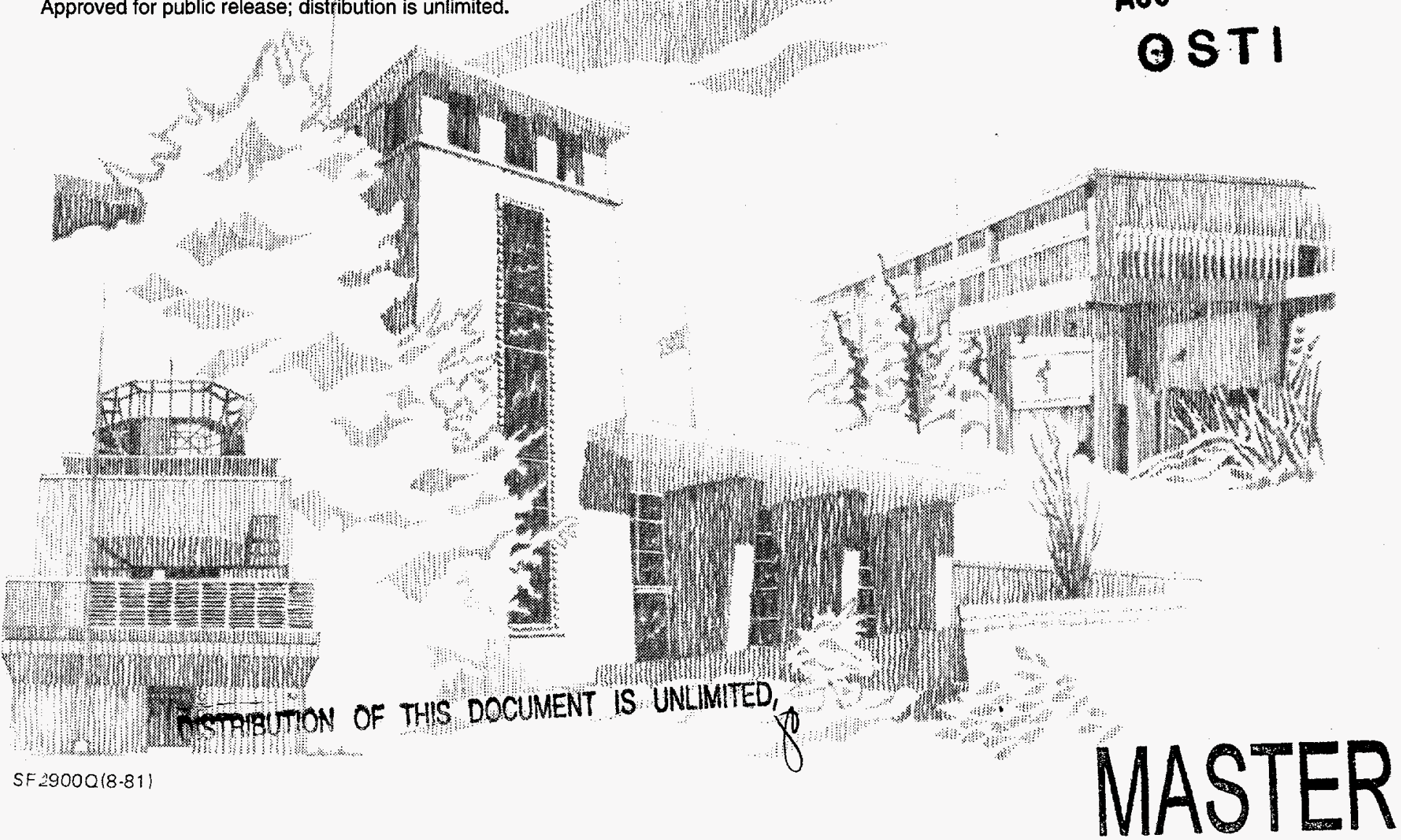

RECEIVED AUG 151996 OSTI 
"Prepared by Yucca Mountain Site Characterization Project (YMSCP) participants as part of the Civilian Radioactive Waste Management Program (CRWM). The YMSCP is managed by the Yucca Mountain Project Office of the U.S. Department of Energy, DOE Field Office, Nevada (DOE/NV). YMSCP work is sponsored by the Office of Geologic Repositories (OGR) of the DOE Office of Civilian Radioactive Waste Management (OCRWM)."

Issued by Sandia National Laboratories, operated for the United States Department of Energy by Sandia Corporation.

NOTICE: This report was prepared as an account of work sponsored by an agency of the United States Government. Neither the United States Government nor any agency thereof, nor any of their employees, nor any of their contractors, subcontractors, or their employees, makes any warranty, express or implied, or assumes any legal liability or responsibility for the accuracy, completeness, or usefulness of any information, apparatus, product, or process disclosed, or represents that its use would not infringe privately owned rights. Reference herein to any specific commercial product, process, or service by trade name, trademark, manufacturer, or otherwise, does not necessarily constitute or imply its endorsement, recommendation, or favoring by the United States Government, any agency thereof or any of their contractors or subcontractors. The views and opinions expressed herein do not necessarily state or reflect those of the United States Government, any agency thereof or any of their contractors.

Printed in the United States of America. This report has been reproduced directly from the best available copy.

Available to DOE and DOE contractors from

Office of Scientific and Technical Information

PO Box 62

Oak Ridge, TN 37831

Prices available from (615) 576-8401, FTS 626-8401

Available to the public from

National Technical Information Service

US Department of Commerce

5285 Port Royal Rd

Springfield, VA 22161

NTIS price codes

Printed copy: A11

Microfiche copy: A01 


\section{DISCLAIMER}

Portions of this document may be illegible electronic image products. Images are produced from the best available original document. 


\title{
Bench-Scale Experimental Determination of the Thermal Diffusivity of Crushed Tuff
}

\author{
E. E. Ryder, R. E. Finley, J. T. George, C. K. Ho \\ R. S. Longenbaugh, J. R. Connolly ${ }^{t}$ \\ Sandia National Laboratories \\ Albuquerque, NM 87185 \\ 'Department of Geology and Institute of Meteoritics \\ University of New Mexico \\ Albuquerque, NM 87131
}

\begin{abstract}
A bench-scale experiment was designed and constructed to determine the effective thermal diffusivity of crushed tuff. Crushed tuff particles ranging from $12.5 \mathrm{~mm}$ to $37.5 \mathrm{~mm}(0.5 \mathrm{in}$. to 1.5 in.) were used to fill a cylindrical volume of $1.58 \mathrm{~m}^{3}$ at an effective porosity of 0.48 . Two iterations of the experiment were completed; the first spanning approximately 502 hours and the second 237 hours. Temperatures near the axial heater reached $700^{\circ} \mathrm{C}$, with a significant volume of the test bed exceeding $100^{\circ} \mathrm{C}$. Three post-test analysis techniques were used to estimate the thermal diffusivity of the crushed tuff. The first approach used nonlinear parameter estimation linked to a one-dimensional radial conduction model to estimate thermal diffusivity from the first 6 hours of test data. The second method used the multiphase TOUGH2 code in conjunction with the first 20 hours of test data not only to estimate the crushed tuff's thermal diffusivity, but also to explore convective behavior within the test bed. Finally, the nonlinear conduction code COYOTEII was used to determine thermal properties based on 111 hours of cool-down data. The post-test thermal diffusivity estimates of $5.0 \times 10^{-7} \mathrm{~m}^{2} / \mathrm{s}$ to $6.6 \times 10^{-7} \mathrm{~m}^{2} / \mathrm{s}$ were converted to effective thermal conductivities and compared to estimates obtained from published porosity-based relationships. No obvious match between the experimental data and published relationships was found to exist; however, additional data for other particle sizes and porosities are needed.
\end{abstract}




\section{PREFACE}

The work documented in this report was performed for the U.S. Department of Energy, Yucca Mountain Site Characterization Project Office, for contract DE-AC0494AL85000; under work descriptions WBS 1.2.2.4.3 and WBS 1.2.4.6.2, Quality Assurance (QA) grading reports 1.2.2.4.3 Revision 00 and 1.2.4.6.2 Revision 00. This work was conducted using controls specified in Sandia National Laboratories Work Agreement WA-111, Revision 00. Data obtained from the experiment documented in this report has been assigned the following data tracking number (DTN):

SNL10012694001.005.

\section{ACKNOWLEDGMENTS}

The authors would like to thank Tom Doering, Archie Richardson, Steve Sobolik, Ellen Dunn, Sharon Shannon, and Corinne Taylor for their assistance in the completion of this experiment and the preparation of this document. The authors also thank Bill Glassley of Lawrence Livermore National Laboratory for his identification of the chemical depositions obtained during the decommissioning of the experiment. 


\section{TABLE OF CONTENTS}

1. Introduction

1.1 Background ................................................................................. 1-1

1.2 Regulatory and Project Framework................................................... 1-3

1.3 Thermal Assessments Related to Backfill .............................................. 1-4

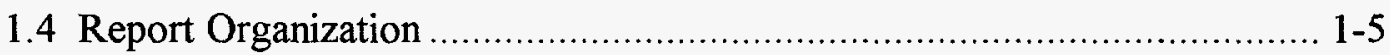

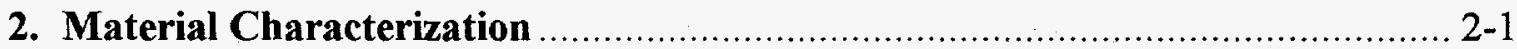

2.1 Hand Sample Descriptions ................................................................... 2-1

2.2 Thin Section Description and Point Count ….......................................... 2-3

2.3 Whole-Rock Chemical Analysis ......................................................... 2-4

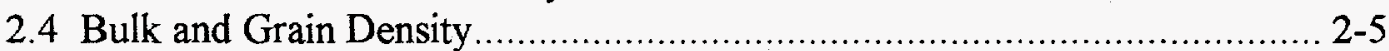

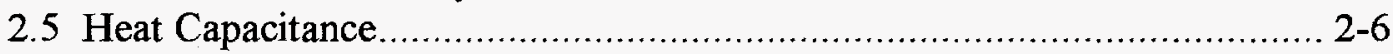

2.5.1 Grain Specific Heat ........................................................... 2-7

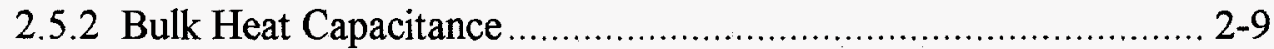

2.6 Intact Thermal Conductivity .............................................................. 2-11

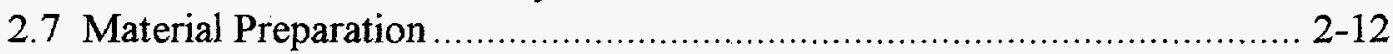

2.7.1 Material Chosen for Test .................................................. 2-12

2.7.2 Particle Shape and Abrasivity ............................................. 2-14

2.8 Representativeness of Selected Material................................................ 2-14

2.8.1 Chemical Composition and Structure ..................................... 2-16

2.8.2 Density, Porosity, Specific Heat, and Thermal Conductivity ...... 2-16

2.8.3 Crushed Particle Shapes and Sizes......................................... 2-17

2.8.4 Summary of Material Representativeness................................ 2-20

3. Test Apparatus, Data, and Observations ................................................... 3-1

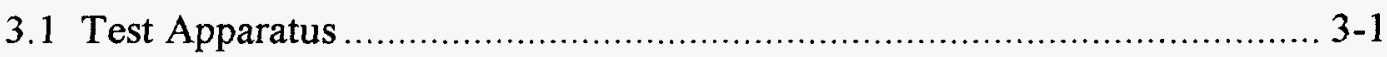

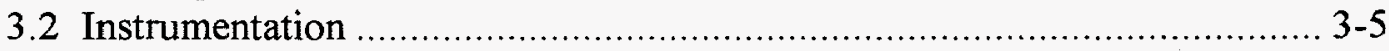

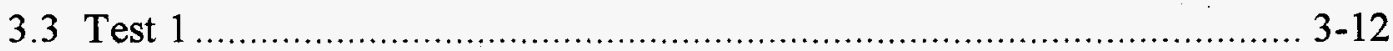

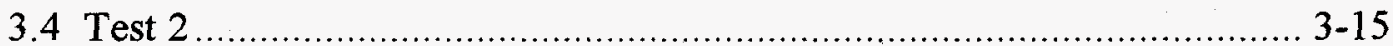

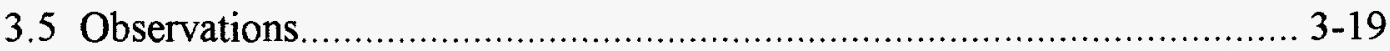

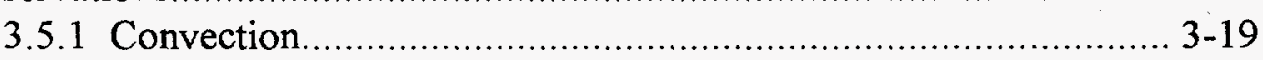

3.5.2 Moisture Content and Circulation......................................... 3-19

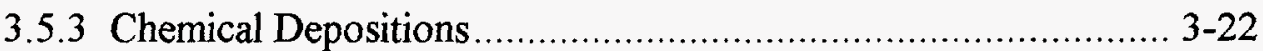

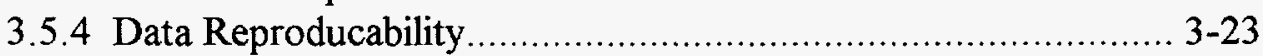

3.5.5 Conduction Along Thermocouple Probes ….......................... 3-26

3.6 Summary of Tests and Observations ................................................ 3-28 
4.1 Parameter Estimation Analyses ...................................................... 4-1

4.1.1 Parameter Estimation Model Description................................. 4-2

4.1.2 Experimental Data Selected for Analysis ............................... 4-3

4.1.3 Parameter Estimation Results ............................................... 4-4

4.1.4 Summary of Parameter Estimation Analyses ........................... 4-9

4.2 TOUGH2 Analyses.................................................................. 4-10

4.2.1 TOUGH2 Model Description ......................................... 4-11

4.2.2 Iterative Estimation of Thermal Diffusivity Using TOUGH2 ..... 4-13

4.2.3 Sensitivity Analyses and Additional Studies ......................... 4-21

4.2.4 Summary of TOUGH2 Analyses...................................... 4-33

4.3 Conduction Analyses of Cool-Down Data........................................ 4-34

4.4 Summary of Post-Test Analyses Results ....................................... 4-42

5. Comparisons to Published Relationships ............................................. 5-1

5.1 Estimates of Equivalent Thermal Conductivities................................ 5-2

5.2 Comparisons to Geometry-Independent Relationships........................... 5-4

5.2.1 Parallel and Series Approximations..................................... 5-4

5.2.2 Hashin and Shtrikman [1962] Bounds ............................. 5-7

5.3 Comparisons to Geometry-Dependent Relationships ............................. 5-7

5.3.1 Pore-Shape Models ............................................................. 5-9

5.3.2 Particle-Shape Models................................................... 5-10

5.4 Effect of Particle Size ................................................................ 5-15

5.5 Large-Particle Relationship ....................................................... 5-15

5.6 Summary of Comparisons ........................................................ 5-16

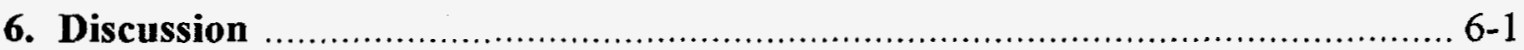

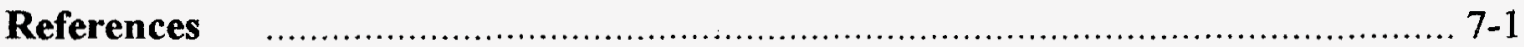

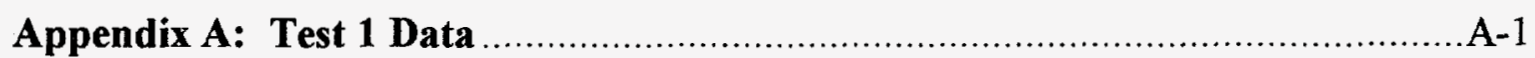

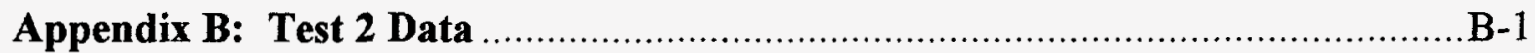

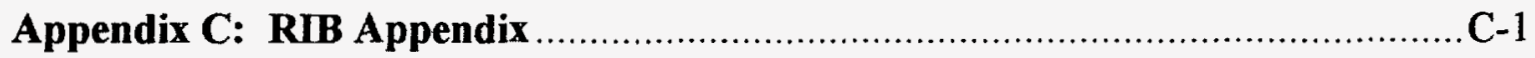




\section{LIST OF FIGURES}

Figure 1-1. In Drift Emplacement Configuration.

$1-2$

Figure 2-1. Map Showing Relative Location of Fran Ridge to

Potential Repository

Figure 2-2. Calculated Grain Specific Heat of Fran Ridge Tuff.

2-10

Figure 2-3. Particle Size Distribution for Crushed Tuff Obtained from Hazen Research, Inc.

Figure 2-4. Normalized Plot of Crushed Tuff Particle Shapes

Used in Experiment.

Figure 2-5. Comparison of Particle Size Distributions for Tuff Broken by Various Methods.

Figure 2-6. Normalized Plot of Tuff Particle Shapes Obtained from

CSM Linear Cutter Experiments

Figure 3-1. Schematic of Support Structure and Test Cylinder

Figure 3-2. Test Apparatus Showing Radial Insulation 3-3

Figure 3-3. Test Apparatus Showing Insulation Cap $3-4$

Figure 3-4. Detail of Heater Showing Shielded Thermocouple and Clamp Assembly

Figure 3-5. Schematic Showing Locations of Thermocouples and Thermocouple Probes 3-8

Figure 3-6. Test Apparatus Showing Relative Locations of Thermocouple Probes. 3-9

Figure 3-7. Detail of Probe 6 $3-10$

Figure 3-8. Test Apparatus Showing Locations of Thermocouples Attached to the Surface of the Steel Cylinder

Figure 3-9. Schematic of Feedback Control Loop. 
Figure 3-10. Volumes Represented by Grab Samples and Associated Initial Moisture Contents.

Figure 3-11. Isothermal Contours for Test 1

Figure 3-12. Isothermal Contours for Test 2

Figure 3-13. Comparison of Heater Surface Temperature Data at Plane 7 for Tests 1 and 2

Figure 3-14. Comparison of Temperature Data from Plane 7 of Probe 3 for Tests 1 and 2

Figure 3-15. Comparison of Data Obtained at 22 hours in Test 1 from Probe 6 and from Plane 6 of Probes 1, 2, and 3

Figure 3-16. Comparison of Data Obtained at 130 hours in Test 1 from Probe 6 and from Plane 6 of Probes 1, 2, and 3

Figure 4-1 One Dimensional Computational Mesh Used for Parameter Estimation. 4-3

Figure 4-2. Experimental Data from Probe 3 Used for Parameter Estimation Modeling of Test 1

Figure 4-3. Experimental Data from Probe 3 Used for Parameter Estimation Modeling of Test 2

Figure 4-4. Experimental Data and Simulated Temperature Predictions $\left(\alpha=6.18 \times 10^{-7} \mathrm{~m}^{2} / \mathrm{s}\right.$ ) for Test 1 , Plane 6 , Probe 3 4-7

Figure 4-5. Experimental Data and Simulated Temperature Predictions $\left(\alpha=6.01 \times 10^{-7} \mathrm{~m}^{2} / \mathrm{s}\right.$ ) for Test 1 , Plane 7 , Probe 3

Figure 4-6. Experimental Data and Simulated Temperature Predictions $\left(\alpha=6.88 \times 10^{-7} \mathrm{~m}^{2} / \mathrm{s}\right)$ for Test 2 , Plane 6 , Probe 3 4-8

Figure 4-7. Experimental Data and Simulated Temperature Predictions $\left(\alpha=6.09 \times 10^{-7} \mathrm{~m}^{2} / \mathrm{s}\right.$ ) for Test 2 , Plane 7 , Probe 3 4-8

Figure 4-8. Two Dimensional, Radial TOUGH2 Model Used to Simulate the Experiment

Figure 4-9. Experimental and Numerical Temperatures Along Probe 1 and Probe 3 at 6000 seconds of Heating for Various Thermal Conductivities 
Figure 4-10. Experimental and Numerical Temperatures Along Probe 1 and Probe 3 at 20 hours of Heating for Various Thermal Conductivities

Figure 4-11. Locations of Intersection Points at 6000 seconds and 20 hours.

Figure 4-12. Experimental and Numerical Temperatures Along Probe 1 and Probe 3 at Two Times for a Thermal Conductivity of $0.6 \mathrm{~W} / \mathrm{m}-\mathrm{K}$.

Figure 4-13. Gas Velocity and Temperature Fields After 20 hours of Heating Using a Thermal Conductivity of $0.6 \mathrm{~W} / \mathrm{m}-\mathrm{K}$.

Figure 4-14. Temperatures Along Probe 1 and Probe 3 at 5 hours Using Two Different Bulk Permeabilities.

Figure 4-15. Temperatures Along Probe 1 and Probe 3 at 20 hours Using Two Different Bulk Permeabilities.

Figure 4-16. Temperature Profiles for Experiment 2

Figure 4-17. Gas Velocity, Temperature, and Liquid Saturation Fields After 1000 seconds of Heating with and Initial Saturation of 0.03 Using a Thermal Conductivity of $1.0 \mathrm{~W} / \mathrm{m}-\mathrm{K}$

Figure 4-18. Gas Velocity, Temperature, and Liquid Saturation Fields After 3000 seconds of Heating with and Initial Saturation of 0.03 Using a Thermal Conductivity of $1.0 \mathrm{~W} / \mathrm{m}-\mathrm{K}$

Figure 4-19. Gas Velocity, Temperature, and Liquid Saturation Fields After 6000 seconds of Heating with and Initial Saturation of 0.03 Using a Thermal Conductivity of $1.0 \mathrm{~W} / \mathrm{m}-\mathrm{K}$

Figure 4-20. TOUGH2 Simulated Temperatures Along Probe 3 for Two Different Initial Conditions 4-30

Figure 4-21. Effect of Heater Length on Temperature Profiles After 1 day of Heating in a Completely Insulated System. 4-32

Figure 4-22. Gas Velocity and Temperature Fields After 5 hours of Cooling $4-35$

Figure 4-23. Gas Velocity and Temperature Fields After 1 day of Cooling. 4-36

Figure 4-24. Gas Velocity and Temperature Fields After 3 days of Cooling. 4-37 
Figure 4-25. Axisymmetric Mesh Used Analyses of Cool-Down Data.

Figure 4-26. Initial Conditions of Cool-Down Analyses

Figure 4-27. Comparison Between Experimental Data and Simulated Temperatures Along Probe 1, Test 1

Figure 4-28. Comparison Between Experimental Data and Simulated Temperatures Along Probe 2, Test 1

Figure 4-29. Comparison Between Experimental Data and Simulated Temperatures Along Probe 3, Test 1

Figure 5-1. Series and Parallel Models for the Effective Thermal Conductivity of a Fluid-Saturated Rock

Figure 5-2. Comparison of Experimental Estimates of Thermal Conductivity to Series, Geometric Mean, and Parallel Approximations.

Figure 5-3. Comparison of Experimental Estimates of Thermal Conductivity to H-S Upper and Lower Bounds

Figure 5-4. Comparison of Experimental Estimates of Thermal Conductivity to Spheroidal Pore Model Estimates Assuming Oblate Pore Shapes.

Figure 5-5. Comparison of Experimental Estimates of Thermal Conductivity to Spheroidal Pore Model Estimates Assuming Prolate Pore Shapes.

Figure 5-6. Comparison of Experimental Estimates of Thermal Conductivity to DeVries Particle Model.

Figure A-1. Comparison of Data from Probes 4 and 5 for Test 1 A-4

Figure A-2. Data Related to Lower Boundary Condition Modeled in TOUGH2 Analyses

Figure A-3. Data Related to Lower Boundary Condition Modeled in Cool-Down Analyses

Figure A-4. Data Related to Constant Temperature Boundary Condition Applied to Insulation Surface in Cool-Down Analyses

Figure A-5. Power Data for the First 20 hours of Test 1 A-10

Figure A-6. Complete Power Data for Test 1 A-11 
Figure A-7. Test 1 Temperature Data. A-12

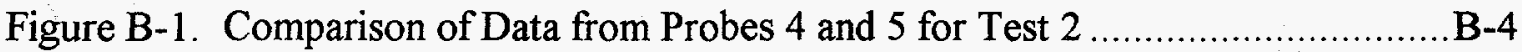

Figure B-2. Data Related to Lower Boundary Condition Modeled in TOUGH2 Analyses.

Figure B-3. Power Data for the First 20 hours of Test 2 B-9

Figure B-4. Complete Power Data for Test 2 B-10

Figure B-5. Test 2 Temperature Data..... B-11 


\section{LIST OF TABLES}

Table 1-1. 10 CFR 60 References to Backfill. $1-3$

Table 2-1. Results of Thin-Section Modal Analysis......................................... 2-4

Table 2-2. Whole Rock Chemical Analysis of Fran Ridge Tuff.............................. 2-5

Table 2-3. Estimated Normative Mineral Phases for Fran Ridge Tuff...................... 2-6

Table 2-4. Measure Bulk and Grain Densities for Fran Ridge Tuff........................... 2-6

Table 2-5. Whole Chemical Analysis Normalized for Calculation of Specific Heat ...... 2-8

Table 2-6. Heat Capacity Coefficients Used in Equation 3.2 for Rock-

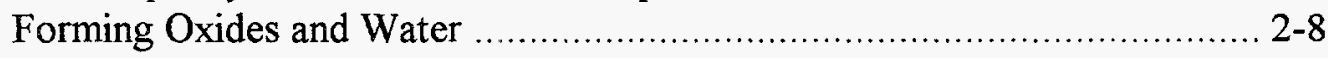

Table 2-7. Laboratory Measurements of Fran Ridge Thermal Conductivity.............. 2-11

Table 2-8. Cumulative Weight Percent Passing versus Particle Size ....................... 2-12

Table 2-9. Comparison of Average Fran Ridge Thermal Conductivities to Those Obtained for the TSw2 Unit from NRG-6.

Table 4-1. Test 1 Parameter Estimation Results................................................ 4-6

Table 4-2. Test 2 Parameter Estimation Results............................................... 4-9

Table 4-3. Test-to-Test Comparison of Estimated Bulk Thermal Diffusivity .............. 4-9

Table 4-4. Properties Used in the TOUGH2 Model ....................................... 4-13

Table 4-5. Summary of Estimated Thermal Diffusivities ................................... 4-42

Table A-1. Maximum and Average Temperature Differences Between Probes 4 and 5 for Test 1

Table B-1. Maximum and Average Temperature Differences Between

Probes 4 and 5 for Test 2 B-3 


\section{Introduction}

\subsection{BACKGROUND}

The Yucca Mountain Site Characterization Project (YMP) is currently assessing the feasibility of locating a high-level nuclear waste repository ${ }^{\dagger}$ at Yucca Mountain, Nevada. Coincident with site characterization activities, the YMP is pursuing the advanced conceptual design (ACD) phase of the potential repository. YMP's historical approach to repository design has been based on a defense-in-depth strategy. This strategy relies on the combined performance of multiple barriers (both natural and engineered) between the waste form and the accessible environment. Engineered barriers such as backfill, a multi-barrier waste package, and zircaloy cladding will play a role in containing the waste and inhibiting radionuclide transport. The specific components that comprise the engineered system for the defense-indepth approach, however, depend on the emplacement and retrieval strategies being pursued.

The original conceptual design for a Yucca Mountain repository is documented in the Site Characterization Plan--Conceptual Design Report (SCP-CDR) [MacDougall et al., 1987]. The SCP-CDR design was predicated on a combination of mechanical mining and drill-and-blast construction techniques. In the SCP-CDR's concept of subsurface operations, waste emplacement options focused on vertical and horizontal borehole emplacement. In the Exploratory Studies Facility Alternatives Study [Dennis, 1991], recommendations were made to change some of the basic repository features identified in the SCP-CDR. Notable among these changes were the reduction in the number of surface accesses and the proposal for more extensive use of Tunnel Boring Machines (TBM) in the construction of emplacement drifts.

T The term repository appears throughout this document and its appendices. The use of the term repository to identify the facility or some portion of the facility that may be constructed and operated at Yucca Mountain is not intended to imply that such a facility will be constructed or operated at the site. 
Accompanying the Project's shift to TBM construction methods was a shift away from borehole emplacement in favor of in drift emplacement [DOE, 1993]. In drift emplacement is a concept that assumes the waste packages will be placed horizontally on the emplacement drift floors (Figure 1-1). When this concept is combined with the circular drift cross-section that will be generated using a TBM, it is clear that additional excavation or an invert filler material may be needed to provide a level surface for emplacement and retrieval operations. One possible choice for such an invert fill is compacted crushed tuff [DOE, 1993].

In addition to being a possible choice for the invert fill, a crushed-tuff backfill has been identified by the Project's repository sealing program as a possible means of limiting deleterious rock movement within the emplacement drifts and around permanent seal locations [DOE, 1988; Fernandez et al., 1987]. Without some structural control, instabilities in the rock-mass (either due to the imposed heat load of the waste, to naturally occurring seismic events, or to the degradation of ground support with time) could result in both a modified permeability zone around the emplacement drifts and potentially harmful rock falls onto and around the waste packages. A crushed tuff backfill in the emplacement drifts could provide structural control of near-field rock movements, as well as provide a deterrence to human entry, and a diversionary path for episodic water intrusions.

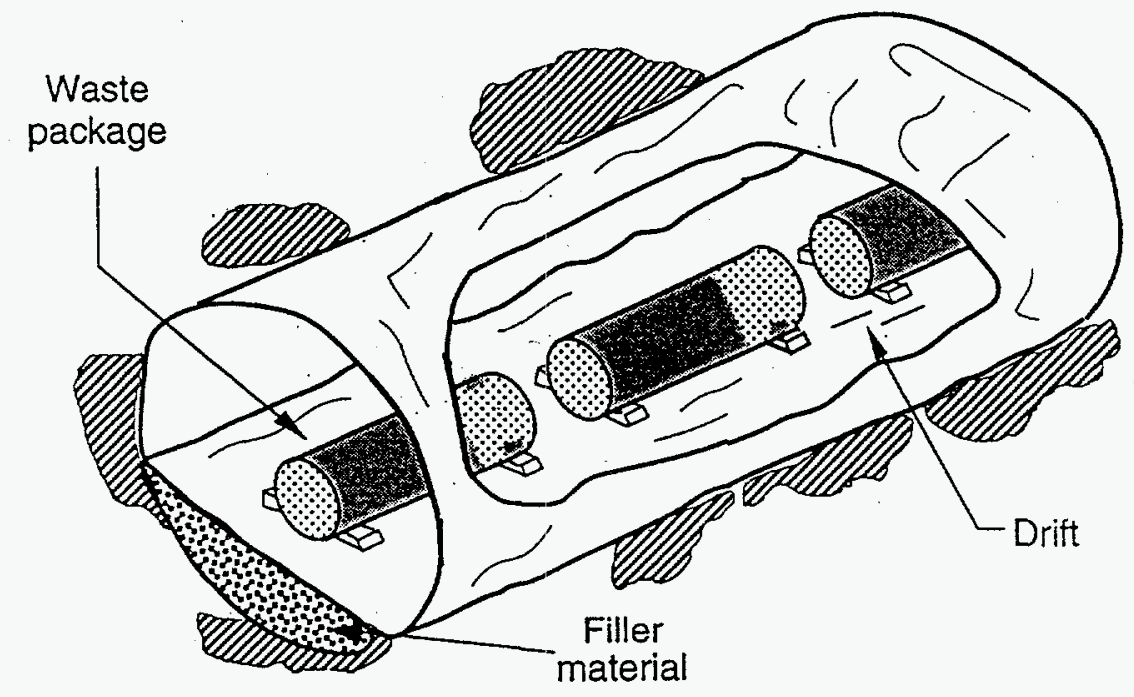

Figure 1-1. In Drift Emplacement Configuration 


\subsection{REGULATORY AND PROJECT FRAMEWORK}

Title 10, part 60 of the code of federal regulations (CFR) contains several explicit references to the characterization of backfill. For the purposes of this discussion, the backfill referred to in 10 CFR 60 [NRC, 1993] is assumed to be composed of crushed tuff. Table 1-1 documents specific references to backfill as they appear in 10 CFR 60. In addition to the explicit references to backfill found in 10 CFR 60, supporting regulations were identified by the Nuclear Regulatory Commission (NRC) in their functional analysis of a high-level radioactive waste repository [NRC, 1992]. These supporting regulations concentrate primarily on the issue of the permanent closure of the facility (e.g., subparts 21(c)(11), 21(c)(15)(vi), $111(\mathrm{~b}))$.

\section{Table 1-1. 10 CFR 60 References to Backfill}

\begin{tabular}{|c|l|}
\hline 10 CFR 60 & \multicolumn{1}{c|}{ Text } \\
\hline \hline $51(\mathrm{a})(4)$ & $\begin{array}{l}\text { DOE shall submit an application to amend the license prior to permanent } \\
\text { closure...including: The results of tests, experiments, and any other } \\
\text { analyses relating to backfill of excavated areas... }\end{array}$ \\
\hline $111(\mathrm{~b})(2)$ & $\begin{array}{l}\text { This requirement shall not preclude decisions by the Commission to allow } \\
\text { backfilling part or all of, or permanent closure of, the geologic repository } \\
\text { operations area prior to the end of the period of design for retrievability. }\end{array}$ \\
\hline 142 & $\begin{array}{l}\text { (a) During the early or developmental stages of construction, a program } \\
\text { for in situ testing of such features as borehole and shaft seals, backfill, and } \\
\text { the thermal interaction effects of the waste packages, backfill, rock, and } \\
\text { ground water shall be conducted. }\end{array}$ \\
\hline & $\begin{array}{l}\text { (c) A backfill test section shall be constructed to test the effectiveness of } \\
\text { backfill placement and compaction procedures against design } \\
\text { requirements before permanent backfill placement is begun. }\end{array}$ \\
\hline
\end{tabular}

The references to backfill in 10 CFR 60 are general. They refer to the backfill of any excavated area. This means that for areas removed from strong thermal interactions (e.g., surface accesses), the Project's primary data needs regarding backfill are related to the hydrologic, the structural, and to some extent, the chemical behavior of the backfill. 
For excavated areas more intimately tied to the heat-generating waste (e.g., emplacement drifts); however, an understanding of backfill thermal response must be added to the list of information needs.

The YMP Controlled Design Assumptions (CDA) document [DOE, 1994] states that one of the key repository design assumptions for $\mathrm{ACD}$ is that the emplacement rooms will be left open through final closure (i.e., no backfill). Recognizing that the backfilling of emplacement rooms represents a major design alternative, the CDA preserves the option to backfill should the Project determine that the use of backfill would enhance the overall performance of the system. To have confidence in such a determination, however, data will be required regarding the hydrologic, structural, chemical, and thermal behavior of a crushed tuff backfill. The remainder of this report focuses on the information need associated with thermal behavior, specifically the need for crushed tuff thermal properties.

\subsection{THERMAL ASSESSMENTS RELATED TO BACKFILL}

The importance of information regarding the thermal properties of crushed tuff was demonstrated in the Project's most recent total systems performance assessment (TSPA) [Wilson et al., 1994]. In developing models of the near-field thermal environment, it was discovered that no site-specific information existed for the effective thermal properties of crushed tuff. Since the TSPA effort assumed that a consolidated crushed tuff invert was present in the drift and that the drift was backfilled 75 years following waste emplacement with a loose crushed tuff, this lack of data introduced significant uncertainties in the prediction of near-field thermal responses.

Operating under the assumption that a crushed tuff backfill or invert can be modeled as a two-phase system of rock and air, theoretical and empirical relationships [Kaviany, 1991] were investigated as a means of estimating the thermal properties of crushed tuff. The range of values that can be calculated from published relationships, however, spans several orders of magnitude. Thus, as recommended by Lappin [1981], a 
theoretical relationship based on a geometric mean approach was used in TSPA to define the thermal conductivity of the crushed-tuff invert and backfill. Application of this approach resulted in a thermal conductivity value for the loose crushed tuff backfill approximately one-tenth the value of surrounding host rock. It is not surprising, therefore, that immediately following the emplacement of backfill in the TSPA simulations (in essence the installation of an insulating material in direct contact with a heat-generating source), predictions of waste package surface temperatures rose from around $200^{\circ} \mathrm{C}$ to well above $450^{\circ} \mathrm{C}$. With a thermal goal for the waste package centerline of $350^{\circ} \mathrm{C}$ [DOE, 1988], the magnitude of this predicted temperature increase is of concern. Resolution of this concern, however, requires data.

\subsection{REPORT ORGANIZATION}

In response to the need for thermal data on crushed tuff (either as a backfill or an invert fill), a bench-scale experiment was designed and constructed to determine the thermal diffusivity of a crushed tuff. This experiment not only represents a first step in the development of crushed tuff thermal properties data, but also provides insight into some of the basic processes that can occur in a heated crushed tuff system.

Characterization of the chosen test material, Topapah Spring welded tuff (TSw2) obtained from Fran Ridge, will be presented first. Specifically, the mineralogy, petrology, and whole-rock chemical analysis of the test material are discussed along with the results of laboratory measurements of density, matrix thermal conductivity, abrasivity, and particle shape. This is followed by a description of the test apparatus along with a discussion of data taken during the tests and visual observations made during the dismantling of the test apparatus. This is followed by the presentation of three sets of post-test analyses used to estimate the thermal diffusivity of the crushed tuff system. Resulting predictions of thermal diffusivities are then converted to effective thermal conductivities and compared to published relationships. 
This page has been intentionally left blank. 
Chapter

Two

\section{Material Characterization}

The material chosen for examination in the bench-scale thermal diffusivity experiment was obtained from the southern portion of Fran Ridge on the Nevada Test Site (Figure 2-1). Fran Ridge is located directly east of the proposed repository location and, owing to faulting and the dip of the rock in the area, is thought to be geologically similar to the Topopah Spring stratigraphic unit identified as the repository horizon (TSw2). Mineralogical, petrologic, and whole-rock chemical analyses were performed on subsamples of the Fran Ridge tuff collected for examination in the experiment. From the chemical analyses, estimates of grain specific heat were calculated. In addition, experimental determinations of bulk density, grain density, thermal conductivity, abrasivity, and particle shape were made. The results of all of the material characterization activities are summarized in this chapter.

\subsection{HAND SAMPLE DESCRIPTIONS}

All samples were dominantly pale reddish-brown in color, with a strongly anisotropic fabric defined by highly elongate lighter colored streaks (typically $1 \mathrm{~mm} \times 3$ to $4 \mathrm{~mm}$ ) in the matrix and somewhat less elongate dark areas. The dark areas resemble altered glass in hand specimen, but they tend to surround lighter cores which texturally resemble pumice, and may actually be zones of alteration around small pumice fragments. Overall, the matrix of the Fran Ridge tuff is very dense and hard, and sample pieces tend to be fractured with sharp edges. Large pumice fragments were not noted in any of the samples, and phenocrysts of any type are rare. No lithophysae were noted in any 
This page has been intentionally left blank. 


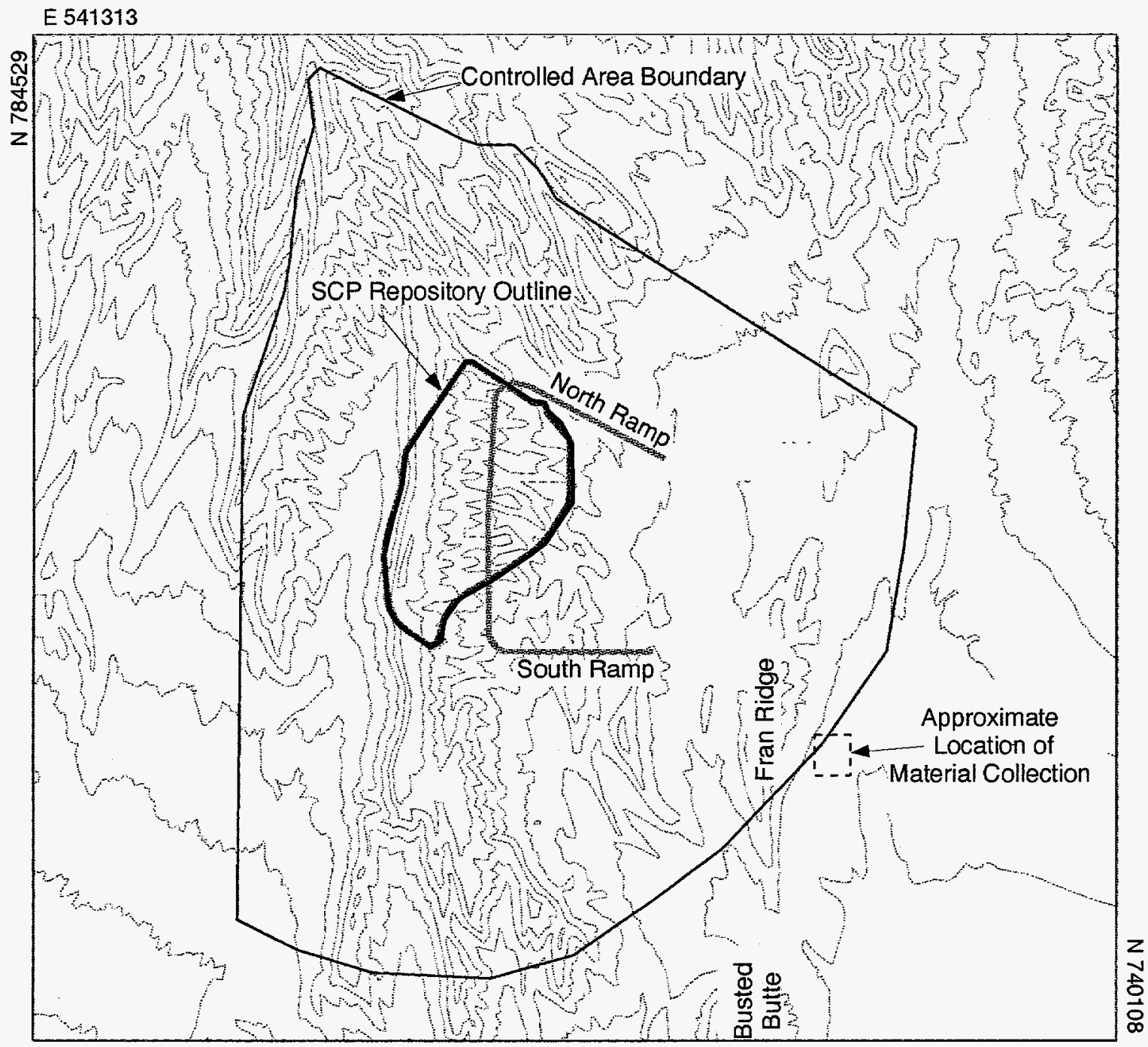

E 555849

Figure 2-1. Map Showing Relative Location of Fran Ridge to Potential Repository 
fragments and areas of vapor-phase alteration are either absent or too small to be seen without a microscope. Some areas of the sections, including the cores of some of the dark areas, show some resemblance to pumice-like textures, but these tend to be very small $(<1$ $\mathrm{cm}$ ) and appear to have been significantly altered by crystallization. Overall, the samples appear to be moderately to densely welded, thoroughly devitrified, crystal- and pumicepoor ash-flow tuff [TDIF, 1994b].

\subsection{THIN SECTION DESCRIPTION AND POINT COUNT}

Two thin sections were prepared from samples of the Fran Ridge tuff. Both thin sections were cut at a high angle to layering. The samples are completely devitrified, but relict shard textures are well preserved. Welding appears to be moderate; strong preferred orientation of shards is accompanied by only moderate deformation. Shards show some reduction of shard cusp apical angles and occasional preservation of somewhat elongate bubbles. Within the shard relics, crystallization of cristobalite (characterized by extremely low birefringence and axiolitic and spherulitic intergrowths, presumably with very finely crystalline feldspar) dominates, while the very finely crystalline inter-shard matrix appears to be dominated by the crystallization of very fine feldspar and quartz. The rock contains virtually no visible porosity $(0.1 \%$ in point count) but because of optical limitations, pores of less than $20 \mu \mathrm{m}$ are very difficult to recognize in thin section. The point count presented in Table 2-1 was done on a single thin section on a grid approximately $0.3 \mathrm{~mm} \mathrm{x}$ $0.6 \mathrm{~mm}$, resulting in a count of 700 points. In the count, an attempt was made to count textural components (shard, fine matrix, pumice, etc.) and to break those elements down further into cristobalite-rich versus quartz-rich areas. The results in Table 2-1 support the qualitative observation that cristobalite is more obviously the dominant silica phase in relict shards and quartz is dominant within the fine inter-shard matrix. It is emphasized that in the point count quartz-rich and cristobalite-rich do not mean those are the only minerals present; chemical considerations require that significant amounts of admixed feldspar be present with both silica phases [TDIF, 1994b]. 
Table 2-1. Results of Thin-Section Modal Analysis [TDIF, 1994b]

\begin{tabular}{|c|c|c|c|}
\hline $\begin{array}{l}\text { Modal } \\
(\text { olume } \%)\end{array}$ & $\begin{array}{l}\text { Gomponent } \\
\text { Tientified }\end{array}$ & $\begin{array}{l}\text { Breakdown or } \\
\text { Conment }\end{array}$ & Wumber or \\
\hline 0.6 & Plagioclase & Phenocryst phase & 4 \\
\hline 0.0 & Alkali Feldspar & Phenocryst phase & 0 \\
\hline 0.0 & Quartz & Phenocryst phase & 0 \\
\hline 0.0 & Biotite & Phenocryst phase & 0 \\
\hline 0.0 & Fe-Ti Oxides & Phenocryst phase & 0 \\
\hline 0.0 & Zircon, Apatite & Phenocryst phase & 0 \\
\hline 0.6 & Devitrified Volcanics & Lithic fragments & 4 \\
\hline 27.0 & Shard Matrix & Cristobalite-rich & 189 \\
\hline 4.7 & Shard Matrix & Quartz-rich & 33 \\
\hline 8.3 & Fine Matrix & Cristobalite-rich & 58 \\
\hline 43.1 & Fine Matrix & Quartz-rich & 302 \\
\hline 2.9 & Pumice & Cristobalite-rich & 20 \\
\hline 8.1 & Pumice & Quartz-rich & 57 \\
\hline 4.6 & Coarse Crystalline Matrix & Quartz-rich & 32 \\
\hline 0.1 & Visible Pores & & 1 \\
\hline $100.0 \%$ & Totals & & 700 \\
\hline
\end{tabular}

\subsection{WHOLE-ROCK CHEMICAL ANALYSIS}

Whole-rock major element chemical analysis was completed for a $21.5 \mathrm{~g}$ sample of the Fran Ridge tuff [TDIF, 1994b]. Table 2-2 shows the actual and normalized chemical analysis results. Table 2-3 provides an estimate of the normative mineral composition of the Fran Ridge tuff. Given the devitrified nature of the tuff, Table 2-3 should be a good approximation of the major mineral phases. All silica phases are included in the normative quartz (about $34 \%$ ) and feldspar phases are the sum of normative albite, anorthite, and orthoclase (about 64\%). Chemical analysis cannot differentiate proportions of silica phases, but proportions estimated from X-ray diffraction of samples of the same material suggests about $10 \%$ quartz and $24 \%$ cristobalite for the samples. About $1 \%$ of the norm is $\mathrm{H}_{2} \mathrm{O}$ and other volatiles $\left(\mathrm{CO}_{2}, \mathrm{SO}_{2}\right)$, and hypersthene and $\mathrm{Fe}-\mathrm{Ti}$ oxides (hematite, ilmenite, and magnetite) comprise the remaining $1 \%$. The latter are represented in thin 
section by small granular and disseminated Fe-Ti oxides and biotite. Of the water, a very small amount is lost at below $110^{\circ} \mathrm{C}\left(0.17 \% \mathrm{H}_{2} \mathrm{O}-\right)$ and represents water trapped in pores. Most water $\left(0.68 \% \mathrm{H}_{2} \mathrm{O}+\right)$ is lost between $110^{\circ} \mathrm{C}$ and $1000^{\circ} \mathrm{C}$ and represents water which is structurally combined with minerals in the sample. The $\mathrm{H}_{2} \mathrm{O}+$ may include other volatiles (typically $\mathrm{CO}_{2}$ and $\mathrm{SO}_{2}$ ), but there was no indication during the analysis that these were present in anything more than very small amounts. Cristobalite, biotite, and disseminated Fe-oxides probably contain the bulk of this structural water, although some may be very tightly held pore water within a very finely crystalline devitrified matrix.

\subsection{BULK AND GRAIN DENSITY}

Bulk and grain density measurements of the Fran Ridge tuff were made as part of the material characterization process [TDIF, 1994a]. Bulk density measurements were performed for air-dried, oven-dried, and vacuum-saturated samples. Table 2-4 documents the results of the bulk density measurements along with associated grain density measurements.

Table 2-2. Whole Rock Chemical Analysis of Fran Ridge Tuff [TDIF, 1994a]

\begin{tabular}{|c|c|c|}
\hline Element & Actual Analysis (\%) & Normalized Analysis (\%) \\
\hline \hline $\mathrm{SiO}_{2}$ & 76.24 & 75.89 \\
\hline $\mathrm{TiO}_{2}$ & 0.11 & 0.11 \\
\hline $\mathrm{Al}_{2} \mathrm{O}_{3}$ & 12.92 & 12.86 \\
\hline $\mathrm{Fe}_{2} \mathrm{O}_{3}$ & 0.67 & 0.67 \\
\hline $\mathrm{FeO}$ & 0.06 & 0.06 \\
\hline $\mathrm{MnO}$ & 0.07 & 0.07 \\
\hline $\mathrm{MgO}$ & 0.17 & 0.17 \\
\hline $\mathrm{CaO}$ & 0.66 & 0.66 \\
\hline $\mathrm{Na}_{2} \mathrm{O}$ & 3.62 & 3.60 \\
\hline $\mathrm{K}_{2} \mathrm{O}$ & 5.08 & 5.06 \\
\hline $\mathrm{H}_{2} \mathrm{O}+\left(+\mathrm{CO}_{2}, \mathrm{SO}_{2}\right)$ & 0.68 & 0.68 \\
\hline $\mathrm{H}_{2} \mathrm{O}-$ & 0.17 & 0.17 \\
\hline $\mathrm{P}_{2} \mathrm{O}_{5}$ & 0.01 & 0.01 \\
\hline \hline Totals & $\mathbf{1 0 0 . 4 6}$ & $\mathbf{1 0 0 . 0 0}$ \\
\hline
\end{tabular}


Table 2-3. Estimated Normative Mineral Phases for Fran Ridge Tuff [TDIF, 1994b]

\begin{tabular}{|c|c|c|}
\hline \begin{tabular}{c} 
Normative Minerals \\
\hline \hline Quartz
\end{tabular} & $\begin{array}{c}\text { Based on Actual Analysis } \\
(\%)\end{array}$ & $\begin{array}{c}\text { Based on Normalized Analysis } \\
(\%)\end{array}$ \\
\hline Corundum & 34.12 & 33.97 \\
\hline Orthoclase & 0.27 & 0.27 \\
\hline Albite & 30.05 & 29.93 \\
\hline Anorthite & 30.59 & 30.43 \\
\hline Hypersthene (En 100\%) & 3.21 & 3.21 \\
\hline Magnetite & 0.43 & 0.43 \\
\hline Hematite & 0.10 & 0.10 \\
\hline Ilmenite & 0.60 & 0.60 \\
\hline Apatite & 0.21 & 0.21 \\
\hline H 20 & 0.02 & 0.02 \\
\hline \hline Totals & 0.82 & 0.85 \\
\hline \hline
\end{tabular}

Table 2-4. Measured Bulk and Grain Densities for Fran Ridge Tuff [TDIF, 1994a]

\begin{tabular}{|c|c|c|c|c|}
\hline \multirow[b]{2}{*}{$\begin{array}{l}10 \\
\text { Source }\end{array}$} & \multicolumn{3}{|c|}{ Bulk Density $(\mathrm{g} / \mathrm{cm})$} & \multirow[b]{2}{*}{$\begin{array}{l}\text { Grain Density } \\
\left(\mathrm{g} / \mathrm{cm}^{3}\right)\end{array}$} \\
\hline & Air-Dry & Oven-Dry & $\begin{array}{l}\text { Vacuum- } \\
\text { Saturated }\end{array}$ & \\
\hline FR-88-62-SNL-A & 2.32 & 2.31 & 2.38 & 2.54 \\
\hline FR-88-62-SNL-B & 2.33 & $2 . \overline{33}$ & 2.41 & 2.54 \\
\hline FR-88-62-SNL-C & 2.34 & 2.33 & 2.39 & 2.51 \\
\hline Averages & 2.33 & 2.32 & 2.39 & 2.53 \\
\hline
\end{tabular}

\subsection{HEAT CAPACITANCE}

Direct experimental measurements of the rock's heat capacitance were not made. Based on the whole-rock chemical analysis and the measured grain and bulk densities, the heat capacitance of the Fran Ridge tuff can be calculated in two steps. First, the grain specific heat is calculated. This quantity is then modified based on the porosity and saturation of the intact rock to provide a bulk heat capacitance. 


\subsubsection{Grain Specific Heat}

The grain specific heat of the Fran Ridge tuff was calculated using the whole chemical analysis presented in Section 2.3 in conjunction with the oxide-summation method detailed by Nimick and Connolly [1991]. The basis of the oxide summation technique is Kopp's rule, which states that the heat capacity of a solid compound is equal to the sum of the weighted heat capacities of its constituent elements:

$$
c_{p}=\sum_{i} x_{i} c_{p, i}
$$

where $x_{i}$ is the fraction of the $i^{\text {th }}$ oxide in the rock and $c_{p, i}$ is the corresponding heat capacity. For this work, $c_{p}$ is represented as a function of temperature:

$$
c_{p}=A+B T+C \sqrt{T}+D^{2}+\frac{E}{\sqrt{T}}+\frac{F}{T}+\frac{G}{T^{2}}
$$

where $\mathrm{T}$ is absolute temperature and A, B, C, etc., are empirically derived constants.

Nimick and Connolly [1991] assumed that $\mathrm{H}_{2} \mathrm{O}$ - represents water present in pores and adsorbed on particle surfaces. For estimates of heat capacity, the whole chemical analysis presented in Table 2-2 must be renormalized to omit this water (Table 2-5).

Table 2-6 documents the heat capacity coefficients for use in the oxide summation approach. The $\mathrm{H}_{2} \mathrm{O}+$ constituent presented in Table 2-6 is assumed to be hydroxl. This assumption is based on Nimick and Connolly's [1991] suggestion that hydroxl is the best choice of $\mathrm{H}_{2} \mathrm{O}+$ when calculating the heat capacity of devitrified samples of tuff. 
Table 2-5. Whole Chemical Analysis Normalized for Calculation of Specific Heat

\begin{tabular}{|c|c|}
\hline \hline Element & Normalized to Omit $\mathbf{H}_{2} \mathbf{O}$-(\%) \\
\hline $\mathrm{SiO}_{2}$ & 76.02 \\
\hline $\mathrm{TiO}_{2}$ & 0.11 \\
\hline $\mathrm{Al}_{2} \mathrm{O}_{3}$ & 12.88 \\
\hline $\mathrm{Fe}_{2} \mathrm{O}_{3}$ & 0.67 \\
\hline $\mathrm{FeO}$ & 0.06 \\
\hline $\mathrm{MnO}$ & 0.07 \\
\hline $\mathrm{MgO}$ & 0.17 \\
\hline $\mathrm{CaO}$ & 0.66 \\
\hline $\mathrm{Na}_{2} \mathrm{O}$ & 3.61 \\
\hline $\mathrm{K}_{2} \mathrm{O}$ & 5.07 \\
\hline $\mathrm{H}_{2} \mathrm{O}+\left(+\mathrm{CO}_{2}, \mathrm{SO}_{2}\right)$ & 0.68 \\
\hline $\mathrm{H}_{2} \mathrm{O}-$ & 0.00 \\
\hline $\mathrm{P}_{2} \mathrm{O}_{5}$ & 0.01 \\
\hline \hline $\mathrm{Total}$ & $\mathbf{1 0 0 . 0 1}$ \\
\hline \hline
\end{tabular}

Table 2-6. Heat Capacity Coefficients Used in Equation 3.2 for Rock-Forming Oxides and Water [Nimick and Connolly, 1991]

\begin{tabular}{|c|c|c|c|c|c|c|c|}
\hline Dlement & A & B. & C & D & E & I. & C \\
\hline $\mathrm{SiO}_{2}$ (Quartz) $^{\text {(Q) }}$ & 0.74223 & $6.2834 \mathrm{E}-4$ & 0.0 & 0.0 & 0.0 & $\overline{0.0}$ & $-1.6673 \mathrm{E} 4$ \\
\hline$\overline{\mathrm{TiO}_{2}}$ & 0.78949 & $1.4152 \mathrm{E}-4$ & 0.0 & 0.0 & -0.070289 & 0.0 & $-1.2344 \mathrm{E} 4$ \\
\hline $\mathrm{Al}_{2} \mathrm{O}_{3}$ & 1.5048 & $1.9302 \mathrm{E}-5$ & 0.0 & 0.0 & -8.833 & 0.0 & $-1.9916 \mathrm{E} 4$ \\
\hline $\mathrm{Fe}_{2} \mathrm{O}_{3}$ & -5.2514 & $-1.4674 \mathrm{E}-2$ & 0.54182 & $3.796 \mathrm{E}-6$ & 0.0 & 0.017422 & 0.0 \\
\hline $\mathrm{FeO}$ & 0.93876 & $5.2379 \mathrm{E}-5$ & 0.0 & 0.0 & -5.3197 & 0.0 & $4.4002 \mathrm{E} 3$ \\
\hline $\mathrm{MnO}$ & 0.84228 & $5.0749 \mathrm{E}-5$ & 0.0 & 0.0 & -3.9845 & 0.0 & $-4.4211 \mathrm{E} 2$ \\
\hline $\mathrm{MgO}$ & 1.618 & $-3.1508 \mathrm{E}-5$ & 0.0 & 0.0 & -9.608 & 0.0 & $-1.1459 \mathrm{E} 4$ \\
\hline $\mathrm{CaO}$ & 0.93479 & $6.5504 \mathrm{E}-5$ & 0.0 & 0.0 & -0.90922 & 0.0 & $-1.3386 \mathrm{E} 4$ \\
\hline $\mathrm{Na}_{2} \mathrm{O}$ & 1.8388 & $1.2078 \mathrm{E}-4$ & 0.0 & 0.0 & -13.123 & 0.0 & 0.0 \\
\hline $\mathrm{K}_{2} \mathrm{O}$ & 0.52301 & $4.8897 \mathrm{E}-4$ & 0.0 & 0.0 & 6.5234 & 0.0 & $-1.4066 \mathrm{E} 4$ \\
\hline $\mathrm{H}_{2} \mathrm{O}$ (Hydroxl) & 7.5934 & $-7.0703 \mathrm{E}-4$ & 0.0 & 0.0 & -96.744 & 0.0 & $3.7165 \overline{\mathrm{E} 4}$ \\
\hline $\mathrm{P}_{2} \mathrm{O}_{5}$ & 0.24686 & $1.5917 \mathrm{E}-3$ & 0.0 & 0.0 & 0.0 & 0.0 & 0.0 \\
\hline
\end{tabular}


Using Kopp's rule and coefficients for Table 2-6, the equation for the specific heat of the Fran Ridge tuff (J/g-K) becomes:

$$
\begin{aligned}
c_{\mathrm{p}}= & 0.87844+\left(0.40694 \times 10^{-3}\right) \mathrm{T}+\left(0.36302 \times 10^{-2}\right) \sqrt{\mathrm{T}}+\left(0.25433 \times 10^{-7}\right) \mathrm{T}^{2}-\frac{1.9669}{\sqrt{\mathrm{T}}} \\
& +\frac{0.11673 \times 10^{-3}}{\mathrm{~T}}-\frac{0.15819 \times 10^{5}}{\mathrm{~T}^{2}}
\end{aligned}
$$

Figure 2-2 shows a plot of the Fran ridge grain specific heat over a range of temperatures.

As indicated by Nimick and Connolly, this approach to heat capacity estimation is only an approximation since it would yield a $\Delta c_{p}$ of zero for any chemical reaction. Heat capacity is affected by order/disorder phenomena in crystals, rotational movement of atoms, and magnetic and electrical effects. However, for temperatures removed from absolute zero, Kopp's rule provides a reasonable approximation of the heat capacities of most substances.

\subsubsection{Bulk Heat Capacitance}

Using a modified version of the technique outlined in Nimick and Connolly [1991] for calculating rock-mass heat capacitance, the grain specific heat calculated in the previous section can be modified to represent the bulk heat capacitance of the intact Fran Ridge tuff. Specifically, the bulk heat capacitance of the tuff can be approximated as:

$$
\left(\rho c_{p}\right)_{s}=\rho_{g}\left(1-\phi_{m}\right) c_{p, g}+\phi_{m} s \rho_{w} c_{p, w}
$$

where $\rho_{\mathrm{g}}$ is grain density, $\phi_{\mathrm{m}}$ is matrix porosity, $\mathrm{c}_{\mathrm{p}, \mathrm{g}}$ is grain specific heat, $s$ is saturation, $\rho_{\mathrm{w}}$ is the density of water and $c_{p, w}$ is the specific heat of water. Calculations of bulk heat capacitance will be delayed until Chapter 5 . 


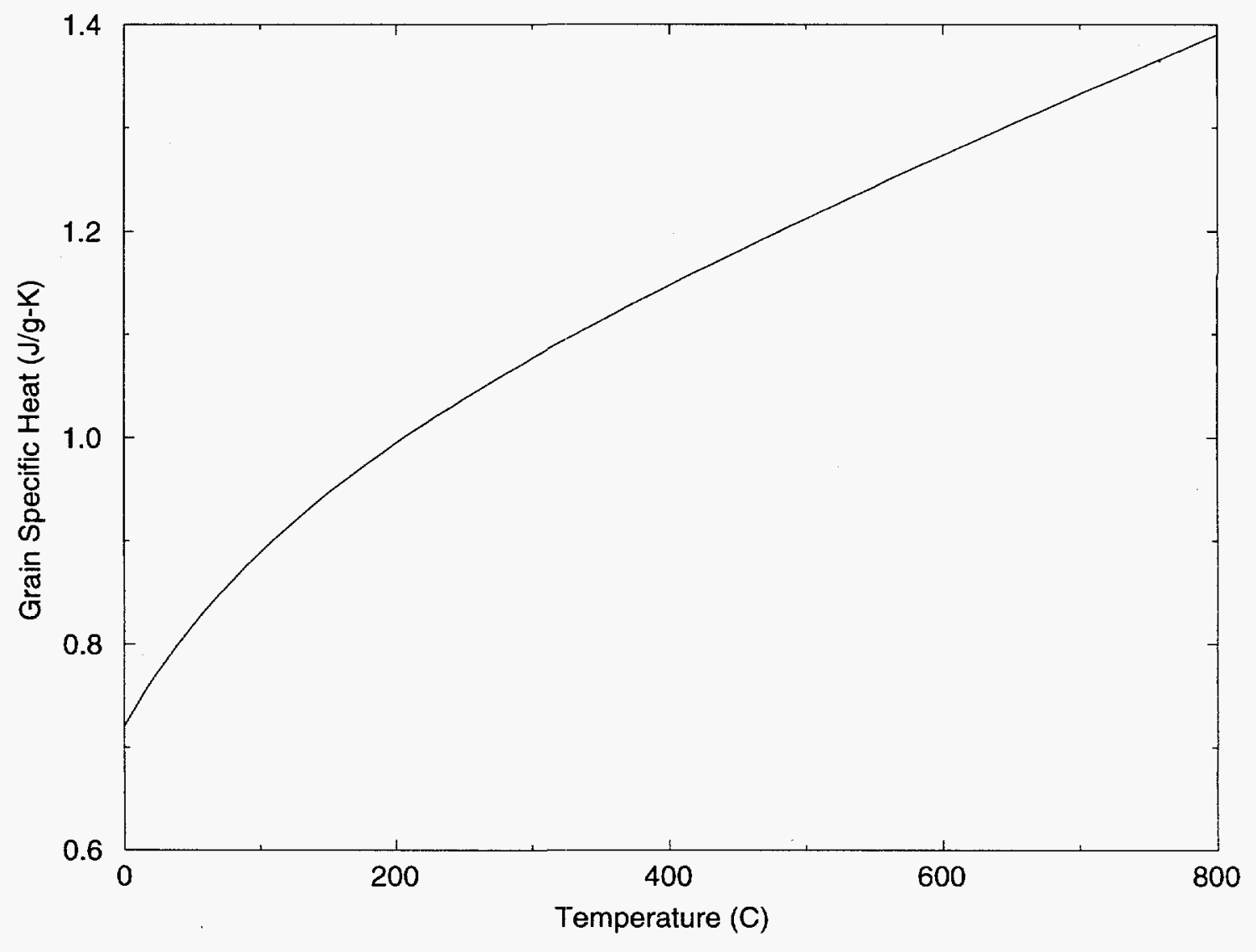

Figure 2-2. Calculated Grain Specific Heat of Fran Ridge Tuff 


\subsection{INTACT THERMAL CONDUCTIVITY}

Laboratory measurements of the thermal conductivity of intact Fran Ridge tuff were made using the guarded-heat-flow method [TDIF, 1994c]. Samples were nominally $5.1 \mathrm{~cm}(2 \mathrm{in}$.) in diameter and $1.3 \mathrm{~cm}(0.5 \mathrm{in}$.) long. Thermal conductivity was measured for three samples under air-dry conditions. These samples were then oven dried and tested again. Air dry measurements of thermal conductivity were taken for temperatures of $30^{\circ} \mathrm{C}, 50^{\circ} \mathrm{C}$, and $70^{\circ} \mathrm{C}$. Oven dry measurements were obtained at temperatures of $30^{\circ}$ $\mathrm{C}, 50^{\circ} \mathrm{C}, 70^{\circ} \mathrm{C}, 110^{\circ} \mathrm{C}, 155^{\circ} \mathrm{C}, 200^{\circ} \mathrm{C}, 245^{\circ} \mathrm{C}$, and $290^{\circ} \mathrm{C}$. In addition, vacuum saturated samples were tested at $30^{\circ} \mathrm{C}, 50^{\circ} \mathrm{C}$, and $70^{\circ} \mathrm{C}$. Table 2-7 documents the results of the laboratory intact thermal conductivity measurements.

Table 2-7. Laboratory Measurements of Fran Ridge Thermal Conductivity [TDIF, 1994c]

\begin{tabular}{|c|c|c|c|c|c|c|c|c|c|}
\hline \multirow[b]{2}{*}{$\begin{array}{l}\text { Subsample of } \\
\text { Source }\end{array}$} & \multirow[b]{2}{*}{$\begin{array}{l}\text { Sample } \\
\text { Preparation }\end{array}$} & \multicolumn{8}{|c|}{ Thermal Conductivity (W/m.K) } \\
\hline & & $30^{\circ} \mathrm{C}$ & $50^{\circ} \mathrm{C}$ & $7^{\circ} \mathrm{C}$ & $110^{\circ} \mathrm{C}$ & $155^{\circ} \mathrm{C}$ & $200^{\circ} \mathrm{C}$ & $245^{\circ} \mathrm{C}$ & $290^{\circ} \mathrm{C}$ \\
\hline \multirow[t]{3}{*}{ FR-88-62-SNL-A } & Air Dry & 1.82 & 1.85 & 1.70 & & & & & \\
\hline & Oven Dry & 1.67 & 1.69 & 1.66 & 1.68 & 1.72 & 1.71 & 1.71 & 1.67 \\
\hline & Vacuum Saturated & 2.15 & 2.23 & 2.22 & & $1 / 18$ & & & \\
\hline \multirow[t]{3}{*}{ FR-88-62-SNL-B } & Air Dry & 1.65 & 1.73 & 1.72 & & & & & \\
\hline & Oven Dry & 1.84 & 1.81 & 1.73 & 1.67 & 1.70 & 1.68 & 1.68 & 1.67 \\
\hline & Vacuum Saturated & 2.33 & 2.29 & 2.12 & & & & & \\
\hline \multirow[t]{3}{*}{ FR-88-62-SNL-C } & Air Dry & 1.78 & 1.81 & 1.81 & & 4 & & & \\
\hline & Oven Dry & 1.67 & 1.71 & 1.65 & 1.68 & 1.80 & 1.79 & 1.79 & 1.76 \\
\hline & Vacuum Saturated & 2.37 & 2.29 & 2.22 & & W & & & \\
\hline \multirow[t]{3}{*}{ Averages } & Air Dry & 1.75 & 1.80 & 1.74 & & \% & & & \\
\hline & Oven Dry & 1.73 & 1.74 & 1.68 & 1.68 & 1.74 & 1.73 & 1.73 & 1.70 \\
\hline & Vacuum Saturated & 2.28 & 2.27 & 2.19 & & & & & \\
\hline
\end{tabular}




\subsection{MATERIAL PREPARATION}

Approximately $4100 \mathrm{~kg}(9,000 \mathrm{lb})$ of TSw2 were collected from Fran Ridge and transported to Hazen Research, Inc. in Denver, Colorado for secondary crushing. The rock was crushed to a maximum particle size (smallest dimension) of $37.5 \mathrm{~mm}$ (1.5 in.) and sieved as shown in Table 2-8. Figure 2-3 is a plot of cumulative percent of particles passing the various sieve sizes presented in Table 2-8. The crushed rock was transported to a temporary lab facility in Grand Junction, Colorado. Drums containing the crushed tuff were sealed to prevent significant changes in moisture content during shipping and storage.

Table 2-8. Cumulative Weight Percent Passing versus Particle Size

\begin{tabular}{|c|c|c|c|c|c|}
\hline Sieve Size & kg & 16 & $\begin{array}{l}\text { Percent } \\
\text { Weight }\end{array}$ & $\begin{array}{l}\text { Percent } \\
\text { Passing }\end{array}$ & $\begin{array}{l}\text { Percent } \\
\text { Retained }\end{array}$ \\
\hline $37.5 \mathrm{~mm}(1.5 \mathrm{in})$. & 4115 & 9072 & 100.0 & 100.0 & \\
\hline $25.4 \mathrm{~mm}$ (1.0 in.) & 1627 & 3587 & 39.5 & 60.5 & 29.5 \\
\hline $12.5 \mathrm{~mm}(0.5 \mathrm{in})$. & 1227 & 2705 & 29.8 & 30.6 & 69.4 \\
\hline \#4 mesh $(4.74 \mathrm{~mm})$ & 660 & 1456 & 18.0 & 14.6 & 86.4 \\
\hline$\# 40$ mesh $(0.425 \mathrm{~mm})$ & 474 & 1044 & 11.5 & 3.1 & 96.9 \\
\hline$-\# 40$ mesh $(<0.425 \mathrm{~mm})$ & 127 & 280 & 3.1 & & \\
\hline
\end{tabular}

\subsubsection{Material Chosen For Test}

It was estimated that approximately two tons of crushed rock would be required to fill the test apparatus. Because only a limited amount of crushed material was available for each particle size (Table 2-8), a mixture of the material with particle sizes ranging from $12.5 \mathrm{~mm}$. to $37.5 \mathrm{~mm}$ ( $0.5 \mathrm{in}$. to $1.5 \mathrm{in}$.) was used as the test material. This coarser material is of initial interest given its applicability to any future efforts aimed at designing a capillary barrier for use in the emplacement drifts. 


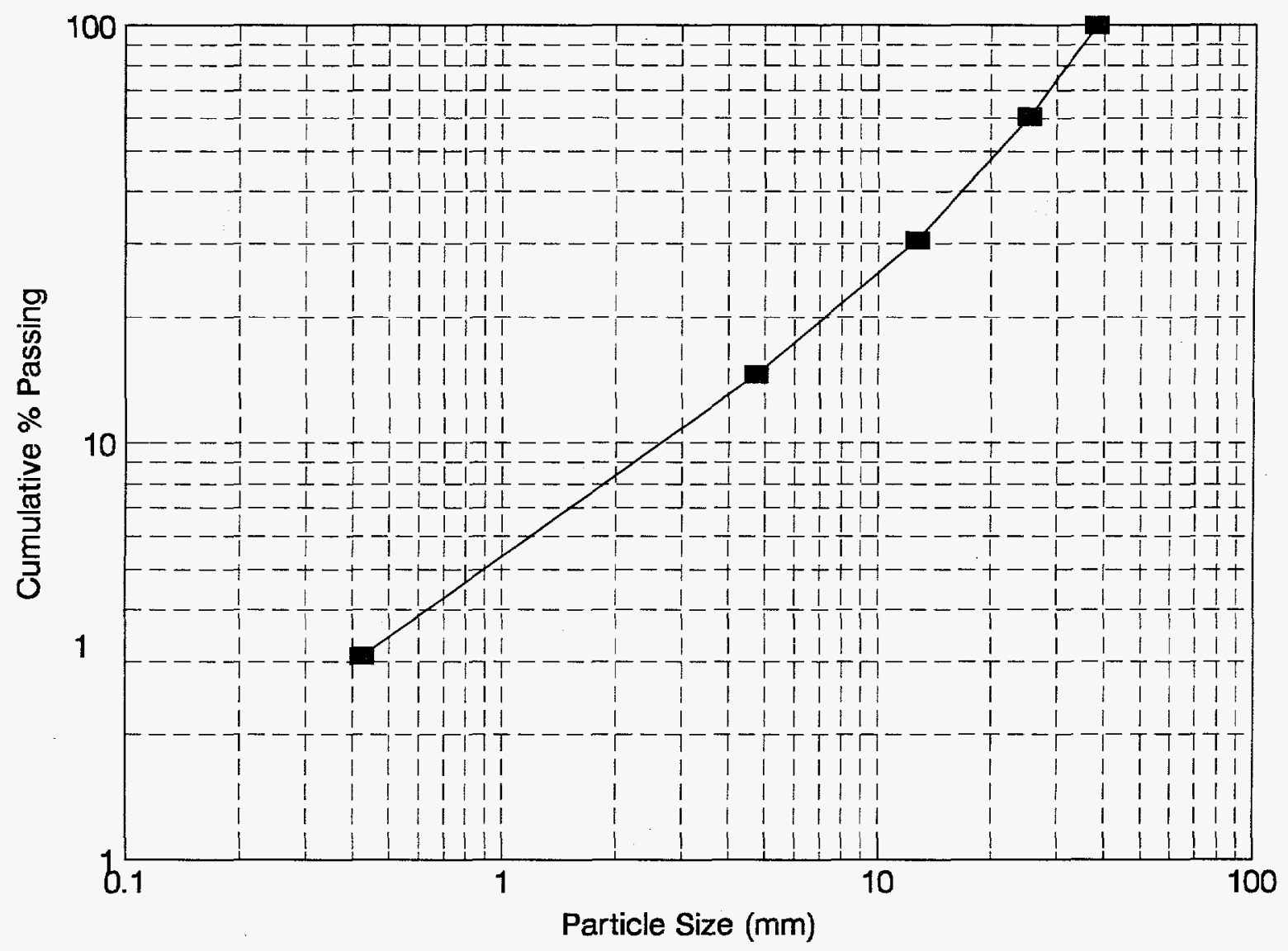

Figure 2-3. Particle Size Distribution for Crushed Tuff Obtained from Hazen Resarch, Inc. 


\subsubsection{Particle Shape and Abrasivity}

From the total $12.5 \mathrm{~mm}$ to $37.5 \mathrm{~mm}$ ( $0.5 \mathrm{in}$. to $1.5 \mathrm{in}$.) inventory of $2,854 \mathrm{~kg}$ $(6,292 \mathrm{lb})$, samples were removed randomly during the filling of the test apparatus for measurements of particle size and shape and for laboratory determination of initial moisture content and abrasivity. The crushed tuff size and shape were determined by measuring the lengths of the three major axes using a digital vernier caliper. This is similar to the procedure used in sedimentology to characterize the particle shapes of sediments [e.g., Sneed and Folk, 1958]. Figure 2-4 shows a normalized plot of particle shape for the crushed tuff used in the experiment. The figure shows that most of the particles are diskshaped or bladed.

An abrasive blast test was performed on a randomly selected sample of the 0.5 to 1.5 in. crushed tuff. This test is used to determine wear rates for pneumatic stowing equipment used for backfilling underground mines. The abrasive blast test was performed at a $45^{\circ}$ plate angle with 90 psi nozzle pressure on an SAE 1018 hot rolled steel plate. A one kilogram sample of $-14+28$ mesh material produced from jaw and roll crushing of the Fran Ridge tuff was used as the test material. A $45^{\circ}$ cutting rate of 0.2 grams of metal removed per kilogram of material was measured, placing the Fran Ridge tuff in the low abrasive range.

\subsection{REPRESENTATIVENESS OF SELECTED MATERIAL}

Given that the objective of the experiment is to demonstrate not only a method for obtaining the thermal diffusivity of a crushed rock bed, but also to gain site specific insight for future design, performance assessment, and sealing evaluations, it is important to understand the representativeness of the material chosen for examination in this experiment. Currently, only a limited set of characterization data exists at depth for the site. It is difficult therefore to make any firm conclusions regarding the representativeness of the Fran Ridge tuff chosen for this test. For completeness, however, available data for 


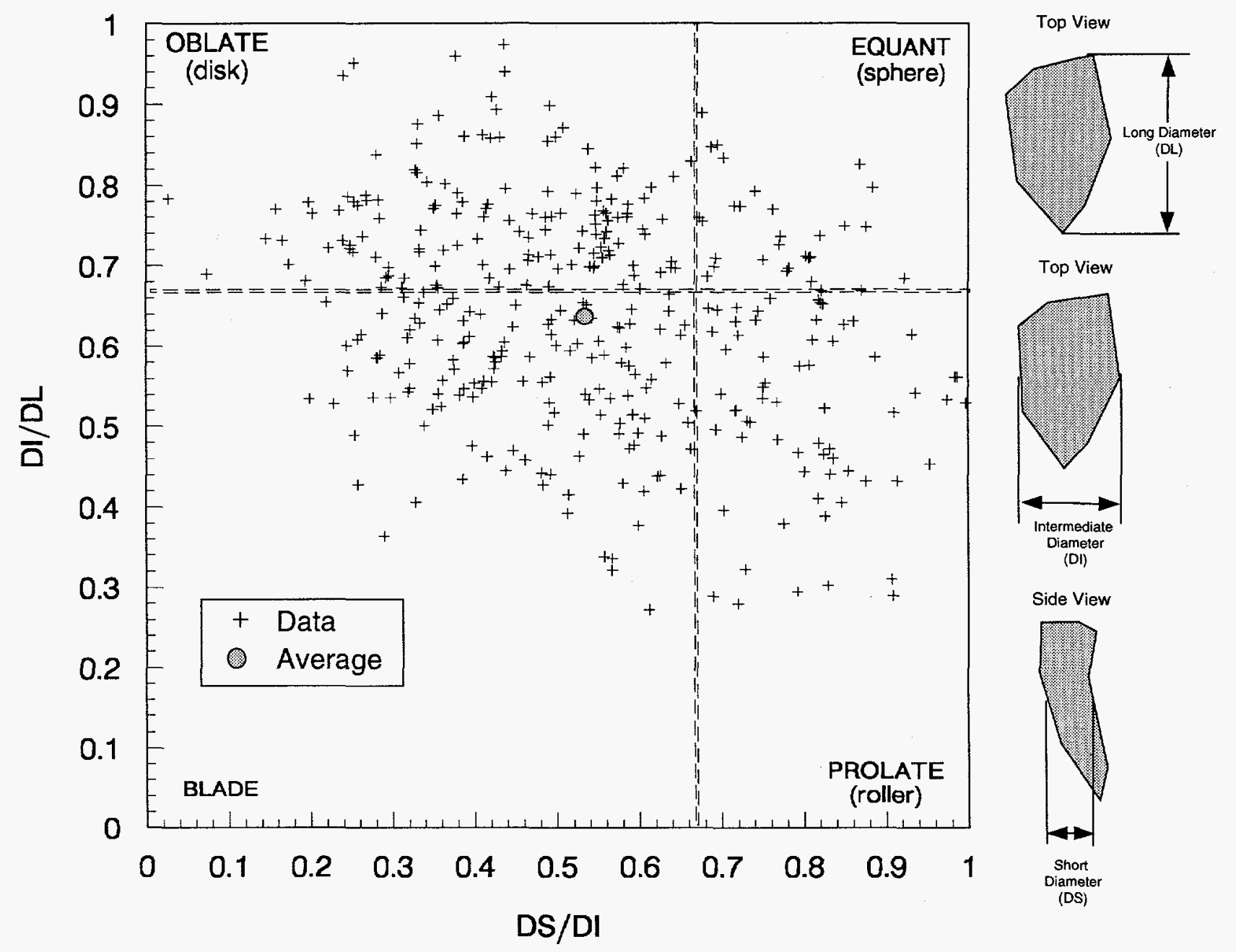

Figure 2-4. Normalized Plot of Crushed Tuff Particle Shapes Used in Experiment 
density, specific heat, and thermal conductivity for the TSw2 unit from north ramp geologic hole NRG-6 will be presented for comparison. In addition, general comparisons of the mineralogy and petrology of the Fran Ridge tuff to TSw2 data from selected drillholes will also be discussed.

\subsubsection{Chemical Composition and Structure}

It is notable that relative to samples of welded tuff from all units of the Topopah Spring Member observed from drill holes in Yucca Mountain to the north [Connolly, 1991a and 1991b], the material obtained from Fran Ridge contains very small pumice fragments, less lithic fragments and phenocrysts, and shows a much higher degree of textural homogeneity than other TSw2 samples. This is consistent with the much more distal location of Fran Ridge relative to the source caldera of the Paintbrush Tuff.

The chemical analysis indicates a high-silica rhyolite composition similar to most other analyzed samples of the devitrified and welded units of the Paintbrush Tuff (including the Tiva Canyon and Topopah Spring Members) previously studied [Connolly, 1991a, 1991b]. Water content is typical for a glass-free devitrified tuff.

\subsubsection{Density, Porosity, Specific Heat, and Thermal Conductivity}

Grain density measurements for NRG-6 samples of TSw2 were not available for comparison. Comparisons of bulk density measurements, however, indicate that the Fran Ridge Tuff is more dense than the material tested from NRG-6. Dry bulk densities for 16 NRG-6 samples of TSw2 ranged from $2.19 \mathrm{~g} / \mathrm{cm}^{3}$ to $2.31 \mathrm{~g} / \mathrm{cm}^{3}$, with an average of 2.25 $\mathrm{g} / \mathrm{cm}^{3}$ [TDIF, 1994d]. The average Fran Ridge dry bulk density of $2.32 \mathrm{~g} / \mathrm{cm}^{3}$, places the tested material just outside the upperbound of the NRG- 6 material, but only $3 \%$ above the average value.

Matrix porosity estimates for the 16 NRG-6 samples of TSw2 range from $8.2 \%$ to $13.9 \%$ [TDIF, 1994d], with an average of $10.0 \%$. The matrix porosity of the Fran Ridge samples averages $7 \%$ (ranging from $6 \%$ to $8 \%$ ). This is consistent with the hand sample 
and thin section descriptions that indicate the Fran Ridge tuff is unusually dense in comparison to other TSw2 samples.

Estimates of grain specific heat were made using whole chemical analyses for six TSw2 samples from NRG-6 [TDIF, 1995]. Grain specific heat values calculated using temperature-dependent relationships derived for the NRG -6 samples agreed with the Fran Ridge tuff values to within 1 percent over a range of $0^{\circ} \mathrm{C}$ to $700^{\circ} \mathrm{C}$. Although the grain specific heat values agreed, differences in the matrix porosity and bulk densities indicate that the bulk heat capacitance of the Fran Ridge tuff is likely to be noticeably different than that of the NRG-6. As discussed in Hertel and Ryder [1991], however, variations in temperature predictions due to heat capacitance variations can be considered second-order when compared to the effects of thermal conductivity variations.

Laboratory measurements of thermal conductivity for eight samples of TSw2 obtained from NRG-6 were used to assess the representativeness of the Fran Ridge thermal conductivity data. Table 2-9 presents the average thermal conductivity data obtained for the Fran Ridge tuff as well as the averages of data obtained for eight samples of TSw2 tested from NRG-6 [TDIF, 1994d]. It is apparent that the Fran Ridge tuff has consistently higher values of thermal conductivity than the NRG-6 samples. Should results from more extensive site characterization activities indicate that the NRG-6 data is more representative of the target horizon, these differences in thermal conductivity may be important. Until additional data is obtained, no firm conclusions regarding the representativeness of the Fran Ridge thermal conductivity data can be made.

\subsubsection{Crushed Particle Shapes and Sizes}

The shapes and sizes of the particles are a strong function of the comminution process. For this experiment a jaw crusher was used to create the particles used to fill the test apparatus. Jaw crushers produce a geometrically different particle than would be produced by the disc cutters on a TBM. As an indication of the differences, particle shapes created by the Colorado School of Mines (CSM) during linear disc cutting 
Table 2-9. Comparison of Average Fran Ridge Thermal Conductivities to Those Obtained for the TSw2 Unit From NRG-6

\begin{tabular}{|c|c|c|c|c|c|c|c|c|c|}
\hline \multirow{2}{*}{ Source } & \multirow[b]{2}{*}{$\begin{array}{l}\text { Sample } \\
\text { Preparation }\end{array}$} & \multicolumn{8}{|c|}{ Average Thermal Conductivity (W/m-K) } \\
\hline & & $30^{\circ} \mathrm{C}$ & $50^{\circ} \mathrm{C}$ & $70^{\circ} \mathrm{C}$ & $110^{\circ} \mathrm{C}$ & $155^{\circ} \mathrm{C}$ & $200^{\circ} \mathrm{C}$ & $245^{\circ} \mathrm{C}$ & $290^{\circ} \mathrm{C}$ \\
\hline \multirow{3}{*}{$\begin{array}{l}\text { Fran Ridge } \\
\text { (TSw2) }\end{array}$} & Air Dry & 1.75 & 1.80 & 1.74 & & 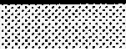 & & & \\
\hline & Oven Dry & 1.73 & 1.74 & 1.68 & 1.68 & 1.74 & 1.73 & 1.73 & 1.70 \\
\hline & Vacuum Saturated & 2.28 & 2.27 & 2.19 & & & & & \\
\hline \multirow{3}{*}{$\begin{array}{l}\text { NRG-6 } \\
\text { (TSw2) }\end{array}$} & Air Dry & 1.71 & 1.65 & 1.62 & & & & & \\
\hline & Oven Dry & 1.47 & 1.49 & 1.51 & 1.60 & 1.65 & 1.64 & 1.62 & 1.56 \\
\hline & Vacuum Saturated & 2.04 & 2.03 & 1.93 & & & & & \\
\hline \multirow{3}{*}{$\begin{array}{l}\text { Percent } \\
\text { Difference }\end{array}$} & Air Dry & 2.3 & 8.3 & 6.9 & & & & & \\
\hline & Oven Dry & 15.0 & 14.4 & 10.1 & 4.8 & 5.2 & 5.2 & 6.4 & 8.2 \\
\hline & Vacuum Saturated & 10.5 & 10.6 & 11.9 & & & & & \\
\hline
\end{tabular}

experiments on Yucca Mountain tuffs [Gertsch and Ozdemir, 1992] are presented for comparison. Linear disc cutters were used to simulate the roller cutters used on a TBM. As such, the mechanisms of fracture are identical, and should produce rock fragments of similar geometry for a given rock type The size of fragments is dependent on the spacing of the discs on the TBM cutter head. In general disc cutters will produce a higher percentage of fines than other crushing methods (e.g., jaw crushers). Figure 2-5 illustrates particle size distributions for rock broken by various methods. Lines 3 and 4 on Figure 25 are from linear cutting studies on welded tuffs for Yucca Mountain [Gertsch and Ozdemir, 1992]. The results appear consistent with the size distribution obtained for this study (line 8 on Figure 2-5). These linear cutting studies reported on the percent finer than $25.4 \mathrm{~mm}$ ( 1 in.) sieve. These curves show that about 40 to $50 \%$ of the particles resulting from these tests are greater than $25.4 \mathrm{~mm}$ in size. Both the size and shape are important for backfilling because some emplacement techniques may be incompatible with large particle sizes and particle shapes will influence emplaced porosity. 


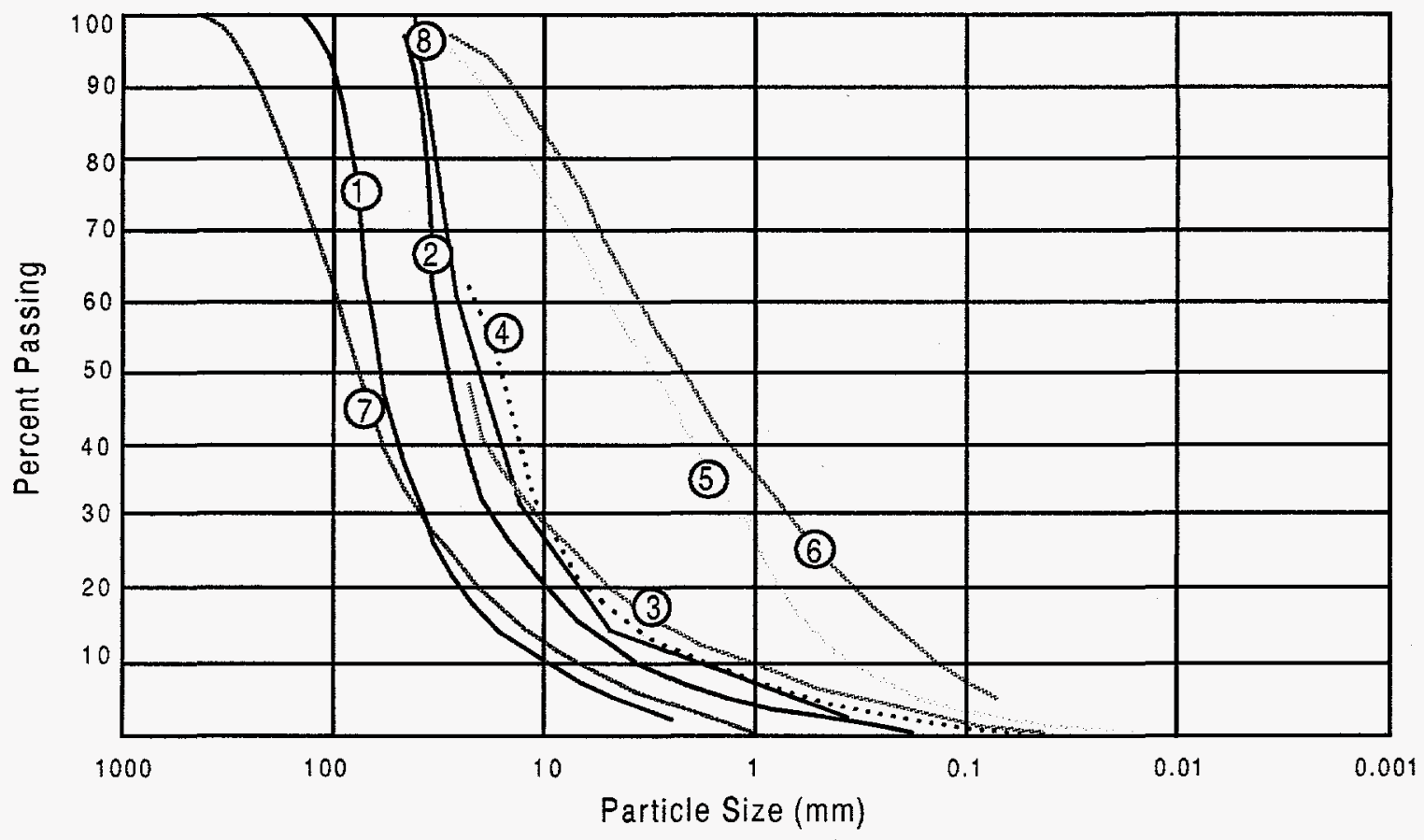

\begin{tabular}{|c|c|c|}
\hline \multicolumn{3}{|c|}{ LEGEND } \\
\hline 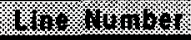 & sormoss & Thes \\
\hline 1 & Laboratory Jaw Crusher: 3" Opening & Crushed Tuff \\
\hline 2 & Laboratory Jaw Crusher: $1.5^{n}$ Opening & Crushed Tuff \\
\hline 3 & Linear Cutter: Disc & Colorado School of Mines (CSM) \\
\hline 4 & Linear Cutter: Pick & Colorado School of Mines (CSM) \\
\hline 5 & Mined Tuff & $\begin{array}{l}\text { Little Skull Mountain: Bedded Gray Tuff Wahmonie } \\
\text { Formation }\end{array}$ \\
\hline 6 & Mined Tuff & $\begin{array}{l}\text { Little Skull Mountain: Lower Red Tuff Wahmonie } \\
\text { Formation }\end{array}$ \\
\hline 7 & Drill \& Blast & Estimated \\
\hline 8 & Jaw Crusher & Fran Ridge Tuff Used in This Study \\
\hline
\end{tabular}

Figure 2-5. Comparison of Particle Size Distributions for Tuff Broken by Various Methods 
Comparing Figure 2-6 with Figure 2-4, the particle shapes that result from the CSM disc cutting experiments are clearly more disk or bladed in shape than the particles used in this experiment. Differences in particle shape can affect both the porosity and effective thermal diffusivity of the emplaced backfill.

\subsubsection{Summary of Material Representativeness}

The material chosen for examination in this experiment is chemically similar to that of the stratigraphic unit comprising the repository horizon (TSw2), but exhibits minor variations in matrix porosity and density. The particle sizes chosen for examination are consistent with various backfill emplacement techniques (e.g., pneumatic stowing). The lack of a significant amount of fines in the system is likely to influence not only the effective thermal properties derived, but also the basic thermal processes that occur within the system (e.g., convection). The effects of particle sizes and shapes should be included in future studies. 


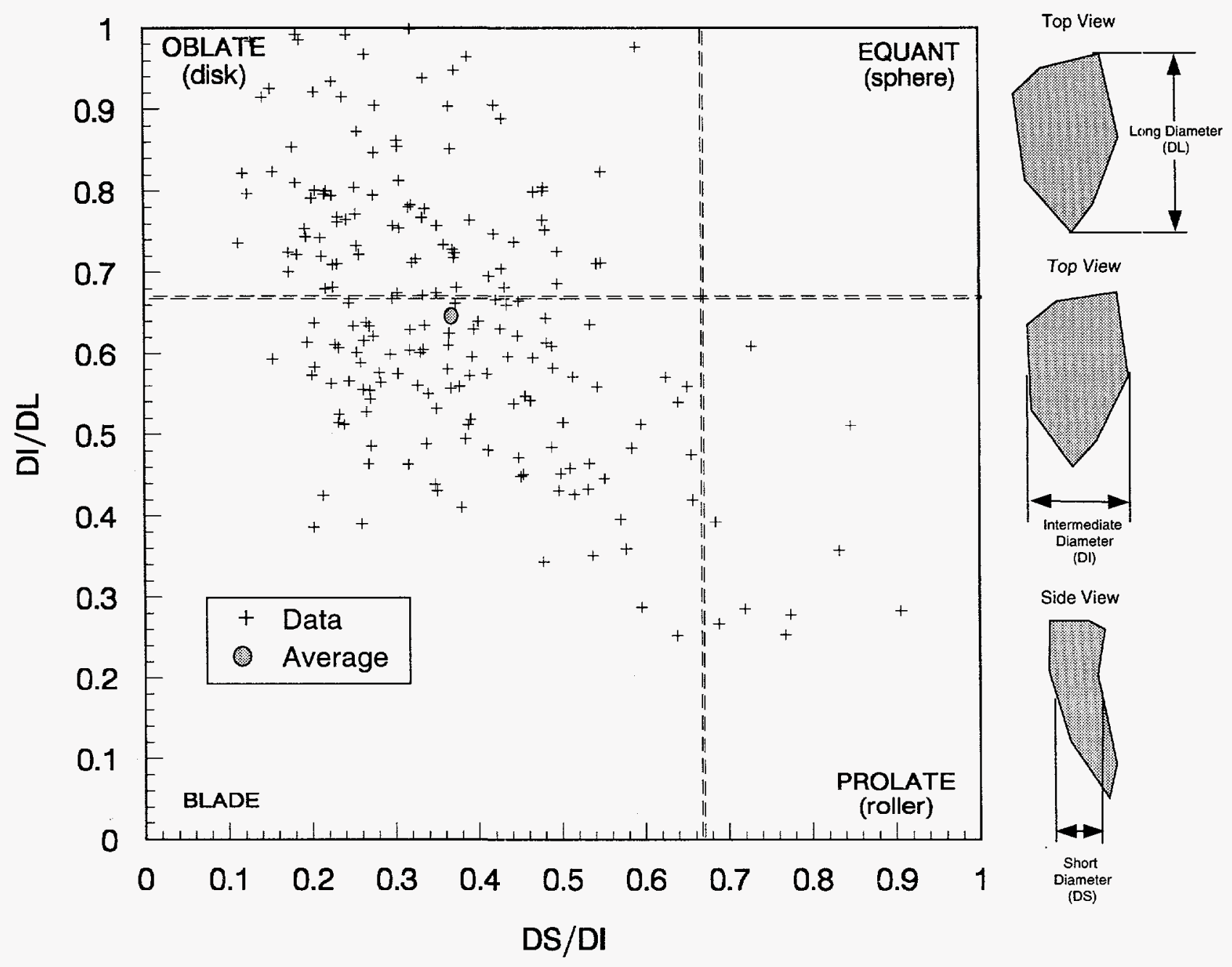

Figure 2-6. Normalized Plot of Tuff Particle Shapes Obtained from CSM Linear Cutter Experiments 


\section{Test Apparatus, Data, and Observations}

\subsection{TEST APPARATUS}

One of the primary goals in designing this experiment was to make use of axisymmetry to simplify post-test analyses of the resulting data. A vertical cylinder of material heated along its axial line of symmetry was chosen as the most appropriate geometry. The scale of the experiment was determined based on a qualitative assessment of such factors as the potential for ordering in the crushed tuff particles due to the presence of a boundary, the representativeness of the heated volume, and the potential for data skewing due to end heat losses. The final container design for the crushed tuff test bed consisted of a $2.1 \mathrm{~m}$-long ( $82.5 \mathrm{in}$.) mild steel cylinder with an outer radius of $0.5 \mathrm{~m}$ (19.6 in.) and a wall thickness of $1.5 \mathrm{~cm}(0.58 \mathrm{in}$.). The cylindrical container was placed in an upright position on a single layer of low density $\left(0.66 \mathrm{~g} / \mathrm{cm}^{3}\right)$, low thermal conductivity $(0.26 \mathrm{~W} / \mathrm{m}-\mathrm{K})$ refractory bricks which were placed on the concrete floor of the test facility. The fire brick was chosen due to its ability to support the expected weight of the filled cylinder and because its insulating qualities would, in the absence of significant convective effects, assist in developing one dimensional heat flow in the radial direction. (As will be discussed later, convection did play an important role in the experiment). To provide support and access to the test bed, the steel cylinder and refractory brick were placed within a fabricated support structure as shown in Figure 3-1.

To provide control of the radial boundary condition, the entire circumference of the container was insulated with a $7.6 \mathrm{~cm}(3 \mathrm{in}$.) blanket of high temperature refractory material (Kaowool ${ }^{\mathrm{TM}}$ ). At the top of the container, three layers of Kaowool ${ }^{\mathrm{TM}}$ (approximately $23 \mathrm{~cm}$ ) were used for thermal insulation (Figures 3-2 and 3-3). 


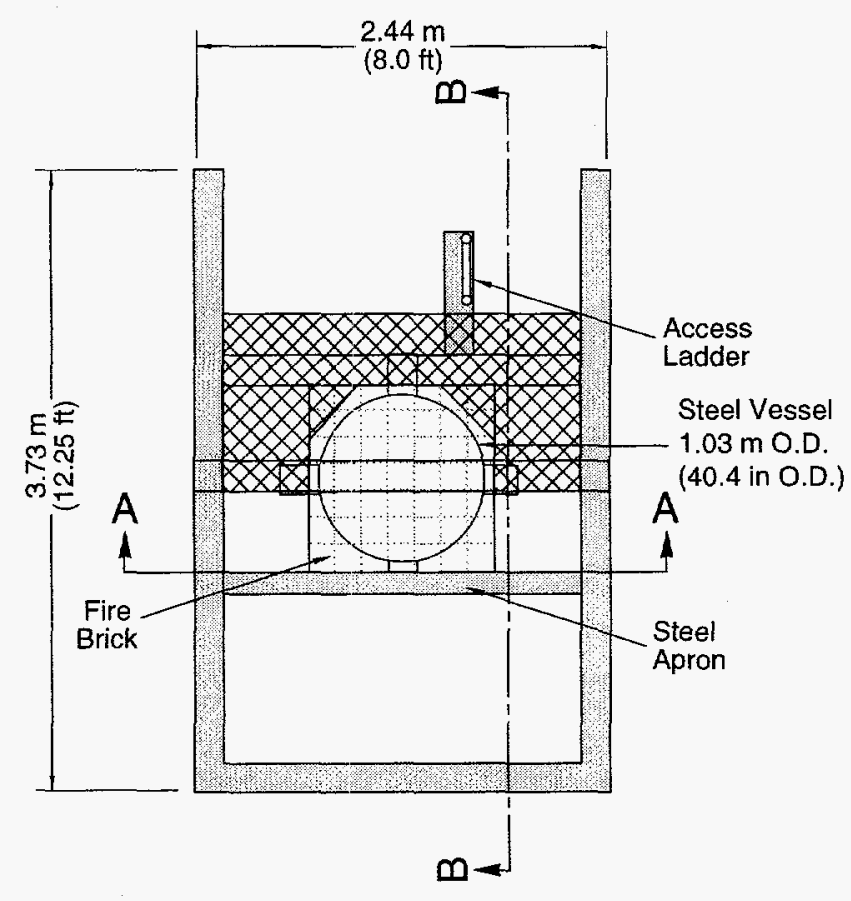

Plan View

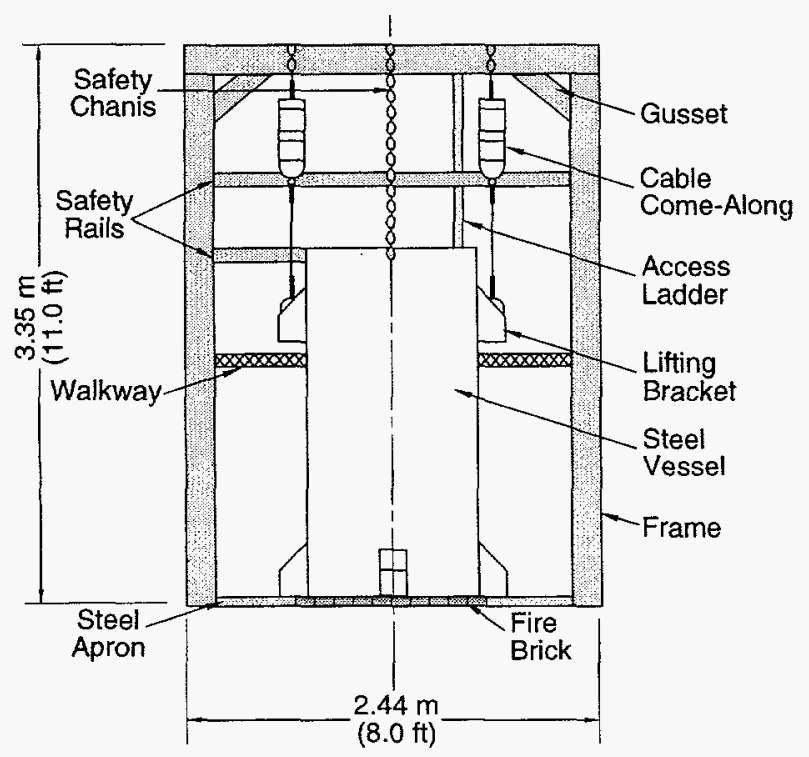

$A-A$

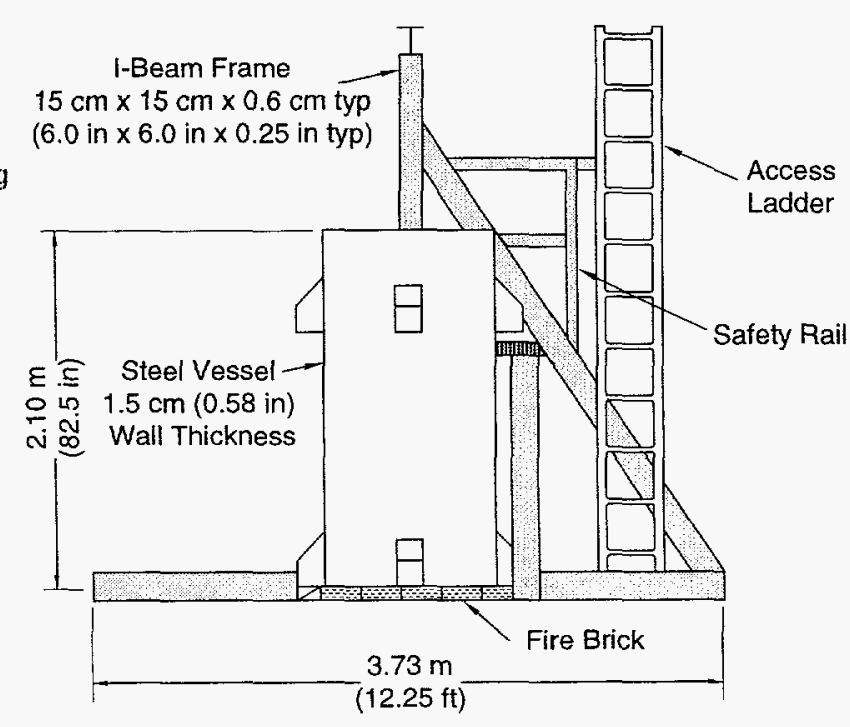

$\mathrm{B}-\mathrm{B}$

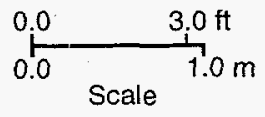

TRl-6313-42-0

Figure 3-1. Schematics of Support Structure and Test Cylinder 


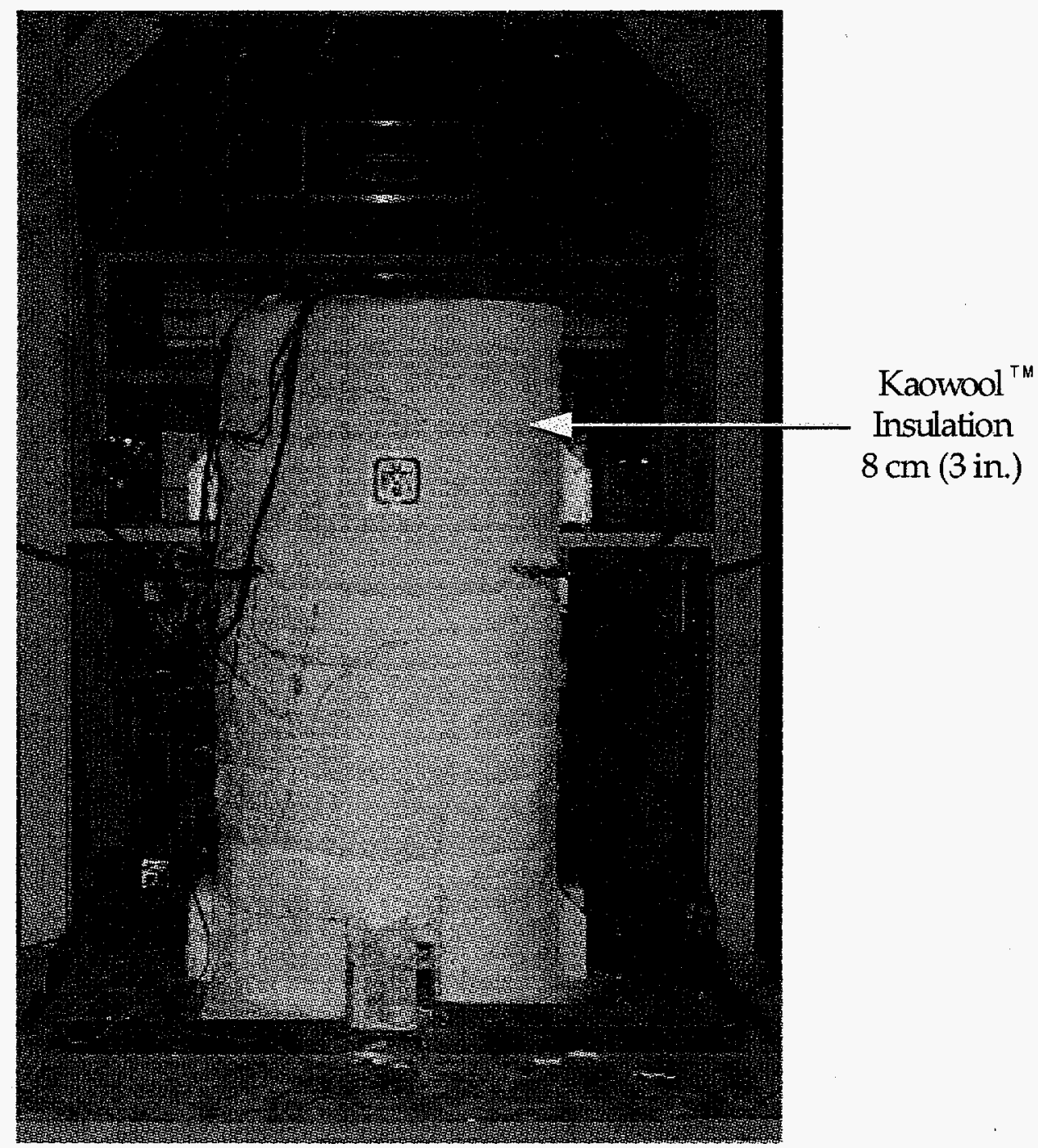

Figure 3-2. Test Apparatus Showing Radial Insulation 


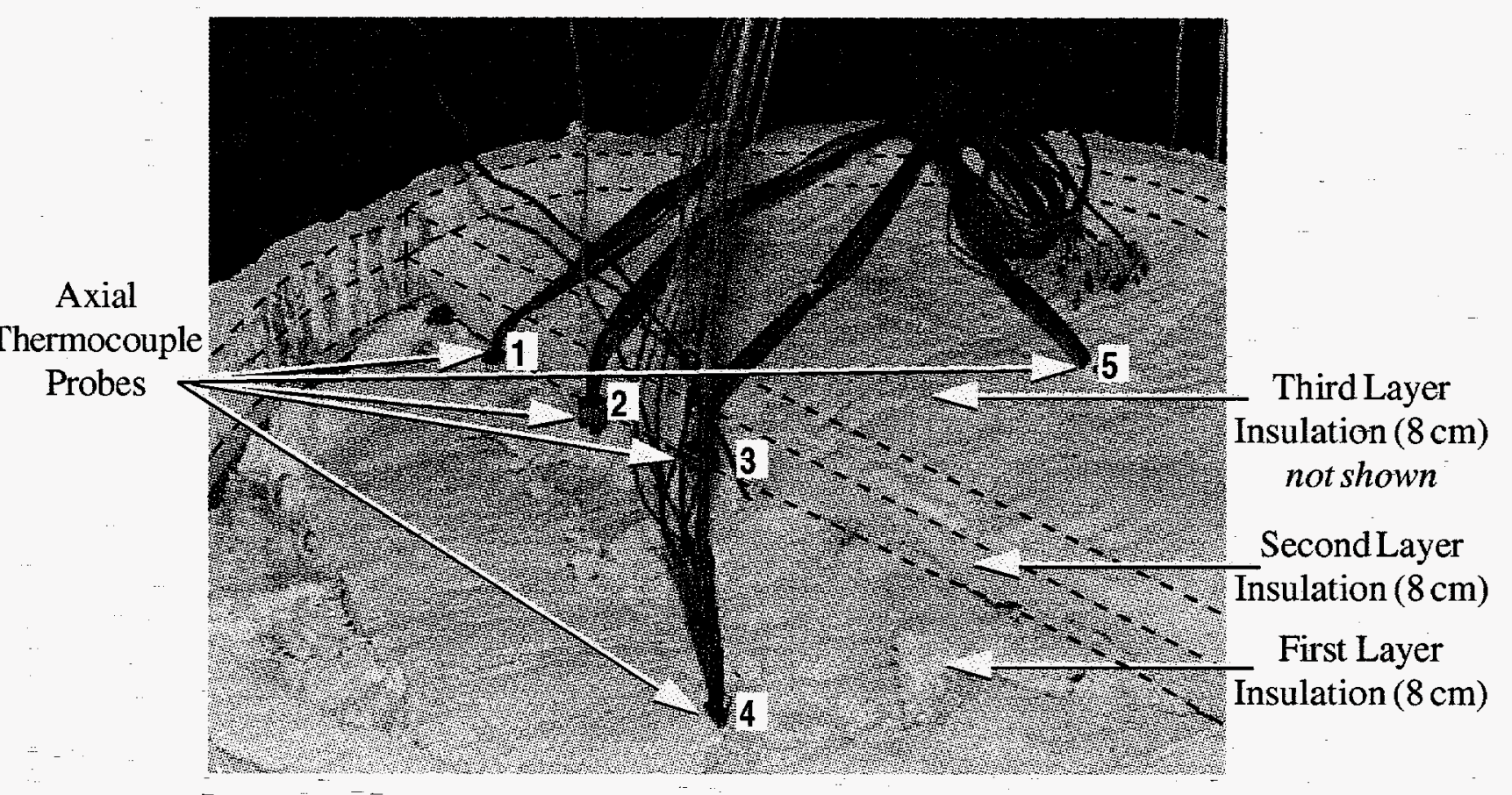

Figüre 3-3. Test Apparatus Showing Insulation Cap 


\subsection{INSTRUMENTATION}

A single linear heat source with a nominal maximum power output of $1800 \mathrm{~W}$ was placed along the container's axial line of symmetry. The heater was approximately 0.64 $\mathrm{cm}(0.25 \mathrm{in}$.) in diameter and $1.9 \mathrm{~m}$ (75 in.) in length with $2.5-\mathrm{cm}(1 \mathrm{in}$.$) long insulated$ ceramic end connectors on either end. The heater was elevated above the bottom of the container by placing it on an additional fire brick (about $6.4 \mathrm{~cm}$ thick).

The test cylinder was instrumented to record temperatures at 73 locations: 54 within the crushed rock, 5 within the refractory-brick base, 9 on the surface of the cylindrical container (between the steel cylinder and the insulation blanket), 4 on the insulation surface, and 1 at a site away from the test cylinder (for ambient temperature measurement). Type- $\mathrm{K}$ thermocouples were selected for all temperature measurement sites because of their wide range of applicability $\left(-250^{\circ} \mathrm{C}\right.$ and $\left.1260^{\circ} \mathrm{C}\right)$.

Within the crushed rock, three high-temperature shielded Type-K thermocouples were clamped to the heater (Figure 3-4) at the elevations shown in Figure 3-5. Temperature measurements at the remaining 51 locations within the crushed tuff were made using thermocouple probes manufactured by STI Manufacturing, Inc. These probes are constructed using Type-K thermocouples individually sheathed in 304 stainless steel with the entire bundle encased within a $0.64-\mathrm{cm}(0.25 \mathrm{in}$.) diameter stainless steel tube. The thermocouple probes are internally packed with powdered magnesium-oxide.

Figure 3-5 is a schematic showing the relative locations of the five, 203-cm long ( $80 \mathrm{in}$.) probes placed within the test cylinder along with the elevations of the 10 themocouples on each probe. These probes were imbedded $2.9 \mathrm{~cm}(1.125 \mathrm{in}$.) into the refractory brick base. This was done to fix the locations of the axial probes, as well as to provide temperature readings within the brick base. As a result, only 9 of the 10 thermocouples from each probe read temperatures in the crushed rock. The remaining 6 temperature sampling locations within the crushed tuff were made using a $55.9-\mathrm{cm}$ (22 in.) long STI thermocouple probe installed along a radius of the cylinder. Figure 3-6 shows the relative locations of the heater, the axial thermocouple probes, and the radial thermocouple probe. 
Also shown are two temporary plywood templates used to hold the heater and the axial probes in place during the filling of the test cylinder with crushed tuff. These templates were removed as the crushed rock reached these levels.

The majority of temperature sampling within the test cylinder was established parallel to the heater based on the theory that measurement errors associated with conduction along the intrusive thermocouple probes would be minimized if they were placed perpendicular to the expected direction of heat flow. The single radial probe was installed to provide comparative data for an assessment of this approach to instrumentation.

Primary data were designated to come from Probes 1, 2, and 3, with data necessary to confirm axisymmetric conditions designed to come from Probes 4 and 5 (Figure 3-5). Probe 6 was located along a radius of the test cylinder $94.9 \mathrm{~cm}$ above the brick base, in a plane approximately $60^{\circ}$ from the plane containing Probes 1,2 , and 3 (Figure 3-6). As shown in Figure 3-7, the tip of Probe 6 was set approximately $8.9 \mathrm{~cm}$ (3.5 in.) from the heater. Tuff was carefully placed by hand between the tip of Probe 6 and the heater to reduce potential radiative thermal effects and also over the probe to reduce the potential for damage from subsequent filling operations.

Nine Type-K thermocouples were attached to the outside surface of the container (under the insulation) using high temperature adhesive (Figure 3-8). These thermocouples were located at the same elevations and along the same axial plane as the thermocouples in Probes 1, 2, and 3 (Figure 3-5). Four additional Type-K thermocouples were attached to the insulation blanket, three along the vertical plane containing Probes 1,2,3, and the fourth on the insulation cap at the top of the test cylinder. Finally, one thermocouple was placed away from the cylinder to measure the ambient room temperature.

In addition to temperature measurements, heater power, heater current, and heater voltage were also recorded throughout the heat-up cycle of the experiments. During a portion of the experiments, heater power was controlled using a temperature feedback loop from the thermocouple located at the tip of Probe 6 ( $3.5 \mathrm{in}$. from the heater). 


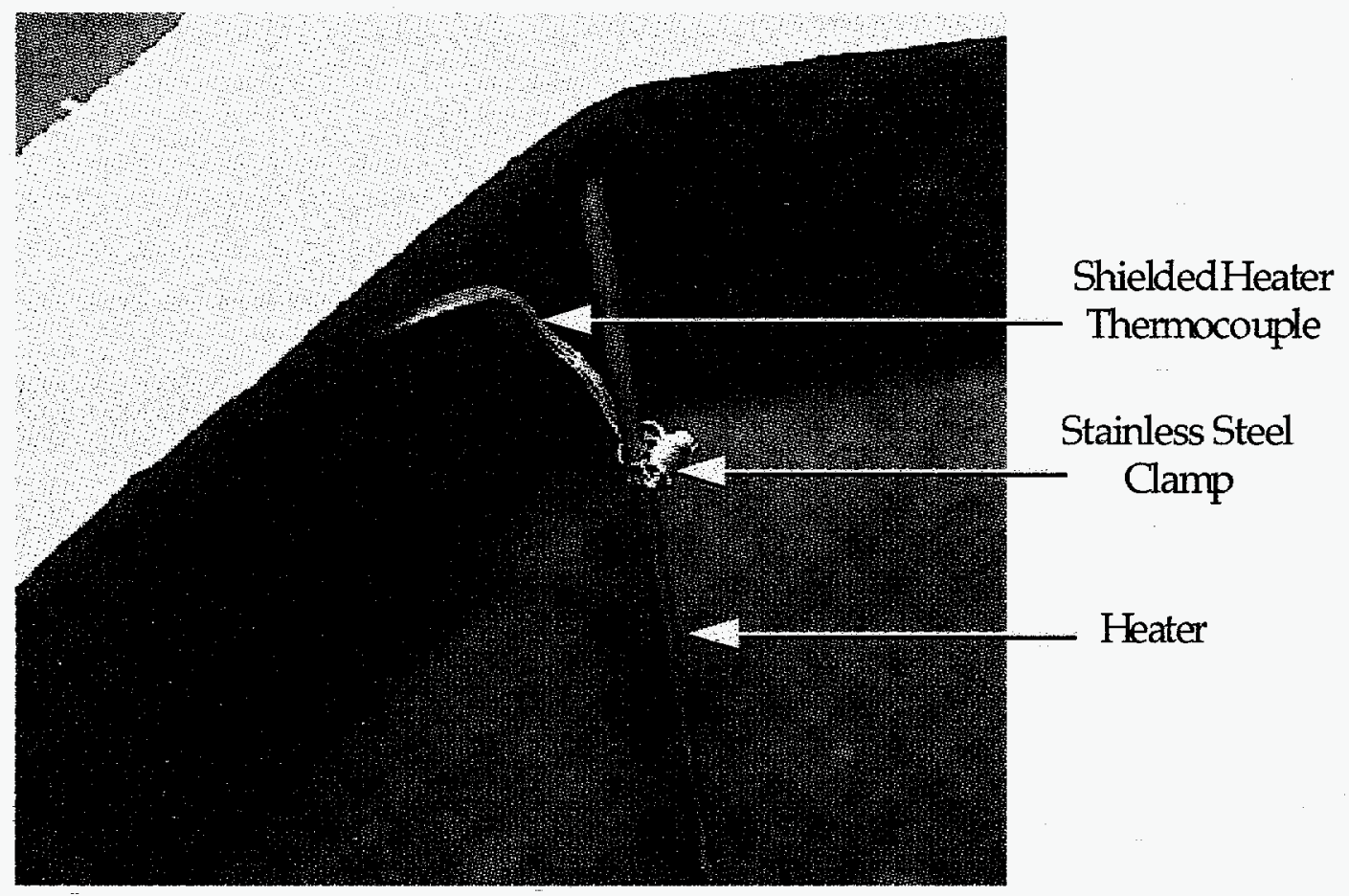

Figure 3-4. Detail of Heater Showing Shielded Thermocouple and ClampAssembly 

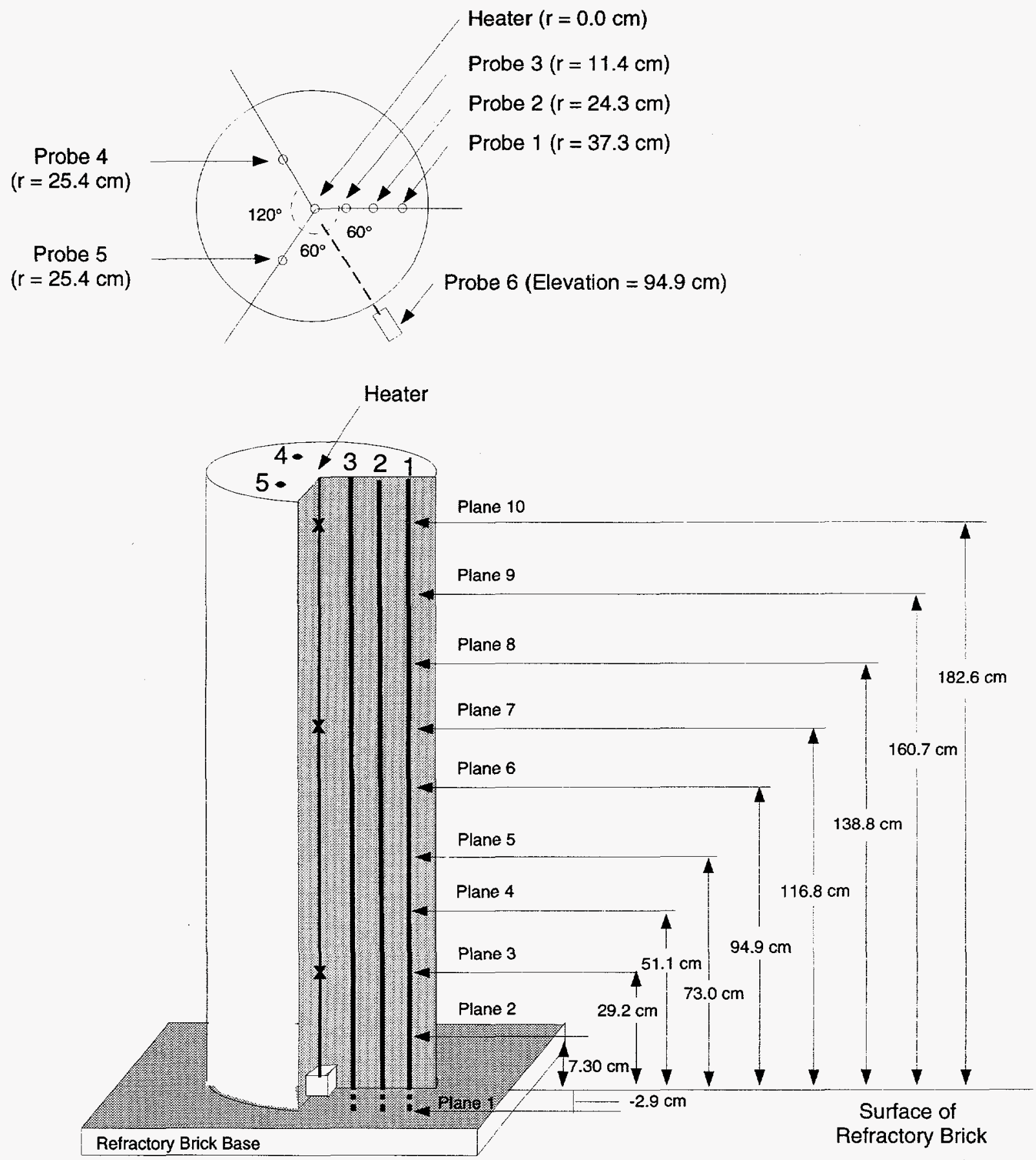

Notes: Drawings not to scale

$X$ on heater indicates location of thermocouples (Planes 3,7 , and 10)

Thermocouples on exterior of steel cylinder not shown, elevations of exterior thermocouples correspond to Planes 2 through 10

Thermocouples on insulation not shown, elevations of radial insulation thermocouples correspond to Planes 3,7 , and 10 . One thermocouple placed on insulation cap.

Figure 3-5. Schematic Showing Locations of Thermocouples and Thermocouple Probes 
This page has been intentionally left blank. 


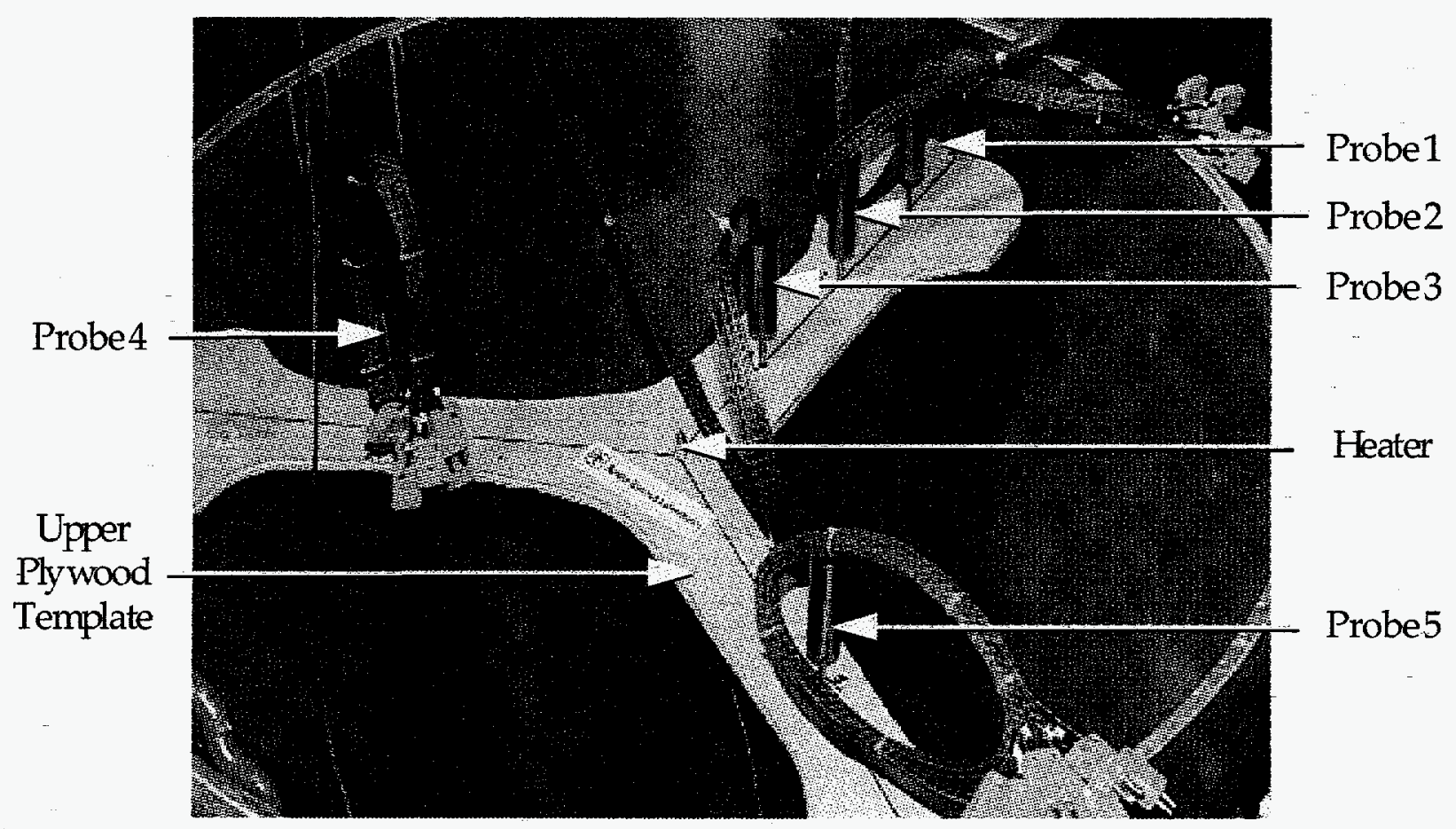

(a)

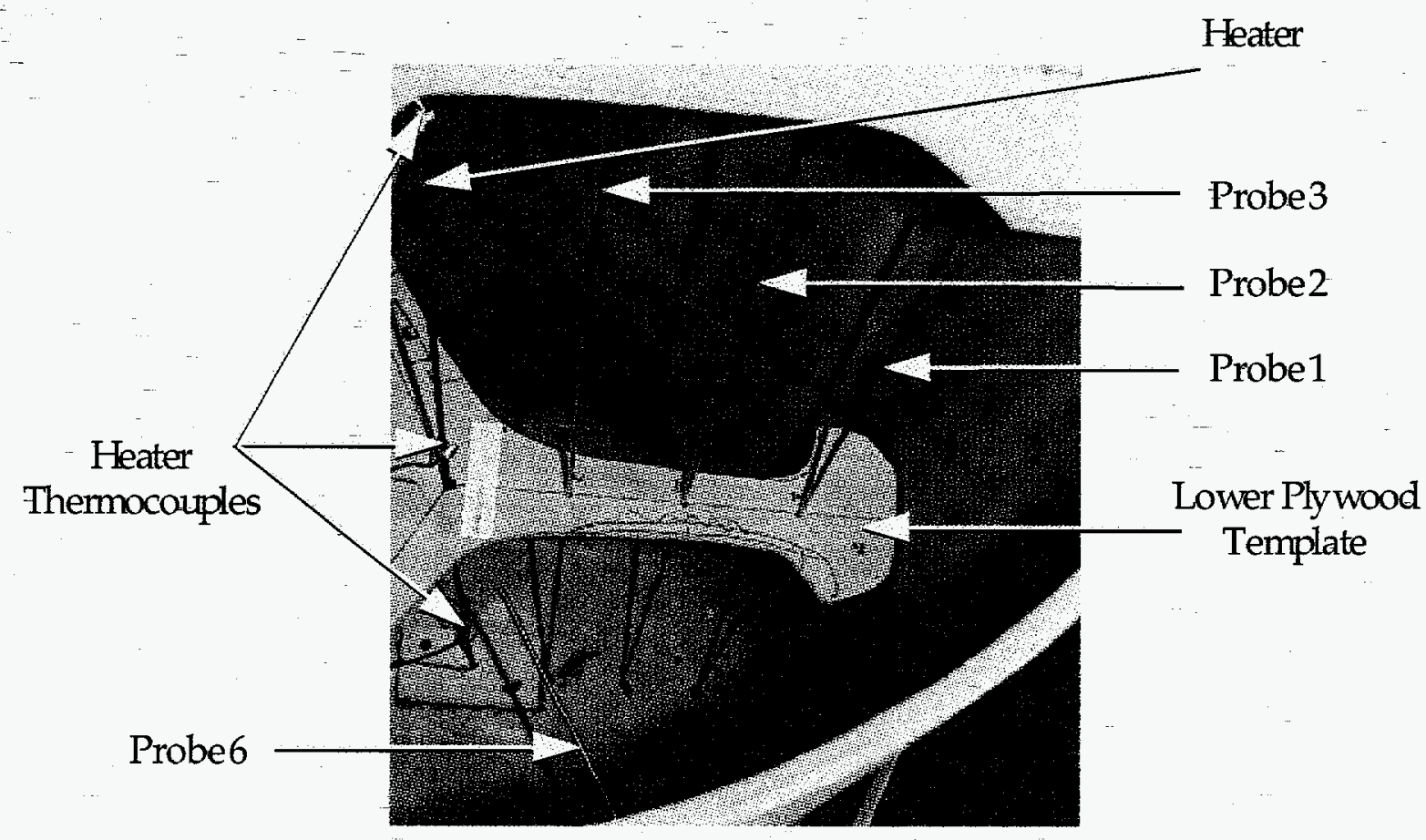

(b)

Figure3-6. Test Apparatus ShowingRelative Locations of Thermocouple Probes 


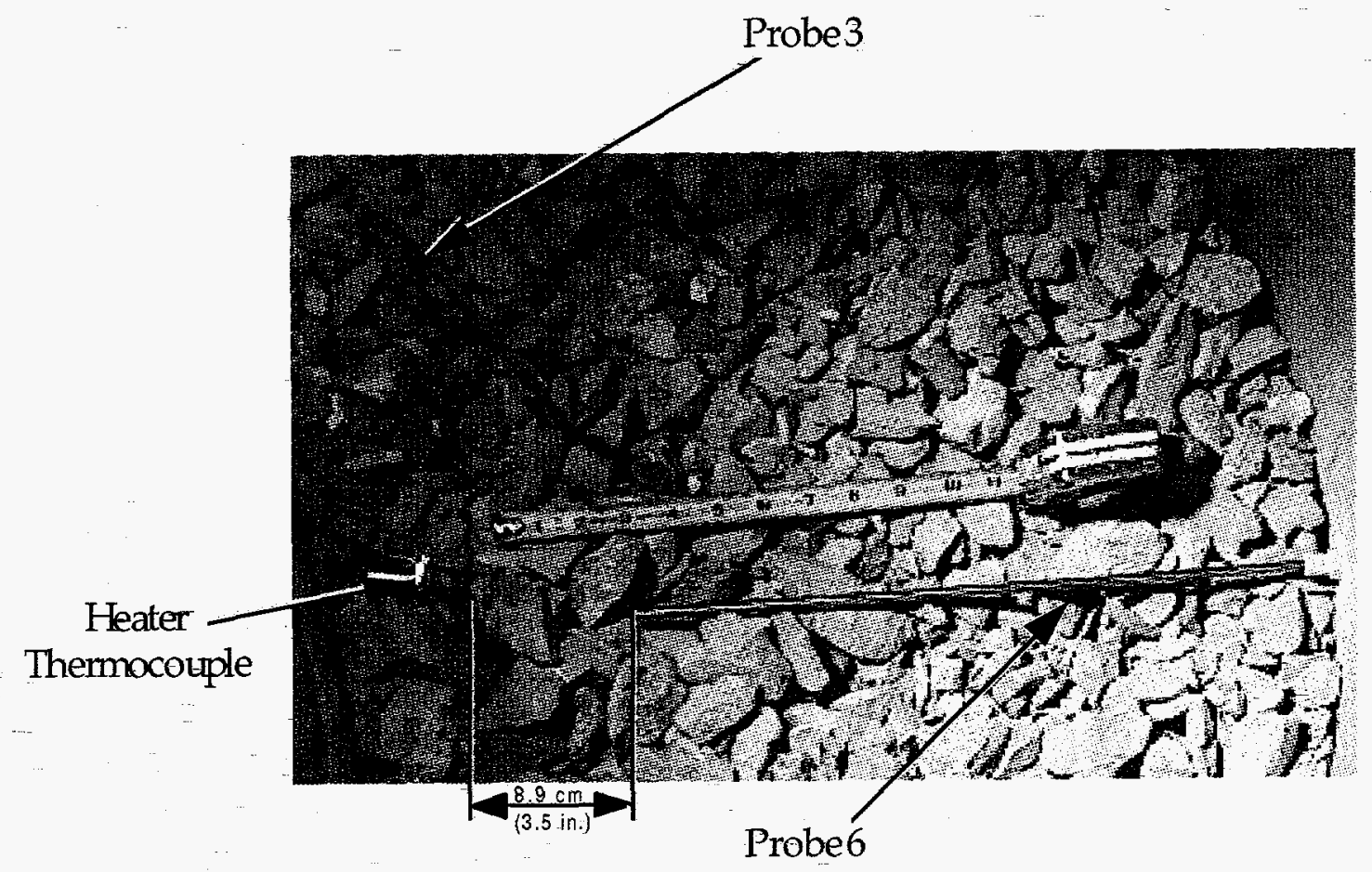

Figure 3-7. Detail of Probe 6 


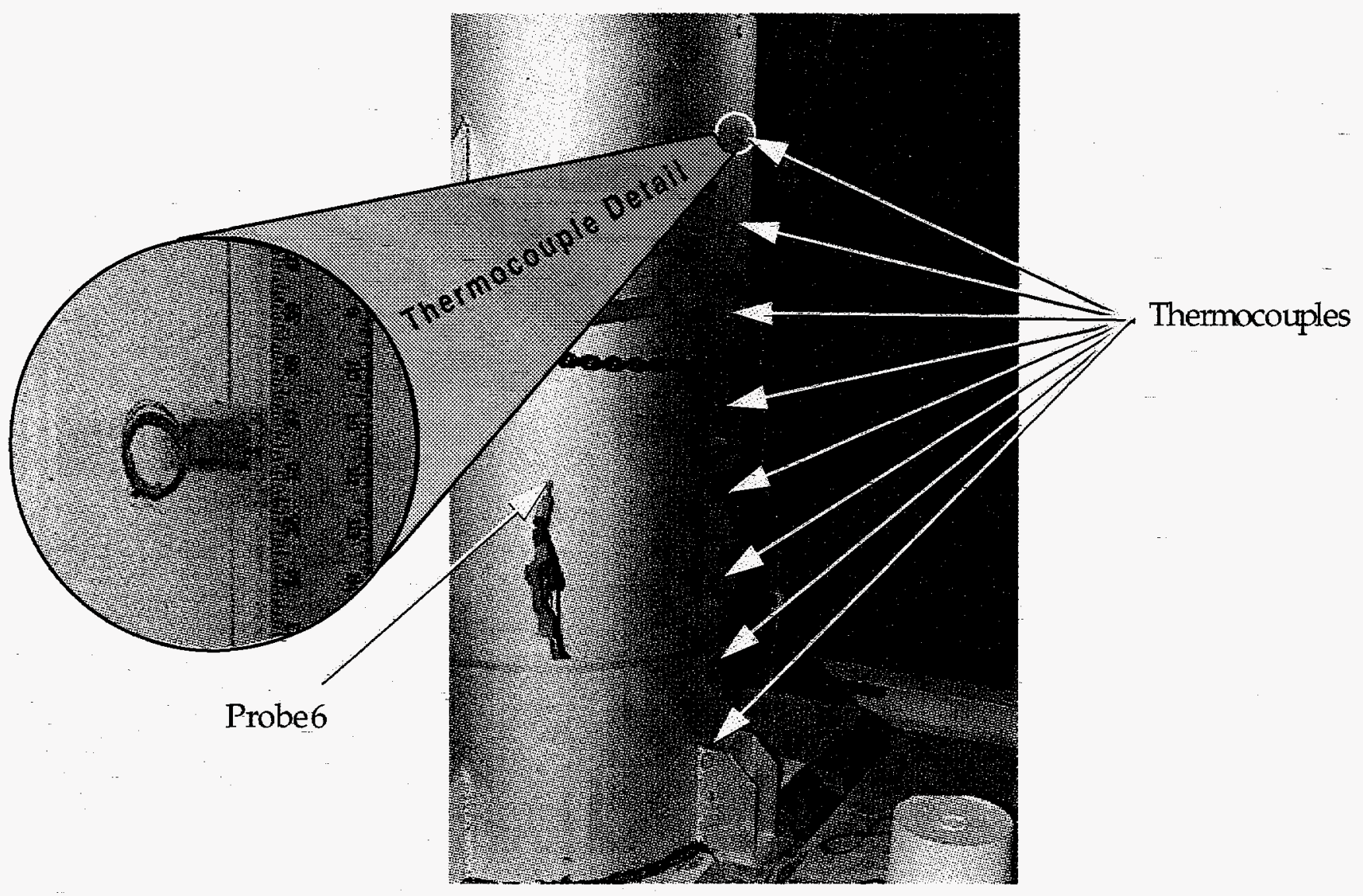

Figure 3-8. Test Apparatus Showing Locations of Thermocouples Attached to the Surface of the Steel Cylinder 
The feedback loop (Figure 3-9) consisted of the control thermocouple, a silicon controlled rectifier (SCR) used to regulate current to the heater, a microprocessor-based process control unit, and a Magtrol power monitor. Readings from the control thermocouple were routed to the data acquisition system (DAS) and to the process control unit which checked the output against a set temperature. The process control unit then transmitted a control signal to the power control unit. The current supplied to the heater, and hence the heater power output, was then modified up to eight times per second to minimize the difference between the feedback thermocouple's temperature reading and the programmed set temperature.

Data were collected using a data acquisition system consisting of a HewlettPackard HP-3497 data acquisition control unit and an IBM-386 PC. Data were collected continuously throughout the duration of both the heat-up and cool-down phases of the experiments.

\subsection{TEST 1}

During the filling of the test cylinder, the weight of the rock placed in the test apparatus was recorded and five grab samples totaling $15 \mathrm{~kg}(33 \mathrm{lb})$ were taken. The grab samples were used to establish the initial moisture content of the crushed tuff. Moisture contents were determined using the procedure outlined in ASTM standard C566-89 [ASTM, 1989]. The results indicate that the crushed tuff used in the experiment had a volume weighted average initial moisture content of $1.31 \%$ by weight (range $1.14 \%$ to $2.04 \%$ ). The individual samples were assumed to be representative of the initial moisture contents of the regions shown in Figure 3-10.

The average bulk density of the solid particles, corrected for a $1.31 \%$ initial moisture content, is $2.35 \mathrm{~g} / \mathrm{cm}^{3}$. The total weight of crushed tuff filling the container was, therefore, $1,940 \mathrm{~kg}(4276 \mathrm{lb})$. This weight, coupled with the particle density and the filled container volume of $1.58 \mathrm{~m}^{3}\left(96,310 \mathrm{in}^{3}\right)$ yields a porosity of approximately $48 \%$ for the 
This page has been intentionally left blank. 


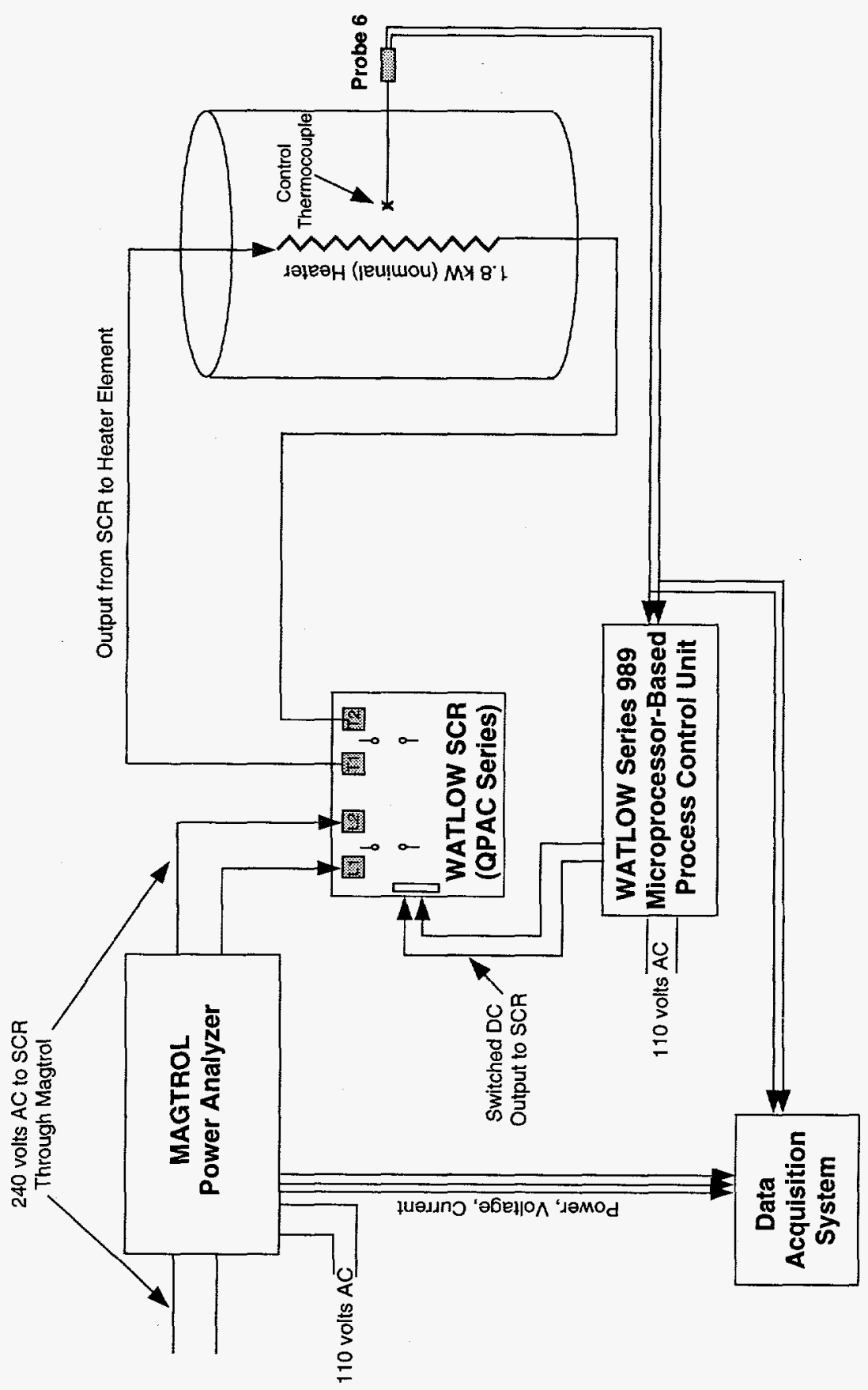

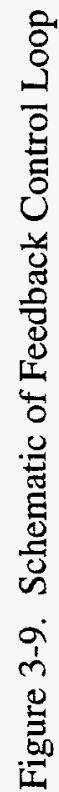




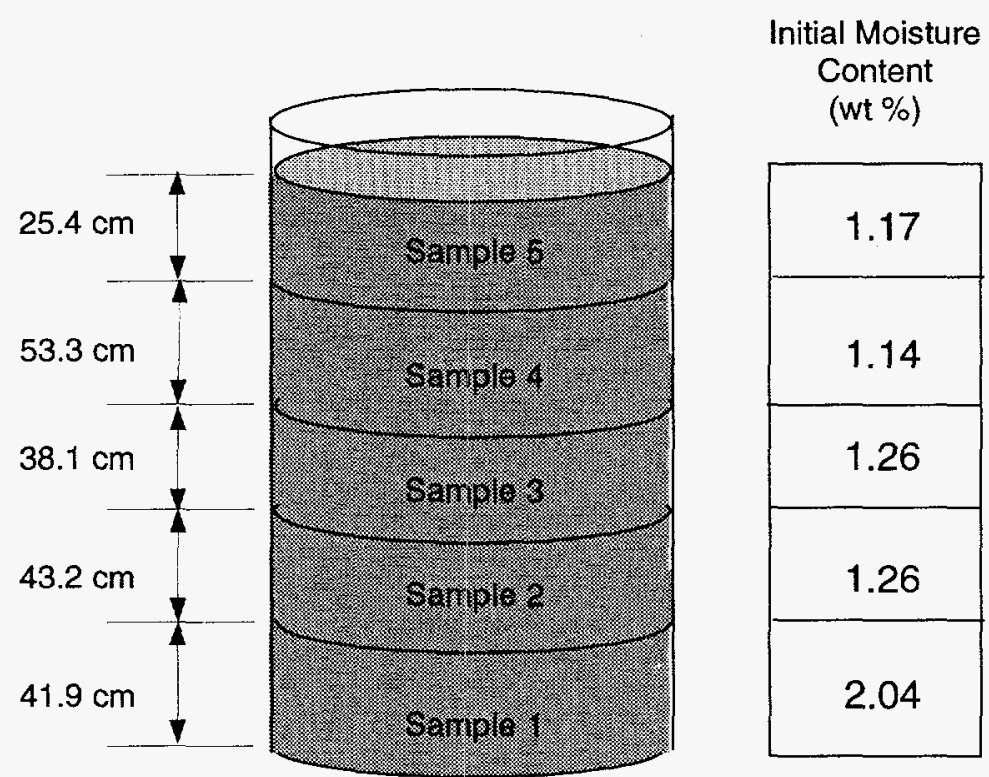

Filled volume of test apparatus

Figure 3-10. Volumes Represented by Grab Samples and Associated Initial Moisture Contents 
crushed tuff in the container. This porosity is consistent with the 25 to $53 \%$ porosities obtained in large-scale laboratory tests of backfill emplacement techniques reported by Stout and Friel [1982].

Once the test set-up was complete, full power was applied to the heater for approximately 23.5 hours. Due to power grid fluctuations, the actual heater power ranged from approximately $1730 \mathrm{~W}$ to $1940 \mathrm{~W}$. Based on linear regression of the data, the mean power output of the heater over the first 23.5 hours was $1853 \mathrm{~W}$. After 23.5 hours, temperatures near the potting adapters of the thermocouple probes were such that the heater power had to be regulated to guarantee survival of the instruments. The set point on the feedback loop was therefore set to $250^{\circ} \mathrm{C}$. Since the feedback thermocouple was already reading $273^{\circ} \mathrm{C}$, this resulted in a short power-down cycle (approximately 1 hour) followed by a continuous regulation of the heater power for an additional 72.5 hours. Heater power was terminated when the temperature readings for all thermocouples on Probes $1,2,3$, and 6 showed less than a $0.3^{\circ} \mathrm{C} / \mathrm{hr}$ rate of change. Measurements of temperature continued for approximately 18 days following the termination of heater power. Figures 3-11 presents isothermal plots of the experimental data for Probes 1, 2, and 3 and the outer shell thermocouples at various times during Test 1 . Complete heater power and thermocouple data from Test 1 are presented in Appendix A.

\subsection{TEST 2}

A second heating and cooling cycle of the test bed was completed prior to the dismantling of the experiment. The purpose of the second test was to obtain some temperature data over the time period between 5 and 13 hours of full-power heating. This time period corresponds to a failure in the Test 1 data acquisition system during which no temperature data were recorded. In addition, Test 2 was used as a means of developing a limited assessment of the reproducibility of the data obtained in the first experiment. Full power was applied to the heater for approximately 11.6 hours followed by 10.8 hours of regulated power. During the full-power cycle, power readings ranged from $1740 \mathrm{~W}$ to 

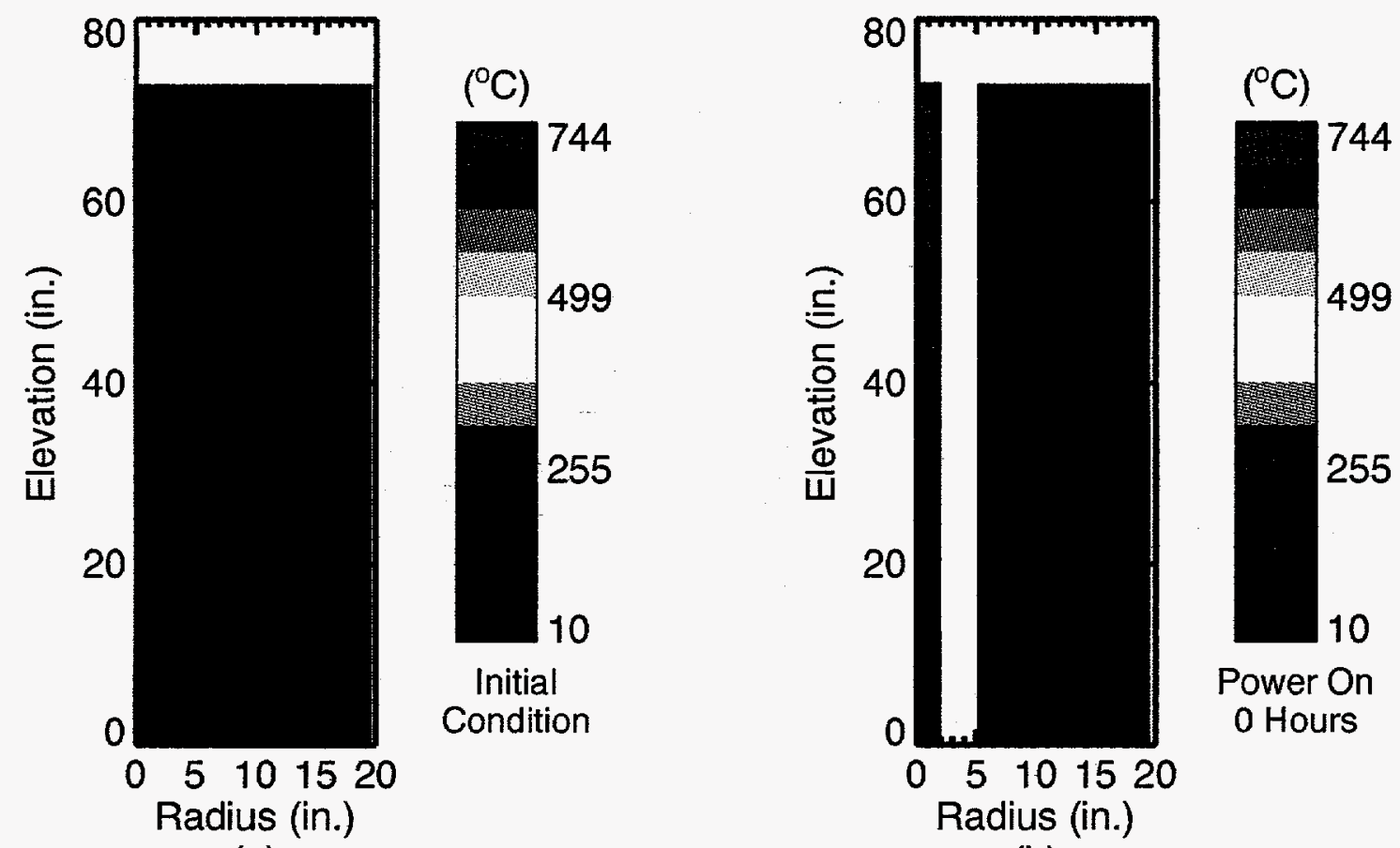

(a)
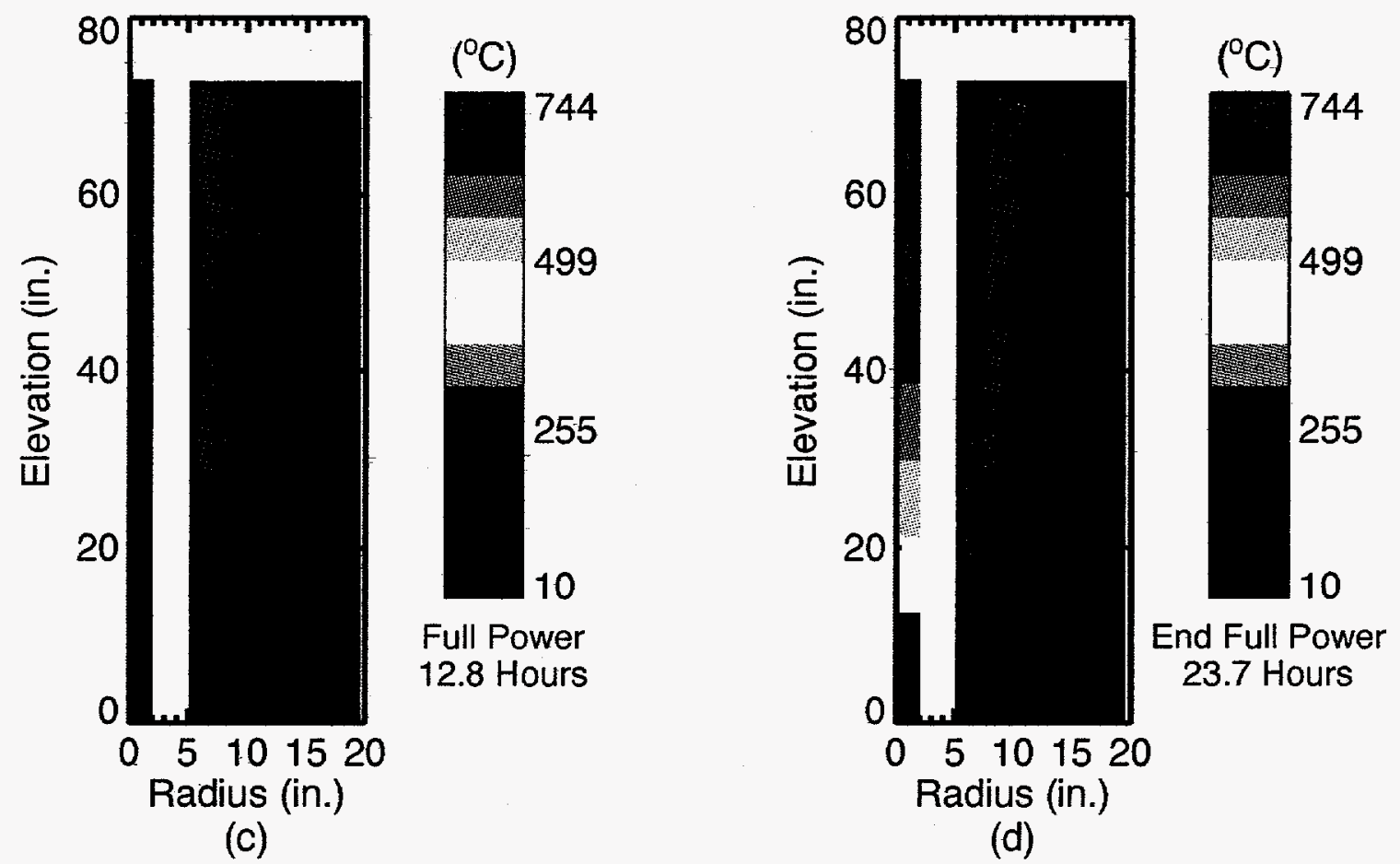

Note: Due to the steepness of the thermal gradient between the heater and Probe 3, no interpolations of isothermal contours are presented in this region.

Figure 3-11. Isothermal Contours for Test 1 


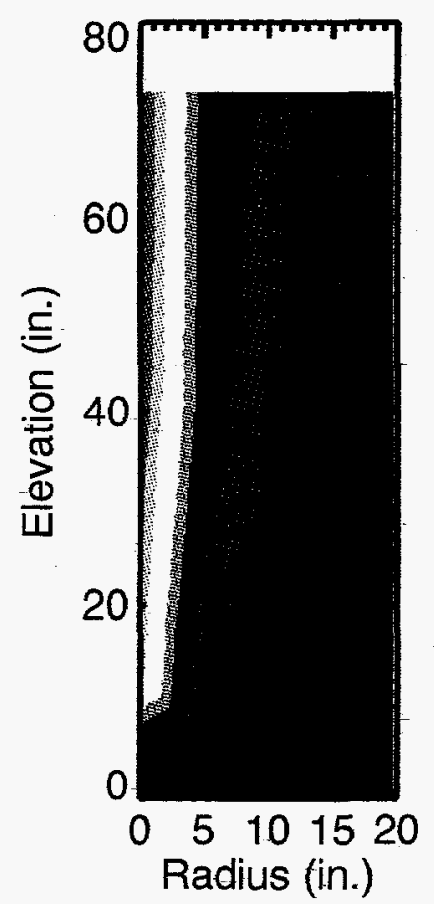

(e)

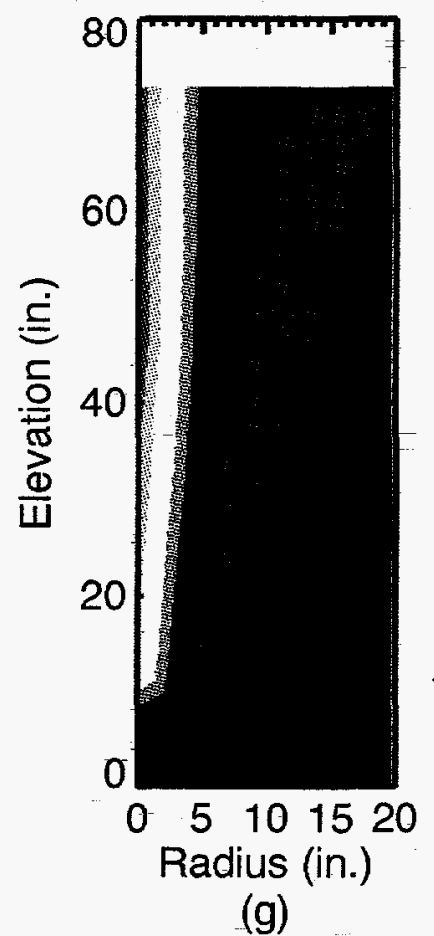

$\left({ }^{\circ} \mathrm{C}\right)$

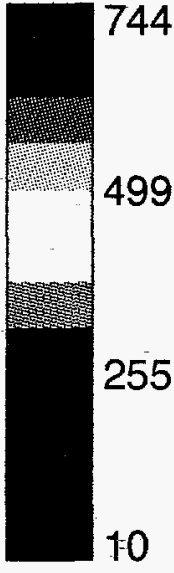

Start of Tuned Power 25.0 Hours

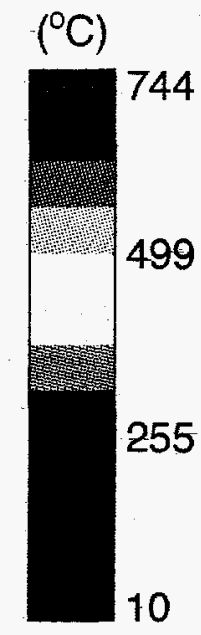
Tuned Power 62.1 Hours

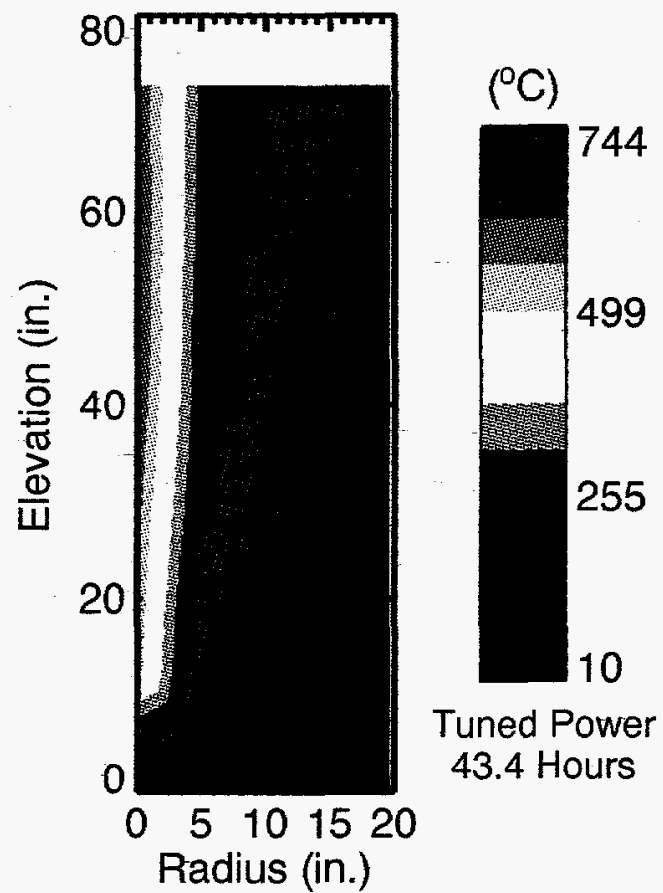

(f)

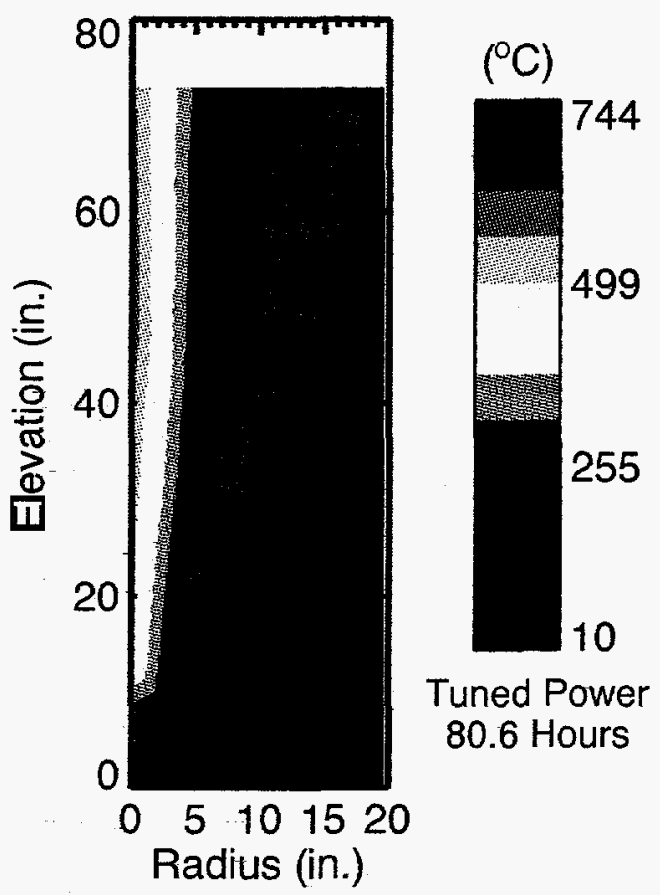

(h)

Figure 3-11. Isothermal Contours for Test 1 (continued) 

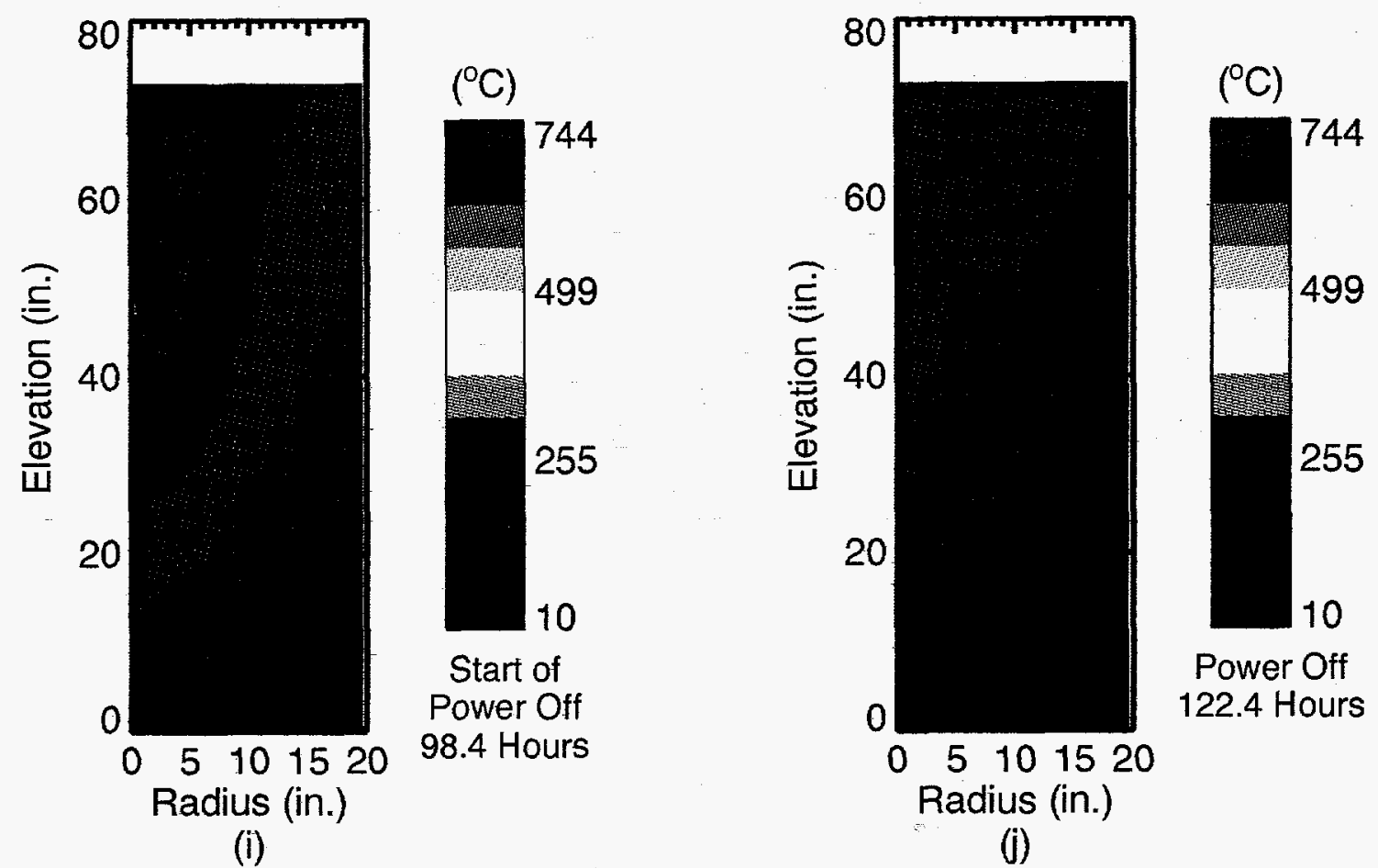

Power Off 98.4 Hours

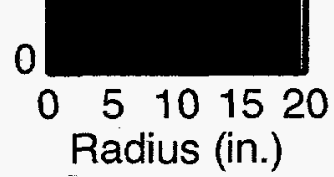

Power Off 122.4 Hours
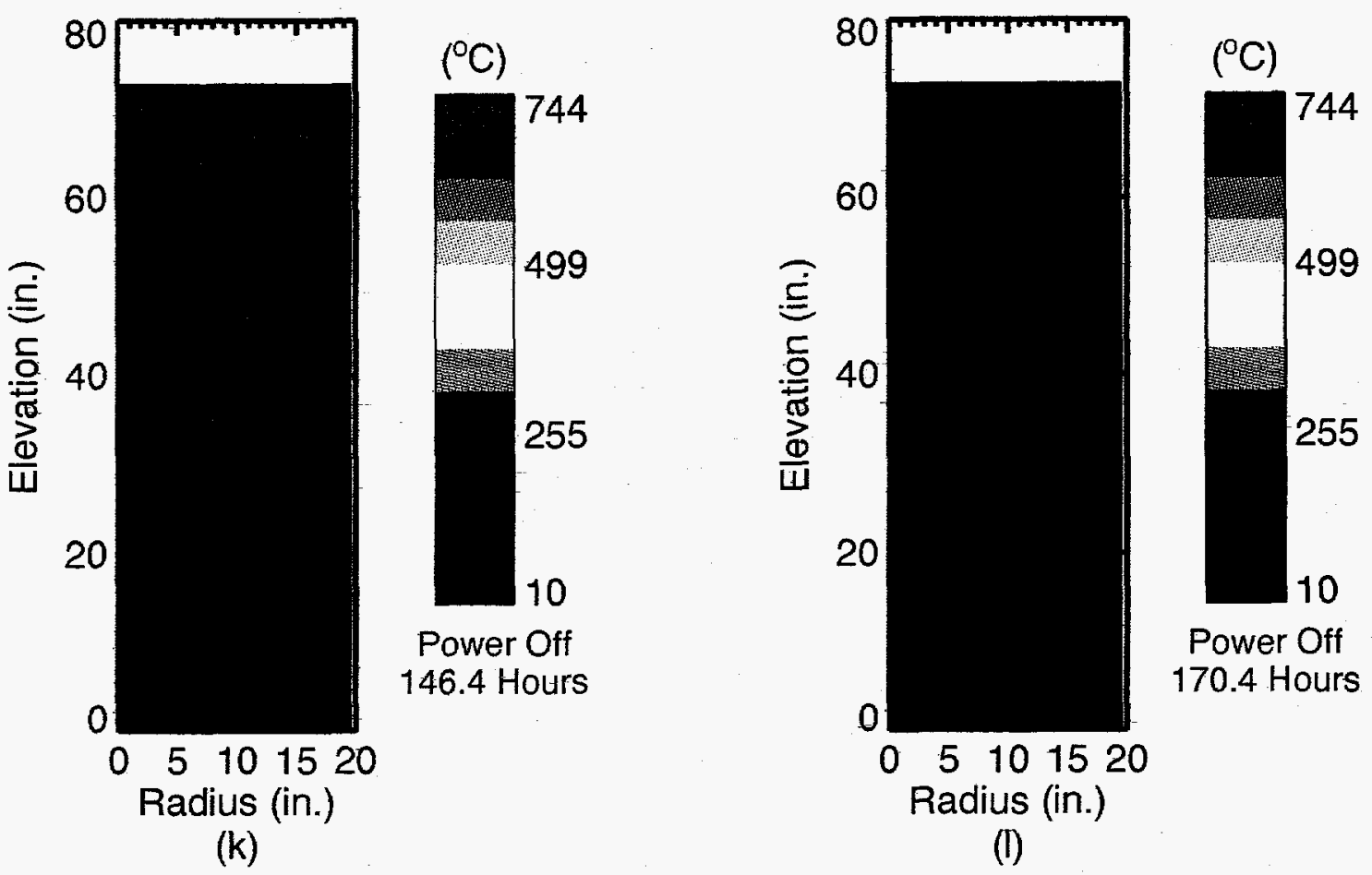

Figure 3-11. Isothermal Contours for Test 1 (concluded) 
$1890 \mathrm{~W}$, with the mean calculated as $1839 \mathrm{~W}$. A mean of $1576 \mathrm{~W}$ was calculated for the 10.8 hour period of regulated power. Following the termination of heater power, cooldown data was recorded for nine days. Figure 3-12 presents isothermal plots of the experimental data for Probes 1, 2, and 3 and the outer shell thermocouples at various times during Test 2. Complete heater power and thermocouple data from Test 2 are presented in Appendix B.

\subsection{OBSERVATIONS}

\subsubsection{Convection}

The temperature data obtained from the axial thermocouple probes indicate that convection played an important role in the heat transfer occurring within the test apparatus. Figure 3-11 (c) through (h) are typical examples of the type of behavior observed. The increased temperatures near the top of the container are indicative of convective effects. Similarly, the slow movement in temperature readings registered by the thermocouples imbedded in the refractory brick (i.e., the tip of each axial probe) also indicates that strong convection was present during heating. The issue of convection will be explored further in Chapter 4 .

\subsubsection{Moisture Content and Circulation}

During the heating phase of the first experiment, small amounts of moisture were seen to exit the system through instrumentation gaps in the upper insulation cap. It is believed that a significant amount of the moisture originally present in the system (approximately 25 liters) was able to exit the system during Test 1 . Because of the tortuous path the escaping moisture had to follow, however, it is hypothesized that the loss of moisture from the experiment was gradual (requiring on the order of 3 to 4 days). The final moisture content of the test bed was determined using samples of crushed tuff 
This page has been intentionally left blank. 


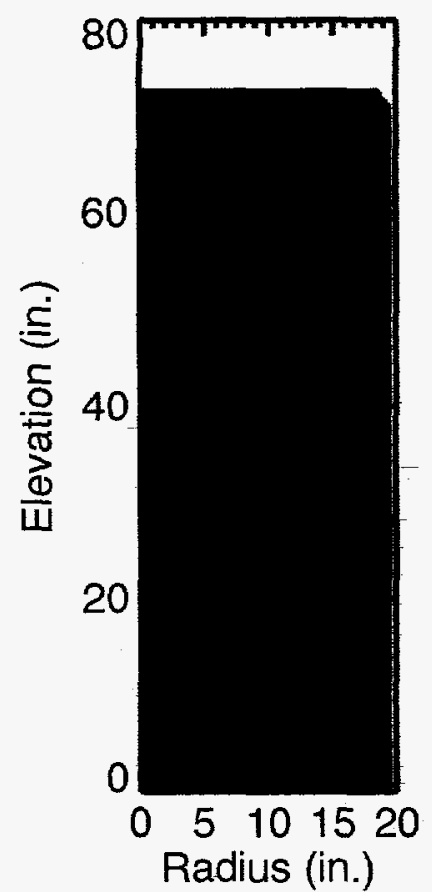

(a)

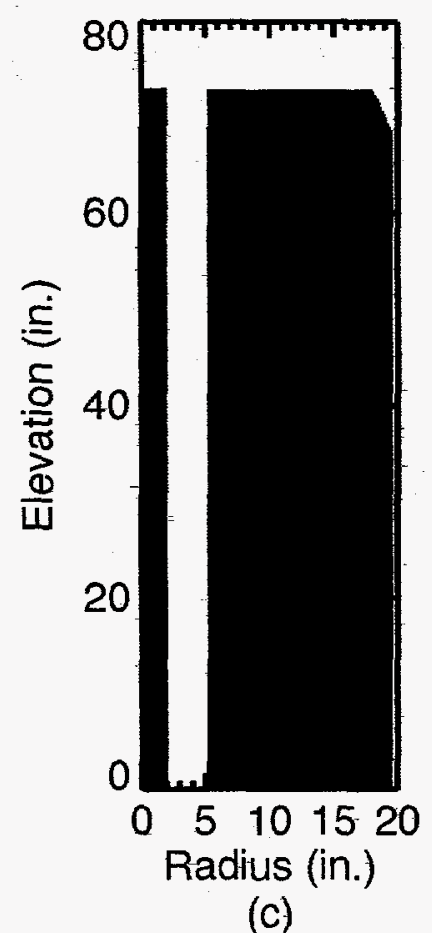

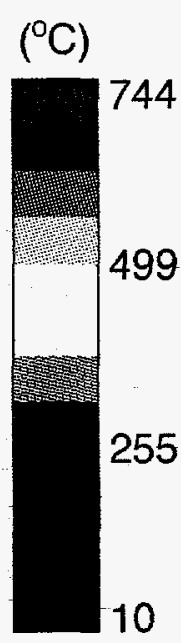

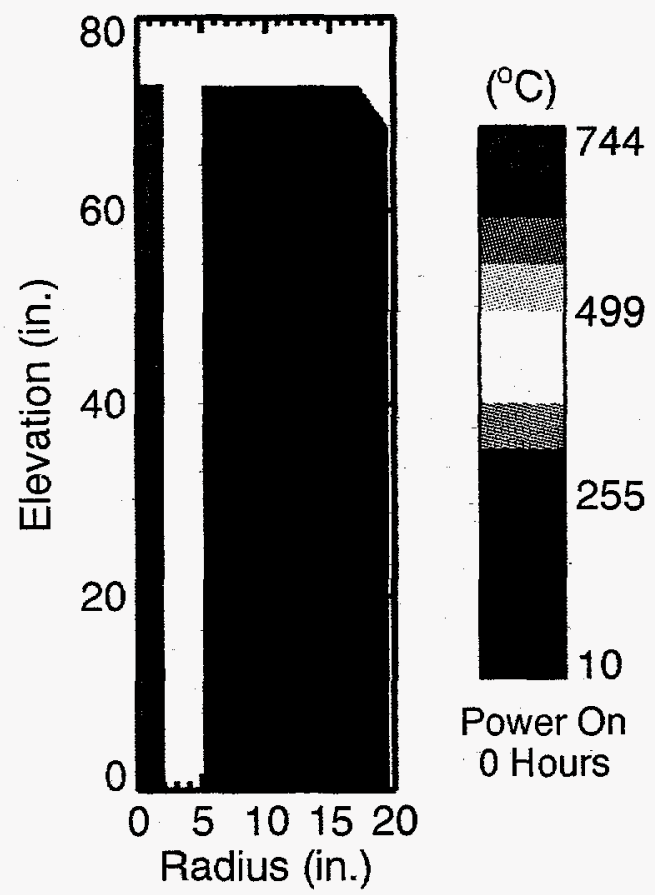

Initial

Condition

(b)

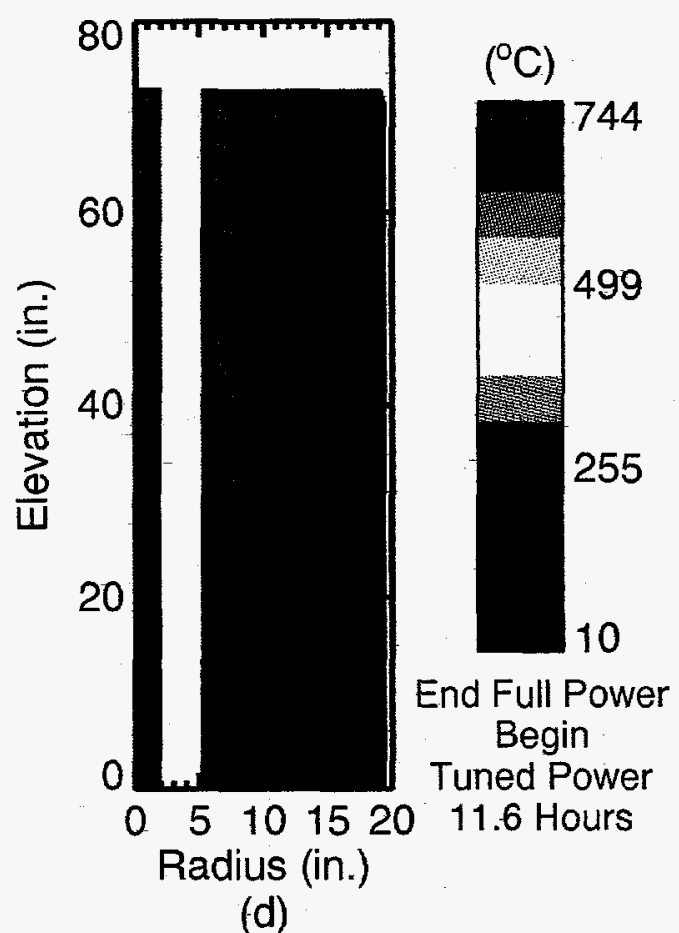

Note: Due to the steepness of the thermal gradient between the heater and Probe 3, no interpolations of isothermal contours are presented in this region.

Figure 3-12. Isothermal Contours for Test 2 

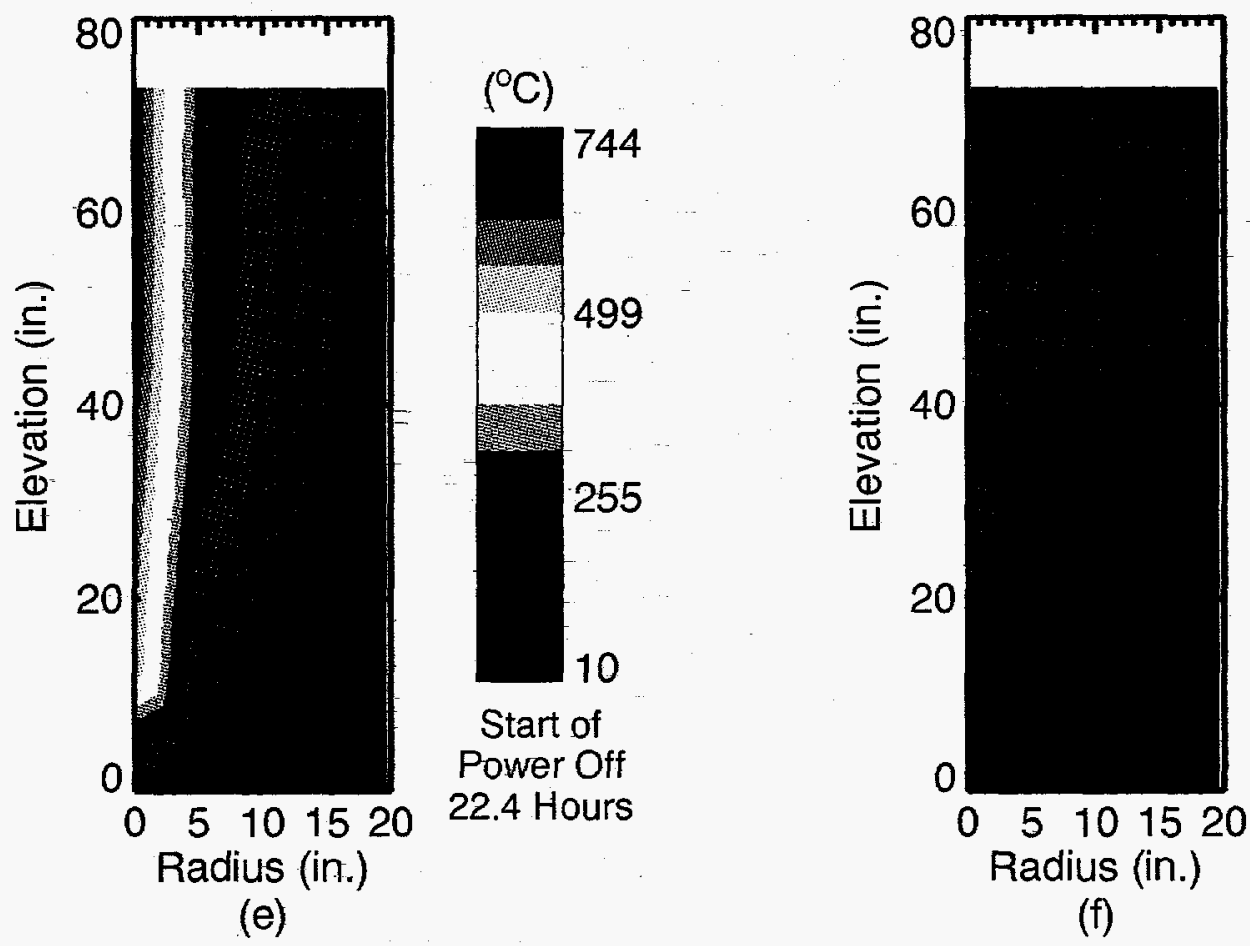

$\left({ }^{\circ} \mathrm{C}\right)$

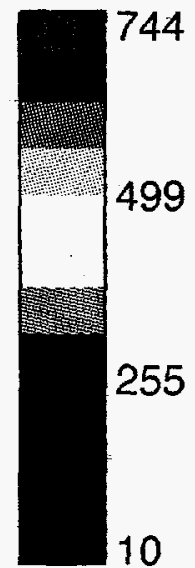

Power Off 46.4 Hours
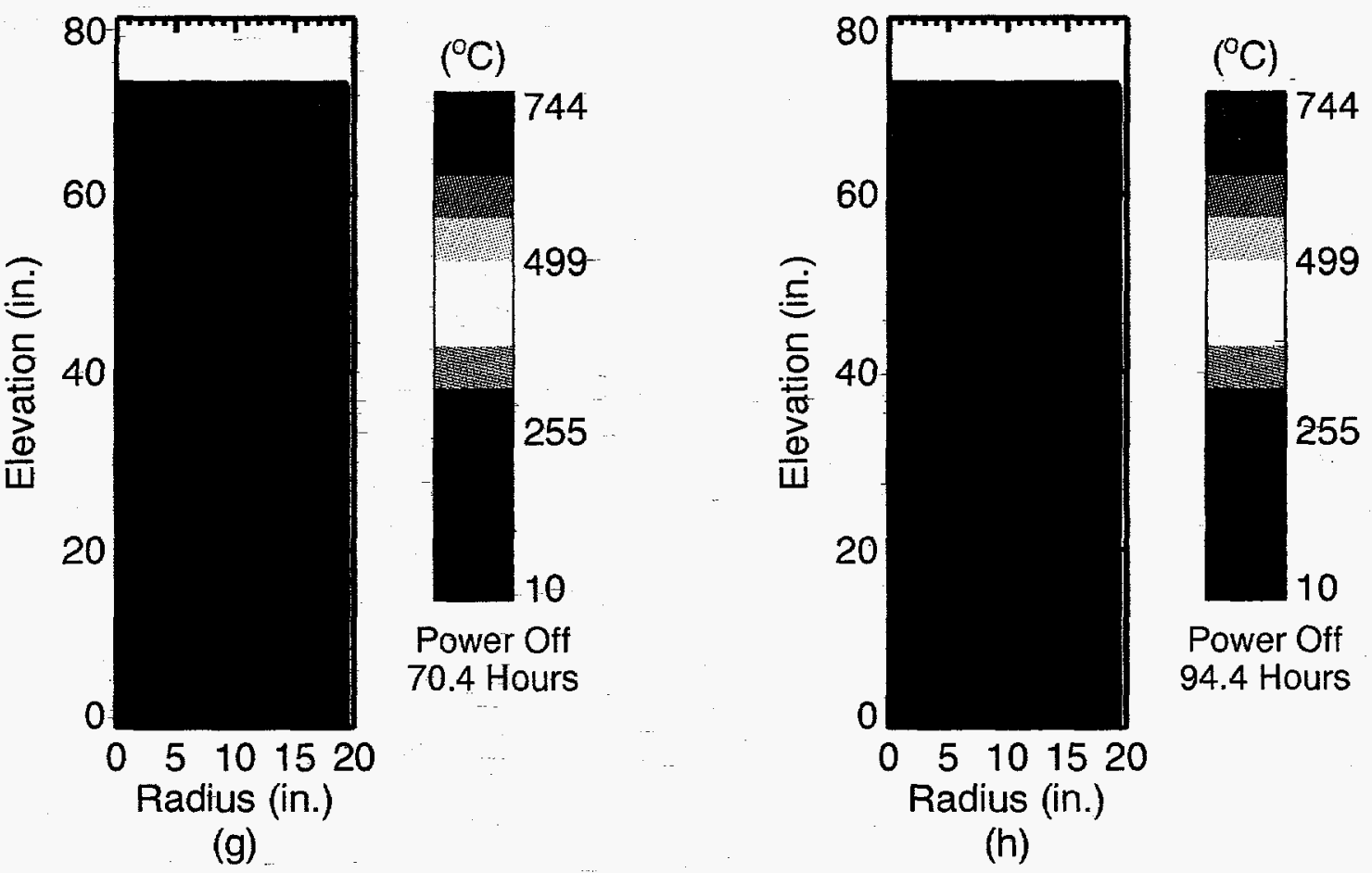

Figure 3-12. Isothermal Contours for Test 2 (concluded) 
taken during the dismantling of the experiment. Using the same procedure discussed in Section 3.3, the final average moisture content (following Test 2) was found to be $0.14 \%$ by weight (as compared to $1.31 \%$ at the start of Test 1 ).

Confirming the hypothesis that moisture was circulating within the test bed, probably during Test 1 , are observations of large amounts of new rust on the interior surface of the steel cylinder. Visual observations suggest that moisture condensed on the inner surface of the cylinder in sufficient quantities to create rivulets of moisture that in turn resulted in noticeable quantities of new rust. The rivulets were of sufficient mass that they were able to deposit significant amounts of the corrosion products on crushed tuff particles in contact with the cylinder wall.

\subsubsection{Chemical Depositions}

During the dismantling of the experimental apparatus, chemical depositions of a yellow material were observed on particles that were in contact with or very near the heating element. Samples of the material were analyzed using optical microscopy, scanning electron microscopy, and X-ray spectrometry. Under the optical microscope, the material occurs most commonly as coatings on secondary calcite, although it was also observed on fresh rock surfaces that had no visible calcite present. The material was seen to occur as bright yellow, "fluffy" masses. Under the scanning electron microscope, the material is seen to occur as very fine grained, irregular clumps, scattered across a finegrained matrix. X-ray spectra of the clumps shows them to consist predominately of chromium and calcium. Very minor amounts of iron and aluminum may also be present, although it is impossible to determine if these elements actually occur in the yellow material, or are confined to the matrix. The combination of color and chemistry indicates this material to be calcium chromate $\left(\mathrm{CaCrO}_{4} \bullet \mathrm{H}_{2} \mathrm{O}\right)$. In the formation of the calcium chromate, $\mathrm{CO}_{2}$ is liberated. Combining the $\mathrm{CO}_{2}$ with circulating steam may have formed a weak solution of carbonic acid. This is one explanation for the large amounts of new rust seen on the containment vessel during decommissioning. 
Since the calcium chromate depositions were only observed on rocks in extreme proximity to the heater element, the logical source of the chromium has to be the heater element and/or the three thermocouples and clamps attached to the heater. The heater element is made from Inconel. Inconel has a chromium content ranging from 16 to $21 \%$ [Baumeister and Marks, 1967]. Similarly, the stainless steel comprising the sheaths of the high temperature thermocouples and the clamps attaching them to the heater has between 17 and 19\% chromium [Baumeister and Marks, 1967]. Given these percentages, it appears that the heater and thermocouple assemblies are the logical source of chromium in the formation of the calcium chromate.

\subsubsection{Data Reproducibility}

With respect to the issue of data reproducibility between Test 1 and Test 2, only the first 5.3 hours of the two tests are directly comparable. This is because no data exists for Test 1 between 5.3 and 13.6 hours and because Test 2 entered a regulated power state after 11.6 hours of full power, much earlier than in Test 1 . The first 5.3 hours of data from both experiments does allow for a limited assessment of data reproducibility.

During the first 5.3 hours of both experiments, only thermocouples on the heater and on Probe 3 record significant thermal responses. Examining the temperature data from both tests for the three thermocouples attached to the heater, it appears that the magnitudes and shapes of the temperature histories are consistent (e.g., Figure 3-13). It is noted that there is some early scatter present in the heater thermocouple data for Test 1 due to fluctuations in heater power caused by the initial programming of the SCR feedback loop. Shifting attention to a comparison of data obtained for Probe 3 , Figure 3-14 illustrates a trend observed for each of the 10 thermocouple sites on Probe 3. Specifically, the general shapes of the data traces from both tests are similar; however, the Test 1 data is always lower than the Test 2 data. One possible explanation for this is that during the early stages of Test 1 a significant portion of the energy introduced by the heater went into the vaporization of the moisture within the crushed tuff. On the order of 


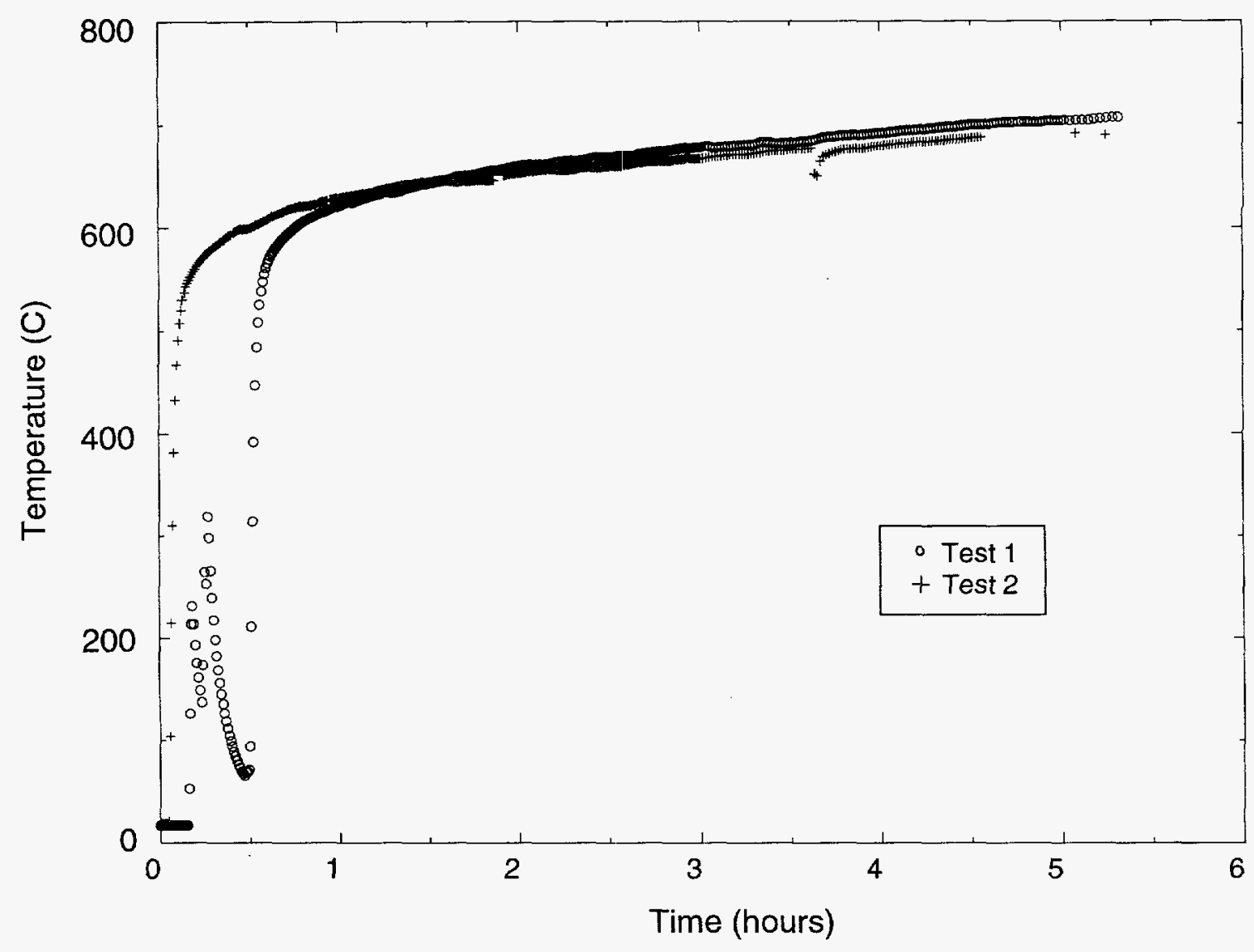

Figure 3-13. Comparison of Heater Surface Temperature Data at Plane 7 for Tests 1 and 2 


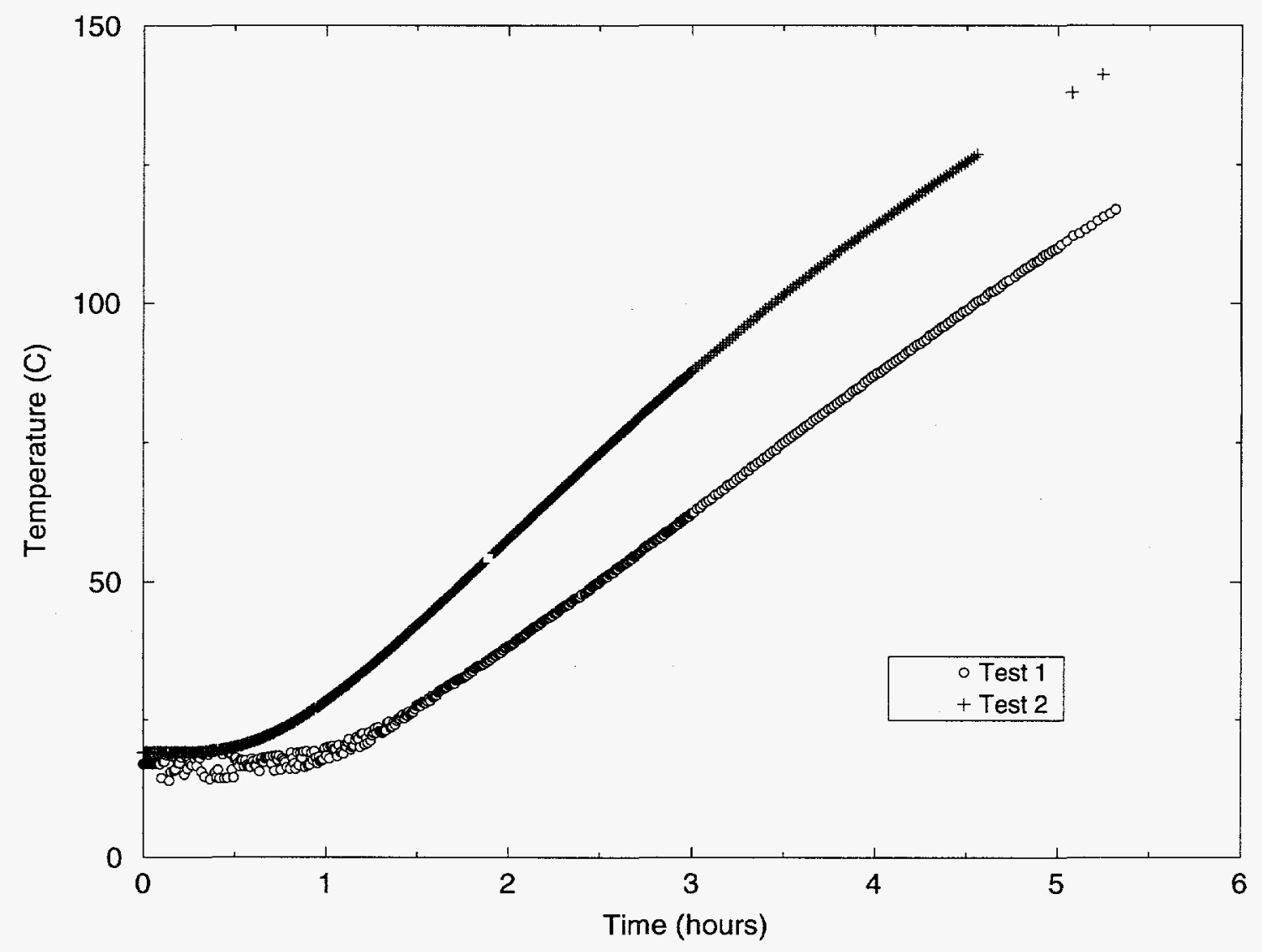

Figure 3-14. Comparison of Temperature Data from Plane 7 of Probe 3 for Tests 1 and 2 
$90 \%$ of the moisture initially present in the crushed tuff is hypothesized as having been driven off before the start of Test 2 . Hence, it is reasonable to expect that the thermal response recorded by Probe 3 in Test 2 would be higher than that recorded in Test 1 . The correspondence of the general shapes of the thermal responses, however, gives confidence that the data obtained from both tests are reasonable and that similar tests conducted at a later date would provide similar results.

\subsubsection{Conduction Along Thermocouple Probes}

As indicated in Section 3.2, Probe 6 was installed to provide data related to measurement errors resulting from thermal conduction along the stainless steel outer sheath of the STI thermocouple probes. To establish a quantitative assessment of this type of measurement error, a significant region of one-dimensional radial heat transfer would need to exist around the location of the radial probe. Due to convective effects, such a region did not develop in these experiments. However, the thermal profiles are sufficiently flat around Probe 6 to allow for a qualitative assessment of the effects of heat conduction along the STI probes.

Using data from Test 1 as examples, Figure 3-15 is typical of the relationship observed during heating between data from Probe 6 and data from plane 6 of Probes 1, 2, and 3. It appears from Figure 3-15 that the Probe 6 data is lower than would be predicted based on extrapolation of the Probe 1,2, and 3 data. This may indicate that Probe 6 was acting like a fin with the ambient environment and recording lower temperatures as a result. This is not an unreasonable hypothesis given the fact that the potting adapter of Probe 6 extended beyond the radial insulation of the test apparatus and was observed to increase in temperature during the experiment. The general trend in data illustrated by Figure 3-15 was found to persist in Test 1 for approximately 20 hours past the termination of heater power. This is as expected, since the thermal mass established by the heater still acts as a strong driving force for radial heat flow for some time after the conclusion of the heating cycle. 


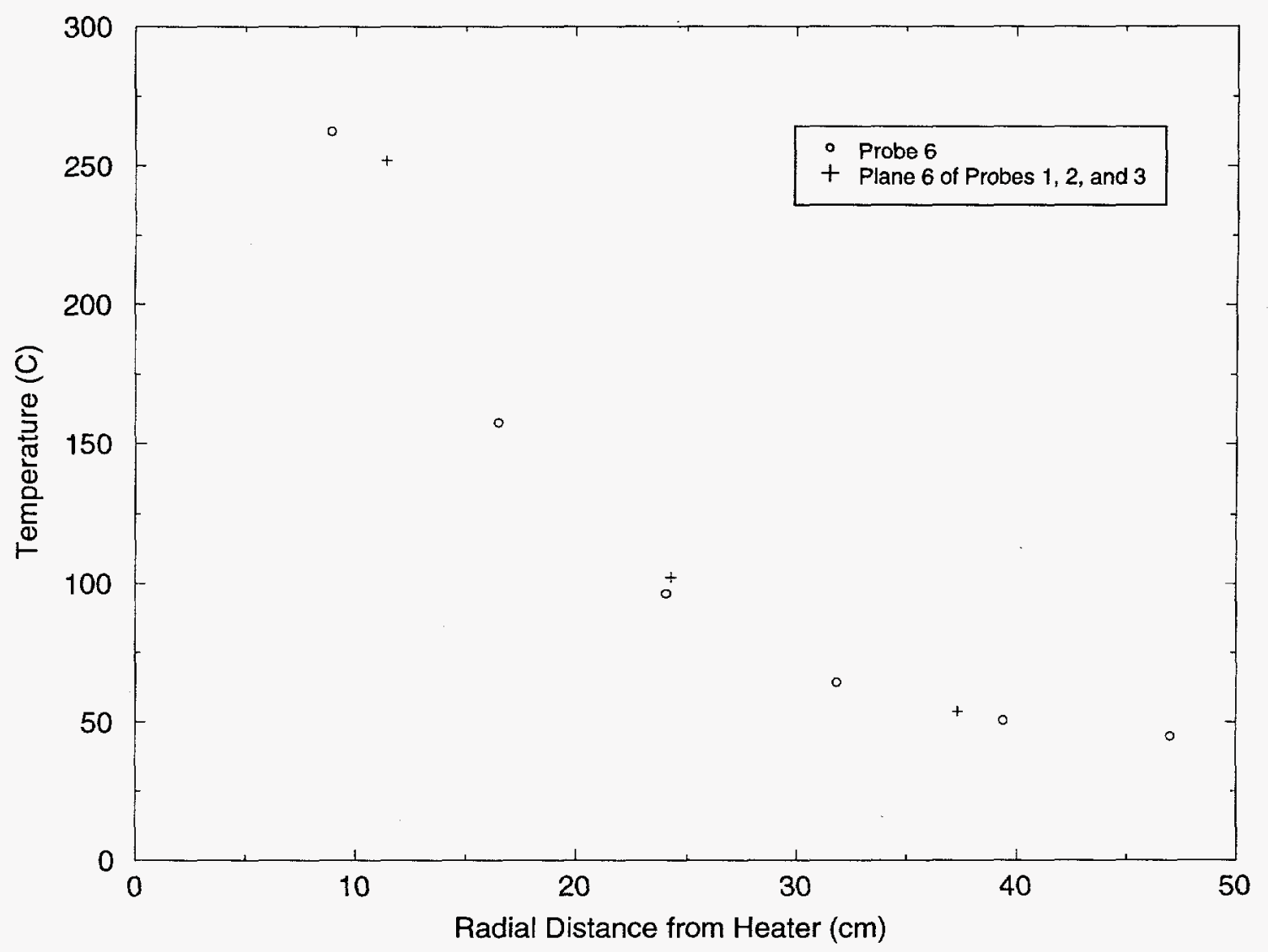

Figure 3-15. Comparison of Data Obtained at 22 hours in Test 1 from Probe 6 and from Plane 6 of Probes 1, 2, and 3 
The driving force for radial heat flow diminishes with time; however, and the relative strength of the component of axial heat flow (due to the low temperature of the bottom boundary) increases. This results in a rotation of the effective orientations of Probes $1,2,3$, and 6 to the direction of heat flow. The effect of this rotation is evident in Figure 3-16 where the trends seen in Figure 3-15 are reversed. Specifically, the data from Probe 6 are now higher than would be predicted by an extrapolation of the data from Probes 1,2, and 3. Given that a strong axial component to the heat transfer is present, this may indicate the Probes 1,2 , and 3 are now acting as fins, linked to the lower boundary of the test apparatus.

During both the heating and the cooling cycles of the experiments documented in this report, two-dimensional heat transfer occurred. This means that neither the axial probes nor the radial probe were perfectly perpendicular or parallel to the direction of heat flow. Figures 3-15 and 3-16 do indicate that thermal conduction along the STI thermocouple probes can affect temperature readings. The exact error introduced by conduction along the probes is currently unknown; however, it is believed to be relatively small.

\subsection{SUMMARY OF TESTS AND OBSERVATIONS}

Two tests were conducted to examine the thermal response of crushed tuff to heating. The crushed tuff test bed had an approximate bulk porosity of $48 \%$. For both experiments, the instrumentation (heaters, thermocouples, and controllers) appeared to work well, with no failures. Several notes were made during decommissioning that may have implications to future crushed tuff experiments or to other large-scale thermal experiments that may be conducted in support of YMP. 


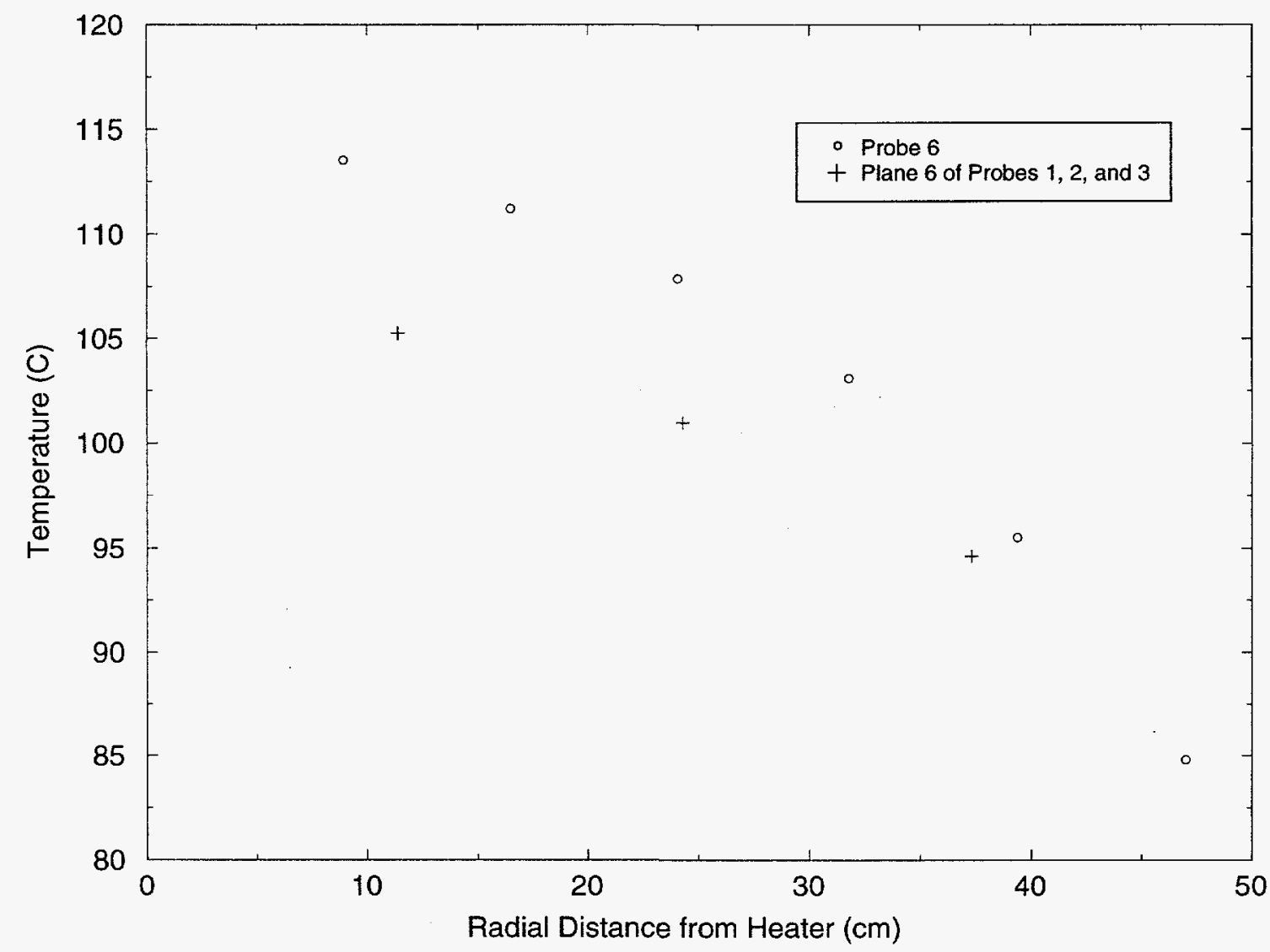

Figure 3-16. Comparison of Data Obtained at 130 hours in Test 1 from Probe 6 and from Plane 6 of Probes 1, 2, and 3 
With regard to the STI thermocouple probes, they were convenient to install and appeared to be sufficiently responsive to the changing thermal environment. The epoxy used in the potting adapters, however, is sensitive to temperature and appears to destabilize at temperatures above $250^{\circ} \mathrm{C}$. Any future probe specifications should be made with a conscious effort to remove the potting adapters from regions of high temperature $\left(>250^{\circ} \mathrm{C}\right)$. Alternatively, other stabilizing compounds could be investigated. Also, the issue of measurement error introduced due to thermal conduction along the probes should be investigated.

The calcium chromate recovered from rocks near the heater points to the apparent participation of the heater with the chemistry of the experiment. If geochemistry is a primary data need from future experiments (laboratory or in situ), the potential effect of the heater material must be considered. Alternate heater materials or the sheathing of the heater may be required to eliminate any biasing of geochemical data.

Finally, a note regarding what was not seen during the decommissioning of the experiment. There was no evidence of thermal or chemical welding of rock particles. This is not to say that other systems would not exhibit some form of bonding, only that for the system examined, it was not observed. It is possible that in systems with greater amounts of circulating water and a pervasive distribution of fine particles, bonding or clumping of particles may be possible. Also, despite the large amounts of cristobalite within the Fran Ridge tuff, there was no evidence of large-scale thermally induced breaking of the particles that might be attributed to silica phase inversions. 


\section{Chapter \\ FOUR}

\section{Post-Test Analyses}

Three methods were used to estimate the thermal diffusivity $(\alpha)$ of the crushed tuff. The first method used nonlinear parameter estimation [Beck and Arnold, 1977] to link a one-dimensional radial conduction model to experimentally determined temperature histories as a method for estimating the bulk thermal diffusivity. As indicated in Chapter 3 , convection appeared to play a significant role in dispersing heat within the crushed-tuff test bed. Therefore, the parameter estimation technique, as coupled with the nonlinear conduction model, could only be applied to data obtained during the first 6 hours of the experiment-prior to the establishment of strong convective effects. A second method using the iterative application of the multiphase TOUGH2 code [Pruess, 1991] allowed not only the estimation of the crushed-tuff thermal diffusivity, but also provided insight into convection within the test bed. The TOUGH2 simulations were limited in temporal extent to the first 20 hours of heating. This time period corresponds to when the heater was at full power, thus simplifying the modeling. Finally, 111 hours of data taken following the termination of the heating cycle of Test 1 were used in conjunction with the nonlinear conduction code COYOTE-II [Gartling and Hogan, 1994] to estimate the crushed tuff's thermal diffusivity.

\subsection{PARAMETER ESTIMATION ANALYSES}

As implemented, the parameter estimation method provides a technique for directly linking experimental information, in the form of temperature measurements, to a one-dimensional, radial, finite-element representation of the heat diffusion equation. The nonlinear parameter estimation model uses a weighted least-squares estimator [Beck and Arnold, 1977] and a set of model parameters (in this case thermal diffusivity) that 
minimizes the sum of squares of residuals, or differences between observed and simulated temperatures. The weighted least-squares estimator uses the following assumptions about the measurement errors: (i) measurement errors are additive, (ii) are random, (iii) are independent, (iv) and have zero mean. With the above assumptions, the parameter estimation model provides estimates of the true standard deviations for the estimated parameters as long as the model converges to the global minimum, and the numerical model simulates the physics of the experiment well.

Since the model representing the heat flow through the crushed tuff is nonlinear, the weighted least-squares estimator is linearized. This linearization is accomplished by using a sensitivity matrix (a matrix of derivatives with respect to the parameters) in conjunction with the Hanson-Krogh quadratic least squares technique [Hanson and Krogh, 1986]. The HECTIC code ${ }^{t}$ was used as a subroutine to the parameter estimation code ESTIM [Hills, 1987] to model the heat diffusion within the crushed tuff. ESTIM provided the sensitivity matrix to the Hanson-Krogh quadratic least squares technique.

The parameter estimates presented are not a function of temperature and are considered to be representative of bulk properties. Therefore, the estimates include, to some degree, the effects of convection and thermal radiation.

\subsubsection{Parameter Estimation Model Description}

This section briefly describes the numerical model used for parameter estimation. The model is a one-dimensional, cylindrical, finite element, representation of the test geometry presented in Chapter 3. Six different measurement planes were investigated for parameter estimates, planes 5 through 10 (Figure 3-5).

The centrally located heating element was not modeled explicitly, rather it was represented by a heat flux boundary condition applied to the inner surface of the modeled

\footnotetext{
\$Hensel, E., 1993. High Energy Conduction Thermal Inverse Code HECTIC 2.0 User's Guide, Simulation Technologies, Las Cruces, NM.
} 


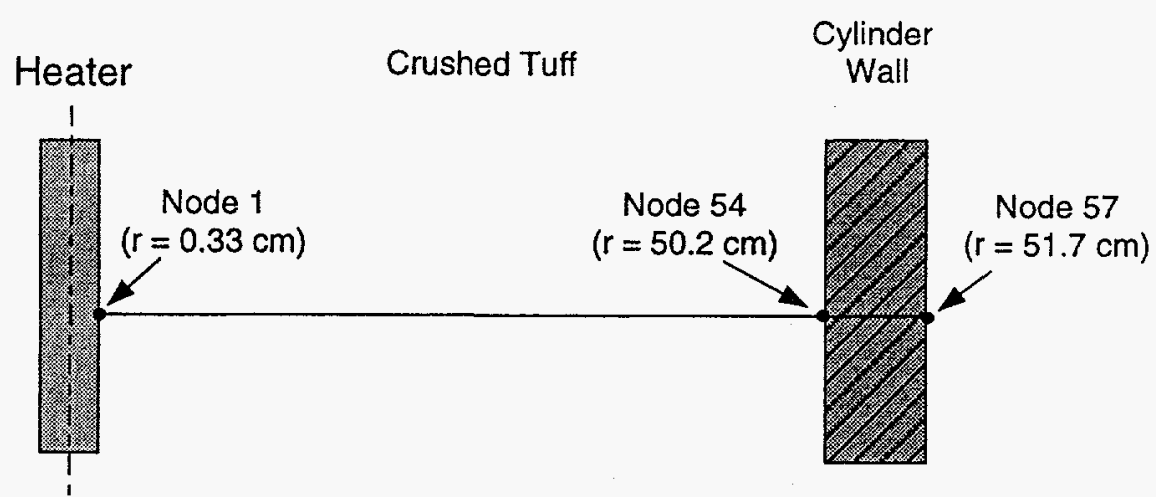

Figure 4-1. One Dimensional Computational Mesh Used for Parameter Estimation

crushed tuff. A constant temperature boundary condition was applied to the outer surface of the steel container. The outer insulation blanket was not modeled. Figure 4-1 is an idealization of the one dimensional computational mesh used for all parameter estimation calculations.

\subsubsection{Experimental Data Selected for Analysis}

It was stated earlier that convection may have played a significant role in the heat transfer occurring within the test apparatus. The primary effect of this was a twodimensional thermal response within the crushed tuff. After reviewing the test data, it was determined that at early test times (less than six hours), there were regions of data that were representative of one-dimensional heat conduction. At these early times, only thermocouples on Probe 3 have responded to the transient heat pulse generated by the heating element. This means that only one measurement location could be used for each parameter estimation calculation. 
Because of potential skewing due to convection, even at early times, thermocouples below plane 5 on Probe 3 were not considered for parameter estimation calculations. Data from planes 5 through 10 from Tests 1 and 2 are shown in Figure 4-2 and 4-3. Each trace consists of approximately 300 data points. These thermocouple locations were chosen for parameter estimation for two reasons; first, they were isolated from any lower boundary effects at early test times, and second, they can be used to assess the variability in parameter estimates caused by convective heat transfer along the vertical extent of Probe 3.

The variability in the test data seems to be consistent from Test 1 to Test 2. Based on the assumption that convective heat flow influenced the temperature profile along the vertical extent of Probe 3, one would expect the temperature to increase vertically along Probe 3. This is not the case. In each test the thermocouple at plane 6 is consistently higher than thermocouples at pianes 7 and 9. In Test 2, readings for plane 6 are higher than for planes 5, 7,9, and 10. While the exact cause of this behavior is unknown, it may be a result of convective effects, a potentially non-uniform heater profile, or heterogeneous thermal properties resulting from variations in packing densities.

\subsubsection{Parameter Estimation Results}

\subsubsection{Results From Test 1}

Results of parameter estimation calculations for Test 1 are presented in Table 4-1. The last column in Table 4-1 shows the square root of the sum of the squares of residuals (SSR) at the completion the parameter estimation calculation. The functional relationship for this term is given by:

$$
\sqrt{\mathrm{SSR}}=\sqrt{\sum_{\mathrm{i}=1}^{\mathrm{n}} \mathrm{R}_{\mathrm{i}}^{2}}
$$

where $\mathrm{R}$ is the residual or difference between experimental observation and the simulated value. The value of $\sqrt{\mathrm{SSR}}$ represents the goodness of fit between experimental and simulated data. 


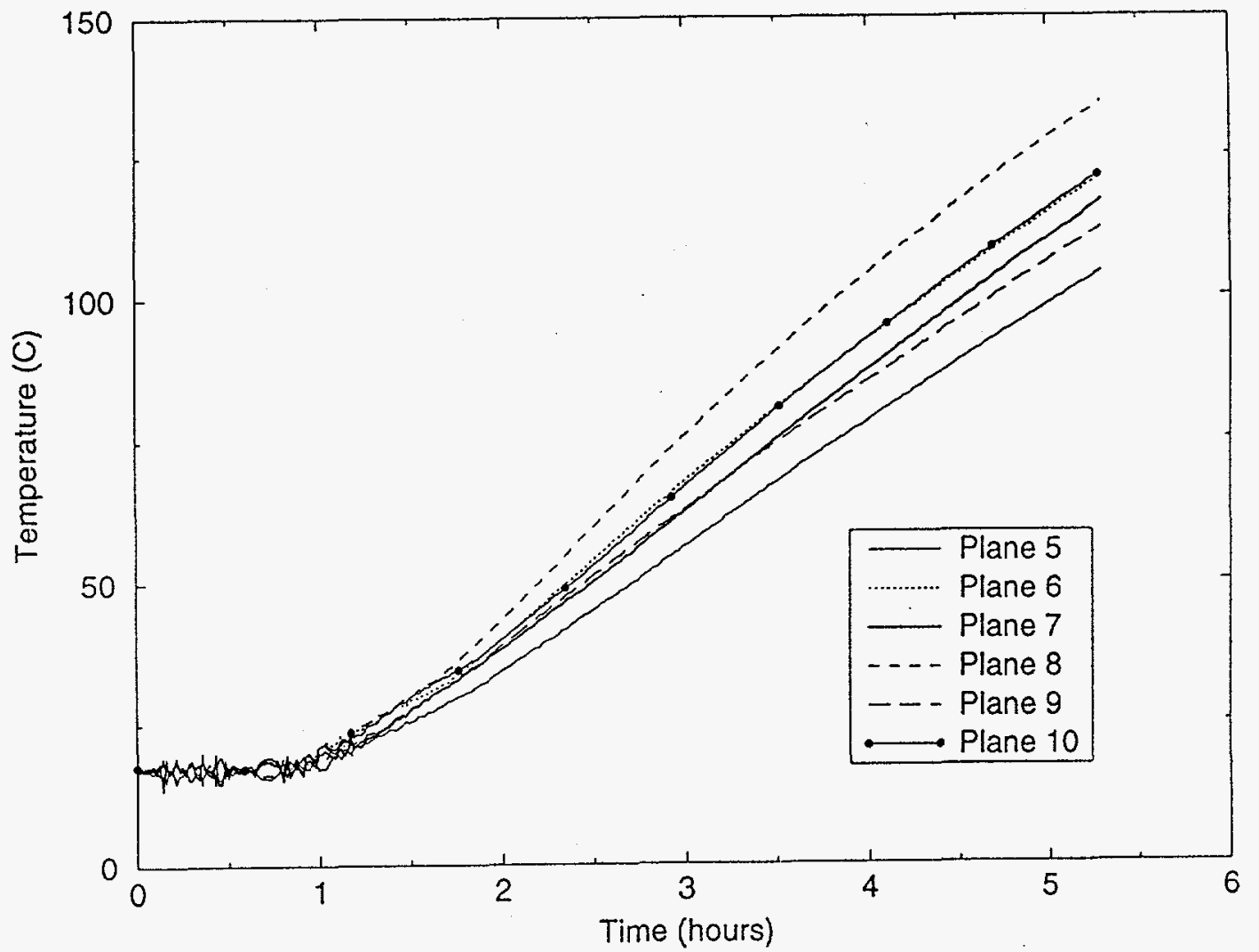

Figure 4-2. Experimental Data from Probe 3 Used for Parameter Estimation Modeling of Test 1

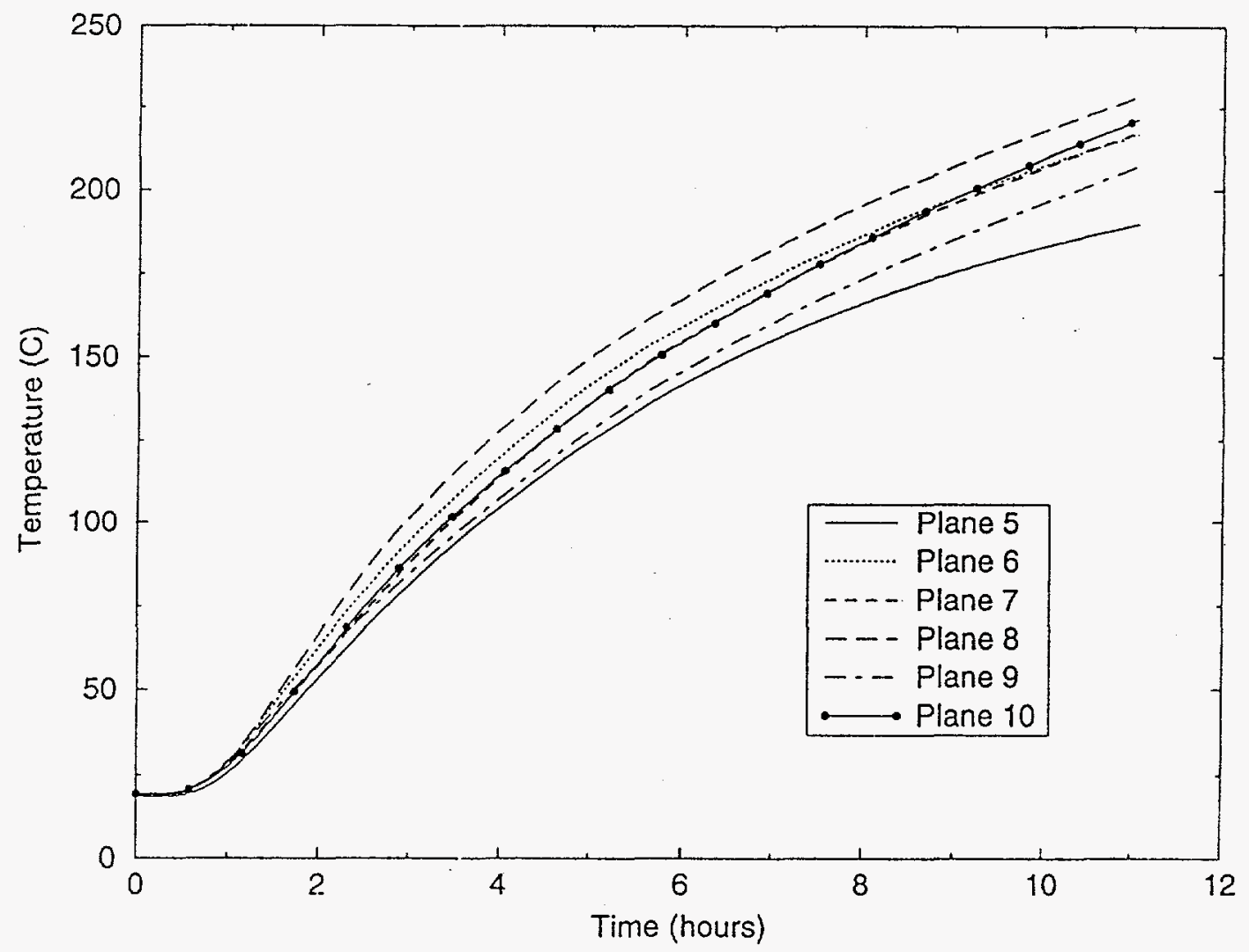

Figure 4-3. Experimental Data from Probe 3 Used for Parameter Estimation Modeling of Test 2 
Plane 7 represents the central measurement plane. Deviations in parameter estimates compared to thermocouple readings for plane 7 are only 11 percent at the plane 5 location.

Table 4-1. Test 1 Parameter Estimation Results

\begin{tabular}{|c|c|c|c|}
\hline $\begin{array}{l}\text { Thermocouple } \\
\text { Plame Along } \\
\text { Probe } 3\end{array}$ & Elevation $(\mathrm{cm})$ & $\begin{array}{l}\text { Estimated Bulk } \\
\text { Thermal } \\
\text { Difmsivity } \\
\left(\mathrm{m}^{2} \mathrm{~s}\right)\end{array}$ & $\begin{array}{l}\sqrt{\text { SSR }} \\
(\% \mathrm{C})\end{array}$ \\
\hline 5 & 75.88 & $5.35 \times 10^{-7}$ & 15.64 \\
\hline 6 & 97.79 & $6.18 \times 10^{-7}$ & 17.29 \\
\hline 7 & 119.70 & $6.01 \times 10^{-7}$ & 19.67 \\
\hline 8 & 141.61 & $6.29 \times 10^{-7}$ & 12.82 \\
\hline 9 & 163.51 & $6.16 \times 10^{-7}$ & 14.15 \\
\hline 10 & 185.42 & $6.10 \times 10^{-7}$ & 19.95 \\
\hline \multicolumn{2}{|l|}{ AVERAGE } & $6.02 \times 10^{-7}$ & \\
\hline
\end{tabular}

To demonstrate how well the parameter estimation models compare with experimental temperature data, Figures 4-4 and 4-5 are presented as examples. Figures 44 and 4-5 show graphical comparisons of estimated temperature profiles using the estimated bulk thermal diffusivities presented in Table 4-1. For the sake of clarity, only every other data point is shown for each experimental trace.

\subsubsection{Results From Test 2}

Results of parameter estimation calculations for Test 2 are presented in Table 4-2. Again using plane 7 as the central measurement plane, the maximum deviation in parameter estimates from plane 7 is 16 percent.

Figures 4-6 and 4-7 are examples of the comparisons between experimental data and estimated temperature profiles using estimated bulk thermal diffusivities presented in Table 4-2. Again, only every other data point is shown for each experimental trace. 


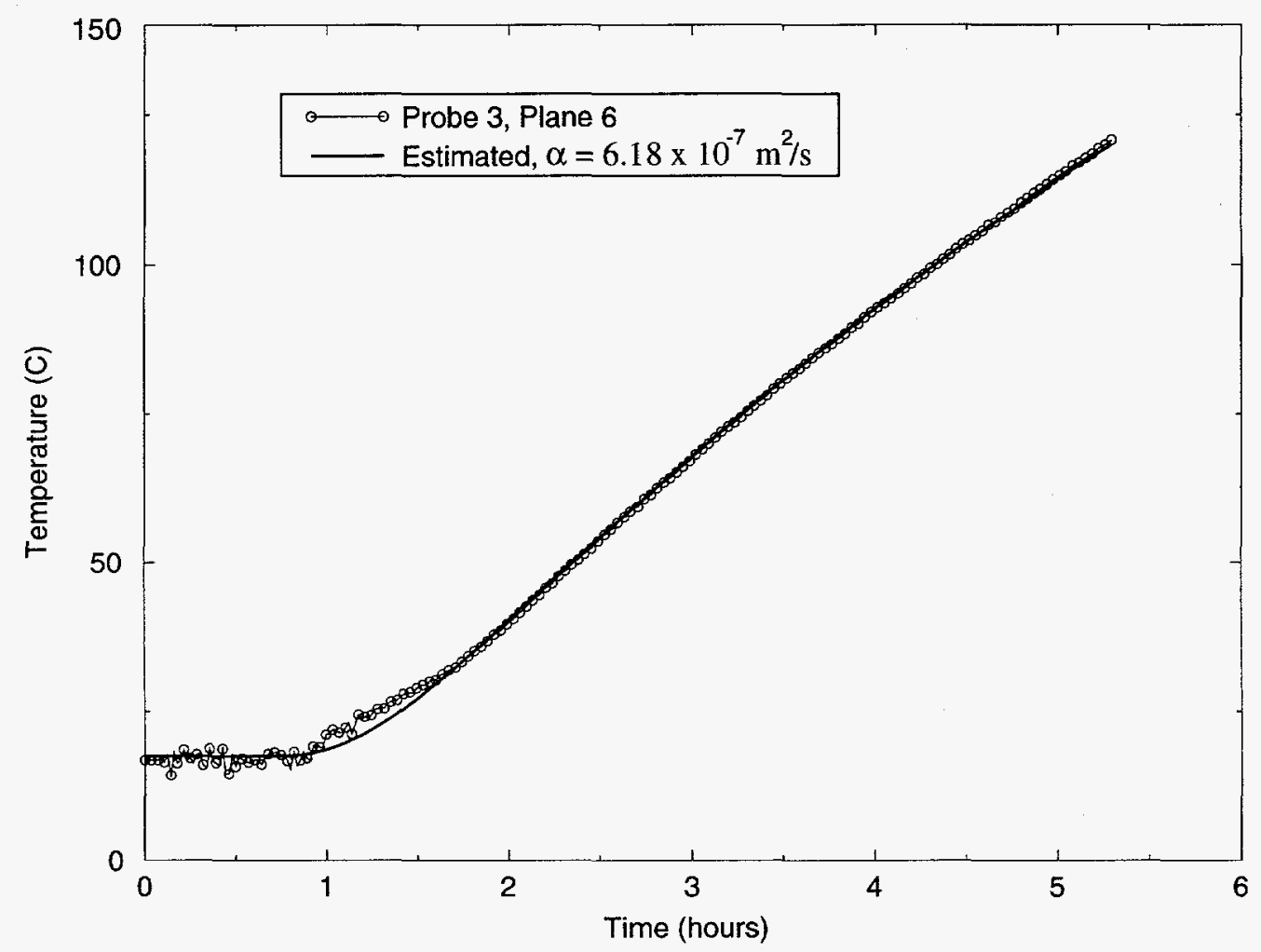

Figure 4-4. Experimental Data and Simulated Temperature Predictions $\left(\alpha=6.18 \times 10^{-7} \mathrm{~m}^{2} / \mathrm{s}\right)$ for Test 1, Plane 6, Probe 3

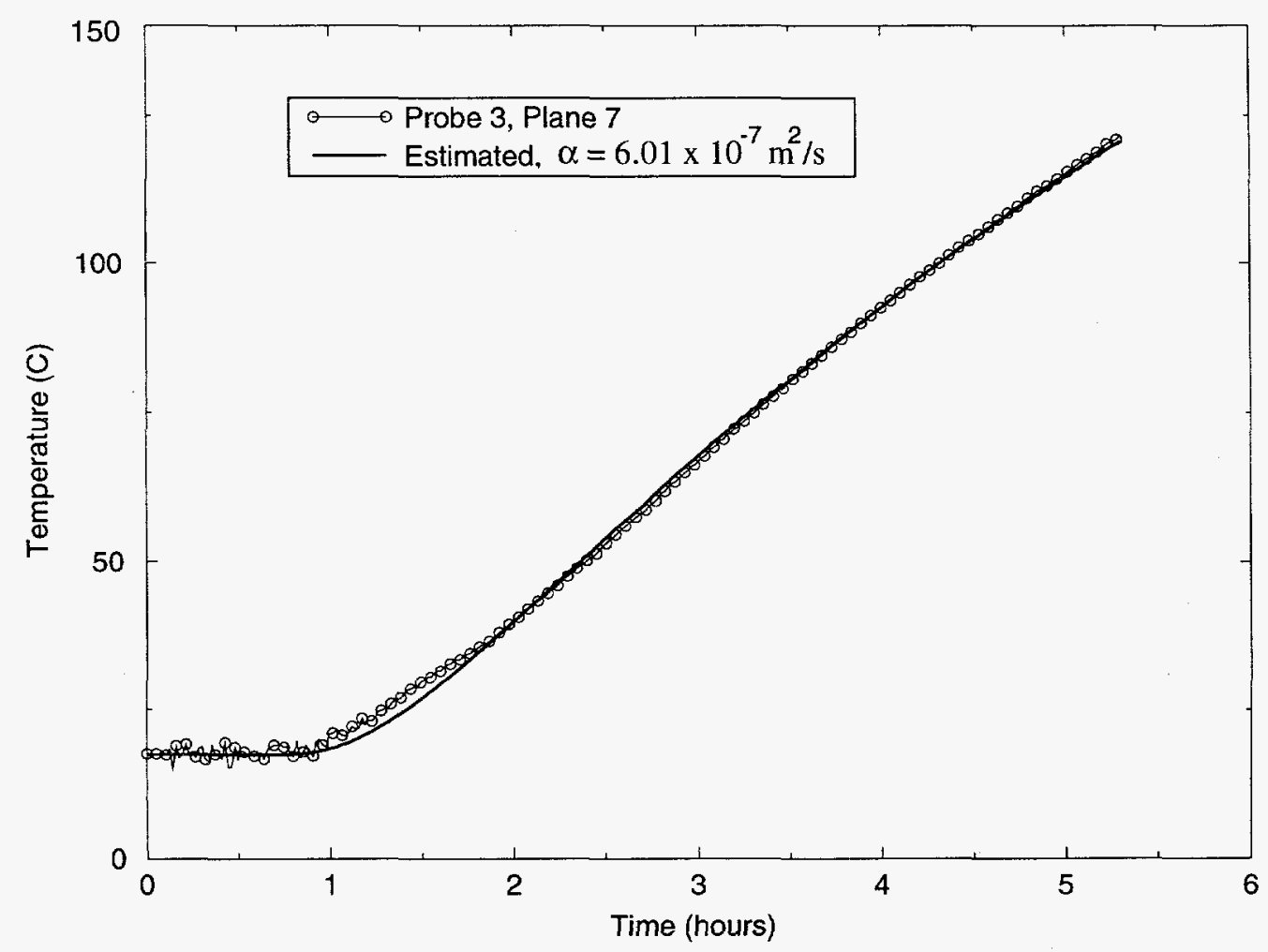

Figure 4-5. Experimental Data and Simulated Temperature Predictions $\left(\alpha=6.01 \times 10^{-7} \mathrm{~m}^{2} / \mathrm{s}\right)$ for Test 1, Plane 7, Probe 3 


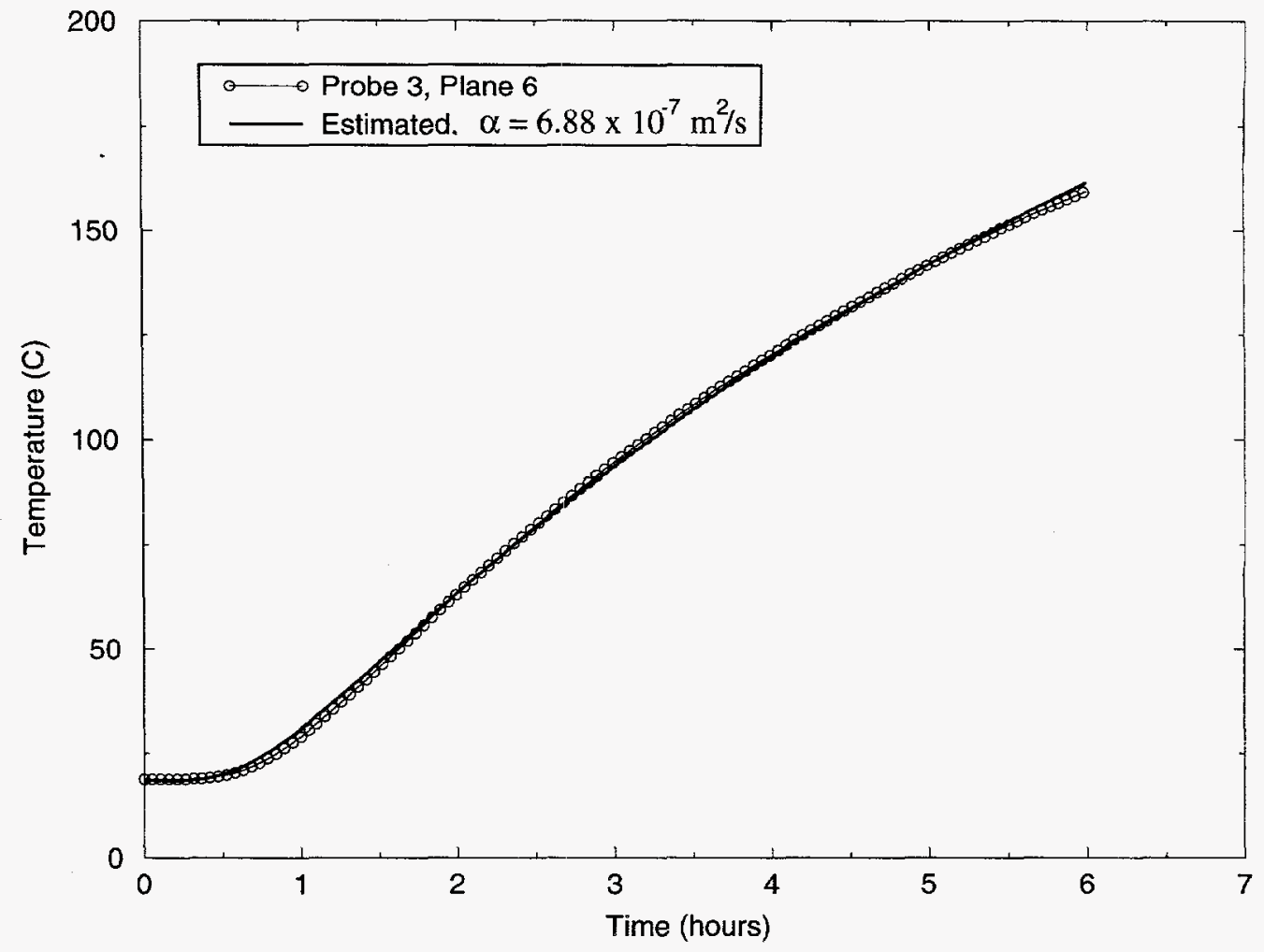

Figure 4-6. Experimental Data and Simulated Temperature Predictions $\left(\alpha=6.88 \times 10^{-7} \mathrm{~m}^{2} / \mathrm{s}\right)$ for Test 2, Plane 6, Probe 3

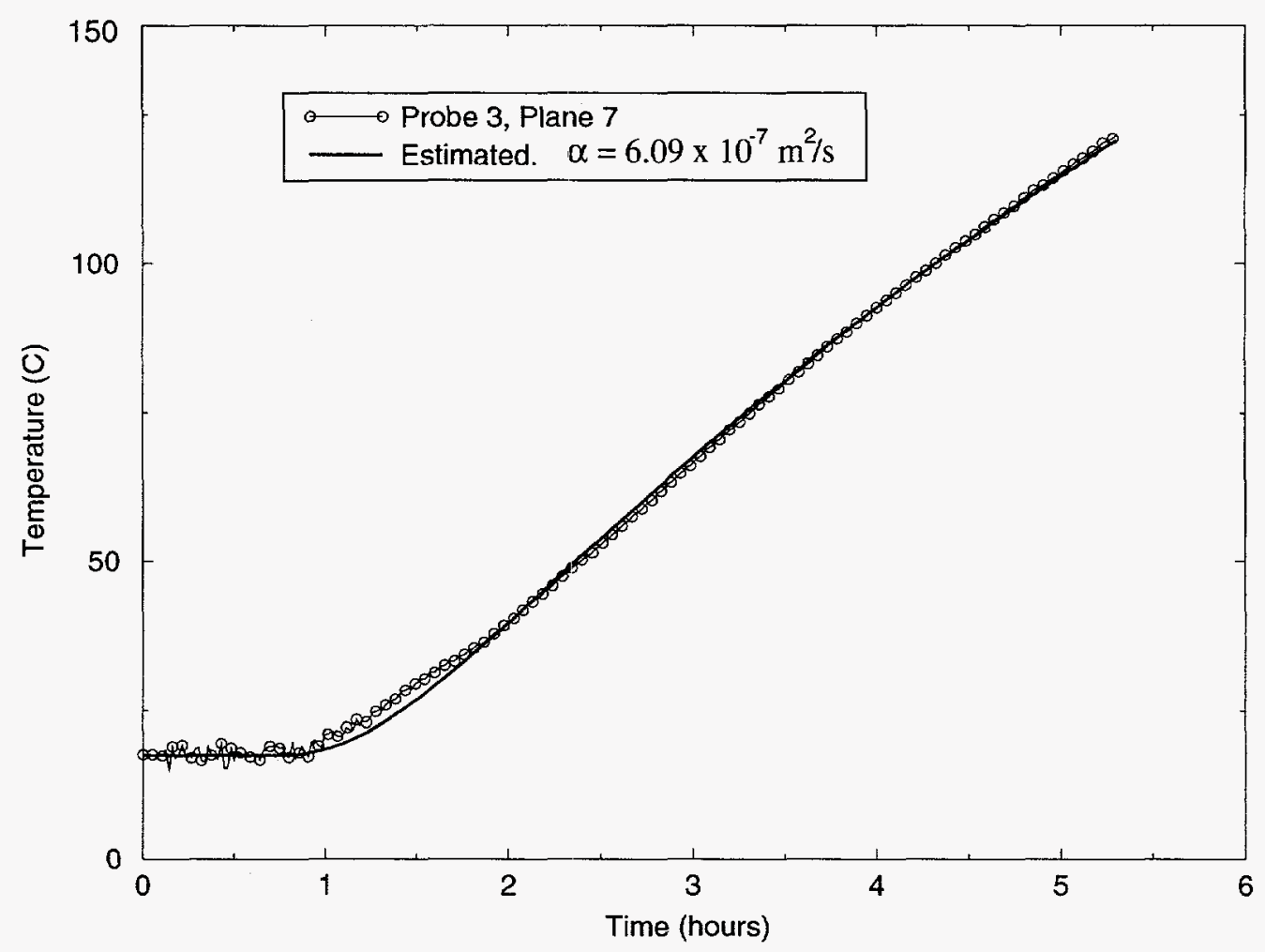

Figure 4-7. Experimental Data and Simulated Temperature Predictions $\left(\alpha=6.09 \times 10^{-7} \mathrm{~m}^{2} / \mathrm{s}\right)$ for Test 2, Plane 7, Probe 3 
Table 4-2. Test 2 Parameter Estimation Results

\begin{tabular}{|c|c|c|c|}
\hline $\begin{array}{c}\text { Thermocouple } \\
\text { Plane Along } \\
\text { Probe 3 }\end{array}$ & $\begin{array}{c}\text { Elevation } \\
(\mathrm{cm})\end{array}$ & $\begin{array}{c}\text { Estimated Bulk } \\
\text { Thermal Diffusivity } \\
\left(\mathrm{m}^{2} / \mathrm{s}\right)\end{array}$ & $\begin{array}{c}\sqrt{\text { SSR }} \\
(\mathbf{C})\end{array}$ \\
\hline \hline 5 & 75.88 & $6.09 \times 10^{-7}$ & 12.21 \\
\hline 6 & 97.79 & $6.88 \times 10^{-7}$ & 17.74 \\
\hline 7 & 119.70 & $6.09 \times 10^{-7}$ & 7.80 \\
\hline 8 & 141.61 & $7.09 \times 10^{-7}$ & 34.20 \\
\hline 9 & 163.51 & $6.70 \times 10^{-7}$ & 5.16 \\
\hline 10 & 185.42 & $6.20 \times 10^{-7}$ & 17.47 \\
\hline \hline AVERAGE & & $\mathbf{6 . 5 1 \times 1 0 ^ { - 7 }}$ & \\
\hline
\end{tabular}

\subsubsection{Test-to-Test Comparison}

Table 4-3 presents the test-to-test comparisons. The largest percent difference occurs at plane 5 and the smallest percent difference occurs at plane 7, the central measurement plane. The average value of thermal diffusivity from Test 2 is only 8 percent larger than that for Test 1.

Table 4-3. Test-to-Test Comparison of Estimated Bulk Thermal Diffusivity

\begin{tabular}{|c|c|}
\hline $\begin{array}{c}\text { Thermocouplé } \\
\text { Plane }\end{array}$ & \% Difference between Test 1 and Test 2 \\
\hline \hline 5 & 13.9 \\
\hline 6 & 11.3 \\
\hline 7 & 1.36 \\
\hline 8 & 12.7 \\
\hline 9 & 8.7 \\
\hline 10 & 1.54 \\
\hline
\end{tabular}

\subsubsection{Summary of Parameter Estimation Analyses}

Results using the parameter estimation technique indicate that within certain regions, the one dimensional heat diffusion equation models the experimental temperature profiles well at early times (less than 6 hours). The goodness of fit between the simulated 
results and the experimental data for each test indicate that the parameter estimation model did converge to a global minimum. Application of the parameter estimation technique yielded average estimates of bulk thermal diffusivity of $6.02 \times 10^{-7} \mathrm{~m}^{2} / \mathrm{s}$ for Test 1 and $6.51 \times 10^{-7} \mathrm{~m}^{2} / \mathrm{s}$ for Test 2 .

Maximum deviations of parameter estimates from the centrally located measurement plane were 11 percent for Test 1 and 16 percent for Test 2 . Test-to-test variations in parameter estimates were greatest $(14 \%)$ at plane 5 . In general there is good test-to-test agreement of the estimated thermal diffusivity.

\subsection{TOUGH2 ANALYSES}

While the parameter estimation technique appears to be a robust method for estimating the thermal diffusivity of the crushed tuff, the limitation of the method to the first 6 hours of experimental data raises questions regarding the basic processes occurring in the test bed at later times and their impacts on the estimation of thermal properties. Extending the temporal range of data examined to 20 hours (a period over which convective effects become significant), a series of analyses using the TOUGH2 hydrothermal code [Pruess, 1991] was pursued. The objective of these analyses was not only to provide an estimate of the thermal diffusivity of the crushed tuff, but also to assist in developing an understanding of the important phenomena occurring within the test bed.

As discussed in Chapter 3, samples of the crushed rock were analyzed for initial water content and results show that the rock samples contained an initial water saturation of about 1 to $2 \%$ by weight. Therefore, gas phase movement resulting from thermally induced density gradients would consist of both water vapor and air components. Temperatures resulting from the experiments suggested that buoyancy driven gas phase flow did exist in the system, but the relative contributions of advection and phase change to the resulting temperature distributions are unclear. It is surmised from the TOUGH2 simulations that heated fluid near the heater rose as a result of density changes, and as the fluid cooled, it descended near the outer regions of the container towards the bottom 
where it circulated back towards the heater. As a result of this process, the temperatures observed near the top of the container are elevated and those toward the bottom are cooler. These processes are considered in the numerical simulations, and the experimental temperatures are presented later with the simulated temperatures.

\subsubsection{TOUGH2 Model Description}

TOUGH2 was used to simulate non-isothermal transport in the crushed-tuff test bed. Figure 4-8 shows a sketch of the TOUGH2 model used in the simulations. An axisymmetric model was developed since temperature data showed axisymmetric conditions existed within the crushed tuff (see Appendix A). In addition, Figure 4-8 shows that a row of constant temperature elements $\left(17^{\circ} \mathrm{C}\right)$ was placed at the bottom of the cylinder to simulate the essentially constant temperatures observed at the bottom of the cylinder during the first 20 hours of the two experiments (see Appendices A and B).

The remaining boundaries of the TOUGH2 model are also shown in Figure 4-8. The heater was located in the center of the cylinder and supplied with a source of constant power (1865 W for Test 1 and $1840 \mathrm{~W}$ for Test 2 ) along its entire length. The heater did. not span the entire vertical length of the cylinder, the top four inches and bottom six inches were modeled as unheated. The top and outside boundaries of the modeled test apparatus were assumed to be insulated.

The properties of the materials comprising the TOUGH2 model are listed in Table 44. To develop an estimate of the crushed tuff's bulk thermal diffusivity, the density and heat capacity of the backfill were assumed fixed while the thermal conductivity was varied. The effective porosity and intact density of the backfill material were estimated from preliminary experimental data and therefore vary slightly from the final experimental values presented in Chapter 2. Since no permeability data are available, the permeability was simply assumed to be the same as that of coarse gravel [Freeze and Cherry, 1979]. Sensitivity analyses were performed to assess the effects of permeability on the temperature fields. The properties of the heater were assumed to be the same as stainless 


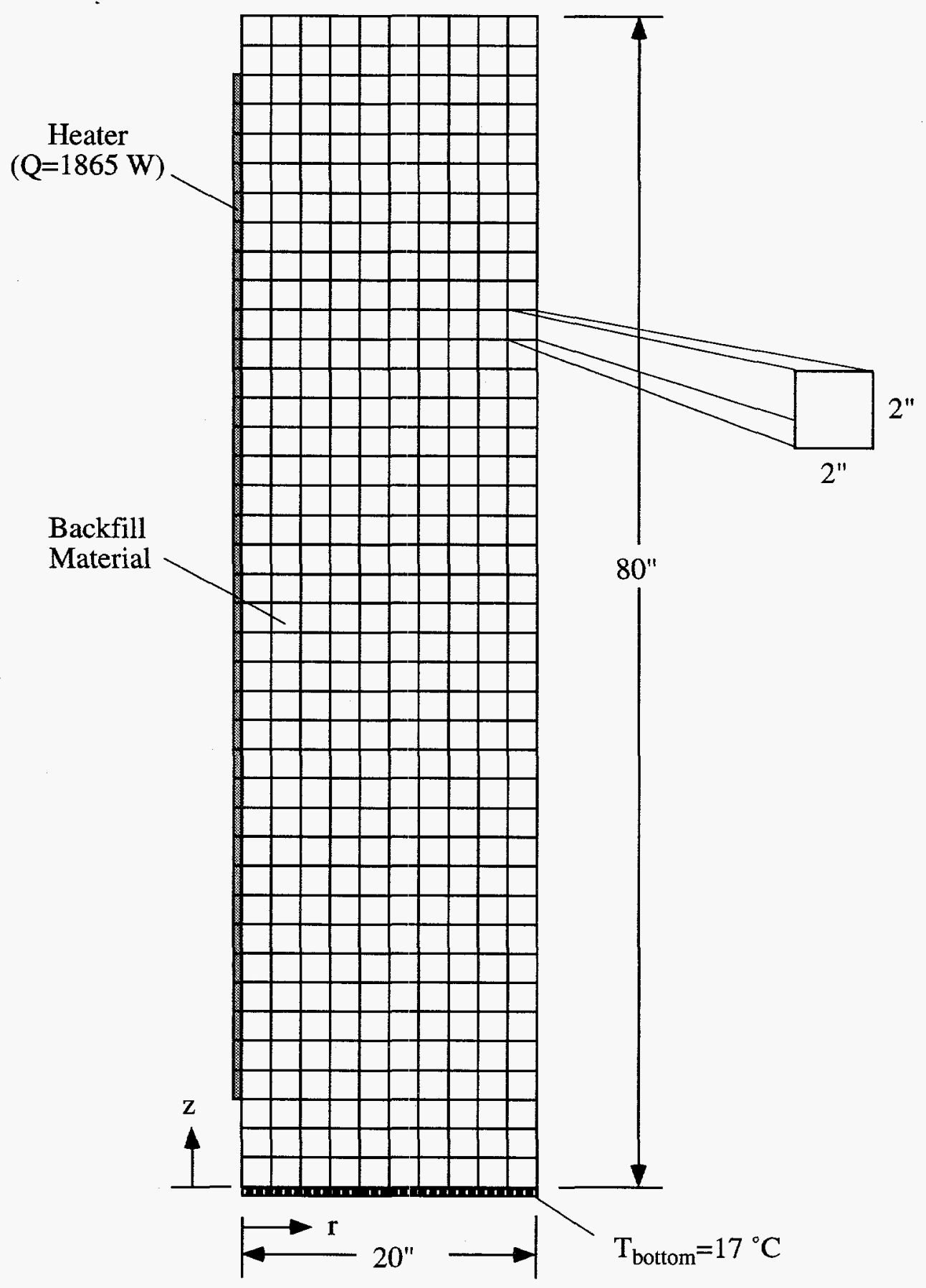

Figure 4-8. Two-dimensional, radial TOUGH2 model used to simulate the experiment. 
steel [Incropera and DeWitt, 1985], and the properties of the bottom boundary were assumed to be fireclay brick [Incropera and DeWitt, 1985]. Data was later obtained for the density and thermal conductivity of the fire brick (Chapter 3). The impact of the deviation of the assumed TOUGH2 parameters from the experimental data is assumed to be negligible.

Table 4-4. Properties Used in the TOUGH2 Model

\begin{tabular}{|c|c|c|c|c|c|}
\hline Material & $\left(\mathrm{Bg} / \mathrm{m}^{3}\right)$ & Porosity & $\begin{array}{l}\text { Permeability } \\
\left(\mathrm{m}^{2}\right)^{-}\end{array}$ & $\begin{array}{l}\text { Thermal } \\
\text { Conductivity } \\
(\mathrm{W} / \mathrm{m}-\mathrm{K})\end{array}$ & $\begin{array}{l}\text { Grain } \\
\text { Specific Ieat } \\
\text { (JAkg-K) }\end{array}$ \\
\hline crushed tuff & 2600 & 0.45 & $1.0 \times 10^{-7}$ & varies & 840 \\
\hline heater & 8000 & 0 & 0 & 15 & 475 \\
\hline bottom boundary & 2645 & 0.1 & 0 & 1 & 960 \\
\hline
\end{tabular}

A note should be made regarding the high temperatures observed near the heater in the experiment. Since TOUGH2 attempts to calculate thermodynamic properties of water and steam regardless of their presence in the system, the code aborts when systems reach temperatures above $500^{\circ} \mathrm{C}$. Therefore, for simulations involving just air with no water present, a statement was added to the TOUGH2 code to ignore the thermodynamic properties of water and steam at temperatures above $500^{\circ} \mathrm{C}$. Sensitivity studies considering the presence of water were run with the original version of TOUGH2, but the problem could only be run until temperatures reached $500^{\circ} \mathrm{C}$.

\subsubsection{Iterative Estimation of Thermal Diffusivity Using TOUGH2}

In this section a series of numerical simulations is presented in a systematic progression towards estimating a bulk thermal diffusivity of the crushed tuff. The density and specific heat of the crushed tuff is fixed while the thermal conductivity is varied, thereby varying the thermal diffusivity. Three different simulations were performed with different thermal conductivities, and temperatures compared along two axial thermocouple probes (Probes 1 and 3 ) at two different times. Probes 1 and 3 were modeled as being 
$38.1 \mathrm{~cm}(15 \mathrm{in}$.) and $12.7 \mathrm{~cm}(5 \mathrm{in}$.) from the center of the cylinder. Based on these simulations, a final simulation using a best guess of the thermal diffusivity is given. ${ }^{\dagger}$

The temperatures along Probes 1 and 3 were compared with the corresponding numerically simulated temperatures at 6000 seconds (100 minutes) and 20 hours using three different thermal conductivities in TOUGH $2(0.4,0.5$, and $1.0 \mathrm{~W} / \mathrm{m}-\mathrm{K})$. These conductivities correspond to thermal diffusivities of $3.3 \times 10^{-7} \mathrm{~m}^{2} / \mathrm{s}, 4.2 \times 10^{-7} \mathrm{~m}^{2} / \mathrm{s}$, and $8.3 \times 10^{-7} \mathrm{~m}^{2} / \mathrm{s}$. Figure $4-9$ shows the temperatures along Probes 1 and 3 at 6000 seconds. Figure 4-10 shows the temperatures along Probes 1 and 3 at 20 hours.

The trends observed in Figures 4-9 and 4-10 can be explained using a generic argument based on the effects of thermal diffusivity on temperature predictions obtained for a one-dimensional radial conduction model. Assuming two different thermal diffusivities, a high and low, there exists a point where the predictions of temperature obtained for the two values of diffusivity intersect. As the radius increases beyond this intersection, the predictions of temperature are greater for the model assuming the higher value of thermal diffusivity. Conversely, for radii less than that of the intersection, a higher value of thermal diffusivity results in a lower temperature prediction. This behavior is conceptualized in Figure 4-11 to explain the behavior seen in the TOUGH2 simulations at 6000 seconds and 20 hours. Specifically, Figure 4-11 (a) shows that at 6000 seconds the intersection point must occur at a radius smaller than that of Probe 3. This explains why predicted temperatures for Probe 3 increase with increases in the modeled thermal diffusivity (Figure 4-9). At 20 hours, the point of intersection has apparently moved beyond Probe 3, but has not yet reached the radius defining the location of Probe 1

(Figure 4-11 (b)). This is supported by Figure 4-10, which shows a decrease in predicted Probe 3 temperatures and a corresponding increase in predicted Probe 1 temperatures with increasing thermal diffusivity.

\footnotetext{
$\dagger$ The iterative procedure of running multiple simulations while varying system parameters to minimize the error between observed and predicted results can be quite subjective. A recently modified version of TOUGH2 called ITOUGH2 (Finsterle, 1993) has been developed to automate this iterative procedure through minimization algorithms to provide objective parameter estimations. Although this particular problem would be well-suited for this code, no attempts have been made to use ITOUGH2 in this study.
} 


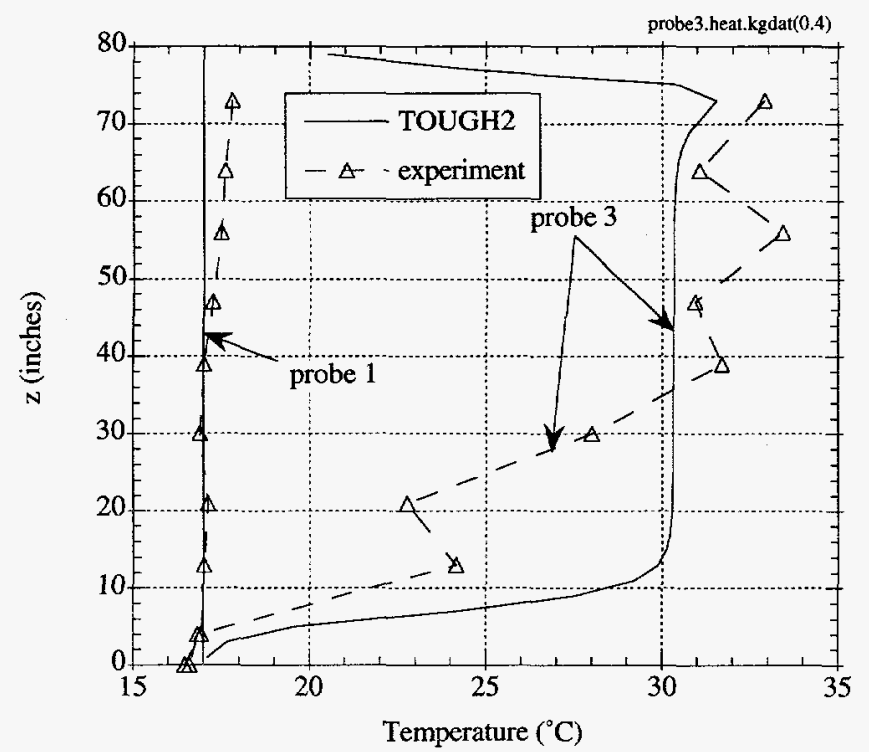

(a)

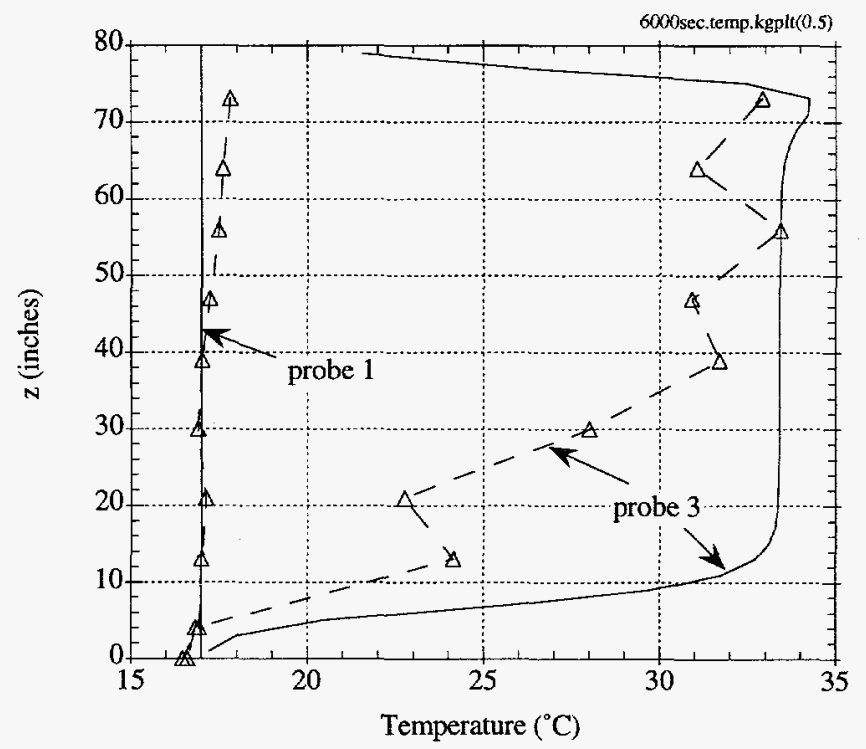

(b)

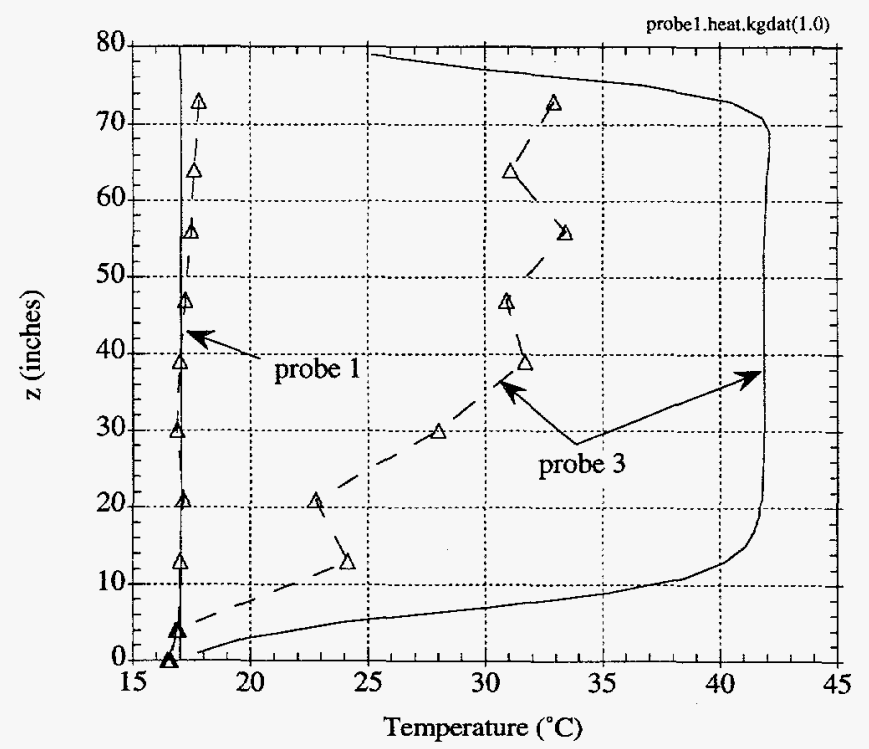

(c)

\section{$\lambda=0.4 \mathrm{~W} / \mathrm{m}-\mathrm{K}$}

\section{$\lambda=0.5 \mathrm{~W} / \mathrm{m}-\mathrm{K}$}

\section{$\lambda=1.0 \mathrm{~W} / \mathrm{m}-\mathrm{K}$}

Figure 4-9. Experimental and numerical temperatures along probe 1 ( $\mathrm{r}=15$ inches) and probe 3 ( 5 inches) at 6000 seconds of heating for thermal conductivities of: a) 0.4 $\mathrm{W} / \mathrm{m}-\mathrm{K}$ b) $0.5 \mathrm{~W} / \mathrm{m}-\mathrm{K}$ and c) $1.0 \mathrm{~W} / \mathrm{m}-\mathrm{K}$. 


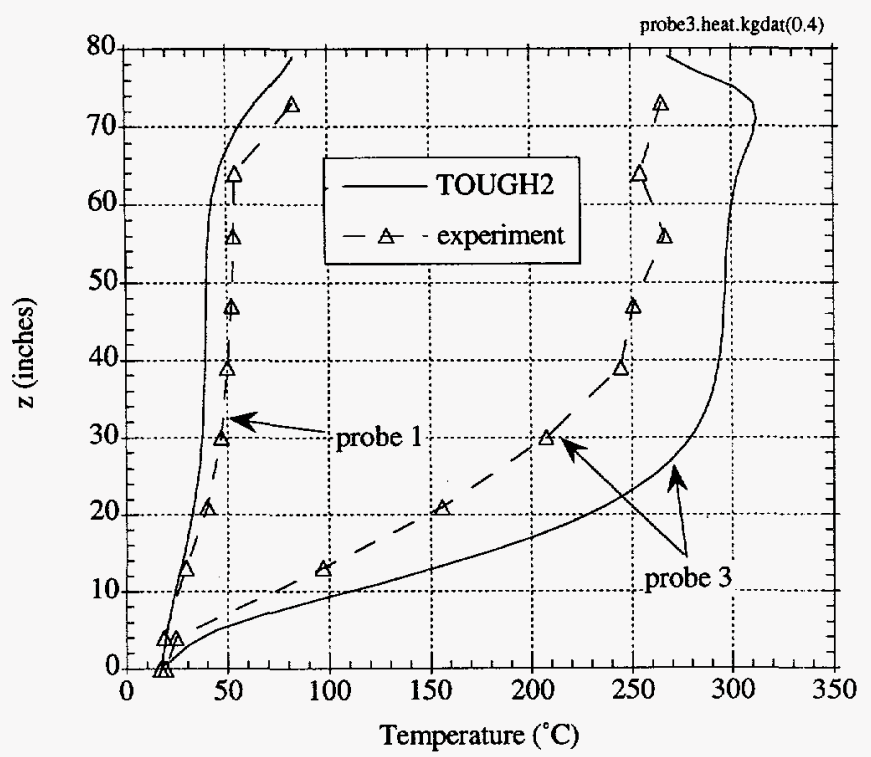

(a)

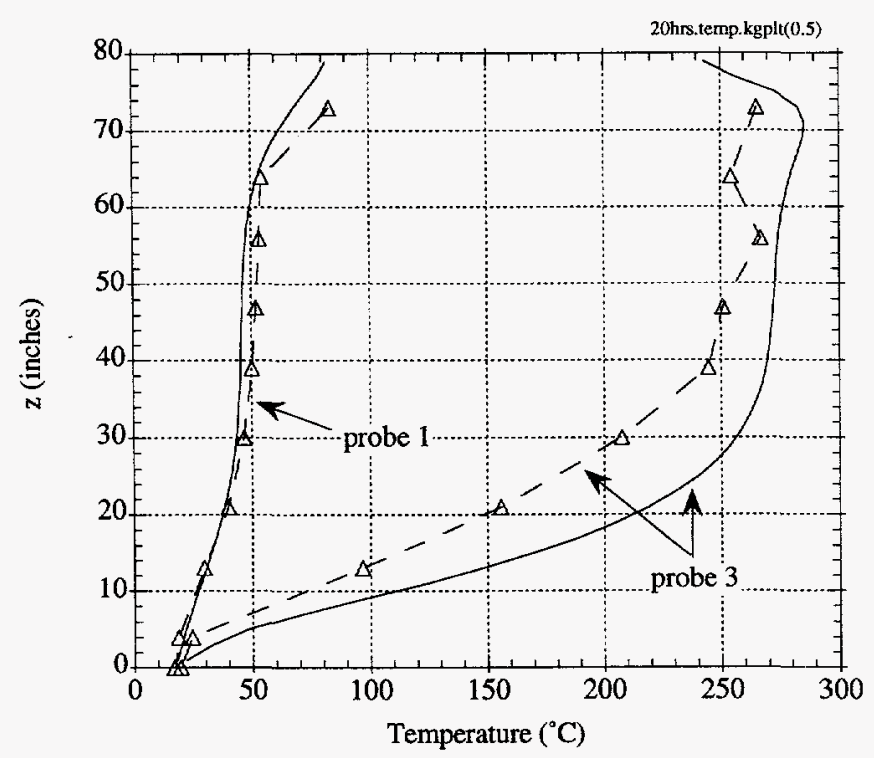

(b)

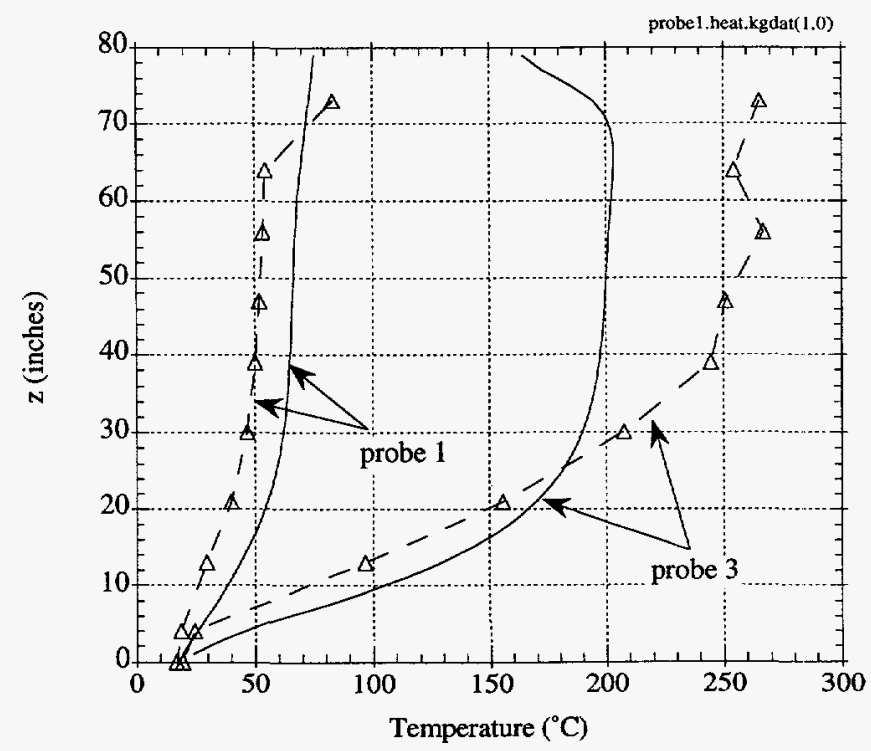

(c)

\section{$\lambda=0.4 \mathrm{~W} / \mathrm{m}-\mathrm{K}$}

$\lambda=0.5 \mathrm{~W} / \mathrm{m}-\mathrm{K}$

\section{$\lambda=1.0 \mathrm{~W} / \mathrm{m}-\mathrm{K}$}

Figure 4-10. Experimental and numerical temperatures along probe 1 ( $\mathrm{r}=15$ inches) and probe 3 ( 5 inches) at 20 hours of heating for thermal conductivities of: a) 0.4 . $\mathrm{W} / \mathrm{m}-\mathrm{K}$ b) $0.5 \mathrm{~W} / \mathrm{m}-\mathrm{K}$ and c) $1.0 \mathrm{~W} / \mathrm{m}-\mathrm{K}$. 


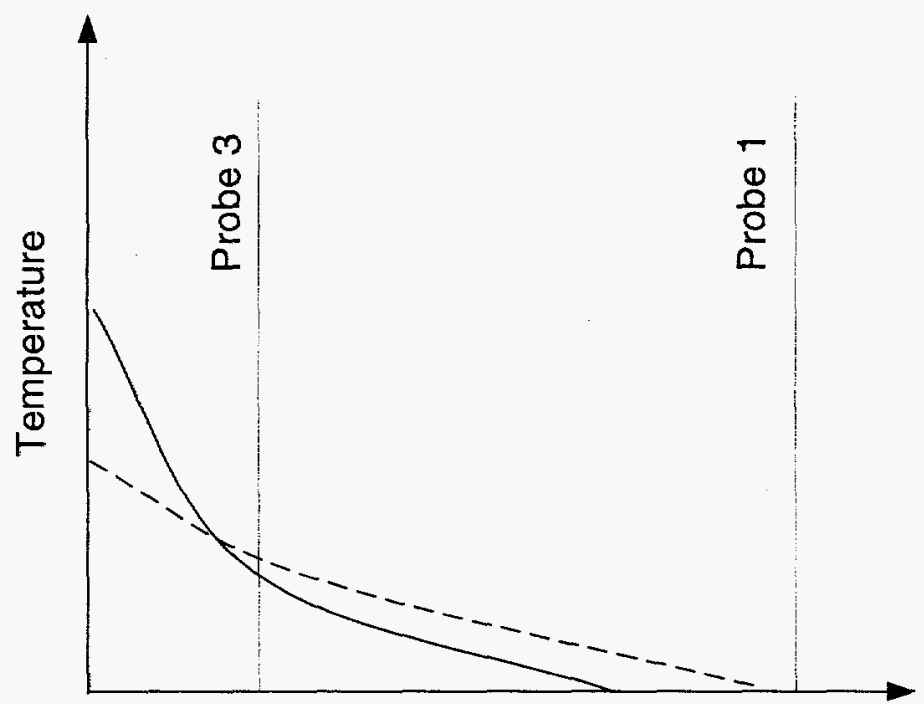

Radius

(a)

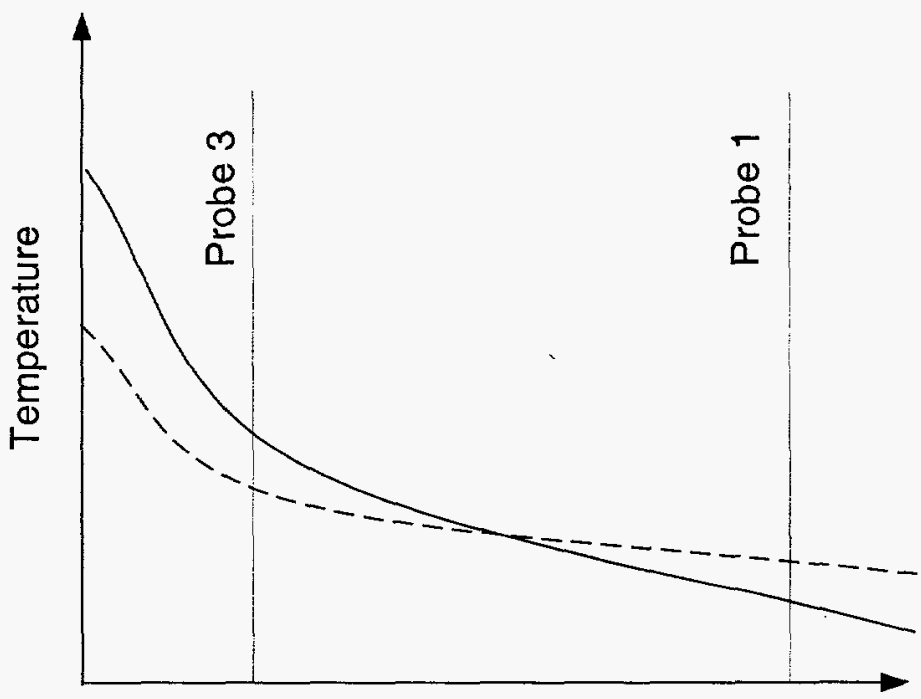

Radius

(b)

Figure 4-11. Locations of Intersection Points at (a) 6000 seconds and (b) 20 hours. 
After analyzing the experimental and numerical temperature profiles shown in Figures 4-9 and 4-10, a best guess for the effective thermal diffusivity was chosen to be $5.0 \times 10^{-7} \mathrm{~m}^{2} / \mathrm{s}$ (based on a thermal conductivity of $0.6 \mathrm{~W} / \mathrm{m}-\mathrm{K}$ ). Calculation of the crushed tuff's bulk thermal diffusivity, $\alpha_{b u l k}$, defined in Equation 4.2, was based on the effective heat capacity of the porous medium, $\overline{\rho c_{p}}$, calculated from Equation 4.3.

$$
\begin{gathered}
\alpha_{\text {bulk }}=\frac{\lambda_{\text {bulk }}}{\rho \mathrm{c}_{\mathrm{p}}} \\
\overline{\rho \mathrm{c}_{\mathrm{p}}}=(1-\Phi)\left(\rho \mathrm{c}_{\mathrm{p}}\right)_{\text {solid }}+\Phi\left(\rho \mathrm{c}_{\mathrm{p}}\right)_{\text {air }}
\end{gathered}
$$

where $\Phi$ is the effective porosity of the crushed tuff and air mixture.

The best guess for the thermal conductivity was used in additional TOUGH2 simulations shown in Figure 4-12. Figure 4-12(a) shows the experimental and numerical temperatures along Probes 1 and 3 after 5 hours of heating, and Figure 4-12(b) shows the same results after 20 hours of heating. Note that the magnitudes of the temperatures, especially at 20 hours, are in good agreement.

Figure 4-13(a) shows the gas-phase velocity field in the cylinder as a result of the natural convection after 20 hours of heating. Hot air near the heater rises upwards towards the top of the cylinder. Since a no-flux condition is modeled at the top, the hot air moves along the top of the container where it is cooled. The release of energy from the hot air is apparent along the top of the container as shown in Figure 4-13(b), where the isotherms are skewed away from the heater. This behavior is also evident in the experimental temperature profiles (Chapter 3 and Appendices A and B). 


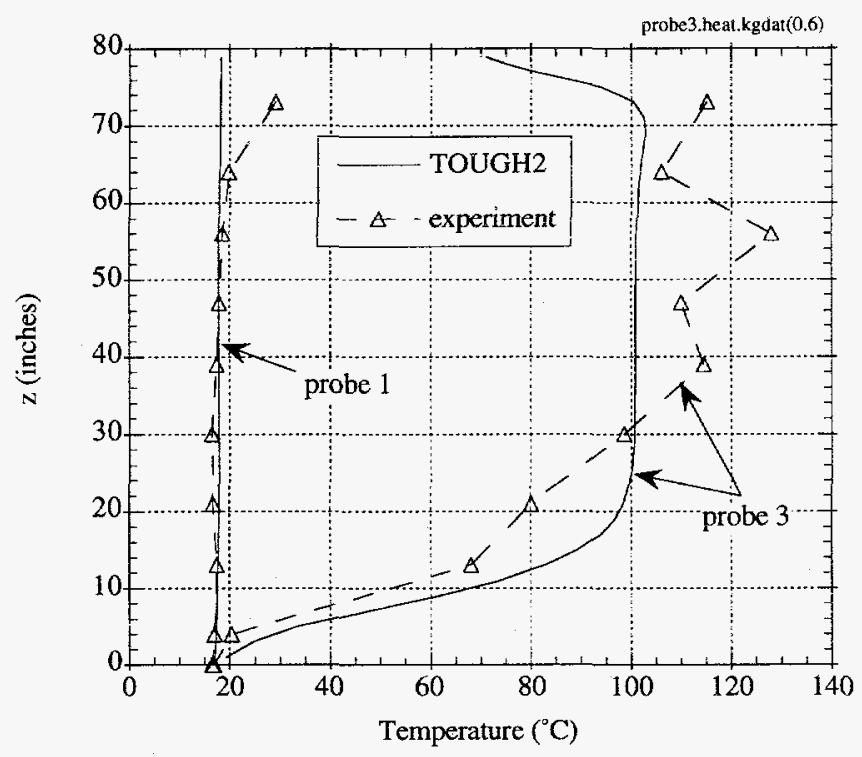

$t=5$ hours

(a)

\section{$\lambda=0.6 \mathrm{~W} / \mathrm{m}-\mathrm{K}$}

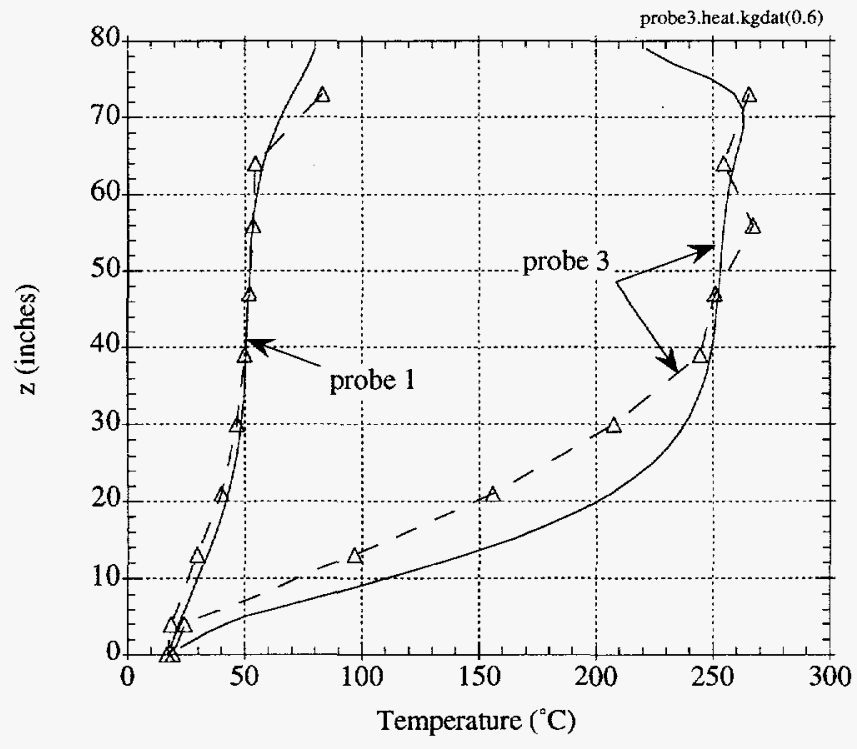

$t=20$ hours

(b)

Figure 4-12. Experimental and numerical temperatures along probe $1(\mathrm{r}=15$ inches) and probe 3 ( 5 inches) at: a) 5 hours and b) 20 hours of heating for a thermal conductivities of $0.6 \mathrm{~W} / \mathrm{m}-\mathrm{K}$. 


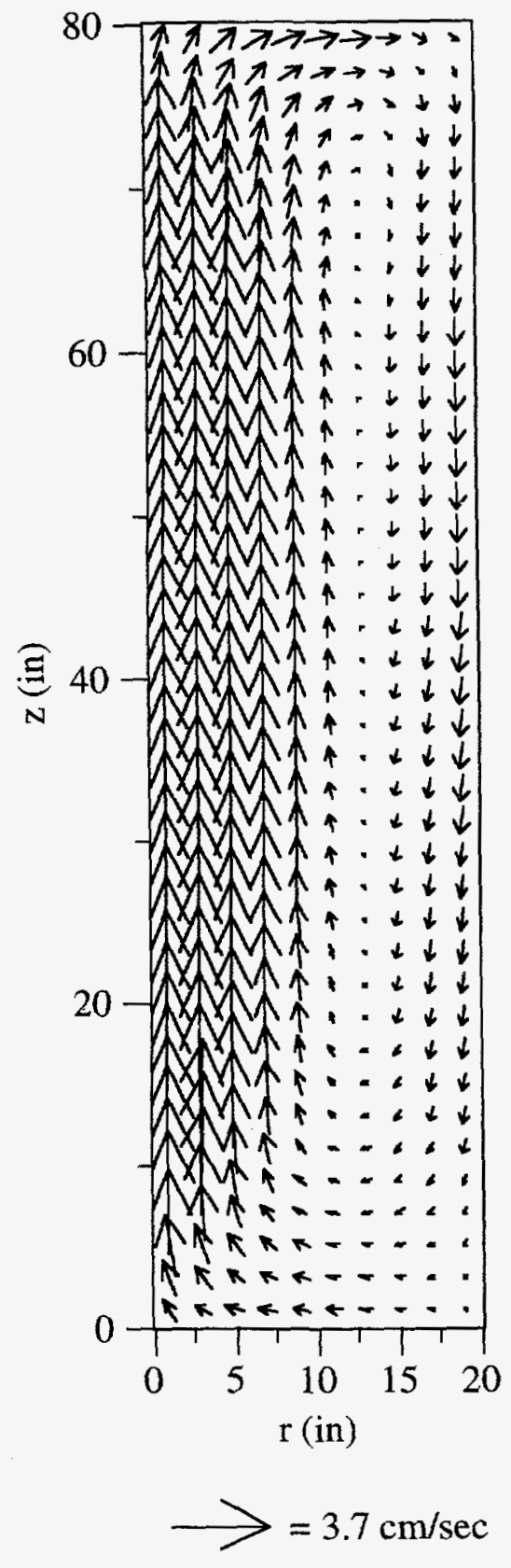

(a)

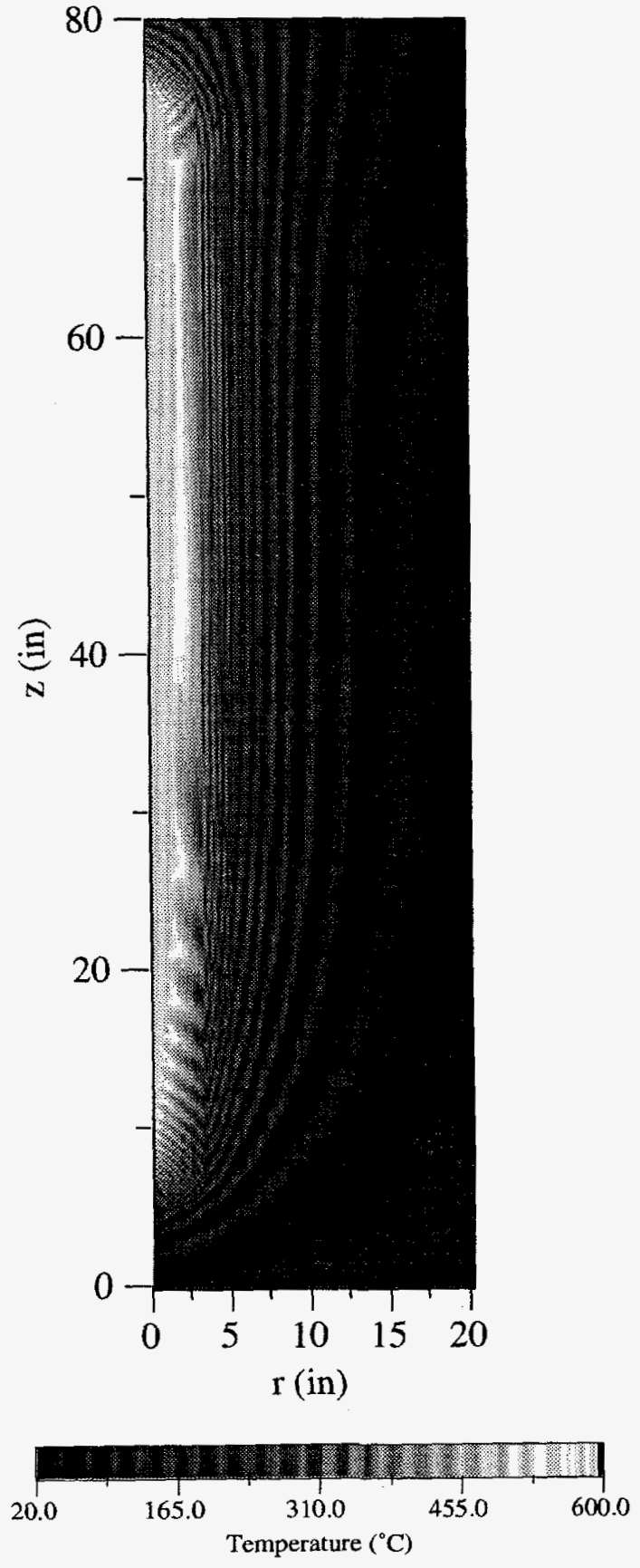

(b)

Figure 4-13. a) Gas velocity and b) temperature fields after 20 hours of heating using a thermal conductivity of $0.6 \mathrm{~W} / \mathrm{m}-\mathrm{K}$. 


\subsubsection{Sensitivity Analyses and Additional Studies}

In this section additional issues will be investigated that were not considered in the previous TOUGH2 simulations. These include the effects of bulk permeability, moisture transport and phase change, non-equilibrium effects, and one-dimensional heating on the observed temperature fields.

\subsubsection{Sensitivity Analysis of Bulk Permeability}

Since the bulk permeability presumably has a significant effect on convective velocities, the bulk permeability was varied to investigate its effect on temperature distributions (all other parameters were fixed using the best guess thermal properties presented earlier). Figure 4-14 shows the temperatures along Probes 1 and 3 for two different bulk permeabilities after 5 hours of heating in the first experiment. The top plot in Figure 4-14 shows the results as presented earlier using a bulk permeability of $1 \times 10^{-7}$ $\mathrm{m}^{2}$, while the bottom plot shows the same results for a bulk permeability of $2 \times 10^{-7} \mathrm{~m}^{2}$. Note that the increase in bulk permeability produced higher temperatures near the top of Probe 3 while decreasing temperatures near the bottom. This was a result of the higher convective velocities which carried warm air to the top of the experiment and cooler air to the bottom. Figure 4-15 shows the same results at 20 hours of heating in the first experiment. The increased bulk permeability $\left(\mathrm{k}=2 \times 10^{-7} \mathrm{~m}^{2}\right)$ seems to provide better agreement in the temperature profiles as a result of the higher convective velocities.

Figure 4-16(a) shows the temperatures along Probes 1 and 3 after 15 hours of heating during the second experiment. The second experiment was nearly identical to the first except for slight changes in the bottom boundary temperature and heater power. A bulk permeability of $2 \times 10^{-7} \mathrm{~m}^{2}$ was used along with the best guess thermal properties determined in the first experiment. Figure 4-16(b) shows the temperatures along Probe 6, which was positioned horizontally in the experiment, after 5, 10, and 15 hours of heating. Good agreement was obtained in all cases. Based on these simulations, the best guess for the bulk permeability of the crushed tuff system is $2 \times 10^{-7} \mathrm{~m}^{2}$. However, caution is 

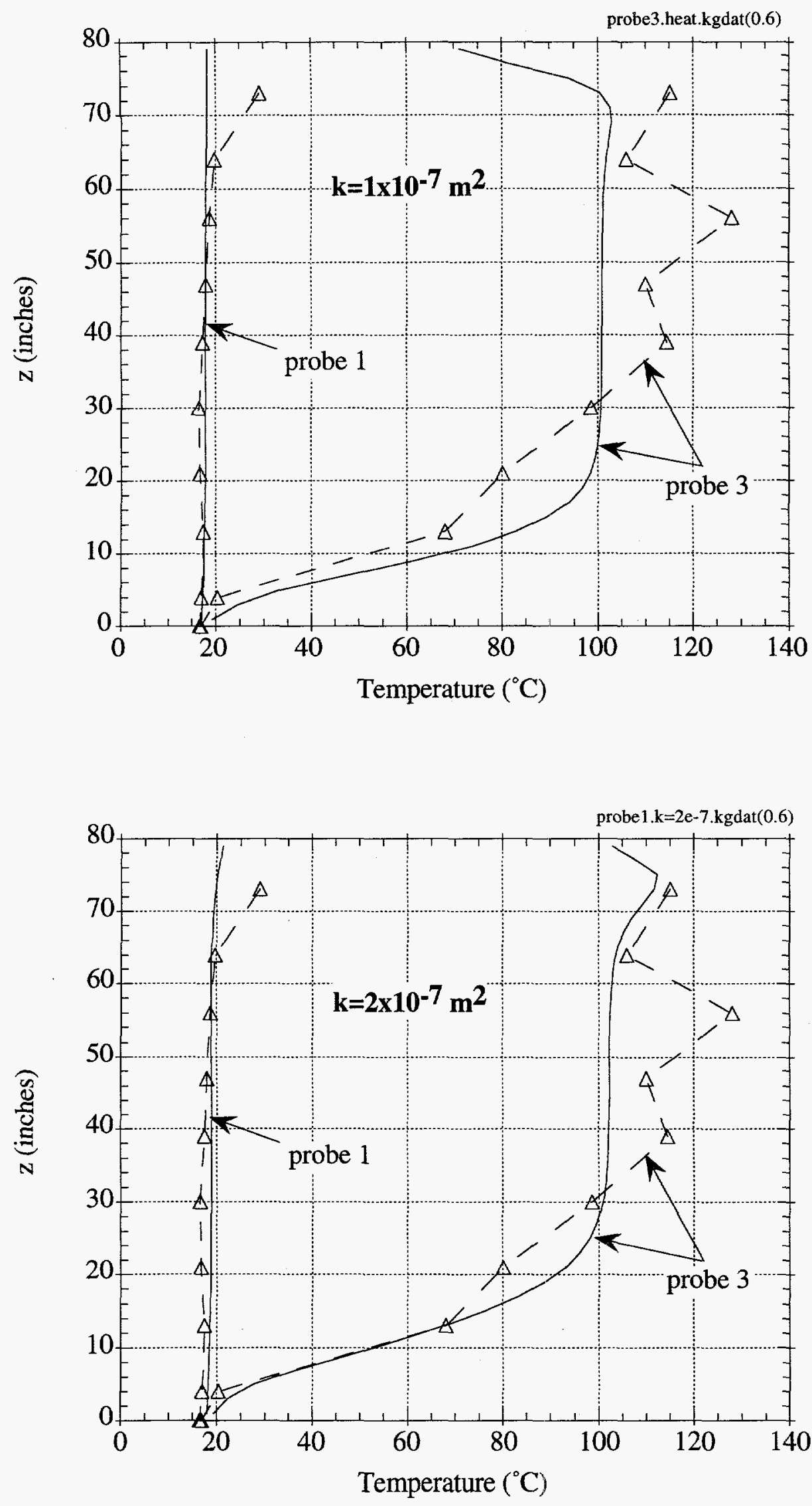

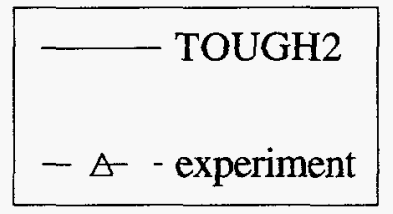

\begin{tabular}{|r|c|}
\hline initial $\mathrm{S}_{1}$ & 0.0 \\
\hline$\rho c_{\mathrm{p}}\left(\mathrm{J} / \mathrm{m}^{3}-\mathrm{K}\right.$ & $2.184 \times 10^{6}$ \\
\hline $\begin{array}{r}\text { thermal } \\
\text { conductivity }(\mathrm{W} / \mathrm{m}-\mathrm{K})\end{array}$ & 0.6 \\
\hline $\mathrm{Q}_{\text {leater }}(\mathrm{W})$ & 1865 \\
\hline $\mathrm{T}_{\text {bottom }}\left({ }^{\circ} \mathrm{C}\right)$ & 17 \\
\hline
\end{tabular}

Figure 4-14. Temperatures along probe 1 ( $\mathrm{r}=15$ inches) and probe 3 ( $r=5$ inches) at 5 hours using two different bulk permeabilities. 

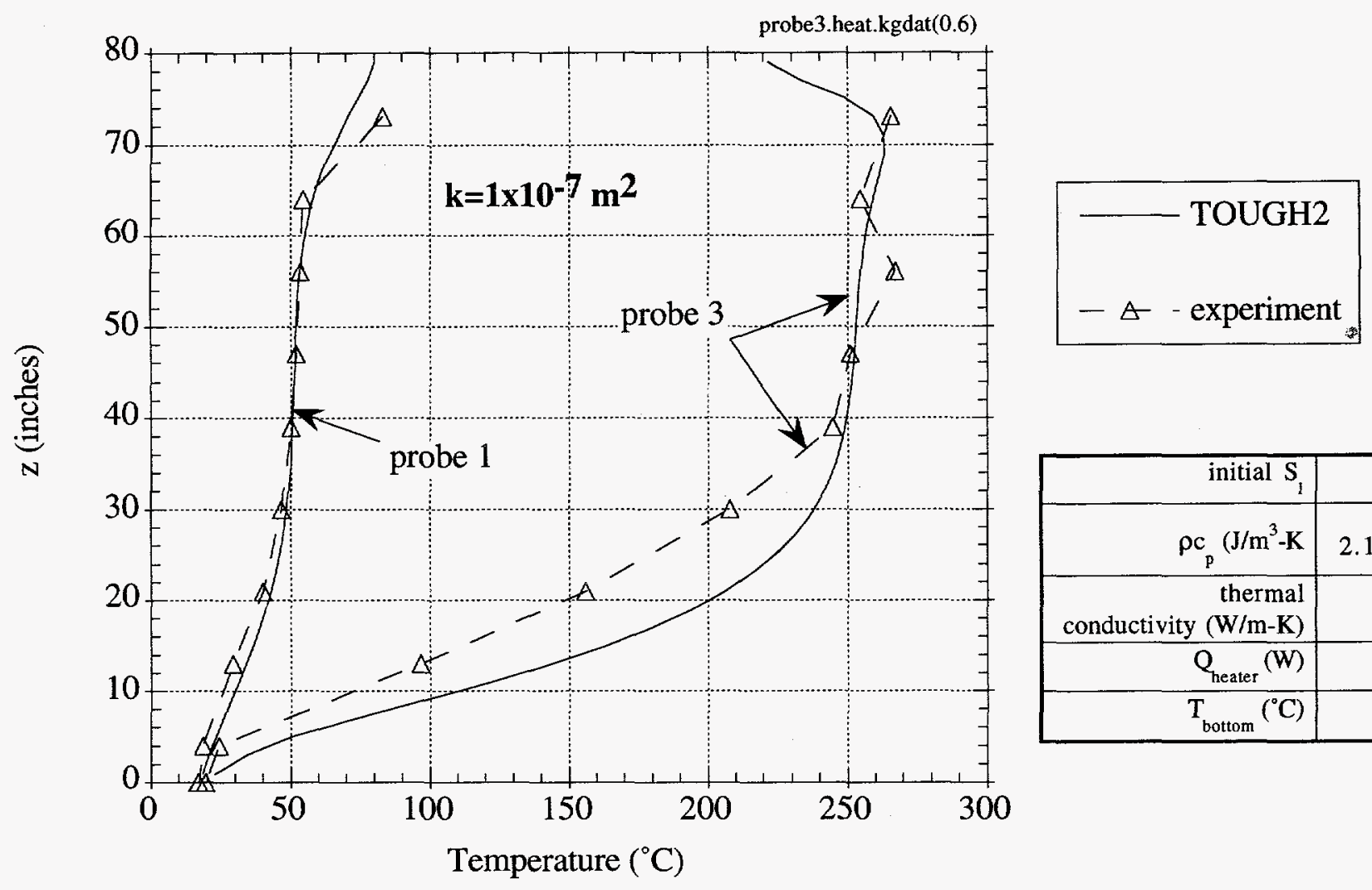

\begin{tabular}{|r|c|}
\hline initial $\mathrm{S}_{1}$ & 0.0 \\
\hline$\rho c_{\mathrm{p}}\left(\mathrm{J} / \mathrm{m}^{3}-\mathrm{K}\right.$ & $2.184 \times 10^{6}$ \\
\hline $\begin{array}{r}\text { thermal } \\
\text { conductivity }(\mathrm{W} / \mathrm{m}-\mathrm{K})\end{array}$ & 0.6 \\
\hline $\mathrm{Q}_{\text {heater }}(\mathrm{W})$ & 1865 \\
\hline $\mathrm{T}_{\text {bottom }}\left({ }^{\circ} \mathrm{C}\right)$ & 17 \\
\hline
\end{tabular}

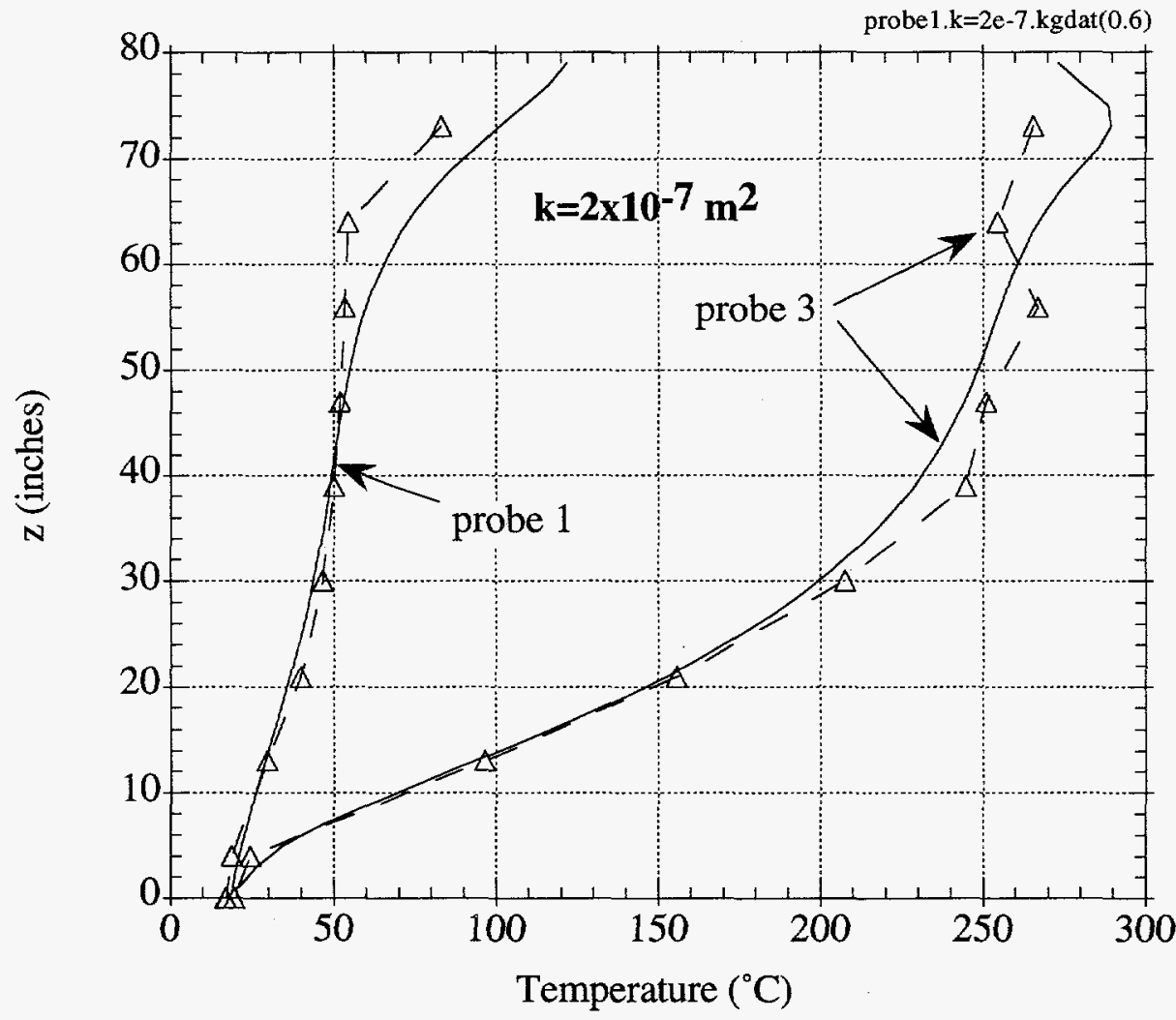

Figure 4-15. Temperatures along probe 1 ( $r=15$ inches) and probe 3 ( $\mathrm{r}=5$ inches) at 20 hours using two different bulk permeabilities. 


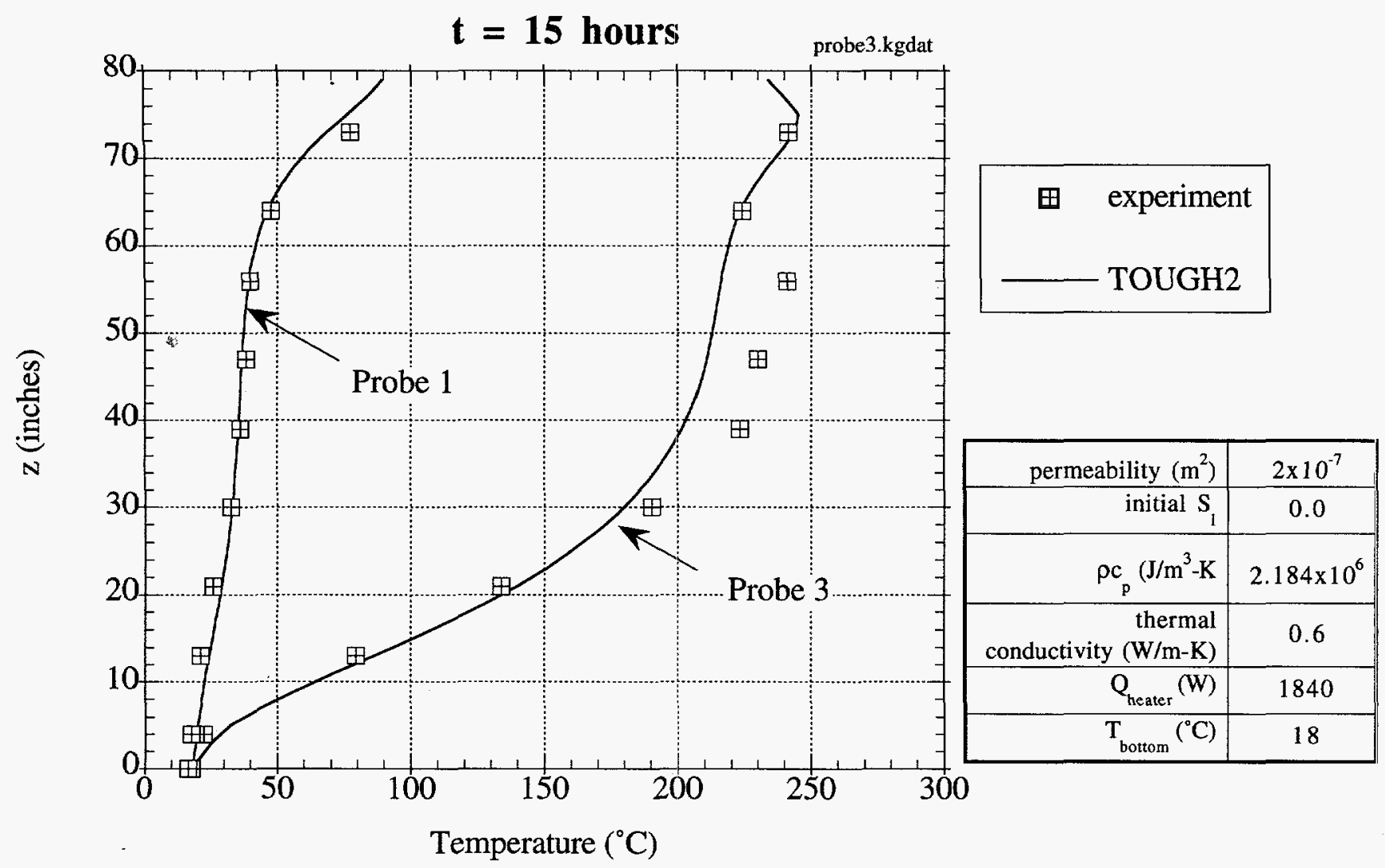

(a)

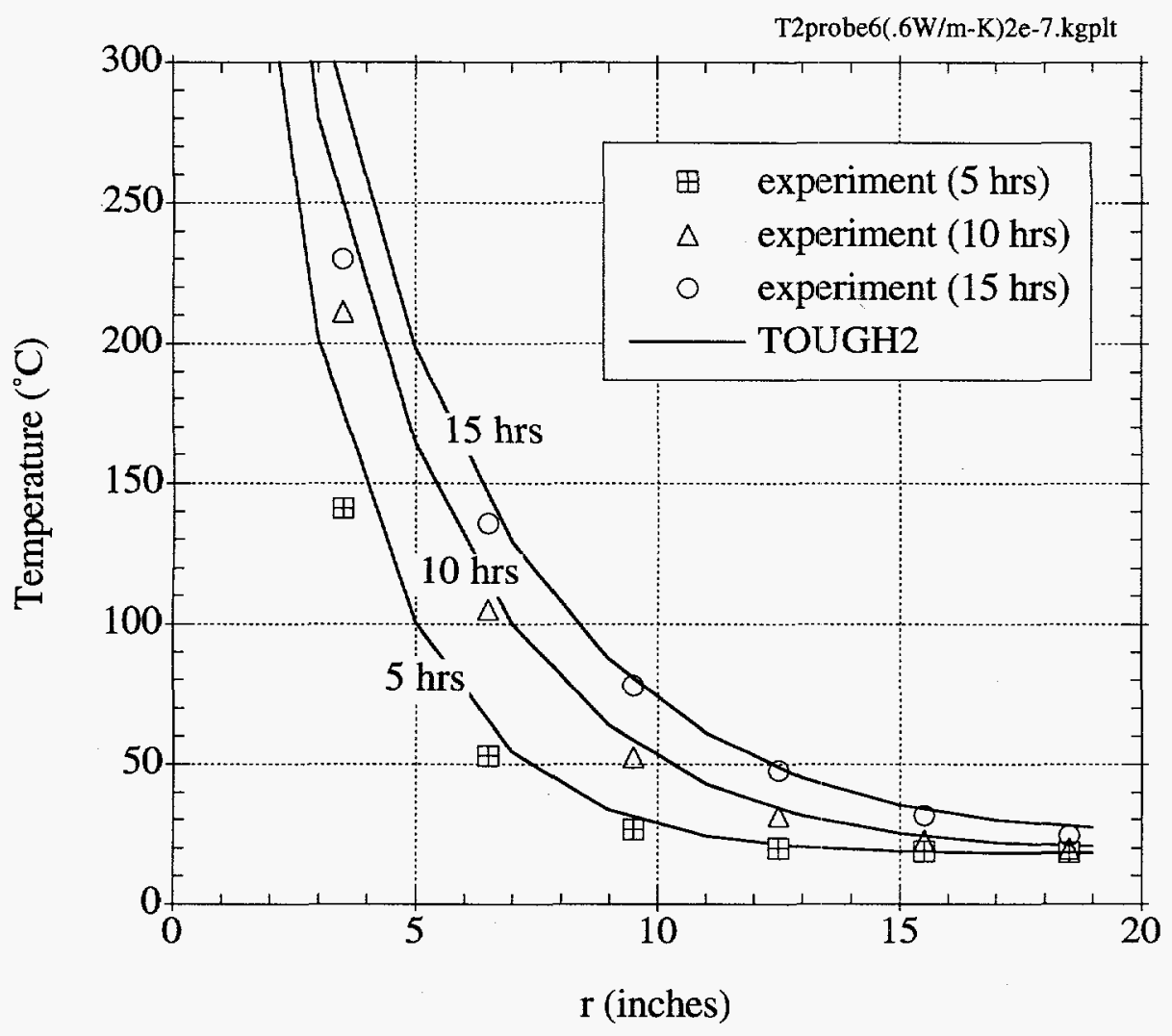

Figure 4-16. Temperature profiles for experiment \#2: a) TOUGH2 and experimental temperatures along probe $1(\mathrm{r}=15$ inches) and probe 3 ( $r=5$ inches) at 15 hours b) TOUGH2 and experimental temperatures along horizontal probe 6 ( $\mathrm{z}=37$ inches) at 5,10 , and 15 hours.

(b) 
advised when using this value for the bulk permeability of the system. The value was obtained by making numerous assumptions about the boundary conditions of the system and the properties of the rock, and the estimate was made for a very specific packing condition. If possible, permeability measurements of the crushed tuff should be made to estimate the bulk permeability for various packing conditions.

A note should also be made in regard to the irregular temperature profile observed near the top of the actual experiment as shown in Figure 4-9 and 4-10. In the simulations, a uniform permeability field was assumed. However, in the experiments, heterogeneous permeability fields may have existed due to non-uniform packing of the system and the large, irregular sizes of the rocks. Local temperatures recorded by the thermocouples could therefore differ in nearby regions if channeling of the hot air occurred. As evidenced in Figures 4-9 and 4-10, a higher temperature near $z=55$ in. (plane 8) may have been caused by channeling of the hot air in that vicinity due to a localized high permeability zone.

\subsubsection{Moisture Transport and Phase Change}

In the previous simulations, the crushed tuff was assumed to be completely dry. However, analysis of the actual rock revealed that the backfill material contained a residual liquid saturation of 1 to $2 \%$ by weight. As the crushed tuff was heated, water vapor was probably liberated from the rock and convected away in the buoyancy-driven gas flow. As the water vapor reached cooler rock away from the heater, the water vapor may have condensed, releasing a large amount of energy. This behavior would augment the already skewed isotherms at the top of the cylinder as shown in Figure 4-13(b).

In order to assess the importance of moisture transport and phase change during the experiment, additional simulations were performed using the model shown in Figure 4-8 with an initially uniform residual liquid saturation of $3 \%$ (higher than the measured upper range). Only gas-phase transport was allowed as a result of the low liquid saturations in the crushed tuff-liquid-phase transport was prohibited by setting the liquid relative permeability equal to zero. The gas-phase relative permeability was constant and equal to 
one. The capillary pressure function for the crushed tuff was chosen to be a linear approximation of the capillary pressures used by Pruess [1991] for tuffaceous rock. Large capillary pressures existed in the backfill as a result of the low liquid saturations and effectively held the water in the rock matrix with no apparent drainage.

Figures 4-17(a)-(c) show the simulated velocity, temperature, and liquid saturation fields, respectively, of the first experiment after 1000 seconds of heating. Drying begins to occur near the bottom of the heater as water is vaporized. As the vapor is convected upwards, it condenses in cooler regions at the top of the cylinder above the heater as shown in Figure 4-17(c). Figures 4-18 and 4-19 show the same results after 3000 seconds and 6000 seconds of heating, respectively. The region near the heater continues to dry as water is vaporized and redistributed to cooler regions toward the top of the cylinder.

Figure 4-20 shows a comparison of the simulated temperatures along Probe 3 between the dry and residually saturated models. The residually saturated case exhibits considerably more heating at the top of the cylinder as a result of condensing water vapor. However, the significance of moisture transport and phase change in the experiment is uncertain since water vapor could escape through the insulation along the top of the cylinder.

\subsubsection{Non-Equilibrium Effects}

Inherent in TOUGH2 is the assumption of local thermal equilibrium conditions. In this particular study, this means that convective hot air in the crushed tuff is modeled as immediately releasing all of its energy in a region of cooler temperature. Although this may be a good approximation at low convective velocities in most porous materials, the simulated results in this system yield high velocities of several centimeters per second. In addition, the crushed tuff is extremely permeable with less surface area (than, say, fine sand) to transfer heat with the convective gas. As a result, convected hot air may have traveled further through the cylinder before releasing its excess energy in cooler regions. The temperature of the rock could therefore have been significantly different than the 

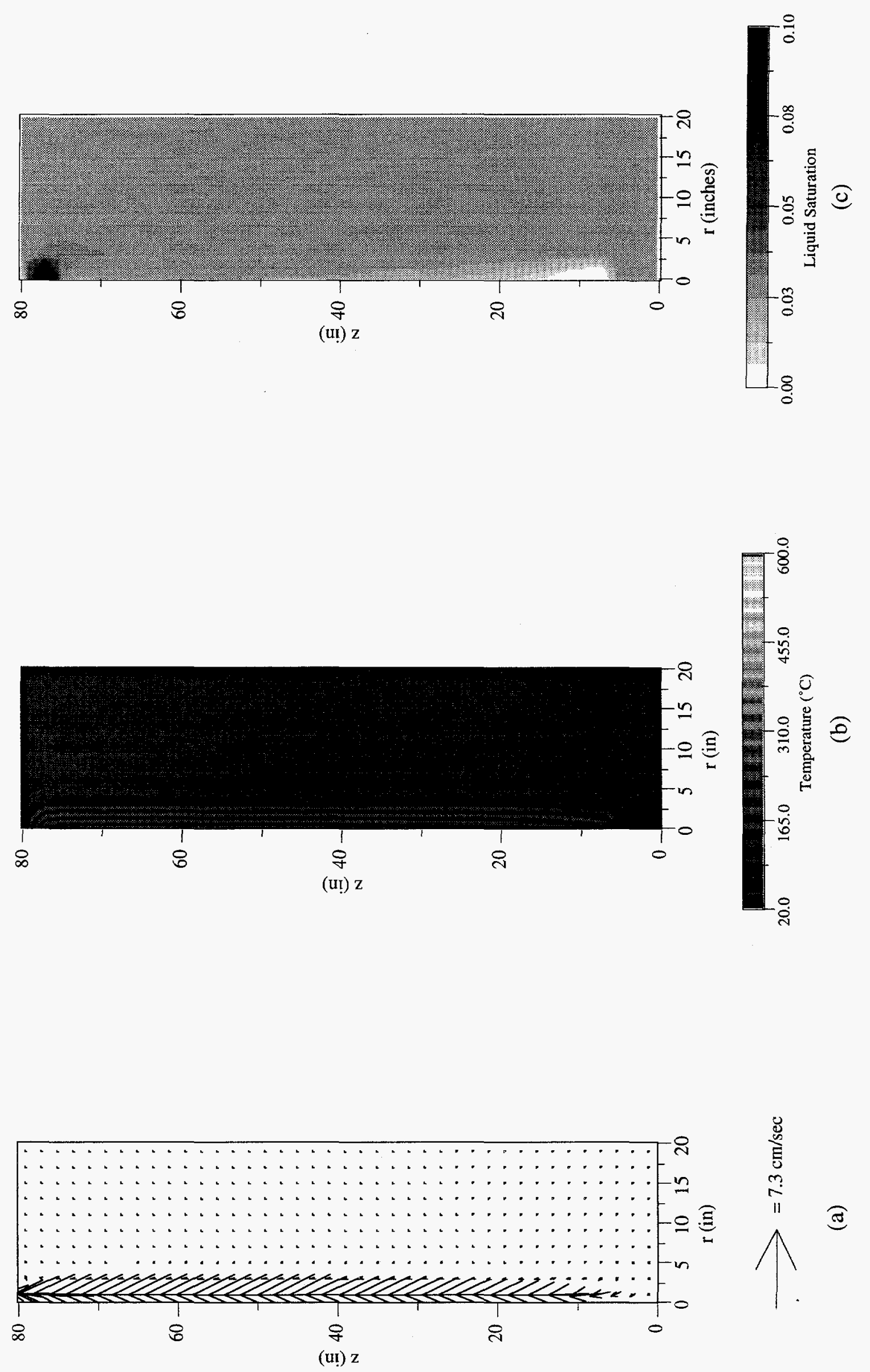

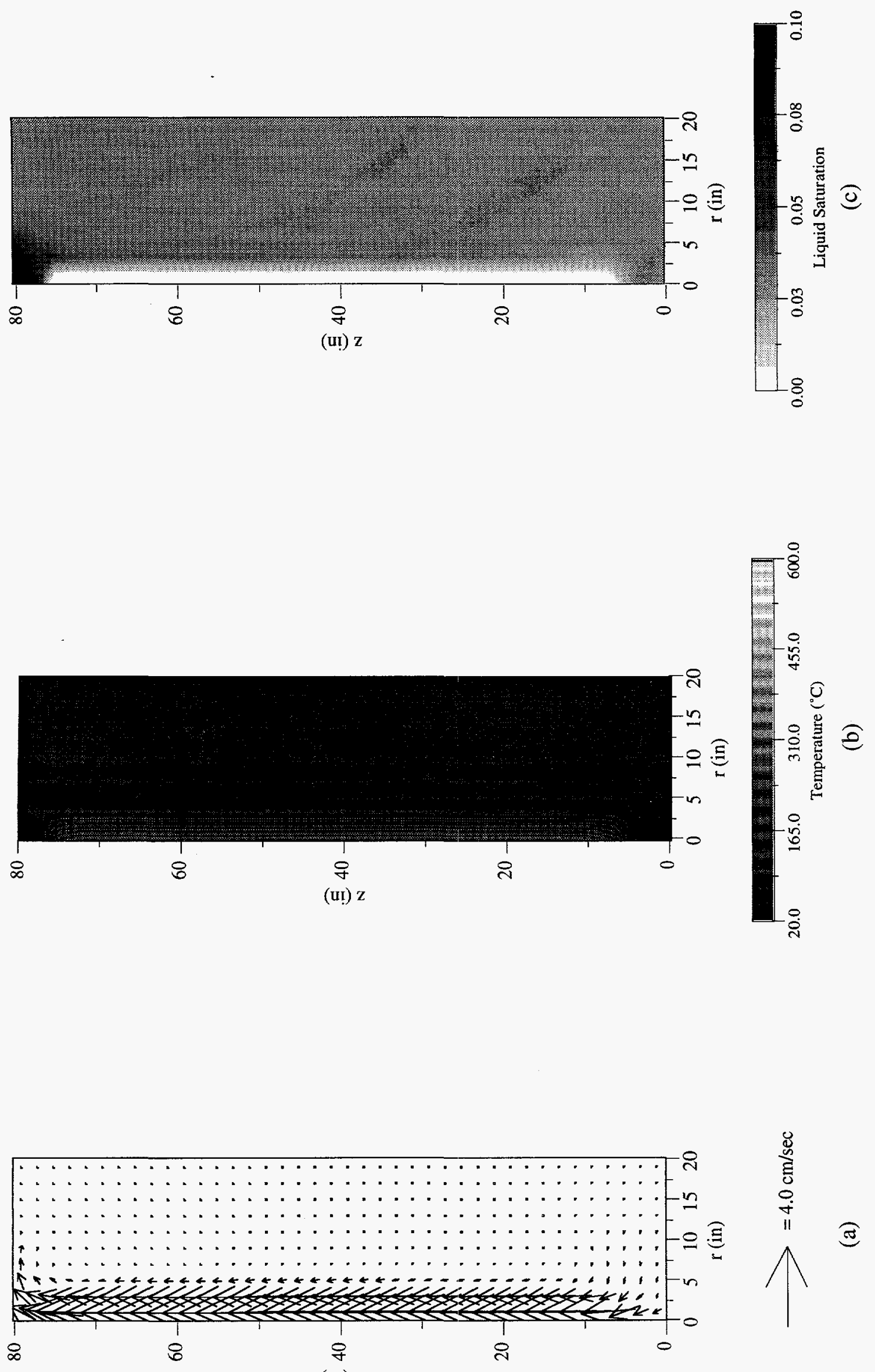

(UI) $\mathrm{z}$ 


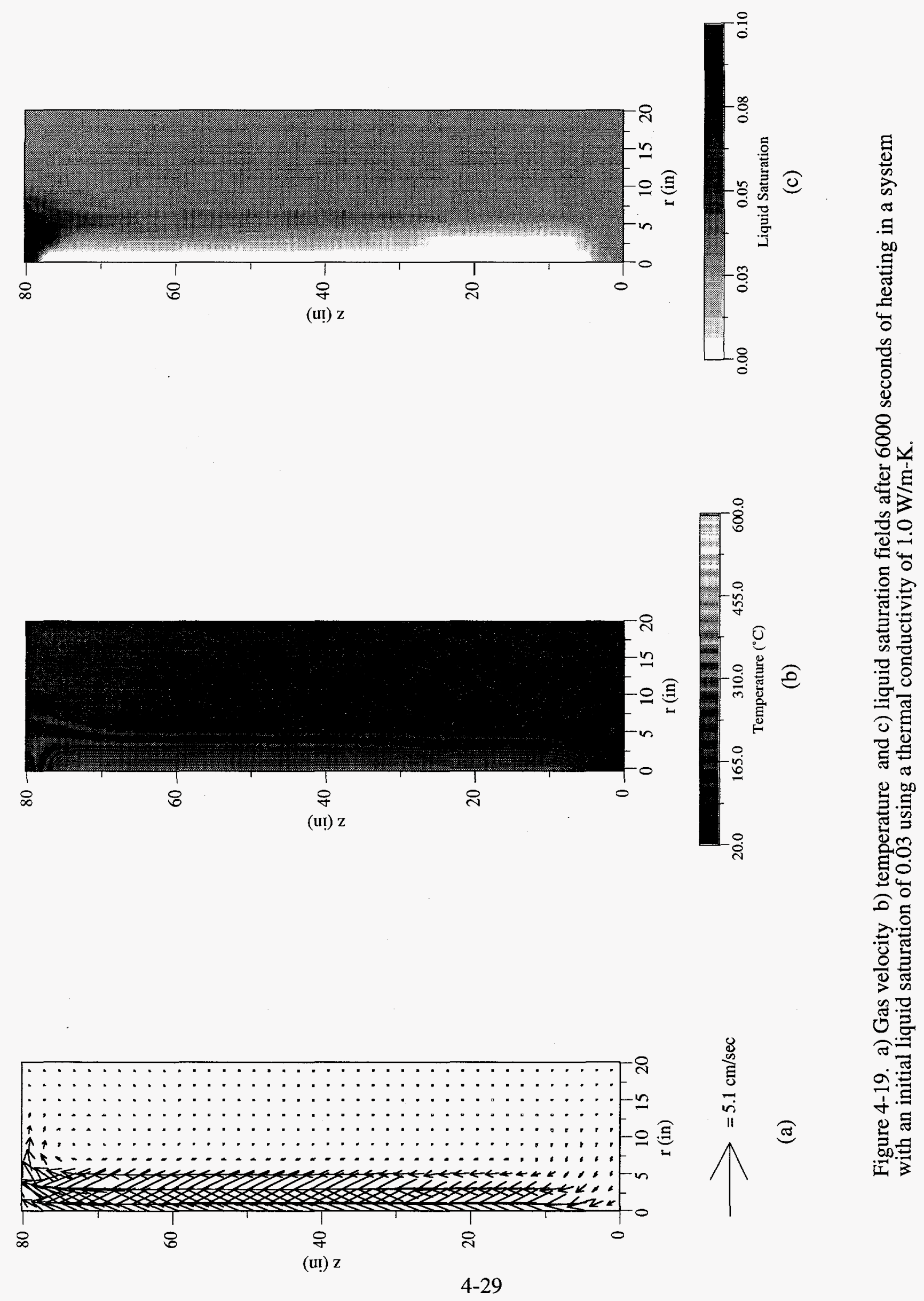




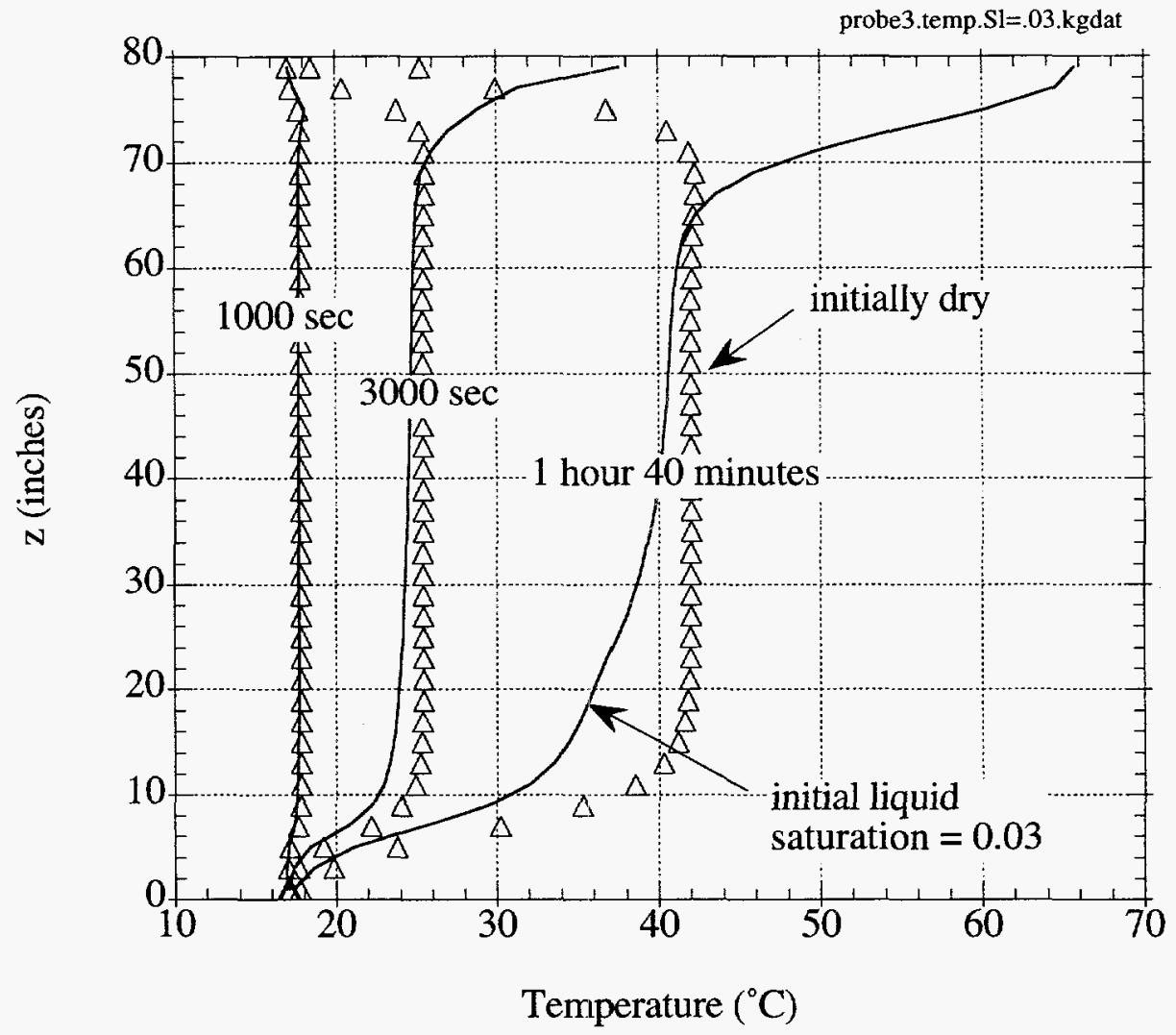

Figure 4-20. TOUGH2 simulated temperatures along probe 3 ( $r=5$ inches) for two different initial conditions. The triangles denote a system that was initially dry, whereas the solid lines represent a system that had an initial liquid saturation of 0.03 . The thermal conductivity that was used in these simulations was $1.0 \mathrm{~W} / \mathrm{m}-\mathrm{K}$. 
temperature of the air at locations that were not in equilibrium. The thermocouples along the top of Probe 1 may have been elevated as a result of this non-equilibrium behavior in the convected hot air.

\subsubsection{One-Dimensional Heating}

The experiment was originally intended to exhibit one-dimensional heating in the radial direction. However, several factors may have caused the temperature profiles in the test bed to exhibit two-dimensional behavior. These included the possibility of insufficient insulation at the bottom boundary and a potential coupling of the experimental apparatus to a constant temperature heat sink (the concrete slab and ground). Also, the relatively short length of the heating element, and convective transport may also be factors in the two-dimensional nature of the data obtained. Convection has already been discussed and was found to be a significant contributor to two-dimensional heating effects. The other two factors, heater length and bottom insulation, will be discussed in this section.

Figure 4-21 shows the difference in heating behavior after 1 day between a short heater (as shown in Figure 4-8) and a longer heater that extends the entire height of the cylinder. In this simulation all boundaries are assumed insulated. Even with perfect insulation, two-dimensional heating effects are observed as a result of natural convection. However, the lack of heating towards the top and bottom of the cylinder as shown in Figure 4-21(a) yields greater deviations from vertically uniform isotherms than heating along the entire height of the cylinder. Therefore, future experiments should apply heating along the entire height of the backfill in order to lessen the two-dimensional effects from convection along the horizontal mid plane of the cylinder.

The apparent constant temperature sink at the bottom of the cylinder is actually the result of convective effects. The temperature field shown in Figure 4-13(b) (using a constant temperature sink along the bottom boundary) is not significantly different than the temperature field shown in Figure 4-21(b) for a completely insulated system. The isotherms along the bottom of the insulated system are also skewed as a result of cool air being convected down towards the bottom of the cylinder. As a result, the cool constant 


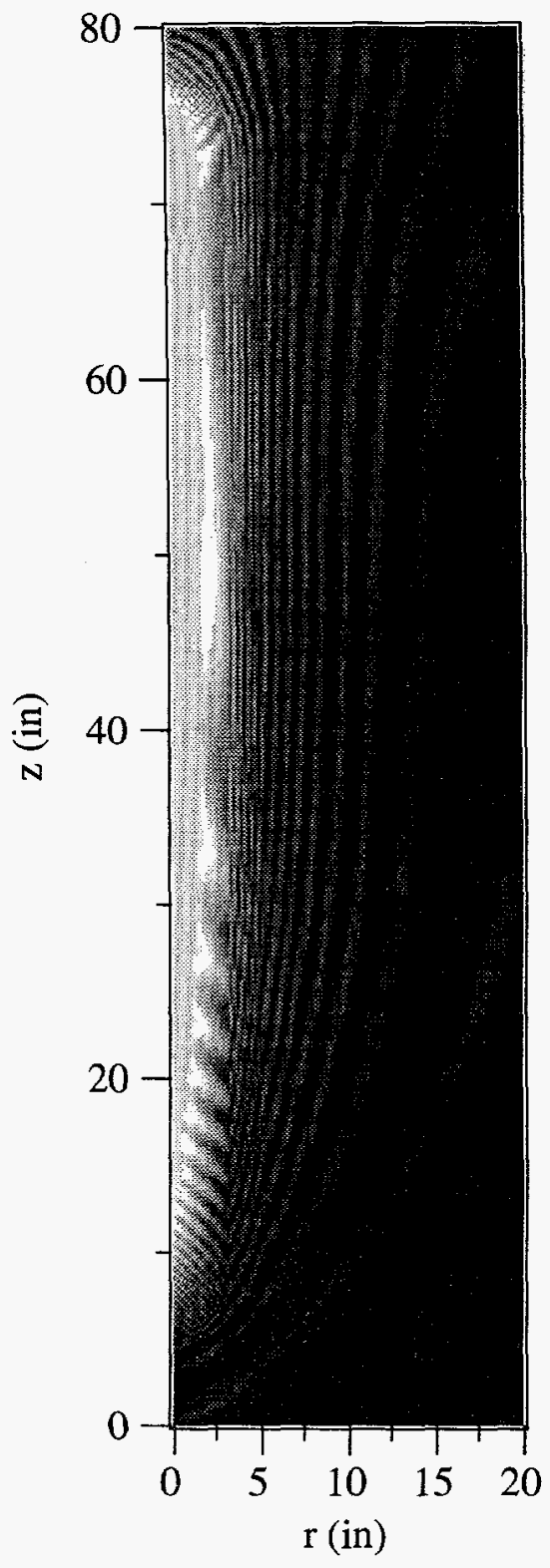

(a)

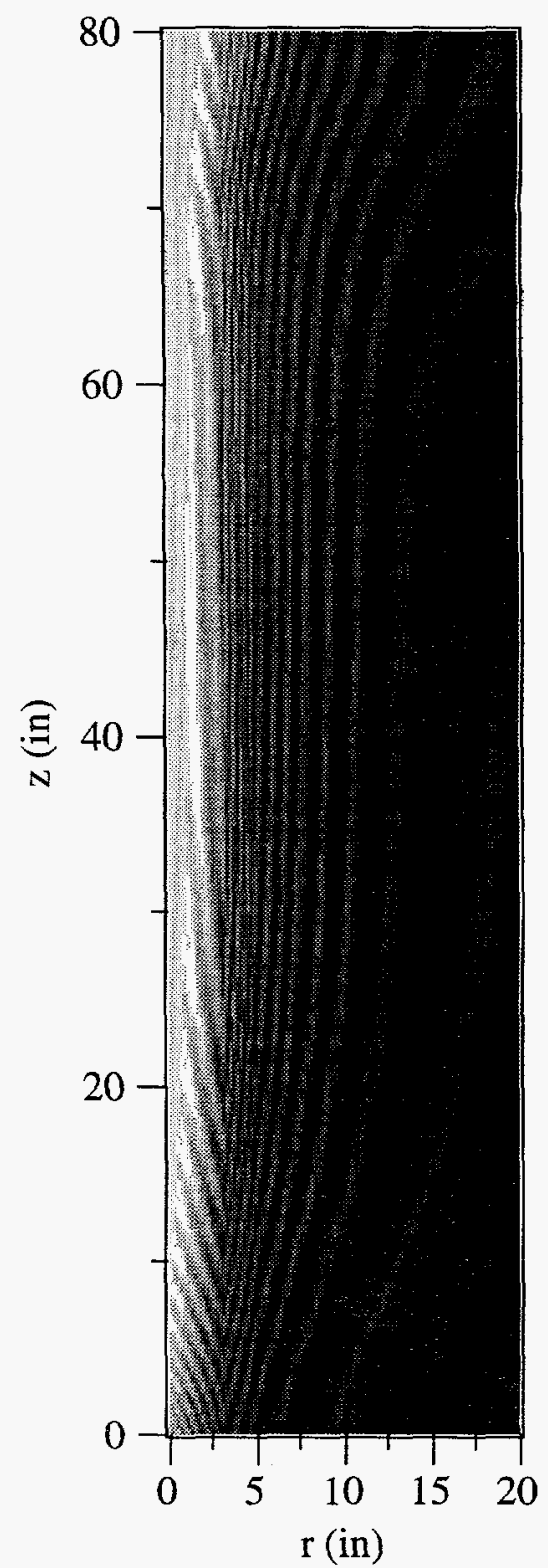

(b)

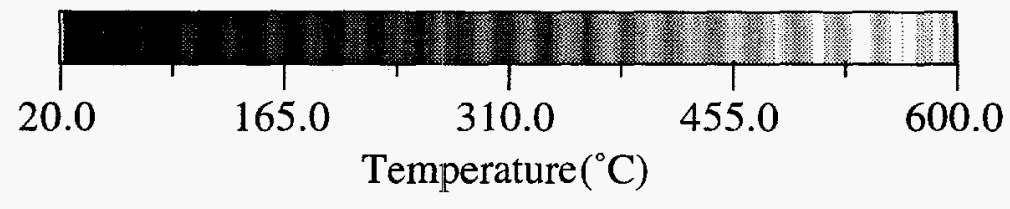

Figure 4-21. Effect of heater length on temperature profiles after 1 day of heating in a completely insulated system: a) short heater (see Figure 4-8) b) long heater extends along the entire height of the cylinder. 
temperature bottom boundary used in the post-test analyses probably had little effect on the development of an effective bulk thermal diffusivity-the temperatures near the bottom would have remained cool as a result of natural convection even without the imposed constant temperature bottom boundary (i.e., if it had been modeled as an insulated surface).

\subsubsection{SUMMARY OF TOUGH2 ANALYSES}

The crushed-tuff thermal diffusivity experiment has been simulated using the numerical code TOUGH2. Simulations were performed iteratively to estimate the effective thermal parameters of the backfill material. In addition, issues regarding various non-isothermal flow processes in the experiment were investigated. The major conclusions from the TOUGH2 simulations can be summarized as follows:

- The best guess estimate for the bulk thermal diffusivity of the crushed tuff examined is $5.0 \times 10^{-7} \mathrm{~m}^{2} / \mathrm{sec}$. This estimate should be used with caution since it is based on a number of assumptions about the system, particularly the bulk permeability which significantly influences convective heat transfer in the system.

- Buoyancy-driven gas-phase convection heated regions near the top of the cylinder while cooling regions at the bottom of the cylinder. This behavior is accentuated if moisture is present due to condensation and evaporation.

- Gas-phase convection was more pronounced in simulations using a higher bulk permeability of the crushed tuffaceous rock. Iterative numerical simulations revealed that using a bulk permeability of $2 \times 10^{-7} \mathrm{~m}^{2}$ yielded good agreement between TOUGH 2 results and observed experimental data. Again, this estimate should be used with caution as a result of the uncertainties in the thermal properties that were assumed for the crushed tuff.

- Two-dimensional heating effects may be diminished in future tests by extending the heater length across the entire height of the backfill and possibly by increasing the insulation on the bottom of the cylinder. However, two-dimensional effects are still likely as a result of natural convection. 


\subsection{CONDUCTION ANALYSES OF COOL-DOWN DATA}

In addition to estimating the thermal properties of the backfill material using data obtained during heating, data obtained after the heater was turned off, cool-down data, were used to back-out thermal properties. Given the large convective effects predicted by the TOUGH2 analyses, it is important to focus the conduction analyses of the cool-down data in a temporal range when convective velocities diminish sufficiently such that a conduction model is applicable.

The TOUGH2 model shown in Figure 4-8 was used to determine when, after the heater was turned off, conduction became the dominant mode of heat transfer within the crushed tuff. The heater in the TOUGH2 simulation was turned off after 20 hours of continuous heating, and then temperature and velocity fields were recorded after 5 hours, 1 day, and 3 days of cooling. Figures 4-22(a)-(b) show the gas-phase velocity field and temperature field in the test bed after 5 hours of cooling. Note that a significant amount of convection still exists in the crushed tuff as a result of temperature gradients in the system. Figures 4-23 and 4-24 show the same plots after 1 and 3 days of cooling. The convective velocities help to flatten the temperature gradients across the cylinder, and after 3 days of cooling the temperatures are fairly uniform in the radial direction. As a result of these simulations, it appears that pure conduction simulations would be applicable to data obtained after at least 1 day of cooling.

Based on the criteria for conduction dominance derived from the TOUGH2 simulations, data obtained over a 111 hour period beginning approximately 25 hours following the shut-down of the heater in Test 1 were used in the cool-down analyses. The analyses were performed using the non-linear conduction code COYOTE-II [Gartling and Hogan, 1994] to analyze the axisymmetric mesh presented in Figure 4-25. Temperature data 25 hours following the shut-down of the heater were mapped onto a finite-element mesh using the MERLIN-II code [Gartling, 1991]. These mapped temperatures became the initial conditions for the analyses (Figure 4-26). The bottom boundary of the model was held at $25^{\circ} \mathrm{C}$. This is consistent with experimental data over the modeled time frame 


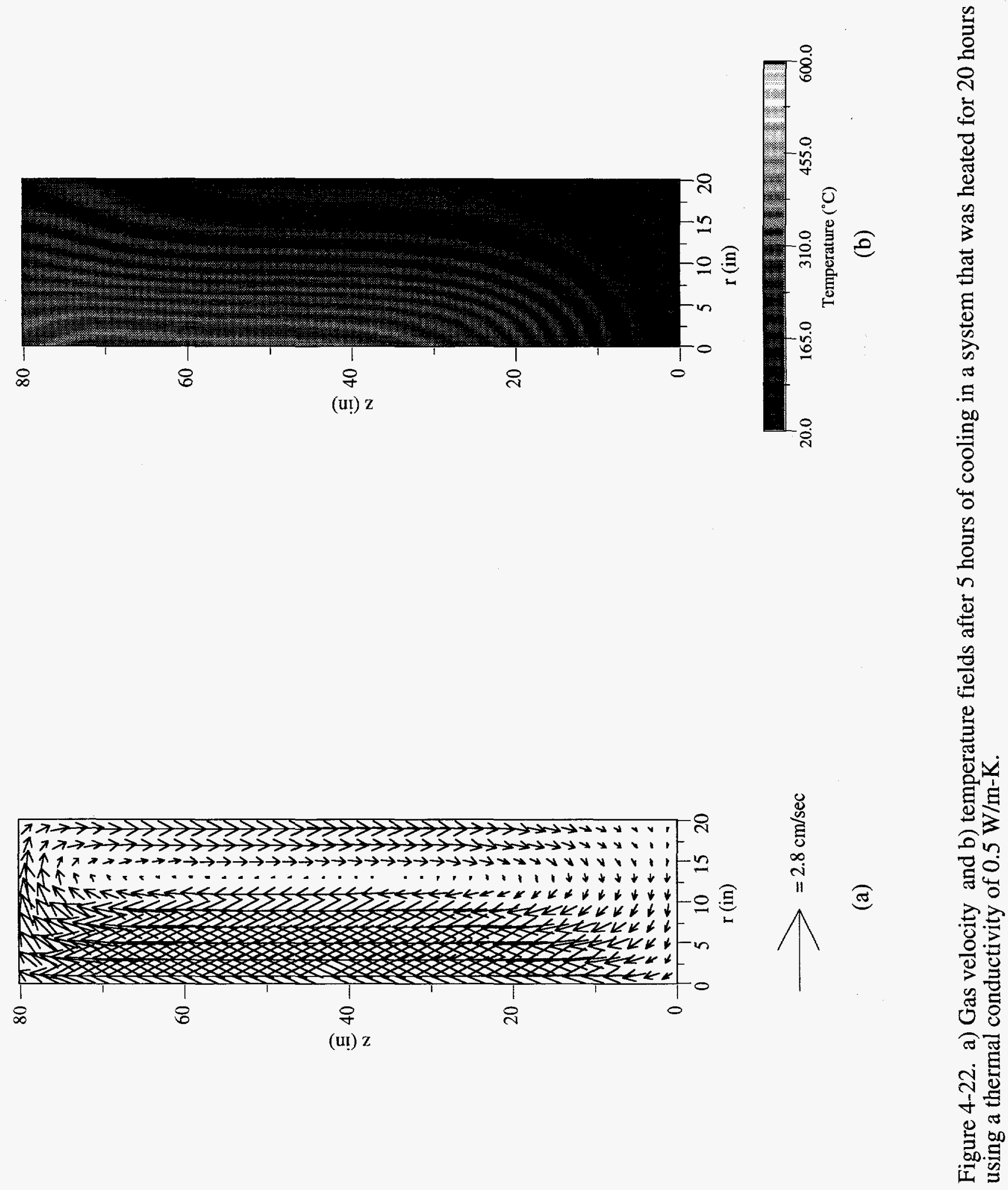




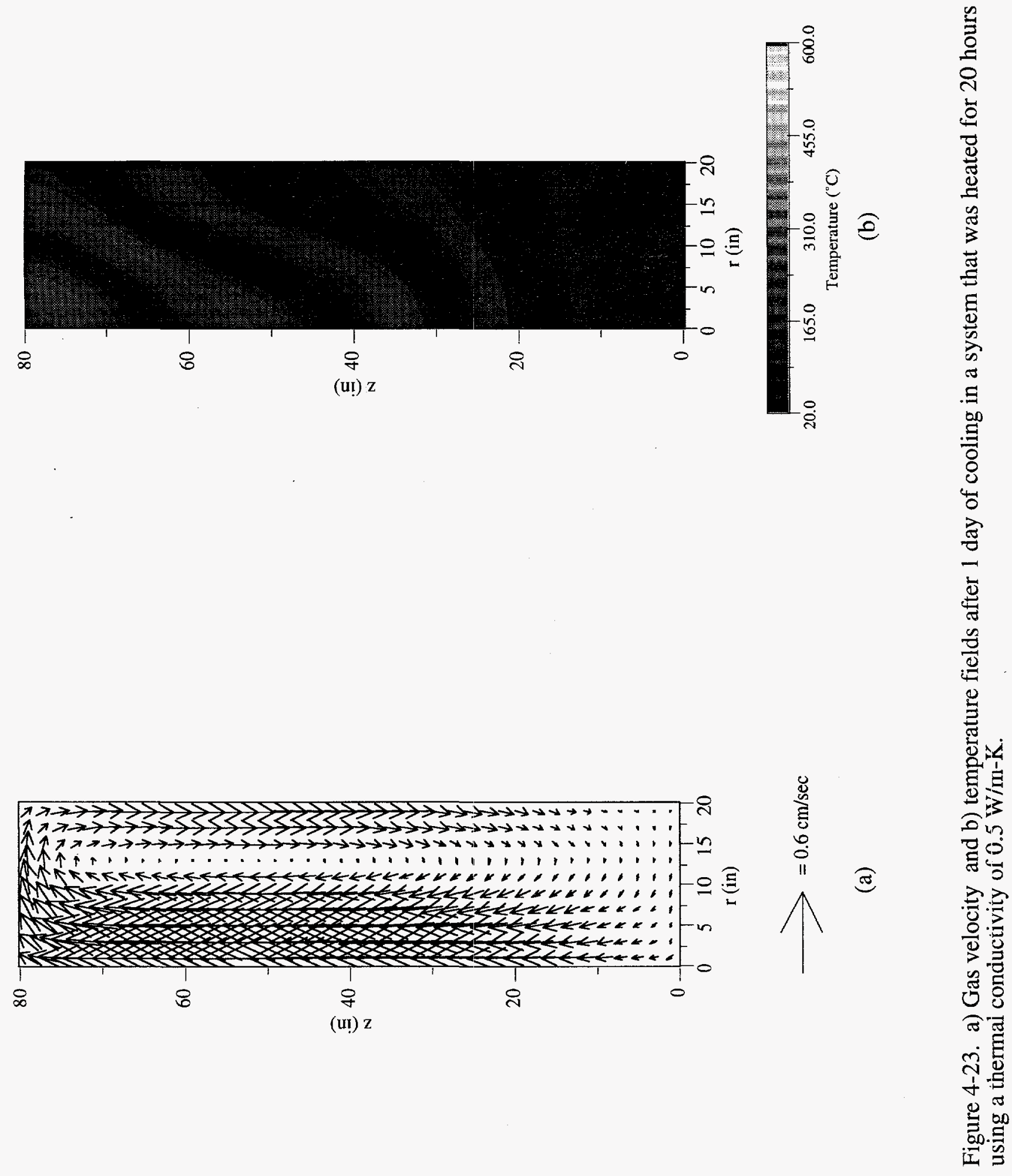



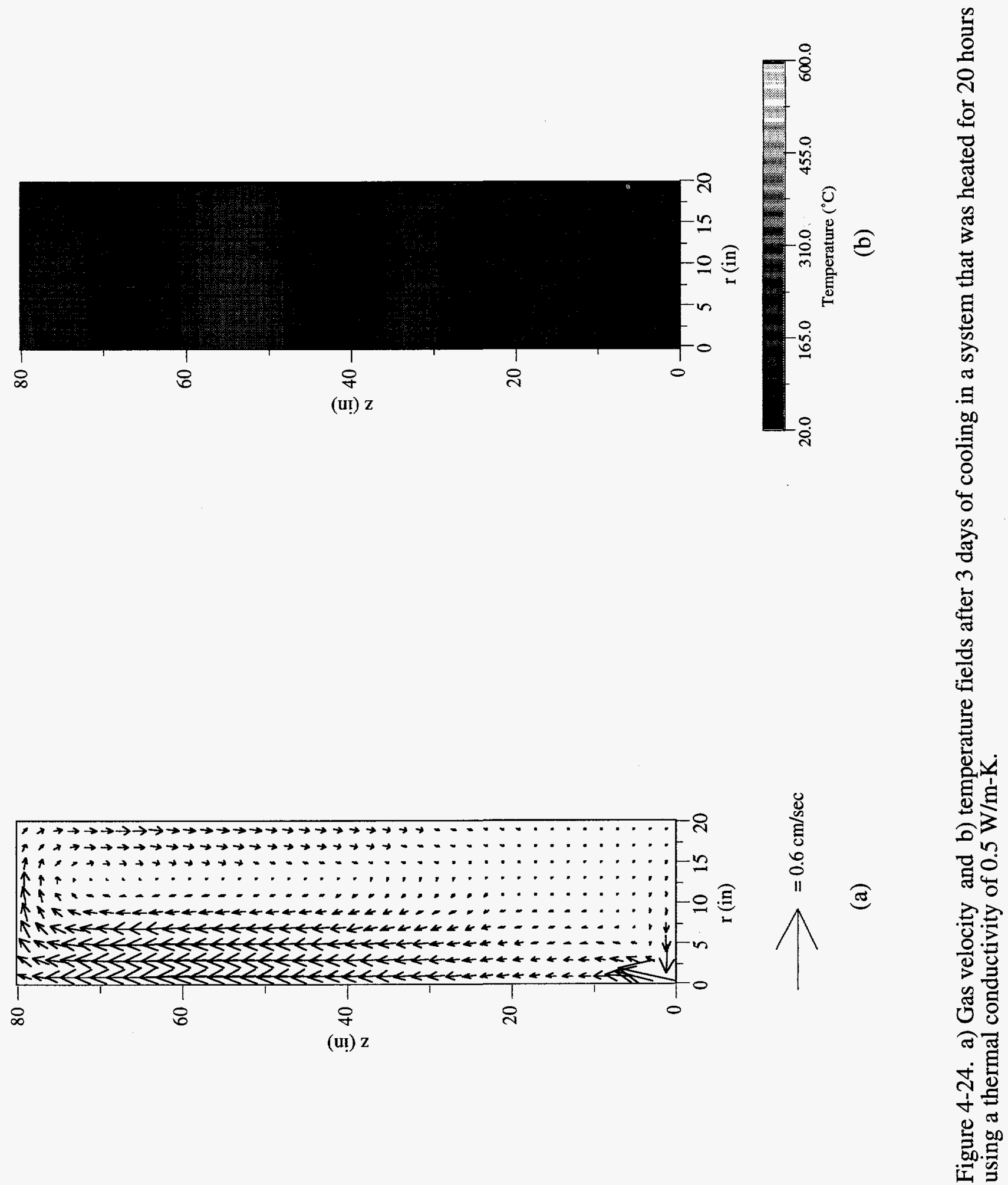


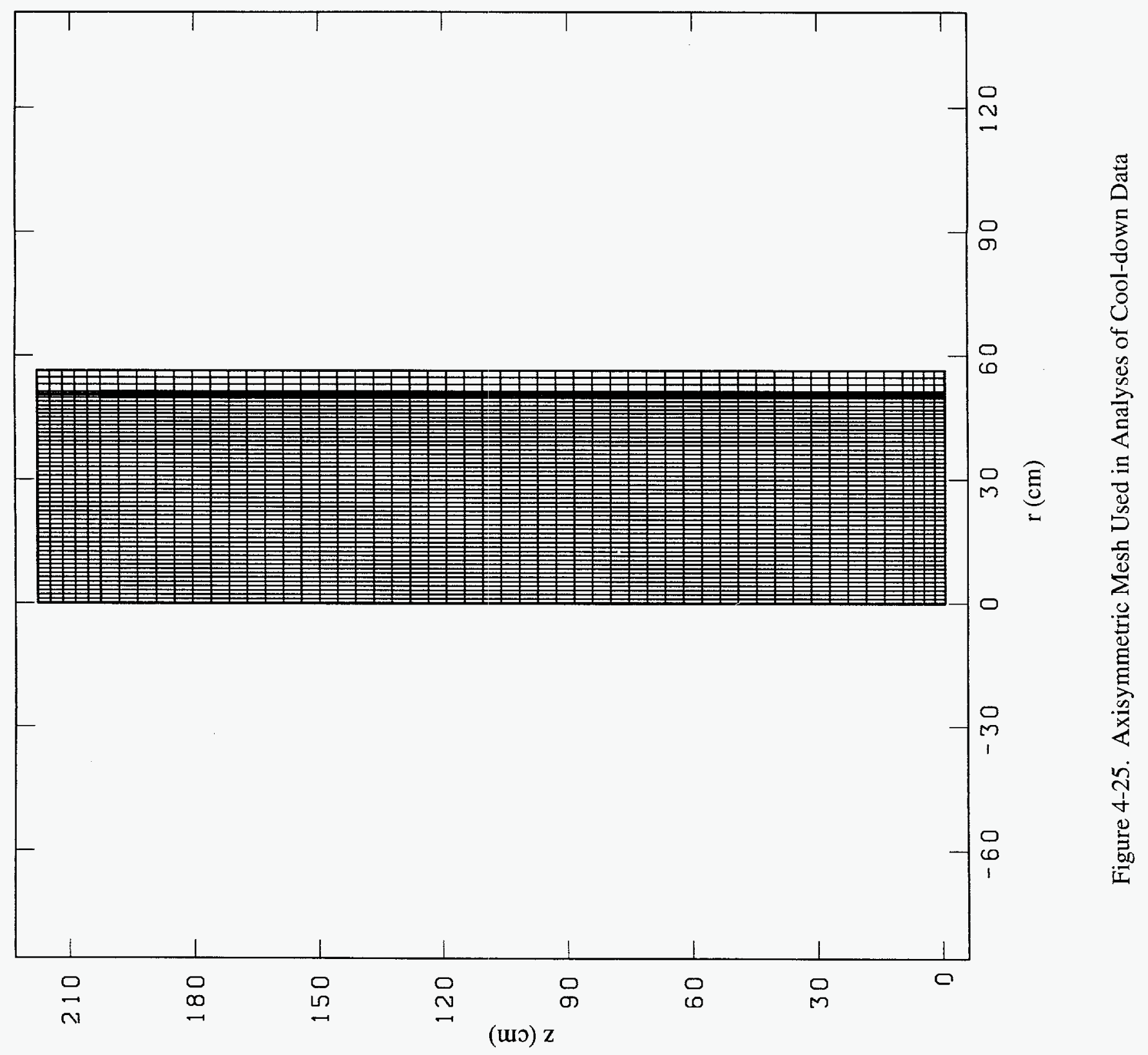




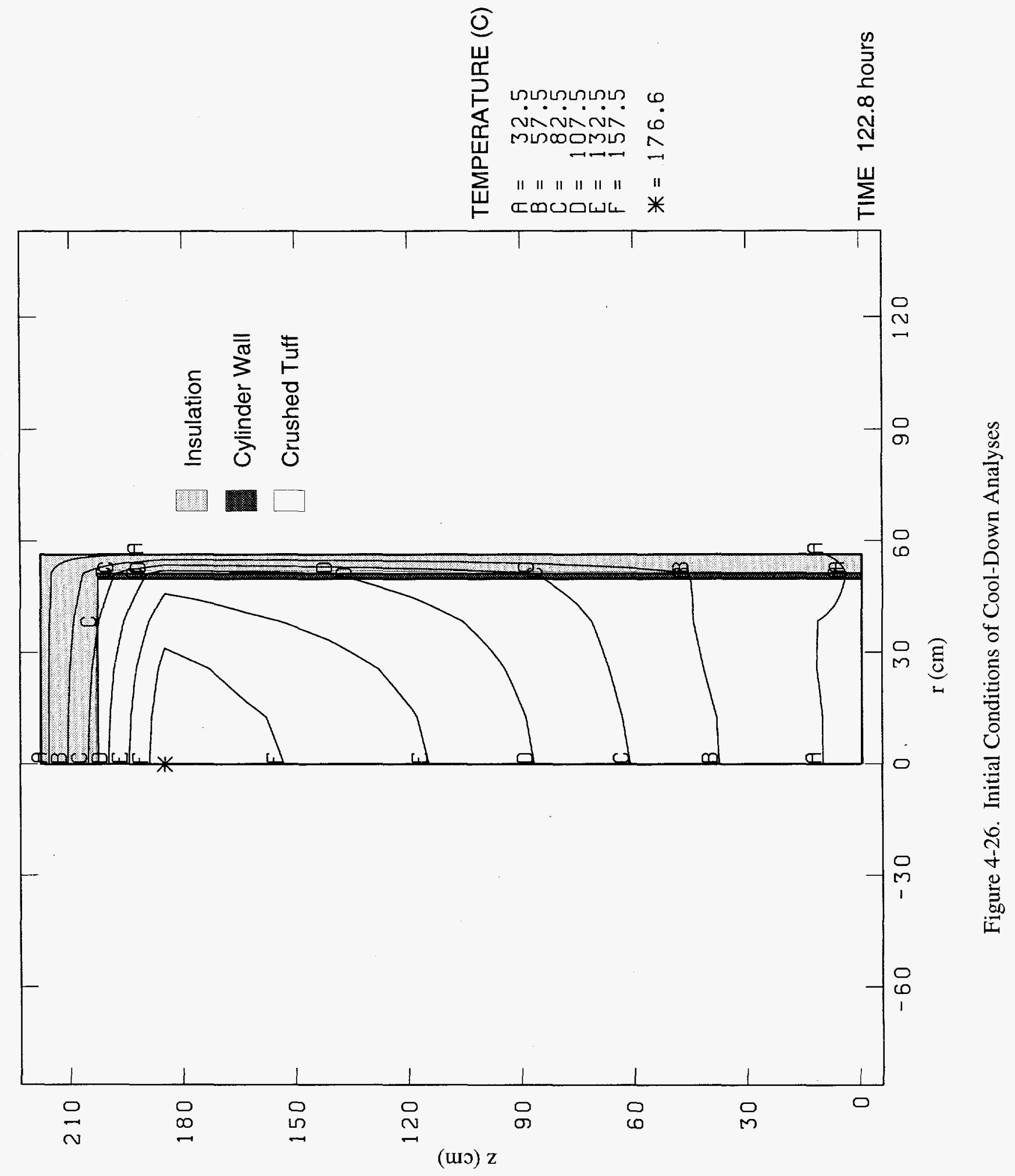


(see Appendix A). The boundary condition imposed on the insulation surface was a constant temperature of $25^{\circ} \mathrm{C}$, consistent with the mean of the data recorded for the thermocouples placed at the boundary of the radial insulation (see Appendix A).

A best-guess estimate of the thermal diffusivity was determined to be $6.6 \times 10^{-7}$ $\mathrm{m}^{2} / \mathrm{s}$. Figures 4-27 through 4-29 show comparisons between the recorded data along Probes 1,2 , and 3 and the simulated temperature results using the best guess estimate of thermal diffusivity.

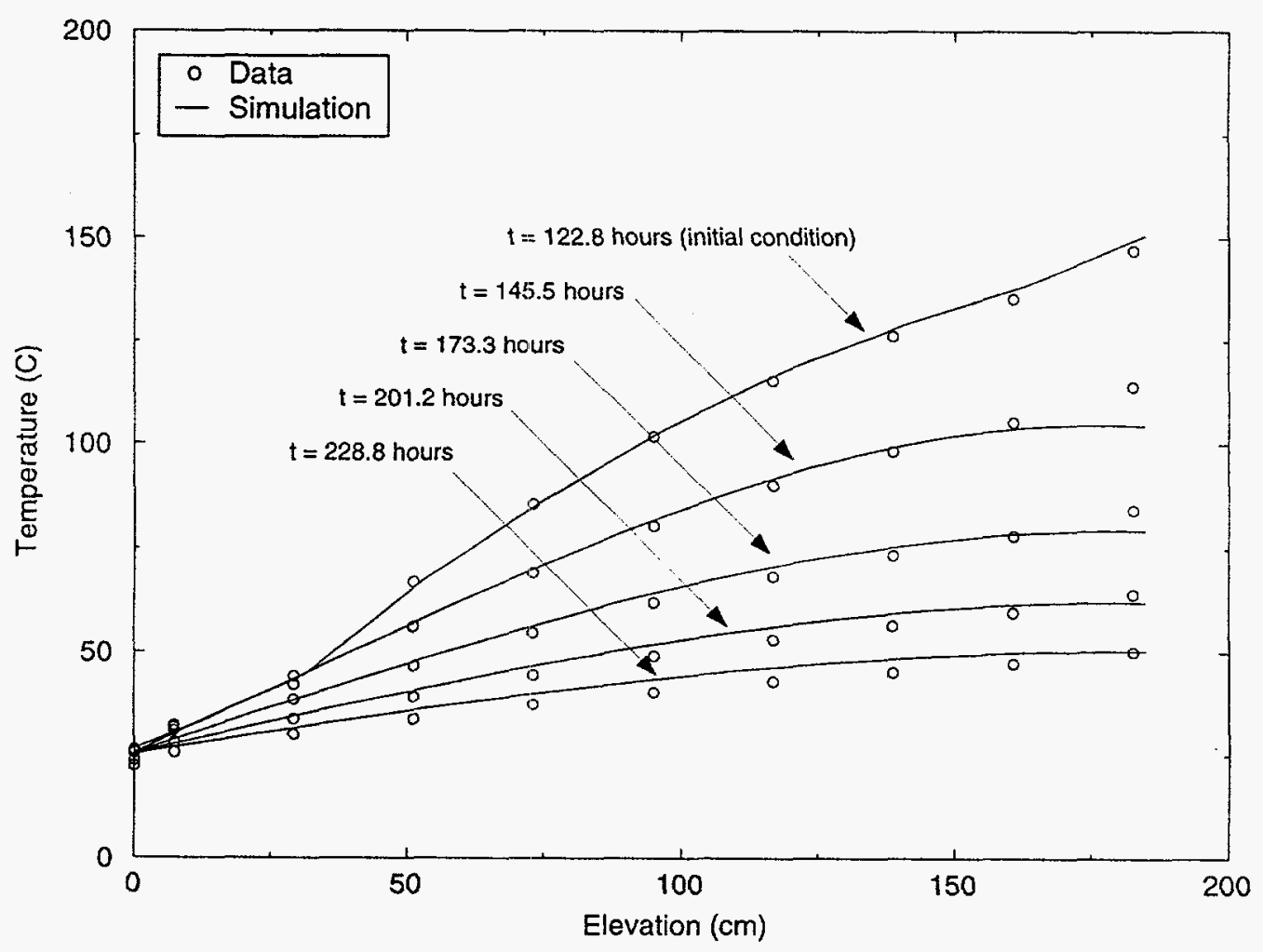

Figure 4-27. Comparison Between Experimental Data and Simulated Temperatures Along Probe 1, Test 1 


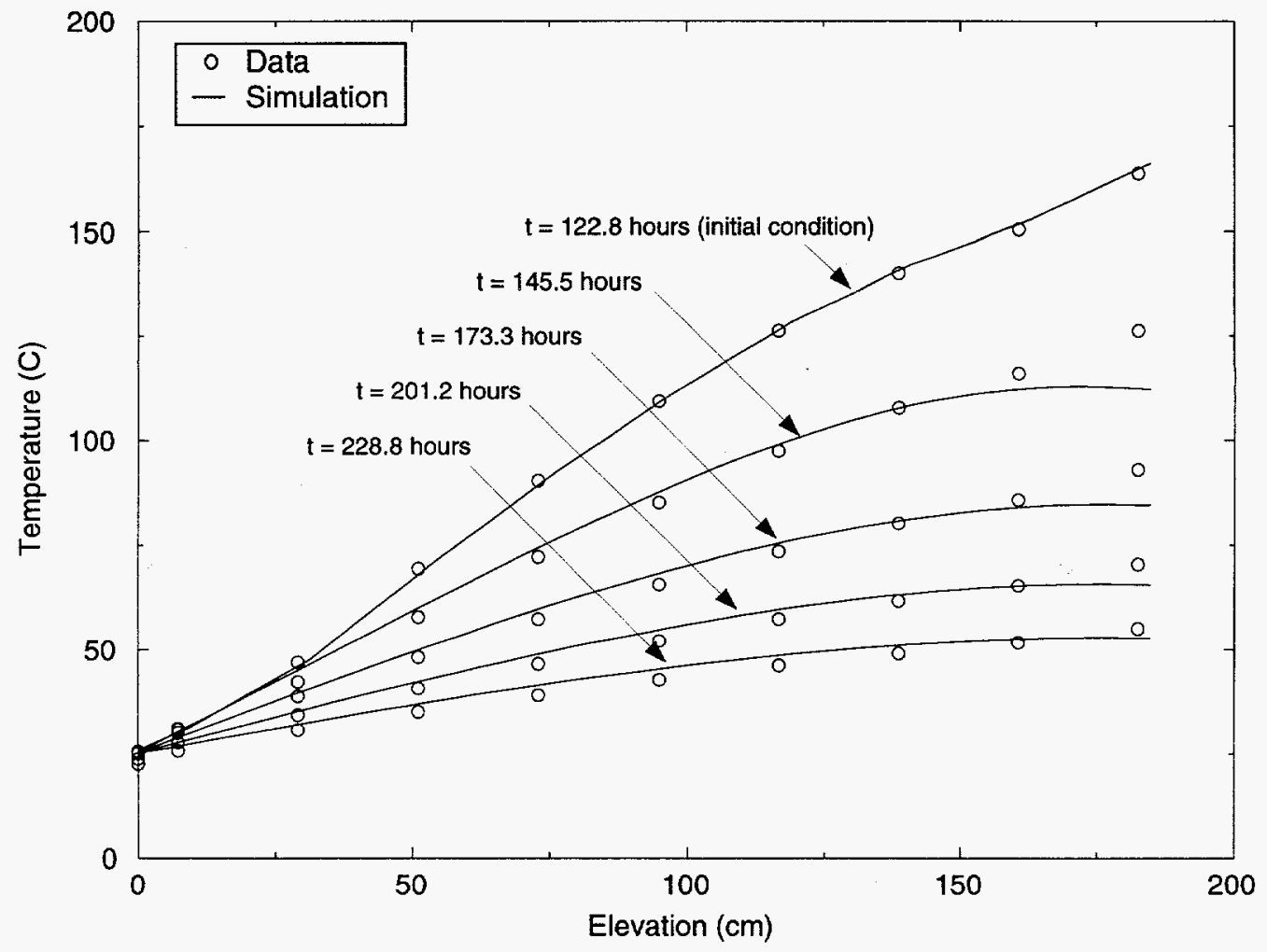

Figure 4-28. Comparison Between Experimental Data and Simulated Temperatures Along Probe 2, Test 1

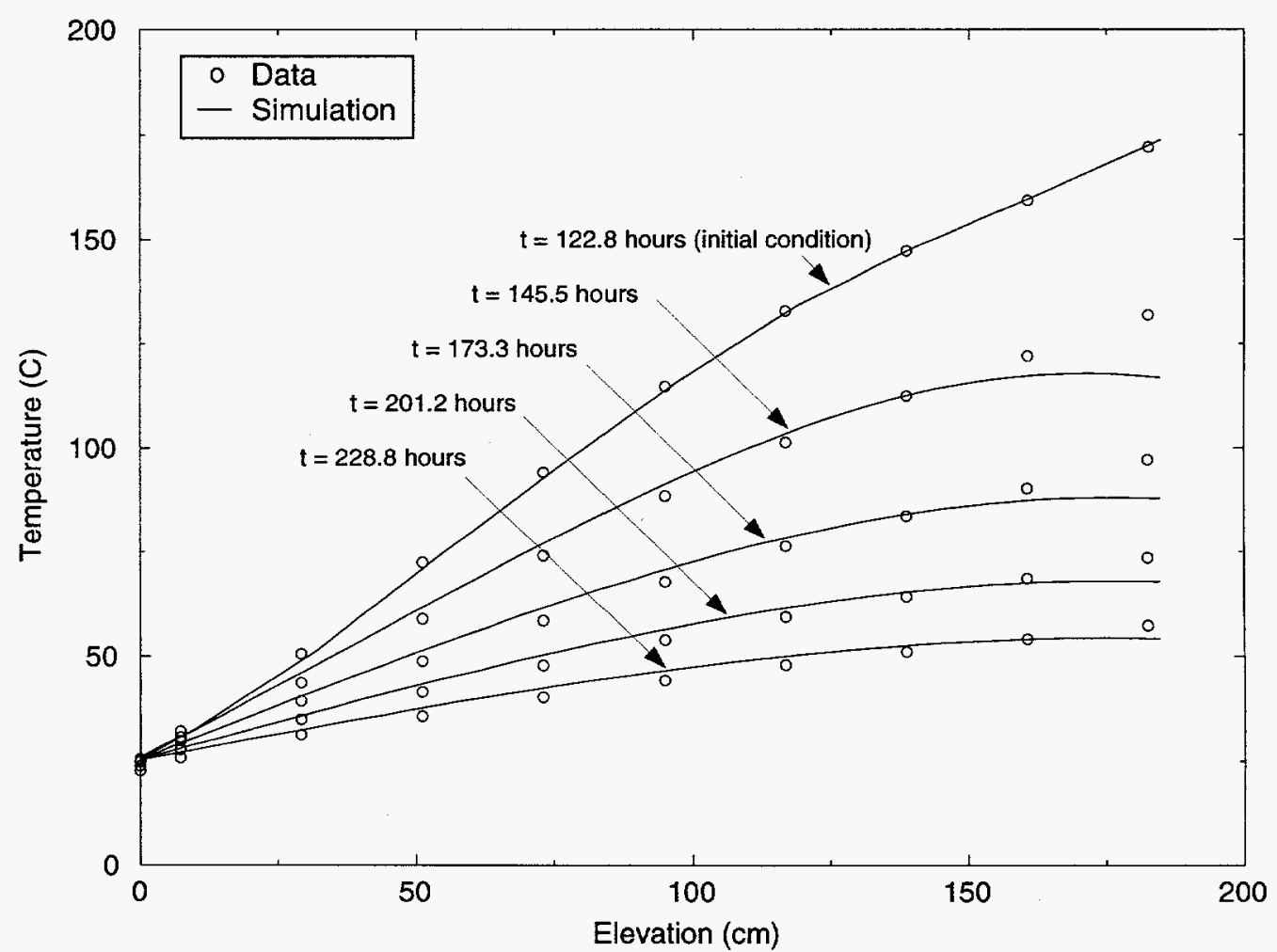

Figure 4-29. Comparison Between Experimental Data and Simulated Temperatures Along Probe 3, Test 1 


\subsection{SUMMARY OF POST-TEST ANALYSES RESULTS}

Three post-test analysis methods were used to estimate the thermal diffusivity of the crushed tuff test bed. The first method, parameter estimation, used the first six hours of data obtained from Tests 1 and 2 to estimate the thermal diffusivity of the crushed tuff. The second method extended the time frame of examination to the first 20 hours of data and used the multiphase code TOUGH2 to not only estimate the thermal diffusivity of the crushed tuff, but also to investigate thermally driven convection within the test apparatus. Finally, 111 hours of data taken during the cooling phase of the experiment were used in conjunction with a non-linear conduction code to derive an effective thermal diffusivity for the system. Table 4-5 summarizes the results of the post-test analysis efforts completed as part of the crushed tuff thermal diffusivity experiments.

Table 4-5. Summary of Estimated Thermal Diffusivities

\begin{tabular}{|l|c|c|}
\hline $\begin{array}{c}\text { Post-test Analysis } \\
\text { Approach }\end{array}$ & \multicolumn{2}{|c|}{$\begin{array}{c}\text { Thermal Diffusivity } \\
\left(\mathrm{m}^{2} / \mathrm{s}\right)\end{array}$} \\
\hline \hline & Test 1 & Test 2 \\
\hline Parameter Estimation & $6.0 \times 10^{-7}$ & $6.5 \times 10^{-7}$ \\
\hline TOUGH2 & $5.0 \times 10^{-7}$ & $5.0 \times 10^{-7}$ \\
\hline Cool-Down Analyses & $6.6 \times 10^{-7}$ & \\
\hline
\end{tabular}




\section{Comparisons to Published Relationships}

Although this experiment provides only one data point for the thermal diffusivity of a non-compacted crushed tuff, it is important to understand where this data point lies in relation to theoretical and empirical relationships presented in the literature.

Assuming the crushed tuff to be an equivalent two-phase system of rock and air, the effective thermal diffusivity of the porous system depends on such parameters as the thermal conductivities of the two phases, the volume concentrations of the two phases, and the distribution of the two phases [Woodside and Messmer, 1961]. Given the temperatures at which the crushed tuff was tested and the high permeability of the system, the effective thermal properties may also be a function of radiative heat transfer in the gas and convective effects.

Given the methods used to back out the thermal diffusivity of the material, convective effects can be ignored. Specifically, the parameter estimation technique was applied at early times when strong convective effects had not yet developed. The TOUGH2 simulations explicitly account for convection, therefore, the values of thermal diffusivity obtained are independent of convection. Similarly, the conduction analyses of the cool-down data were performed in a time domain where convective effects are not considered a significant factor. Thus, the relationships presented in the literature for the effective thermal properties of a porous medium in a stagnant fluid should be applicable for comparison to estimates of bulk thermal diffusivity presented in Chapter 4. 


\subsection{ESTIMATES OF EQUIVALENT THERMAL CONDUCTIVITIES}

As discussed in Singh and Chaudhary [1992], many expressions exist in the literature for the effective thermal conductivity of porous systems, with only limited expressions presented for thermal diffusivity. Since thermal conductivity $(\lambda)$ is defined as the product of the thermal diffusivity $(\alpha)$ and heat capacitance $\left(\rho c_{p}\right)$, approximations of the effective thermal conductivity observed in the experiments can be derived. Specifically, using a modified version of the relationship for effective heat capacitance presented in Woodside and Messmer [1961], an approximation of the effective thermal conductivity observed in the experiment can be derived as:

$$
\lambda_{\mathrm{e}}=(1-\Phi) \rho_{\mathrm{s}} \mathrm{c}_{\mathrm{p}, \mathrm{s}} \alpha_{\mathrm{e}}
$$

where $\lambda_{\mathrm{e}}$ is the calculated effective thermal conductivity, $\Phi$ is the porosity of the rock-air system (0.48), $\rho_{s}$ is the density of the intact rock, $c_{p, s}$ is the specific heat of the intact rock, and $\alpha_{\mathrm{e}}$ is the effective bulk thermal diffusivity of the two-phase system. Substituting the relationship from Equation 2.4 into Equation 5.1:

$$
\lambda_{\mathrm{e}}=(1-\Phi)\left(\rho_{\mathrm{g}}\left(1-\phi_{\mathrm{m}}\right) \mathrm{c}_{\mathrm{p}, \mathrm{g}}+\phi_{\mathrm{m}} \mathrm{s} \rho_{\mathrm{w}} \mathrm{c}_{\mathrm{p}, \mathrm{w}}\right) \alpha_{\mathrm{e}}
$$

Equation 2.3 defines the grain specific heat $\left(c_{p, g}\right)$ of the Fran Ridge tuff as a function of temperature. The published relationships that will form the basis of the following comparisons, however, are independent of temperature. To facilitate the comparison process, therefore, representative temperatures were chosen for calculating grain specific heat. Beginning with the results from the parameter estimation technique, estimated temperatures of $115^{\circ} \mathrm{C}$ for Test 1 and $138^{\circ} \mathrm{C}$ for Test 2 were chosen for the calculation of $c_{p}$. These temperature values represent averages of the temperatures recorded 5 hours following the start of the two tests at the 6 points analyzed by the parameter estimation technique. Using these estimated temperatures, values for grain specific heat of $0.907 \mathrm{~J} / \mathrm{g}-\mathrm{K}$ and $0.933 \mathrm{~J} / \mathrm{g}-\mathrm{K}$ were calculated for Tests 1 and 2 , respectively. Given that the temperatures chosen for the calculation of grain specific heat 
are above the boiling point of water, Equation 5.2 is simplified by the elimination of the heat capacitance term dependent upon saturation. Using the assumptions presented above as well as the average effective thermal diffusivities predicted by the parameter estimation technique in Chapter 4 , effective thermal conductivities of $0.67 \mathrm{~W} / \mathrm{m}-\mathrm{K}$ and $0.74 \mathrm{~W} / \mathrm{m}-\mathrm{K}$ can be calculated for the two tests.

In contrast to the above approach to estimating representative temperatures, a representative temperature consistent with the TOUGH2 simulations was calculated based on an area averaging of data from a plane $1.17 \mathrm{~m}$ ( $46 \mathrm{in}$.) from the bottom of the experimental apparatus. The averaging approach was chosen since the TOUGH2 simulations were used to match data through a 20 hour time period at 18 locations within the test bed. A single plane was chosen to avoid skewing of the temperature due to dominant convective effects observed at the ends of the cylinder. The average temperature was calculated at 20 hours following the initiation of a full power condition on the heater, with a linear relationship assumed between data points. Using this approach, an areally averaged temperature of $149^{\circ} \mathrm{C}$ was calculated for use in defining a grain specific heat of $0.945 \mathrm{~J} / \mathrm{g}-\mathrm{K}$. Using Equation 5.2, this translates into an effective conductivity of $0.58 \mathrm{~W} / \mathrm{m}-\mathrm{K}$.

For the cool-down analyses, representative temperatures were estimated using a volume-based weighting of all of the Test 1 temperature readings along Probes 1,2 , and 3. The weighted average temperatures at the beginning and end of the cool-down simulations are $100^{\circ} \mathrm{C}$ and $39^{\circ} \mathrm{C}$, respectively. These temperatures correspond to grain specific heats of $0.889 \mathrm{~J} / \mathrm{g}-\mathrm{K}$ and $0.798 \mathrm{~J} / \mathrm{g}-\mathrm{K}$. Using equation 5.2 , this corresponds to effective thermal conductivities of $0.72 \mathrm{~W} / \mathrm{m}-\mathrm{K}$ and $0.65 \mathrm{~W} / \mathrm{m}-\mathrm{K}$.

It is noted that there are uncertainties associated with each effective thermal conductivity calculated above. For the purposes of the comparisons that follow, however, only the range of effective conductivity from $0.58 \mathrm{~W} / \mathrm{m}-\mathrm{K}$ to $0.74 \mathrm{~W} / \mathrm{m}-\mathrm{K}$ will be presented for comparison to published relationships, additional error bars will not be included. 


\subsection{COMPARISONS TO GEOMETRY-INDEPENDENT RELATIONSHIPS}

The effective conductivity of two-phase solid/fluid mixtures should lie somewhere between the conductivity of the solid phase and the conductivity of the saturating fluid. One approach to developing a relationship to describe the functional dependence of the effective thermal conductivity on the component thermal conductivities is to ignore pore and particle structure and concentrate strictly on the volume fractions of the phases. Several bounding relationships have been developed using this approach and will be discussed in this section.

\subsubsection{Parallel and Series Approximations}

As discussed in Woodside and Messmer [1961], bounding approximations of effective thermal conductivity can be derived based on parallel and series distributions of the two phases (rock and air). The series approximation assumes that the solid and fluid phases are segregated in a series arrangement that is perpendicular to the direction of heat flow (Figure 5-1). This corresponds to the weighted harmonic mean of the solid and fluid conductivities:

$$
\lambda_{\mathrm{e}, \text { series }}=\frac{\lambda_{\mathrm{s}} \lambda_{\mathrm{f}}}{\left[\Phi \lambda_{\mathrm{s}}+(1-\Phi) \lambda_{\mathrm{f}}\right]}
$$

where $\lambda_{s}$ is the solid component's (intact rock) thermal conductivity and $\lambda_{f}$ is the fluid's (air) thermal conductivity. The series distribution represents a minimum approximation for thermal conductivity.

As a maximum approximation, a parallel distribution of phases with respect to the direction of heat flow (Figure 5-1) represents the weighted arithmetic mean of the conductivities of the two phases:

$$
\lambda_{\text {e, parallel }}=\Phi \lambda_{\mathrm{f}}+(1-\Phi) \lambda_{\mathrm{s}}
$$

For a given porosity, the parallel and series approximations produce values that span a wide range of thermal conductivity. As a middle-range approximation, the 


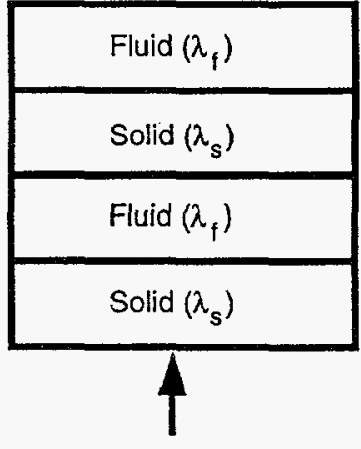

Heat Flow

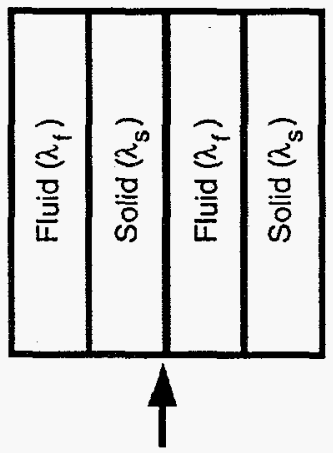

Heat Flow

Figure 5-1. Series and Parallel Models for the Effective Thermal Conductivity of a Fluid-Saturated Rock

geometric mean approach that has historically been used on the Yucca Mountain Project [Lappin, 1981], corresponds to the weighted arithmetic mean of the logarithms of the individual conductivities:

$$
\lambda_{\mathrm{e}, \text { geometric mean }}=\lambda_{\mathrm{f}}^{\Phi} \lambda_{\mathrm{s}}^{(1-\Phi)}
$$

Figure 5-2 shows the series, parallel, and geometric mean relationships as a function of porosity. A value of $1.73 \mathrm{~W} / \mathrm{m}-\mathrm{K}$ was used to represent $\lambda_{\mathrm{s}}$, corresponding to the average of the samples tested in the laboratory over the range of $30^{\circ} \mathrm{C}$ to $155^{\circ} \mathrm{C}$ (air dry and oven dry). For $\lambda_{f}$, a value of $0.033 \mathrm{~W} / \mathrm{m}-\mathrm{K}$ was used. This corresponds to the conductivity of air at 400K [White, 1984]. Superimposed on Figure 5-2 is the range of effective conductivities derived from the post-test analyses. At the experimentally determined system porosity of 0.48 , effective thermal conductivities of $0.067 \mathrm{~W} / \mathrm{m}-\mathrm{K}, 0.26 \mathrm{~W} / \mathrm{m}-\mathrm{K}$, and $0.92 \mathrm{~W} / \mathrm{m}-\mathrm{K}$ are predicted for the series, geometric mean, and parallel approximations. Compared to the experimentally determined range of $0.58 \mathrm{~W} / \mathrm{m}-\mathrm{K}$ to $0.74 \mathrm{~W} / \mathrm{m}-\mathrm{K}$, these theoretical predictions do not appear to satisfactorily represent the effective conductivity of the crushed tuff test bed. Although more data is required before making any definitive conclusions, the existing experimental evidence indicates that YMP's use of the geometric mean relationship [Lappin, 1981] to calculate effective thermal conductivities should be reconsidered. 


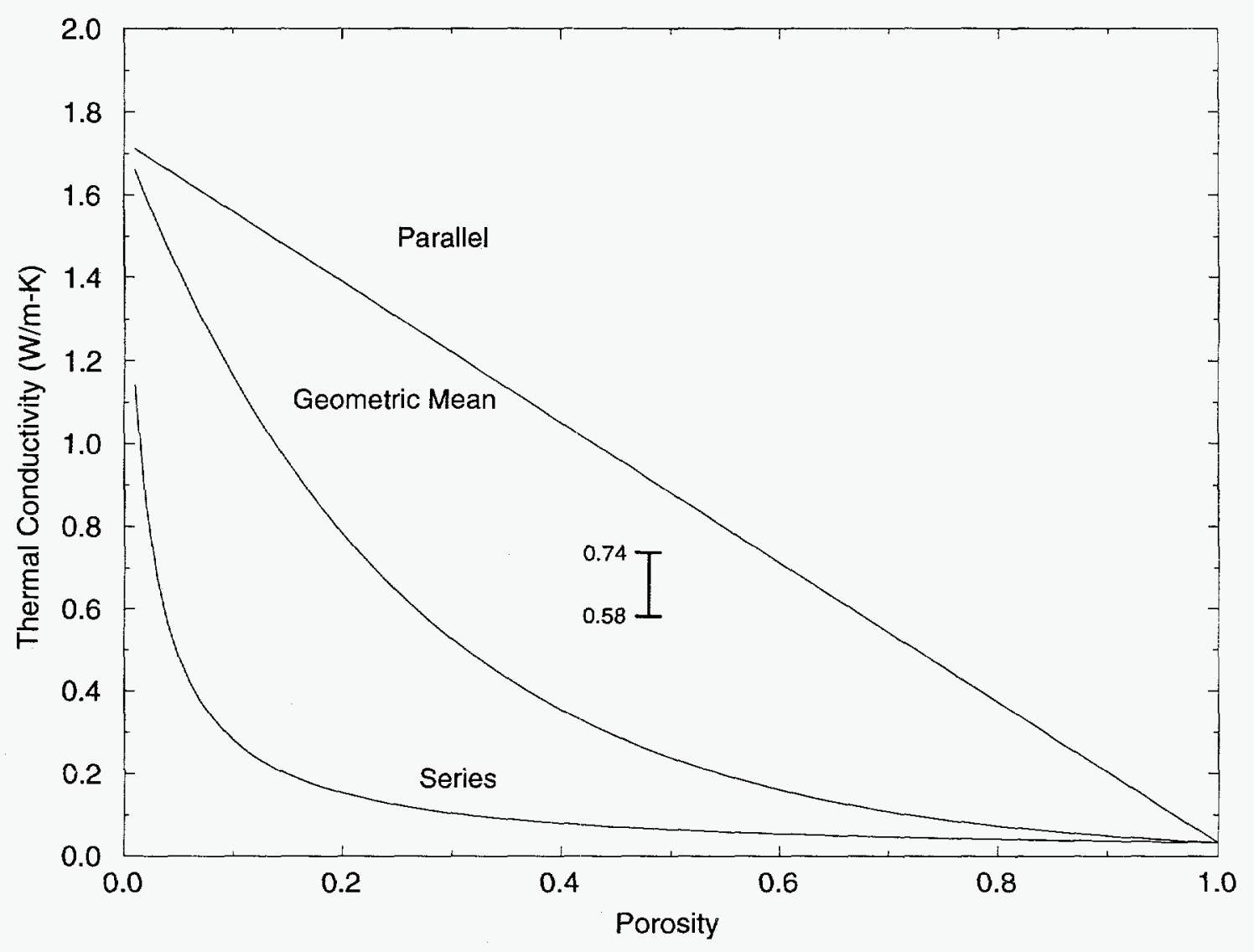

Figure 5-2. Comparison of Experimental Estimates of Thermal Conductivity to Series, Geometric Mean, and Parallel Approximations 


\subsubsection{Hashin and Shtrikman [1962] Bounds}

As discussed in Zimmerman [1989], the range of effective thermal conductivity values that are predicted between the parallel and series approximations are not the narrowest bounds that have been derived independent of pore structure. Hashin and Shtrikman [1962] developed the following relationship that is always more constraining than the parallel and series bounds discussed above:

$$
\lambda_{\mathrm{f}}+\frac{3 \lambda_{\mathrm{f}}\left(\lambda_{\mathrm{s}}-\lambda_{\mathrm{f}}\right)(1-\Phi)}{3 \lambda_{\mathrm{f}}+\left(\lambda_{\mathrm{s}}-\lambda_{\mathrm{f}}\right) \Phi} \leq \lambda_{\mathrm{e}} \leq \lambda_{\mathrm{s}}+\frac{3 \lambda_{\mathrm{s}}\left(\lambda_{\mathrm{f}}-\lambda_{\mathrm{s}}\right) \Phi}{3 \lambda_{\mathrm{s}}+\left(\lambda_{\mathrm{f}}-\lambda_{\mathrm{s}}\right)(1-\Phi)}
$$

Plotting the Hashin and Shtrikman (H-S) bounds for $\lambda_{\mathrm{f}}$ and $\lambda_{\mathrm{s}}$ values of 0.033 and 1.73 $\mathrm{W} / \mathrm{m}-\mathrm{K}$, respectively, the upper range of effective thermal conductivity predicted by the post-test analyses appear to correspond closely with the H-S upper bound (Figure 5-3). The $0.16 \mathrm{~W} / \mathrm{m}-\mathrm{K}$ range in the post-test predictions, however, means that use of the H-S upper bound for future predictions of crushed tuff thermal properties may not be sufficiently conservative. Additional data spanning a range of porosities and particle sizes will be needed prior to the recommendation of any theoretical or empirical relationship.

\subsection{COMPARISONS TO GEOMETRY DEPENDENT RELATIONSHIPS}

The H-S bounds are the best geometry-independent bounds for effective thermal conductivity [Zimmerman, 1989]. As indicated in Figure 5-3, however, the range of effective thermal conductivities bounded by the H-S relationships for the air-saturated system under investigation is too large to be useful for design or performance assessment calculations. There is clearly a need, therefore, to examine the published relationships for effective thermal conductivity that account for either pore structure or grain structure. 


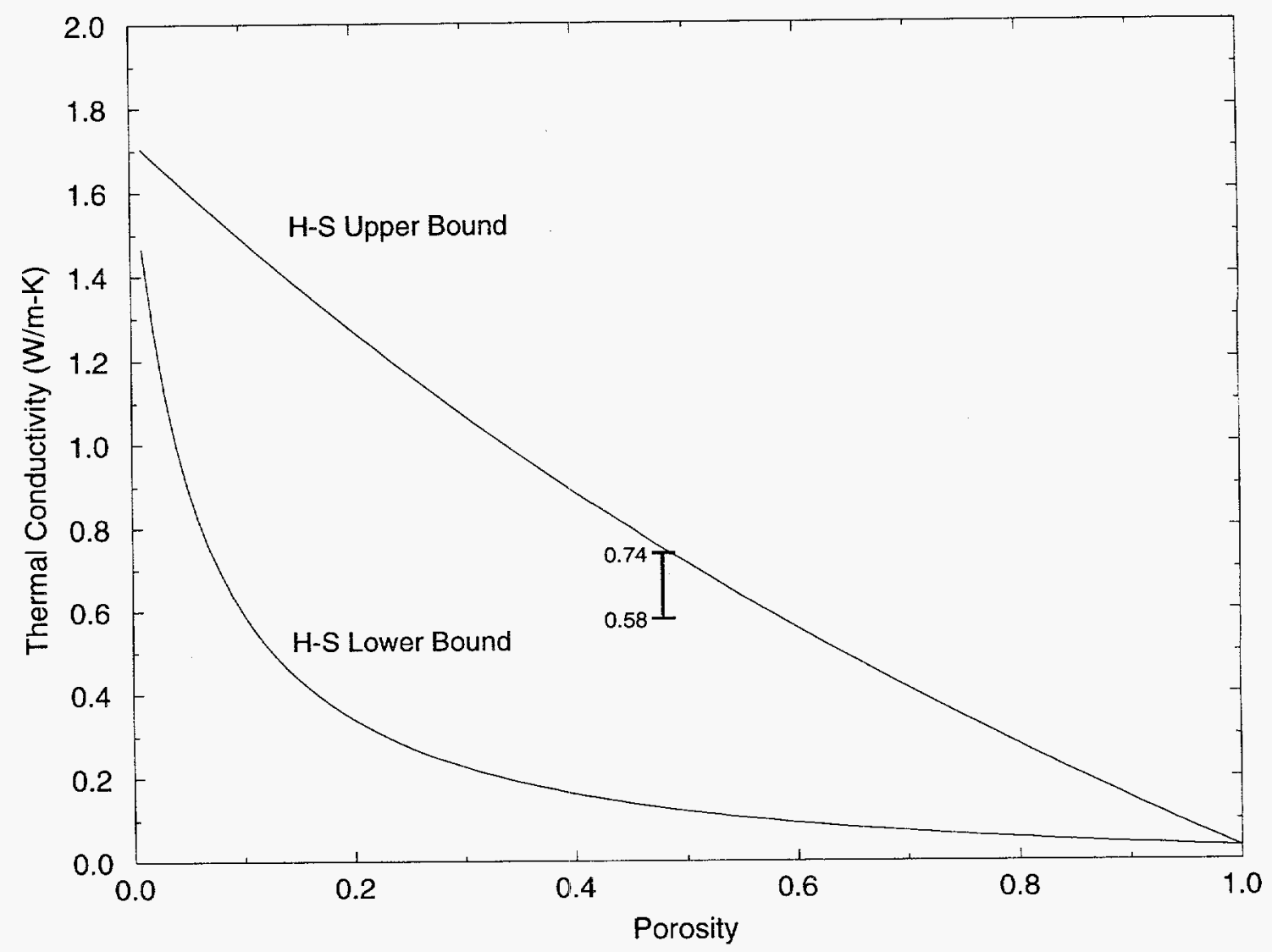

Figure 5-3. Comparison of Experimental Estimates of Thermal Conductivity to H-S Upper and Lower Bounds 


\subsubsection{Pore-Shape Models}

A spheroidal pore model is presented in Zimmerman [1989]. The spheroidal pore model idealizes the two phase system as being composed of a solid permeated with nonintersecting pores of spheroidal shape. Using an effective medium theory developed by Maxwell [as presented in Zimmerman, 1989], this spheroid pore model is extended to account for interactions of neighboring pores. The resulting relationship for effective thermal conductivity is:

$$
\lambda_{\mathrm{e}}=\lambda_{\mathrm{s}} \frac{(1-\Phi)(1-\mathrm{r})+\mathrm{r} \beta \Phi}{(1-\Phi)(1-\mathrm{r})+\beta \Phi}
$$

where

$$
\begin{gathered}
r=\frac{\lambda_{f}}{\lambda_{s}} \\
\beta=\frac{1-r}{3}\left[\frac{4}{2+(r-1) M}+\frac{1}{1+(r-1)(1-M)}\right]
\end{gathered}
$$

For oblate pores $(\gamma<1)$, where $\gamma$ is the ratio of the length of the unequal pore axis to one of the equal axes:

$$
M=\frac{(2 \theta-\sin 2 \theta)}{2 \tan \theta \sin ^{2} \theta}
$$

where $\theta=\arccos (\gamma)$. For prolate pores $(\gamma>1)$ :

$$
M=\frac{1}{\sin ^{2} \theta}-\frac{\cos ^{2} \theta}{2 \sin ^{3} \theta} \ln \left[\frac{1+\sin \theta}{1-\sin \theta}\right]
$$

where $\theta=\arccos \left(\frac{1}{\gamma}\right)$. 
Figure 5-4 shows the range of values predicted for values of $\gamma$ applicable to oblate pore shapes. It is noted that the limiting cases of $\gamma=0$ and $\gamma=1$ correspond to the H-S bounds discussed previously. Superimposing the range of effective thermal conductivity values derived from the experiment, it appears that a $\gamma$ between 0.2 and 0.3 best represents the midrange of values predicted for the crushed tuff. By understanding that as $\gamma$ approaches 0 , the pore structure becomes penny-shaped, and as $\gamma$ approaches 1 , the pore structure becomes spherical, the estimated range for a of 0.2 to 0.3 indicates that the pore structure of the test bed would be more flattened than spherical, with the two equal axes being the longest. This is not considered unreasonable given physical observations of the crushed tuff particles; however, additional data would be required to test this assertion at other porosities and for other particle sizes.

If the pores are assumed to be prolate, Figure 5-5 shows that large values of $\gamma$ provide only marginal correspondence with the upper range of the experimental values. High $\gamma$ values represent needle-like pores, unrealistic for the system investigated.

\subsubsection{Particle-Shape Models}

In addition to models developed based on pore shape, effective thermal conductivity relationships have been derived that attempt to explicitly account for particle shape. One example is that developed by de Vries [as presented in Woodside and Messmer, 1961] for ellipsoid particles dispersed in a continuous fluid phase:

$$
\lambda_{\mathrm{e}}=\frac{\Phi \lambda_{f}+(1-\Phi) F \lambda_{s}}{\Phi+(1-\Phi) F}
$$

where $F$ represents the ratio of the average temperature gradients in the continuous and dispersed phases and is given by:

$$
F=\frac{1}{3} \sum_{i=1}^{3}\left[1+\left(\frac{\lambda_{s}}{\lambda_{f}}-1\right) g_{i}\right]^{-1}
$$




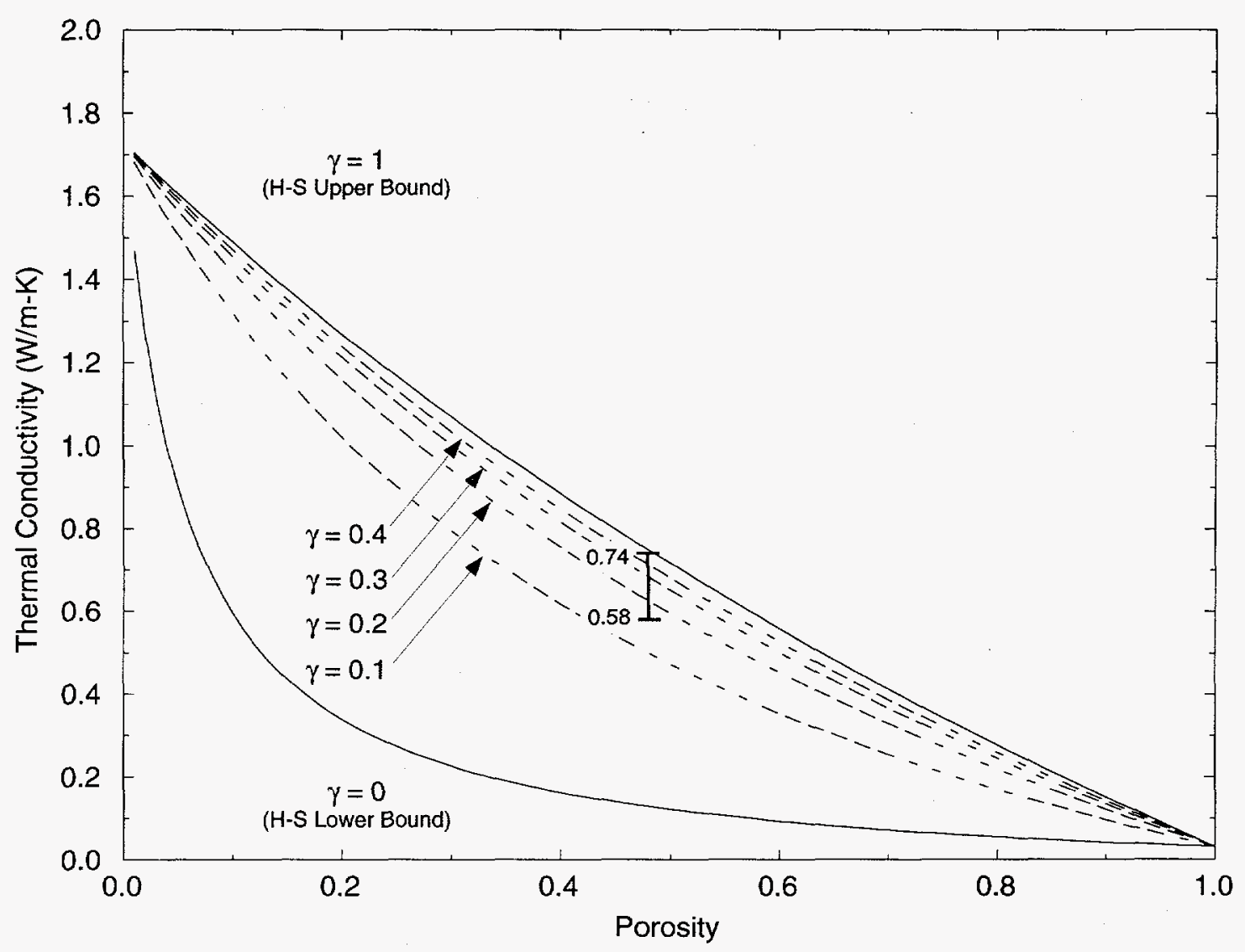

Figure 5-4. Comparison of Experimental Estimates of Thermal Conductivity to Spheroidal Pore Model Estimates Assuming Oblate Pore Shapes 


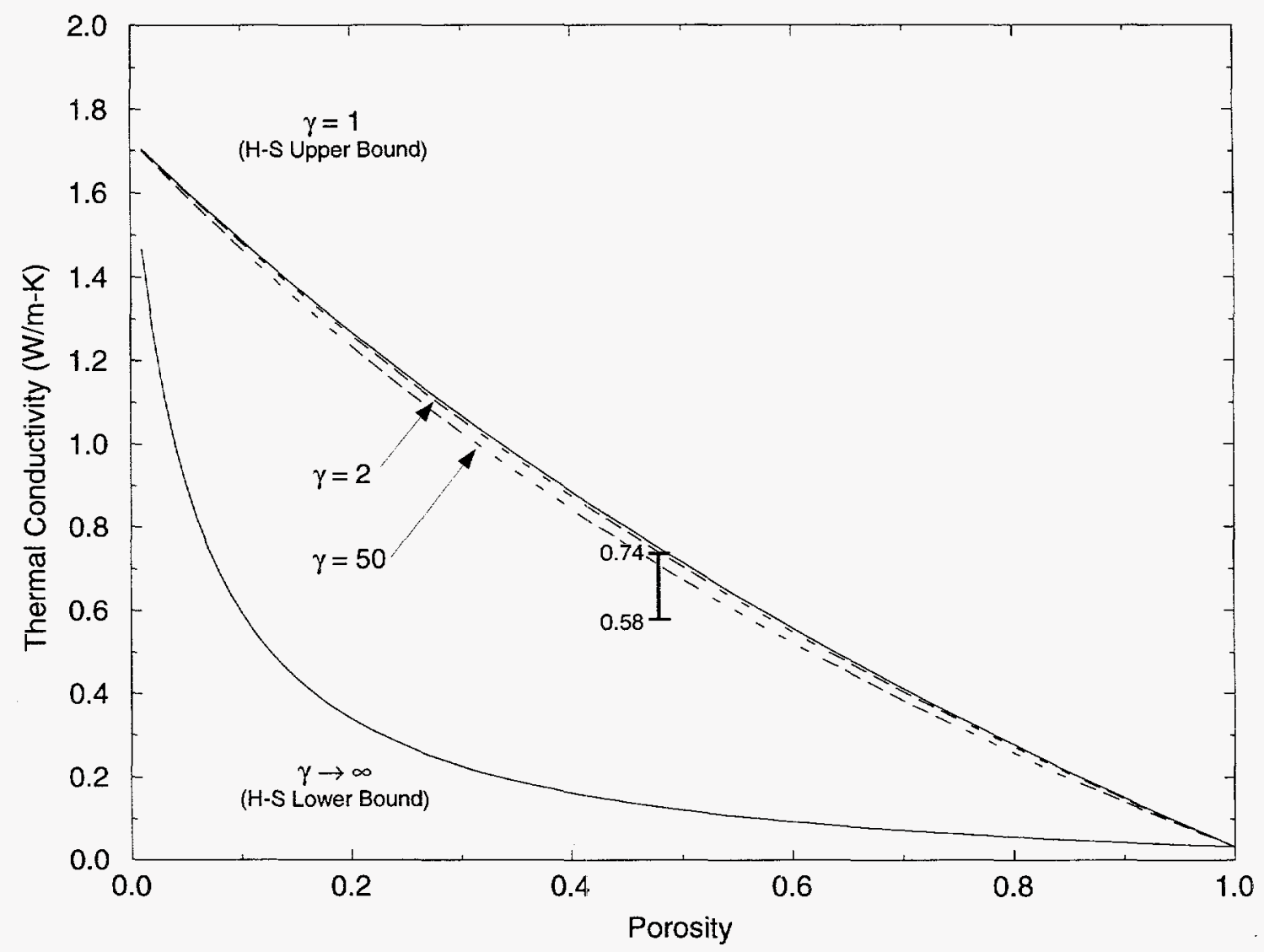

Figure 5-5. Comparison of Experimental Estimates of Thermal Conductivity to Spheroidal Pore Model Estimates Assuming Prolate Pore Shapes 
and the particle shape factors, $\mathrm{g}$, must satisfy:

$$
\sum_{i=1}^{3} g_{i}=1
$$

As discussed in Section 2.7.2, measurements of the long, intermediate, and short axes of a random selection of crushed tuff particles were made. Using average values of these dimensions, representative shape factors of $g_{1}=1 / 6, g_{2}=1 / 3$, and $g_{3}=1 / 2$ can be derived.

As shown in Figure 5-6, these g values produce an effective conductivity at a porosity of 0.48 of $0.15 \mathrm{~W} / \mathrm{m}-\mathrm{K}$, well below the experimental values. Exploring the impact of changes in g values, Figure 5-6 shows that in order to exceed the lower range of the post-test effective conductivity predictions, an equivalent ellipsoid with particle shape factors of $g_{1}=g_{2}=1 / 128$ and $g_{3}=63 / 64$ would be required. This particle description results in a thermal conductivity of $0.62 \mathrm{~W} / \mathrm{m}-\mathrm{K}$, but corresponds to physically unrealistic needlelike particles. For completeness, if the equal radii $\left(g_{1}\right.$ and $\left.g_{2}\right)$ of an ellipsoid particles are assumed to be the long axes, an infinitesimally small $g_{3}$ would be required to even approach the lowest range of the post-test values (Figure 5-6). Again, such an ellipsoid description is physically unrealistic.

The particle-shape relationship discussed above was presented in the literature as having matched experimental data very closely [Woodside and Messmer, 1961]. The correspondence to data from this experiment, however, is not particularly good. The data cited in Woodside and Messmer [1961] that was used to test the equation is limited to small-particle, unconsolidated soils. It is hypothesized that the size of the crushed tuff particles examined may be responsible for the poor correspondence between the experimental data and the de Vries relationship. The next step therefore should include an investigation of the effect particle size has on the determination of effective thermal conductivity. 


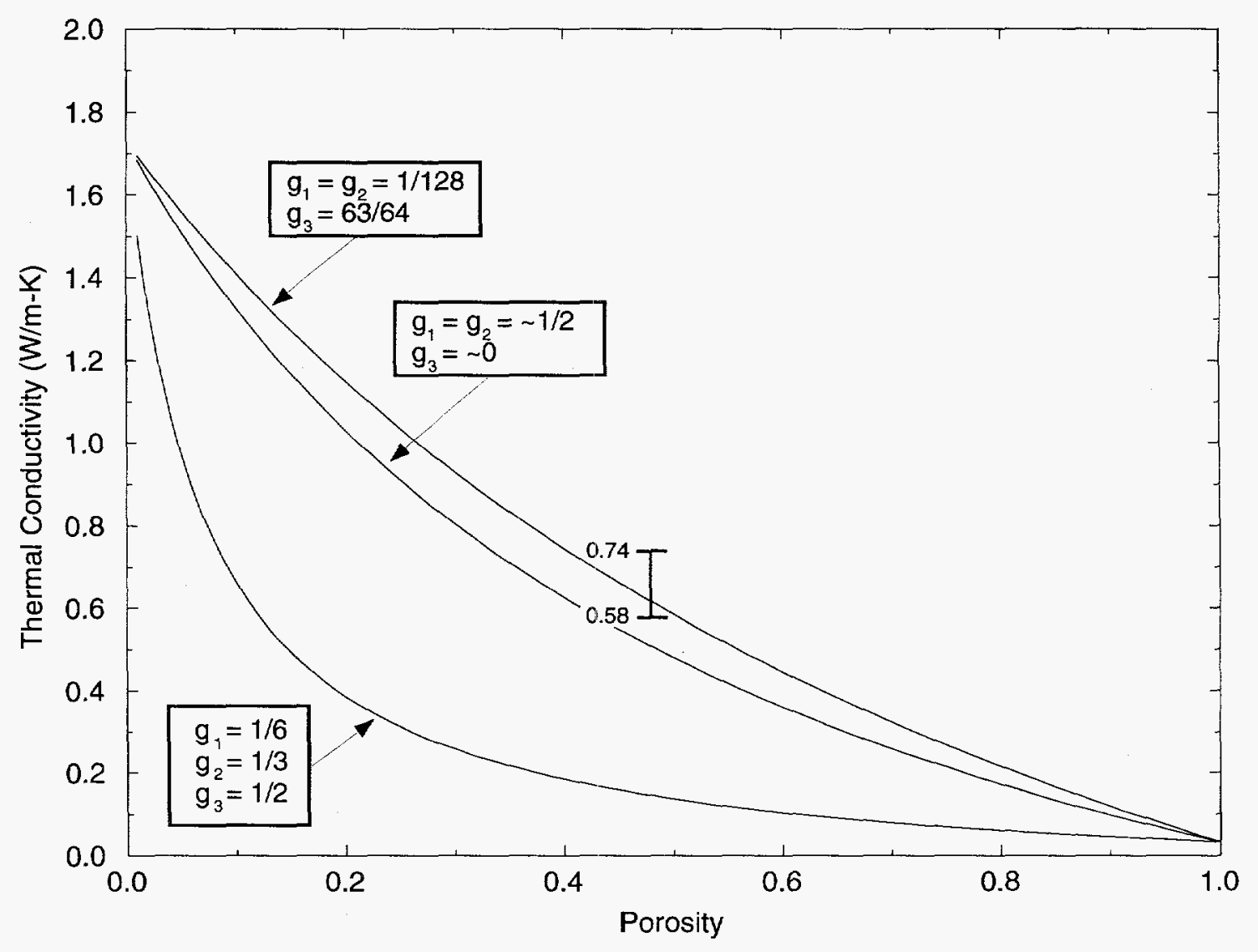

Figure 5-6. Comparison of Experimental Estimates of Thermal Conductivity to DeVries Particle Shape Model 


\subsection{EFFECT OF PARTICLE SIZE}

If the arrangement of the solid particles in a porous system is kept constant, changes in the size of the particles may affect the effective conductivity. As discussed in Ghaffari [1980], the total surface area of the particles exposed to the pores and the total surface area of particle-to-particle contacts is inversely proportional to the characteristic dimensions of the particles. Given a fixed porosity and packing arrangement, therefore, smaller particle systems would have more total surface area and greater particle-to-particle contacts per unit volume. Since contact thermal resistances between particles are likely, it follows that systems with smaller particles would have larger resistances to heat flow, compared to larger grain systems, and would therefore have lower effective thermal conductivities.

This conclusion is consistent with the comparisons provided in the previous sections. The experimentally derived range of values for effective thermal conductivity has been shown to be at the high end of the bounding theories (parallel and H-S maximum). Woodside and Messmer [1961] indicate that the geometric mean (equation 5.5) typically overestimates the effective thermal conductivity of a porous system when $\lambda_{\mathrm{s}} / \lambda_{\mathrm{f}}$ exceeds 20 . The opposite was found to be the case with this experiment $\left(\lambda_{\mathrm{s}} / \lambda_{\mathrm{f}}=\right.$ 52). It is believed that the proximity of the experimental values for crushed tuff to the upper theoretically derived bounds and the underestimation of the geometric mean are partially a result of the large particles used in the experiment.

\subsection{LARGE-PARTICLE RELATIONSHIP}

The majority of the work done in the field of porous-system effective thermal conductivity has focused on small particle systems such as unconsolidated sands, sintered materials, and porous foams. Large particle systems, like crushed tuff, have received little attention. For this particular experiment, if the crushed tuff is visualized as intact rock 
with a high lithopysal content, a potentially applicable model for effective thermal conductivity can be taken from Nimick [1990] as:

$$
\lambda_{e}=\frac{1}{4}\left\{[3(1-\Phi)-1] \lambda_{s}+(3 \Phi-1) \lambda_{f} \pm\left[\left\{[3(1-\Phi)-1] \lambda_{s}+(3 \Phi-1) \lambda_{f}\right\}^{2}+8 \lambda_{s} \lambda_{f}\right]^{\frac{1}{2}}\right\}
$$

Using the experimental porosity of 0.48 , a thermal conductivity for air of 0.033 $\mathrm{W} / \mathrm{m}-\mathrm{K}$, and the laboratory measured matrix thermal conductivity of $1.73 \mathrm{~W} / \mathrm{m}-\mathrm{K}, 0.54$ $\mathrm{W} / \mathrm{m}-\mathrm{K}$ is calculated as the effective thermal conductivity for the crushed tuff system. This is slightly below the low end of values determined from post-test analyses. The result, however, seems promising and Equation 5.15 should be assessed further as a means of estimating the thermal conductivity of large particle systems.

\subsection{SUMMARY OF COMPARISONS}

The effective thermal conductivities derived from post-test analyses were compared to values calculated using published relationships for two-phase systems in a stagnant fluid. Upper-bound predictions made independent of geometry (pore or particle) appear to provide acceptable predictions when compared to the experimental values. However, this correspondence may be highly influenced by the large sizes of the particles examined and the lack of fines in the system. In addition to any potential biasing the uniformly graded nature of the test bed might have, the non-conservative nature (i.e., the higher values) of the effective thermal conductivities predicted by upper-bound, geometryindependent relationships dictates that caution should be exercised prior to the use of such relationships in any future design or performance assessment calculations.

Geometry-dependent relationships (particularly pore-shape models) appear promising. However, the additional descriptive data required to define the pore geometry may be impractical to obtain. It is recommended that additional data be obtained for different porosities and particle sizes (both graded and mixed). Once a sufficient data base is established, firm recommendations regarding applicable theoretical relationships can be made. 


\section{Discussion}

The characterization of crushed tuff is necessary to support information needs identified in 10 CFR 60 [NRC, 1993]. The references in 10 CFR 60 that potentially apply to crushed tuff are predominately related to the backfilling of underground openings, either as part of the repository sealing program or as part of the permanent closure of the facility. A crushed tuff backfill would provide structural control of near-field rock movements, as well as provide a deterrence to human entry. Furthermore, backfilling using graded layers of crushed tuff has been proposed as a means of providing a diversionary path for aqueous moisture intrusions through the establishment of a capillary barrier around the waste packages. Beyond the possibility of using crushed tuff as a backfill material, crushed tuff has also been identified as an invert filler material to provide a level operating surface in the emplacement drifts. Defensible assessments of the impacts of using crushed tuff as a backfill or as an invert filler material will require data.

In response to this data need, a large-scale experiment investigating the thermal diffusivity of crushed tuff was successfully designed, conducted, and analyzed. The experiment focused on the determination of the thermal diffusivity of a loose-packed, crushed, Fran Ridge (TSw2) tuff composed of 0.5 to $1.5 \mathrm{in}$. particles. The design of the experiment successfully resulted in axisymmetric conditions. The apparent high permeability of the system, however, produced two-dimensional temperature profiles due to convective effects. Two iterations of the experiment were completed over a 32 day period; during which time, the instrumentation operated with zero failures. 
During the decommissioning of the experiment, residues of calcium chromate were found on crushed-tuff particles in the vicinity of the heater. This points to a participation of the Inconel heater in the chemistry of the experiment, and should be taken as a caution for future experiments. Also, noticeable quantities of new rust were observed on the interior of the carbon steel test apparatus. The corrosion rates and processes should be investigated in future studies to determine whether the presence of the crushed tuff may have any adverse impact should it be placed in contact with heat-generating waste containers.

Post-test analyses of the data resulting from the experiment provided estimates of thermal diffusivity ranging from $5.0 \times 10^{-7} \mathrm{~m}^{2} / \mathrm{s}$ to $6.6 \times 10^{-7} \mathrm{~m}^{2} / \mathrm{s}$. These values represent the range of best estimates for the specific material, particle size, and packing density tested. Comparisons of this range of values to published relationships provided no obvious match to either a theoretical or an empirical relationship. Additional data will be required before a relationship can be identified or developed to estimate the thermal properties of other crushed tuff systems (i.e., other combinations of particle size and packing densities). The reader is strongly cautioned, therefore, that the use of these values to represent other particle sizes and packing densities may not appropriate.

In order to place the results in perspective, the crushed-tuff backfill modeled in TSPA-93 [Wilson et al., 1994] was assumed to have a thermal diffusivity of $2.3 \times 10^{-7} \mathrm{~m}^{2} / \mathrm{s}$. If the backfill modeled in TSPA-93 were assumed to be composed of the material examined in this study, this value would be considered low. Since the order of magnitude for the thermal diffusivity is the same, however, the resulting spike in waste package surface temperature predicted in the TSPA- 93 calculations are considered reasonable. Only minor modifications in the maximum temperature reached following backfill would be expected if the experimental values presented in this report were used. The effect of backfill on waste package centerline temperatures, therefore, remains a concern. 
The experiment documented in this report represents a first step in developing characterization information for crushed tuff. Additional tests need to be conducted to examine the effects of particle size distributions and packing densities on thermal properties. Concurrent with this, characterization of crushed tuff from a hydrologic perspective needs to be completed so that defensible arguments can be made regarding the potential benefits or detriments crushed tuff may have on the performance of the repository system. 
This page has been intentionally left blank. 


\section{REFERENCES}

American Society for Testing and Materials (ASTM), 1989. Standard Test Method for Total Moisture Content of Aggregate by Drying, C566-89, Philadelphia,

December.

Baumeister, T. and L.S. Marks, eds. 1967. Standard Handbook for Mechanical

Engineers, McGraw-Hill Book Company, New York, NY, pp. 6-41 and 6-80.

Beck, J.V. and K.J. Arnold, 1977. Parameter Estimation in Engineering and Science, John Wiley \& Sons, New York, NY.

Connolly, J.R., 1991a. Mineralogy, Petrology and Whole-Rock Chemistry Data

Compilation for Selected Samples of Yucca Mountain Tuffs, SAND91-7031, Sandia National Laboratories, Albuquerque, NM, December.

Connolly, J.R., 1991b. Mineralogy, Petrology and Whole-Rock Chemistry of Selected Mechanical Test Samples of Yucca Mountain Tuffs, SAND90-7058, Sandia National Laboratories, Albuquerque, NM, December.

Dennis, A.W., ed., 1991. Exploratory Studies Facility Alternatives Study: Final Report, SAND91-0025, Vol. 1, Sandia National Laboratories, Albuquerque, NM, September.

Department of Energy (DOE), 1988. Site Characterization Plan, Yucca Mountain Site, Nevada Research and Development Area, Nevada, DOE/RW-0199, U.S.

Department of Energy, Washington, D.C., December.

Department of Energy (DOE), 1993. Waste Package Design Status Report Fisca Year 1993, B00000000-01717-570500007-00, prepared by TRW for the DOE Yucca Mountain Site Characterization Project Office, Las Vegas, NV, September.

Department of Energy (DOE), 1994. Controlled Design Assumption Document, B00000000-01717-4600-00032, prepared by TRW for the DOE Yucca Mountain Site Characterization Project Office, Las Vegas, NV, June.

Fernandez, J.A., P.C. Kelsall, J.B. Case, and D. Meyer, 1987. Technical Basis for Performance Goals, Design Requirements, and Material Recommendations for the NNWSI Repository Sealing Program, SAND84-1895, Sandia National Laboratories, Albuquerque, NM, September. 
Finsterle, S., 1993. ITOUGH2 User's Guide Version 2.2, LBL-34581, Lawrence Berkeley Laboratory, Berkeley, CA.

Freeze, R.A. and J.A. Cherry, 1979. Groundwater, Prentice-Hall, Inc., Englewood Cliffs, NJ, p. 29.

Gartling, D.K., 1991. MERLIN-II: A Computer Program to Transfer Solution Data Between Finite Element Meshes, SAND89-2989, Sandia National Laboratories, Albuquerque, NM, January.

Gartling, D.K and R.E. Hogan, 1994. COYOTE-II: A Finite Element Computer Program for Nonlinear Heat Conduction Problems Part 1, Theoretical Background, SAND94-1173, Sandia National Laboratories, Albuquerque, NM, October.

Gertsch, R. and L. Ozdemir, 1992. Performance Prediction of Mechanical Excavators from Linear Cutter Tests on Yucca Mountain Welded Tuffs, SAND91-7038, Sandia National Laboratories, Albuquerque, NM, September.

Ghaffari, A., 1980. A Model for Predicting Thermal Conductivity of Rock-Fluid Systems, LBL-11384, PhD Dissertation, University of California, Berkeley, Lawrence Berkeley Laboratory, Berkeley, CA, August.

Hanson, R.J. and F.T. Krogh, 1986. A New Algorithm for Constrained Nonlinear Least Squares Problems, SAND83-0936, Sandia National Laboratories, Albuquerque, NM, July.

Hashin, Z. and H. Shtrikman, 1962. A Variational Approach to the Theory of the Effective Magnetic Permeability of Multiphase Materials, Journal of Applied Physics, Volume 33, Number 10, pp. 3125-3131.

Hertel, E.S., Jr. and E.E. Ryder, 1991. Areal Power Density: A Preliminary Examination of Underground Heat Transfer in a Potential Yucca Mountain Repository and Recommendations for Thermal Design Approaches, SAND891989, Sandia National Laboratories, Albuquerque, NM, November.

Hills, R.G., 1987. ESTIM: A Parameter Estimation Computer Program, SAND87-7063, Sandia National Laboratories, Albuquerque, NM, August.

Incropera, F.P. and D.P. DeWitt, 1985. Introduction to Heat Transfer, John Wiley \& Sons, New York, pp. 388 and 681.

Kaviany, M., 1991. Principles of Heat Transfer in Porous Media, Springer-Verlag, New York, NY, pp. 115-151. 
Lappin, A.R., 1981. Thermal Conductivity of Silicic Tuffs: Predictive Formalism and Comparison with Preliminary Experimental Results, SAND80-0769, Sandia National Laboratories, Albuquerque, NM, April.

MacDougall, H.R., L.W. Scully, and J.R. Tillerson, eds., 1987. Site Characterization Plan Conceptual Design Report, SAND84-2641, Sandia National Laboratories, Albuquerque, NM, September.

Nimick, F.B., 1990. The Thermal Conductivity of the Topopah Spring Member at Yucca Mountain, Nevada, SAND86-0090, Sandia National Laboratories, Albuquerque, NM, April.

Nimick, F.B. and J.R. Connolly, 1991. Calculation of Heat Capacities for Tuffaceous Units from the Unsaturated Zone at Yucca Mountain, Nevada, SAND88-3050, Sandia National Laboratories, Albuquerque, NM, May.

Nuclear Regulatory Commission (NRC), 1992. High-Level Radioactive Waste Repository Functional Analysis, CNWRA 91-001, prepared by Center for Nuclear Waste Regulatory Analyses for the Nuclear Regulatory Commission, March.

Nuclear Regulatory Commission (NRC), 1993. Disposal of High-Level Radioactive Wastes in Geologic Repositories, Code of Federal Regulations, Title 10, Part 60, January.

Pruess, K. 1991. TOUGH2--A General-Purpose Numerical Simulator for Multiphase Fluid and Heat Flow, LBL-29400, Lawrence Berkeley Laboratory, Berkeley, CA.

Singh, A.K. and D.R. Chaudhary, 1992. Experimental Investigation on the Thermophysical Properties of Moist Porous Materials, Heat Recovery Systems \& CHP (Combined Heat and Power), Volume 12, Number 2, pp. 113-121.

Sneed, E.D. and R.L. Folk, 1958. Pebbles in the Lower Colorado River, Texas, A Study in Particle Morphogenesis, Journal of Geology, Volume 66, Number 2, pp. 114150.

Stout, K. and L. Friel, 1982. Stopewall Closure and High-Modulus Backfill, Transactions of the American Institute of Mining, Metallurgical, and Petroleum Engineers, Society of Mining Engineers of the American Institute of Mining Engineers, Littleton, CO, Volume 272, pp. 1836-1842.

Technical Data Information Form (TDIF) No. 303828, Data Tracking Number (DTN) SNL10012694001.002, 1994a. Yucca Mountain Project Central Records Facility, Sandia National Laboratories, Albuquerque, NM, December. 
Technical Data Information Form (TDIF) No. 303831, Data Tracking Number (DTN) SNL10012694001.003, 1994b. Yucca Mountain Project Central Records Facility, Sandia National Laboratories, Albuquerque, NM, December.

Technical Data Information Form (TDIF) No. 303830, Data Tracking Number (DTN) SNL10012694001.004, 1994c. Yucca Mountain Project Central Records Facility, Sandia National Laboratories, Albuquerque, NM, December

Technical Data Information Form (TDIF) No. 303370, Data Tracking Number (DTN) SNL01A05059301.002, 1994d. Yucca Mountain Project Central Records Facility, Sandia National Laboratories, Albuquerque, NM, July.

Technical Data Information Form (TDIF) No. 303824, Data Tracking Number (DTN) SNL04050593001.001, 1995. Yucca Mountain Project Central Records Facility, Sandia National Laboratories, Albuquerque, NM, March.

White, F.M., 1984. Heat Transfer, Addison-Wesley Publishing Company, Menlo Park, CA, pp. 552.

Wilson, M.L. et al., 1994. Total-System Performance Assessment for Yucca Mountain-SNL Second Iteration (TSPA-1993), SAND93-2675, Sandia National Laboratories, Albuquerque, NM, April.

Woodside, W. and J.H. Messmer, 1961. Thermal Conductivity of Porous Media I. Unconsolidated Sands, Journal of Applied Physics, Volume 32, Number 9, pp. 1688-1699, September.

Zimmerman, R.W., 1989. Thermal Conductivity of Fluid-Saturated Rocks, Journal of Petroleum Science and Engineering, Volume 3, Number 3, pp. 219-227. 


\section{APPENDIX A}

\section{Test 1 Data}

Included in this appendix are data obtained during Test 1 . Test 1 was initiated on March 15, 1994 and terminated April 5, 1994. The total duration of Test 1 was 501 hours and 51 minutes. It is noted that a gap in temperature data exists between 5 hours 19 minutes and 13 hours 35 minutes. This gap was caused by a minor programming error in the data acquisition system. Prior to a presentation of the complete power and temperature data for Test 1 , data which directly support modeling assumptions are presented

\section{A.1 AXISYMMETRIC CONDITIONS}

One of the fundamental assumptions in all of the post-test analyses presented in Chapter 4 is that axisymmetric thermal response existed within the test apparatus. As indicated in Chapter 3, Probes 4 and 5 were installed to confirm the validity of this assumption. Probes 4 and 5 were installed at the same radial distance from the heater, $120^{\circ}$ apart. Figure A-1 presents comparisons of the Probe 4 and Probe 5 responses for the ten measurement planes defined in Figure 3-5. Table A-1 documents the maxinum and average differences in temperature readings between Probes 4 and 5. Based on the data from Probes 4 and 5, it appears that axisymmetric conditions did exist within the test apparatus during Test 1 .

\section{A.2 LOWER BOUNDARY CONDITION}

The TOUGH 2 simulations presented in Chapter 4 assume that the lower boundary of the test apparatus is adequately represented by a constant temperature of $17^{\circ} \mathrm{C}$. Figure A-2 is a plot of the first 20 hours of data obtained from plane $1(2.90 \mathrm{~cm}$ into the 
refractory brick base) for all of the axial thermocouple probes. Linear regression of the data results in a lower boundary temperature of $16.3 \pm 4.0^{\circ} \mathrm{C}$. This is consistent with the assumed TOUGH2 boundary condition.

For the cool-down analyses presented in Chapter 3, the lower boundary condition of the test apparatus was assigned a constant temperature of $25^{\circ} \mathrm{C}$. Figure A-3 is a plot of data obtained at plane 1 for all of the axial thermocouple probes over the time period modeled in the cool-down analyses (122.8 to 233.8 hours). Linear regression of the data results in a lower boundary temperature of $24.8 \pm 1.2^{\circ} \mathrm{C}$. This is consistent with the lower boundary condition assumed in the cool-down analyses.

Table A-1. Maximum and Average Temperature Differences Between Probes 4 and 5 for Test 1

\begin{tabular}{|c|c|c|c|c|}
\hline \multirow[b]{2}{*}{ Plane } & \multicolumn{2}{|c|}{$\begin{array}{l}\text { Thermocouple Location } \\
\text { (Probe } 4 \text { and Probe 5) }\end{array}$} & \multirow[b]{2}{*}{$\begin{array}{c}\text { Maximum } \\
\text { Temperature } \\
\text { Difference }\left({ }^{\circ} \mathrm{C}\right)\end{array}$} & \multirow[b]{2}{*}{$\begin{array}{c}\text { Average } \\
\text { Temperature } \\
\text { Difference }\left({ }^{\circ} \mathrm{C}\right) \\
\end{array}$} \\
\hline & $\begin{array}{l}\text { Radial Distance } \\
\text { from Heater } \\
\text { (cm) }\end{array}$ & $\begin{array}{c}\text { Elevation from } \\
\text { Brick Base } \\
\text { (cm) }\end{array}$ & & \\
\hline 1 & 25.4 & -2.90 & 2.36 & $\overline{0.61}$ \\
\hline 2 & 25.4 & 7.30 & 1.16 & 0.32 \\
\hline 3 & 25.4 & 29.2 & 1.41 & 0.25 \\
\hline 4 & 25.4 & 51.1 & 2.96 & 0.69 \\
\hline 5 & 25.4 & 73.0 & 6.51 & 1.36 \\
\hline 6 & 25.4 & 94.9 & 15.6 & 2.58 \\
\hline 7 & 25.4 & 116.8 & 4.36 & 0.68 \\
\hline 8 & 25.4 & 138.8 & 8.95 & 1.51 \\
\hline 9 & 25.4 & 160.7 & 3.36 & 0.74 \\
\hline 10 & 25.4 & 182.6 & 11.5 & 1.35 \\
\hline
\end{tabular}

\section{A.3 INSULATION TEMPERATURE}

The cool-down analyses assume a constant temperature of $25^{\circ} \mathrm{C}$ at the outer surface of the modeled insulation. Figure A-4 presents data from four thermocouples placed at the surface of the insulation ( 3 in the radial insulation and one placed on the 
insulation cap). Linear regression of the data from the modeled time period (122.8 to 233.8 hours) results in an insulation surface temperature of $25.1 \pm 3.9^{\circ} \mathrm{C}$. This is consistent with the insulation surface temperature assumed in the cool-down analyses.

\section{A.4 HEATER POWER}

The TOUGH2 post-test analyses of Test 1 assumed a heater power output of 1865 $\mathrm{W}$ for the first 20 hours of the experiment. Figure A-5 presents the heater power data for the first 20 hours of Test 1 . Linear regression of the data results in a mean power output of $1856 \mathrm{~W}$ with a standard deviation of $40.5 \mathrm{~W}$. The assumed value of $1865 \mathrm{~W}$ is therefore consistent with the recorded data.

\section{A.5 TEST 1 DATA}

Figures A-6 and A-7 present the complete power and temperature data traces for Test 1 . 

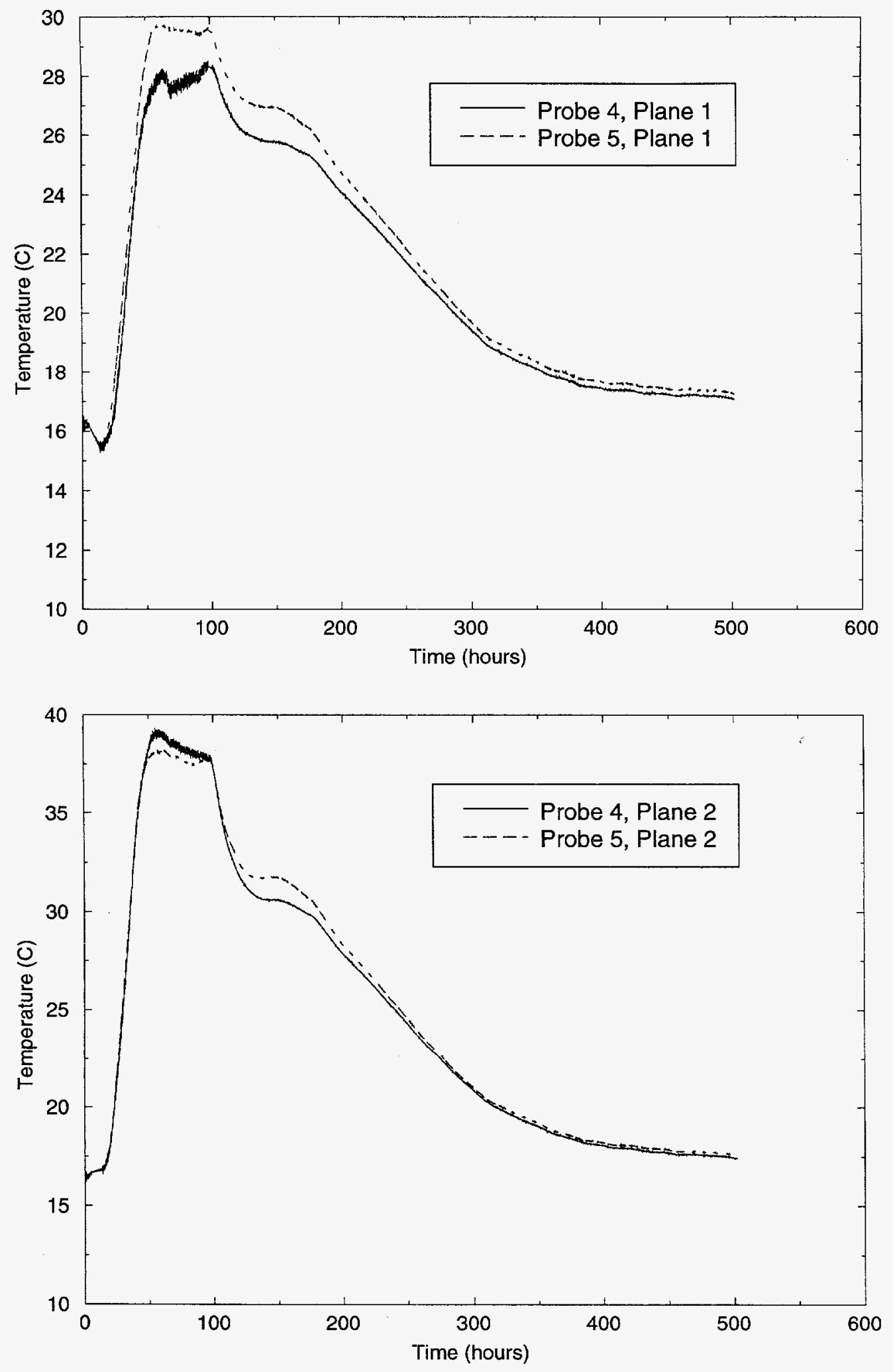

Figure A-1. Comparison of Data from Probes 4 and 5 for Test 1 

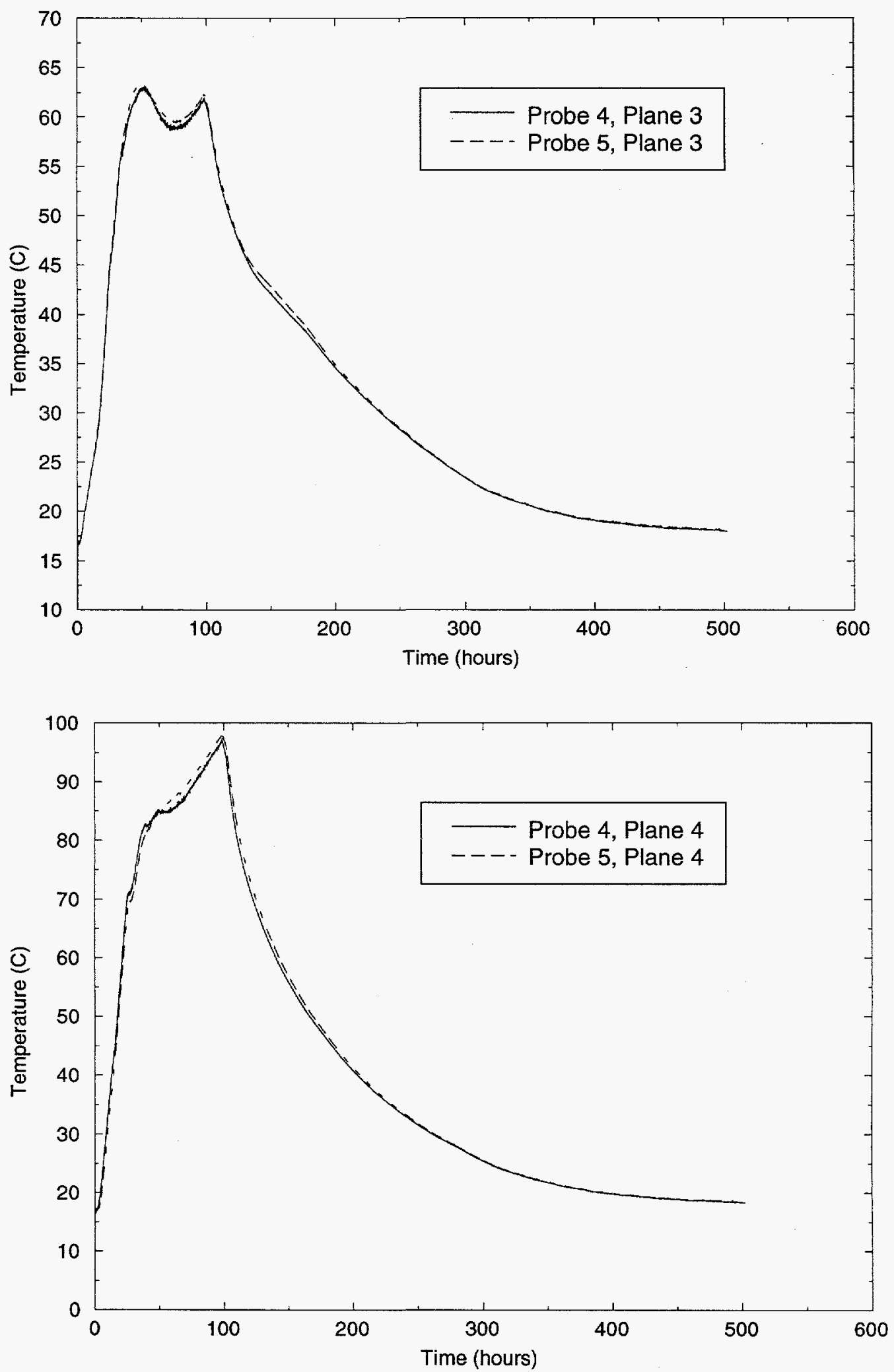

Figure A-1. Comparison of Data from Probes 4 and 5 for Test 1 (continued) 

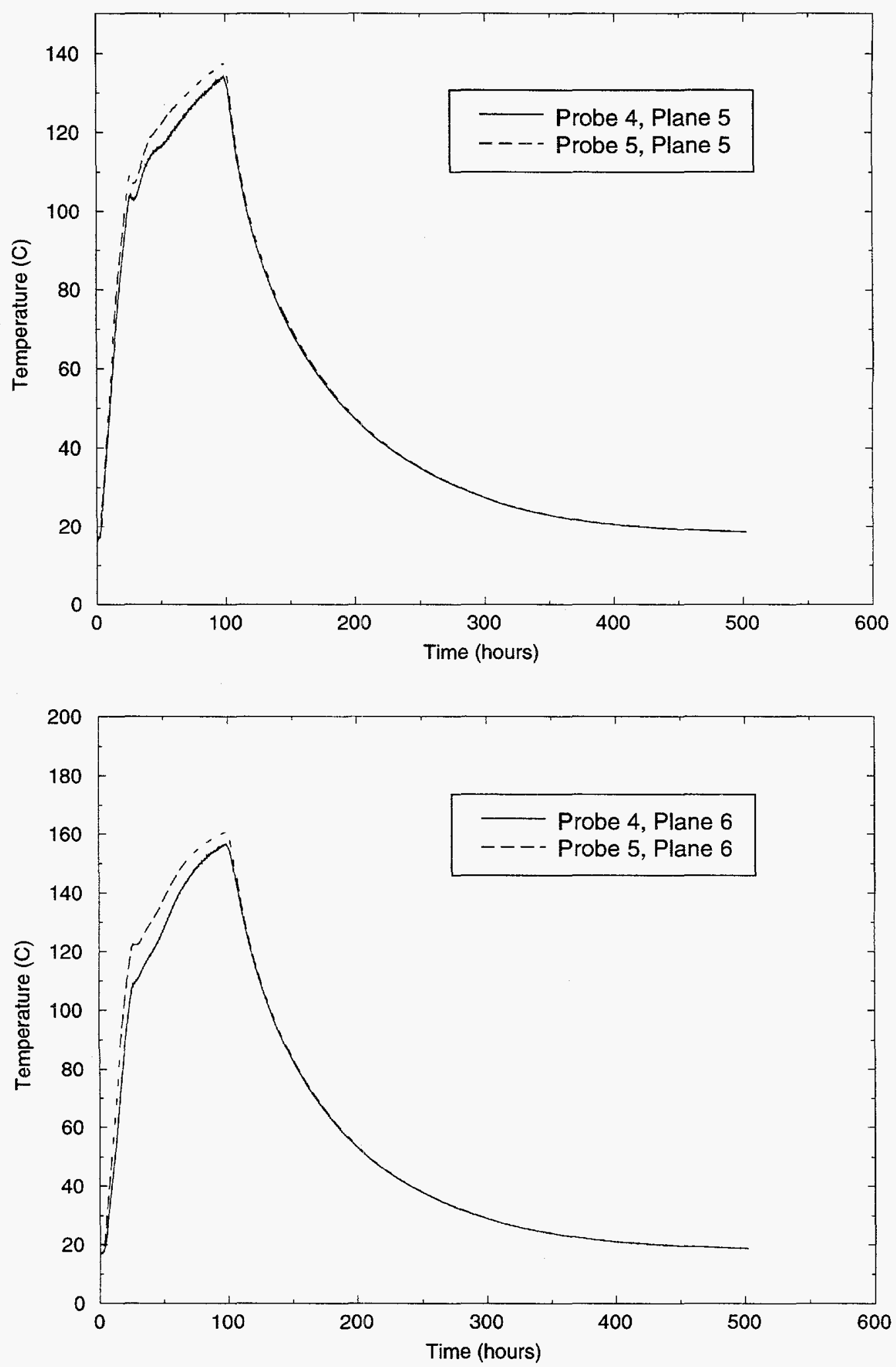

Figure A-1. Comparison of Data from Probes 4 and 5 for Test 1 (continued) 

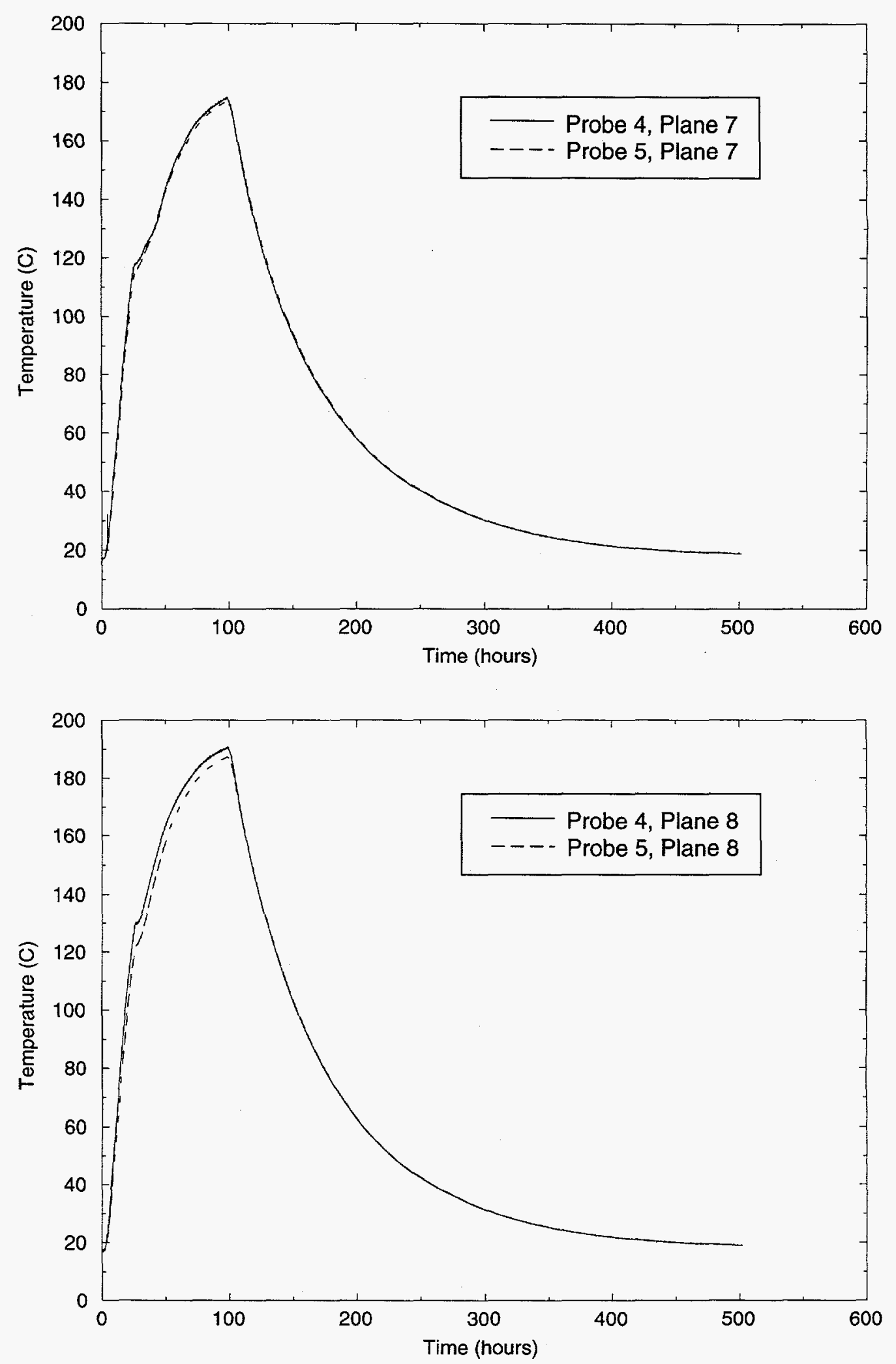

Figure A-1. Comparison of Data from Probes 4 and 5 for Test 1 (continued) 

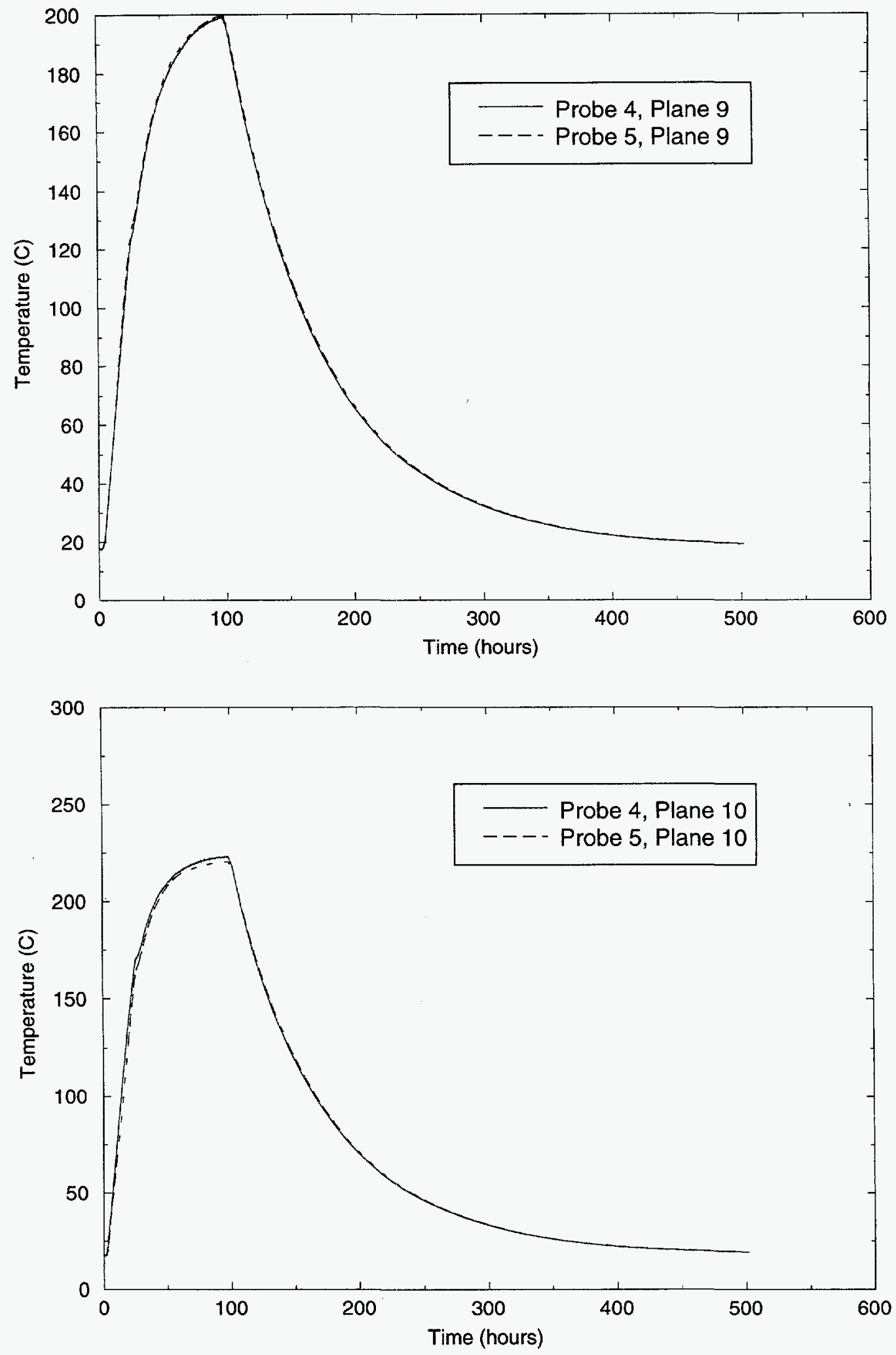

Figure A-1. Comparison of Data from Probes 4 and 5 for Test 1 (concluded) 


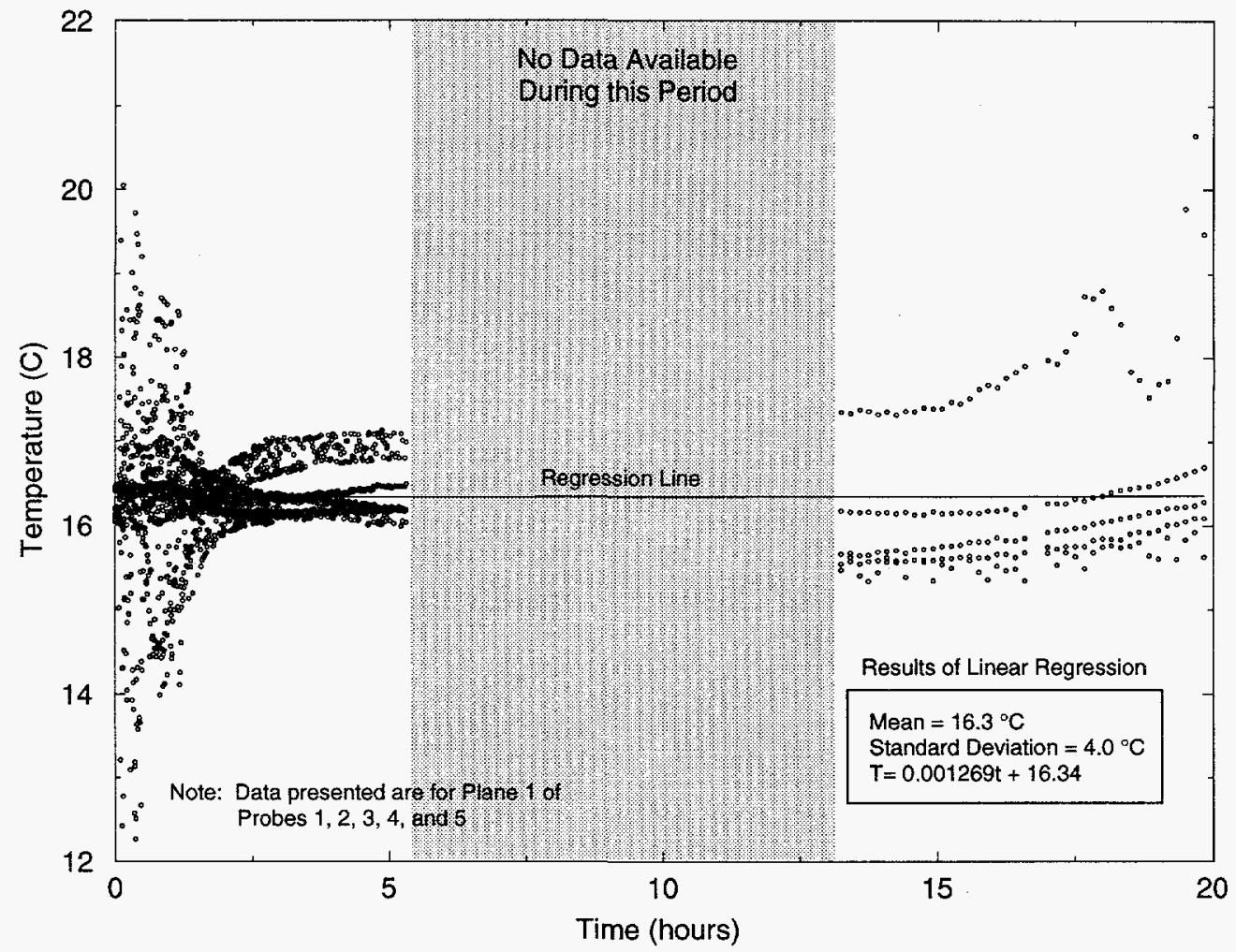

Figure A-2. Data Related to Lower Boundary Condition Modeled in TOUGH2 Analyses

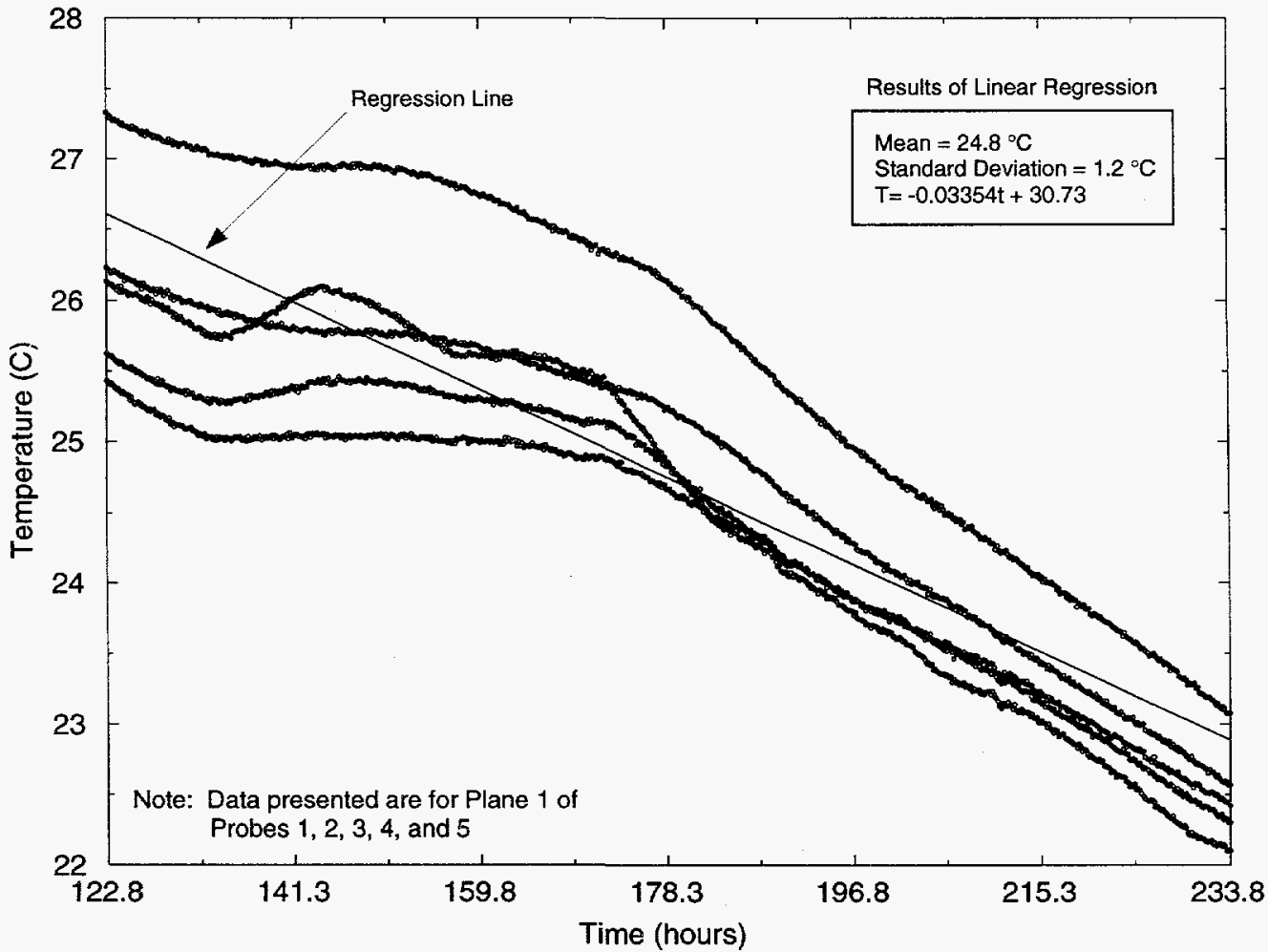

Figure A-3. Data Related to Lower Boundary Condition Modeled in Cool-Down Analyses 


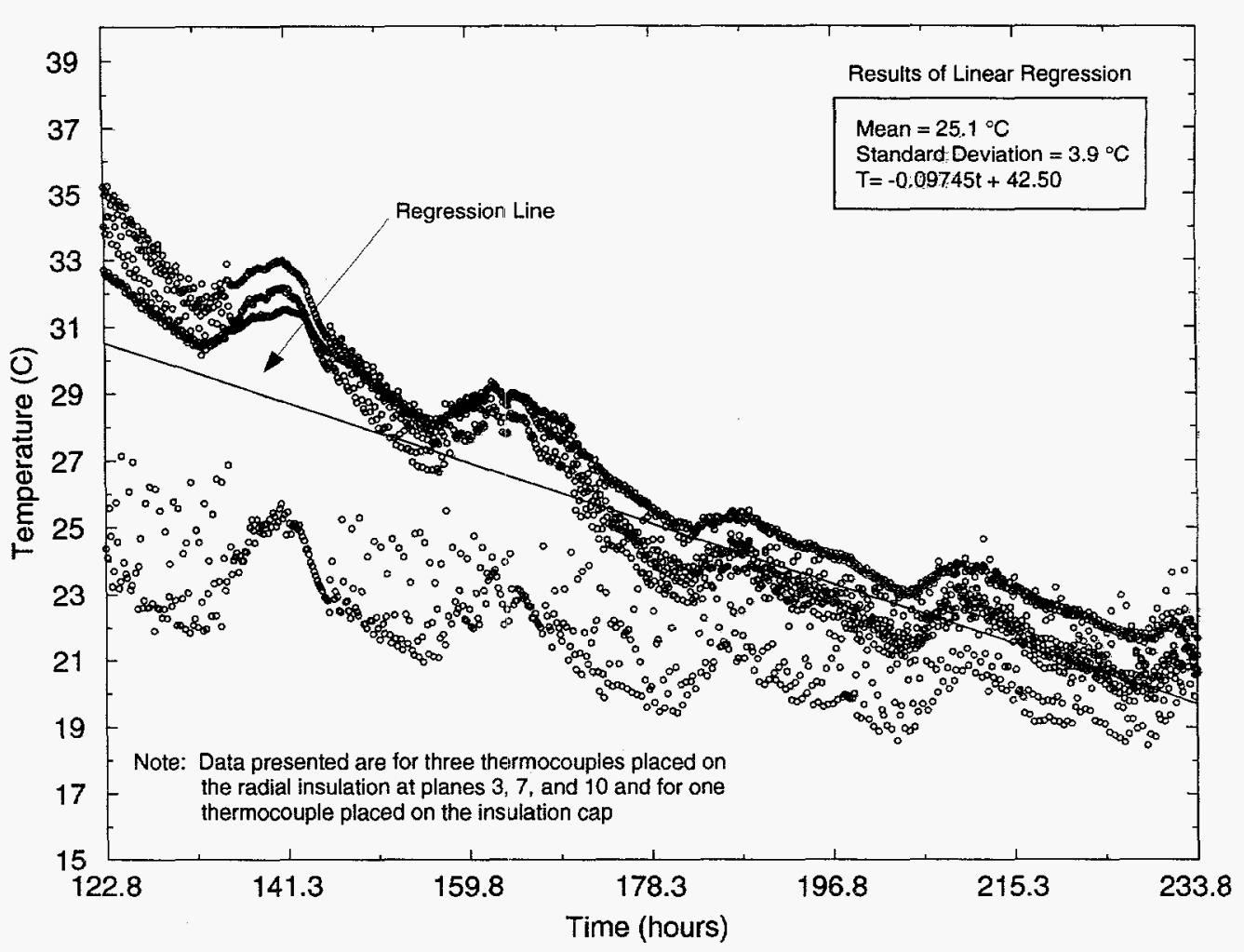

Figure A-4. Data Related to Constant Temperature Boundary Condition Applied to Insulation Surface in Cool-Down Analyses

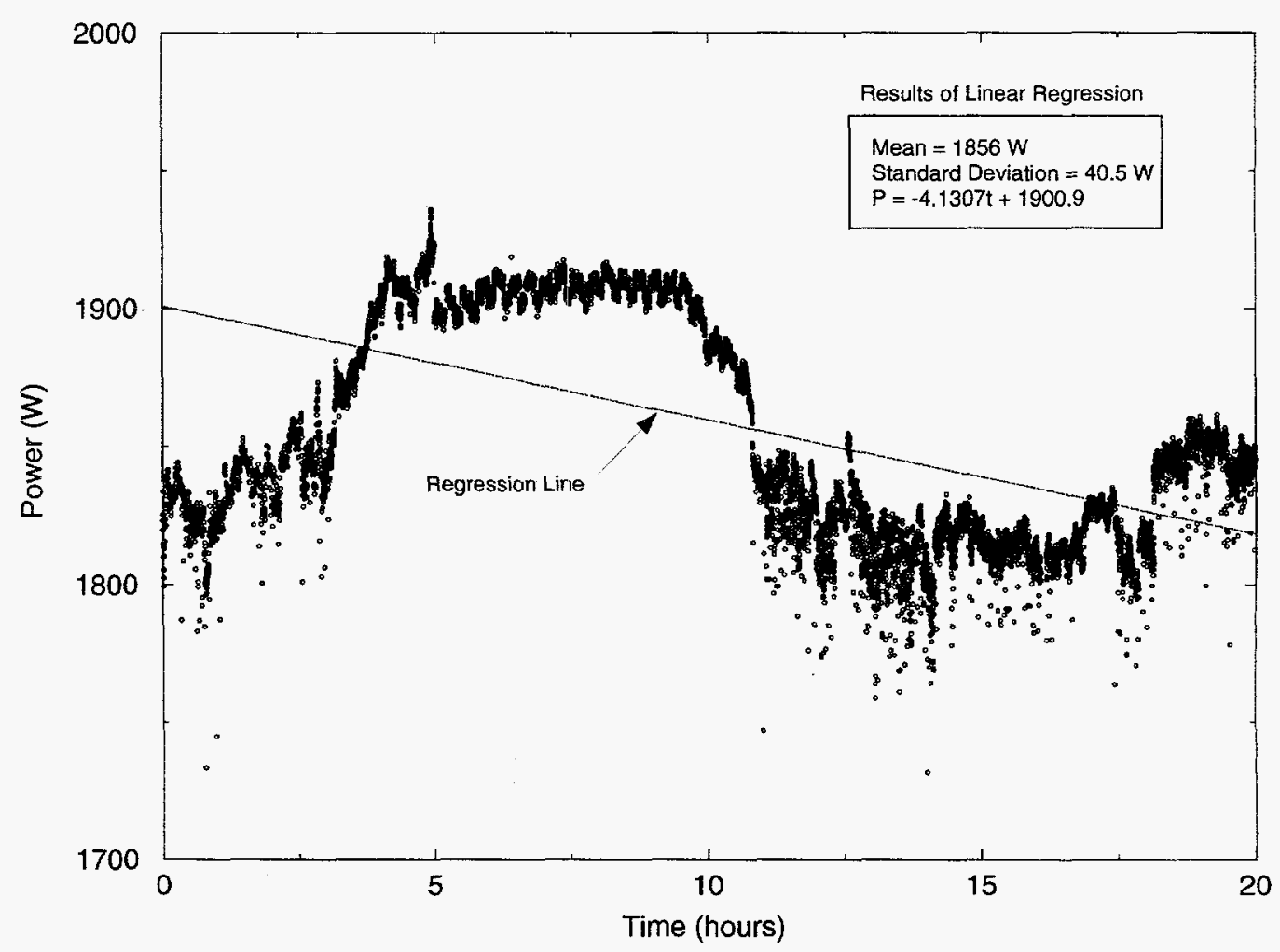

Figure A-5. Power Data for the First 20 Hours of Test 1 


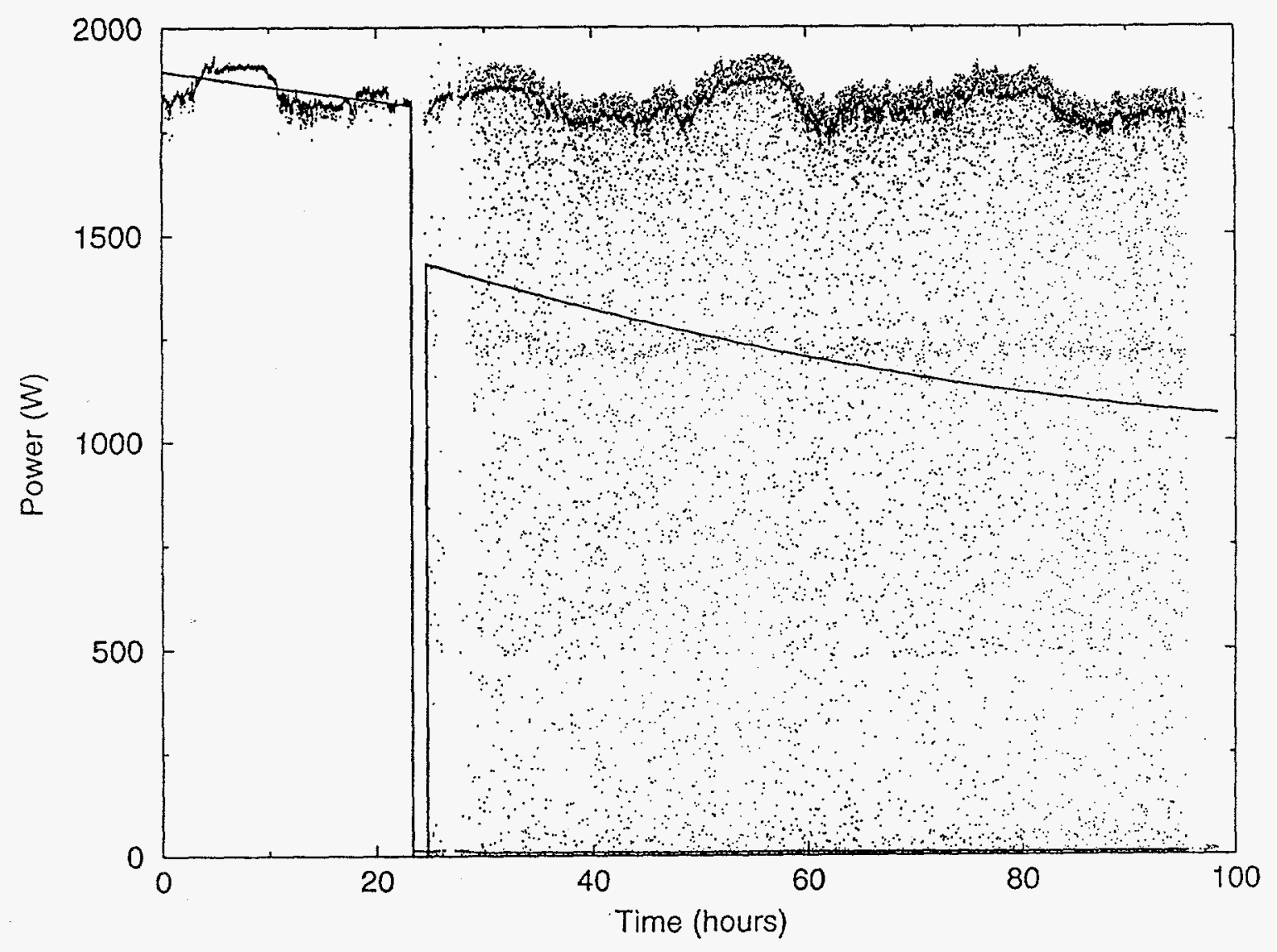

Region $1(0 \mathrm{hr} \leq \mathrm{t} \leq 23.3 \mathrm{hr})$

Region $2(23.3 \mathrm{hr}<\mathrm{t}<24.7 \mathrm{hr})$

Region $3(24.7 \mathrm{hr} \leq \mathrm{t} \leq 98.4 \mathrm{hr})$

Mean $=1853 \mathrm{~W}$

Standard Deviation $=39.2 \mathrm{~W}$

Power Off

Mean $=1216 \mathrm{~W}$

Standard Deviation $=804 \mathrm{~W}$

Power $=-3.5437 t+1896.2$

Power $=1645.4-9.62 t+0.038 t^{2}$

Figure A-6. Complete Power Data for Test 1 

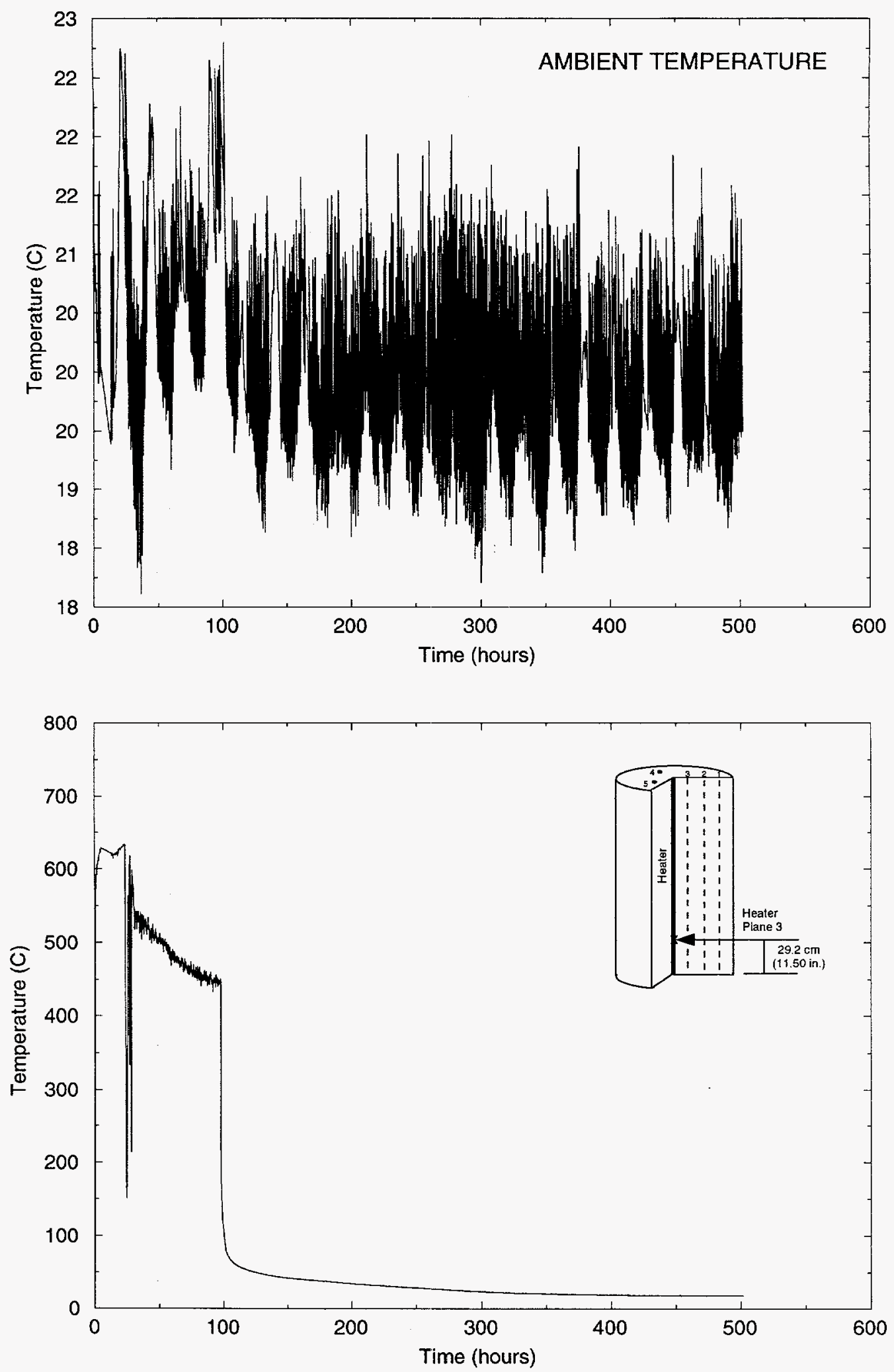

Figure A-7. Test 1 Temperature Data 

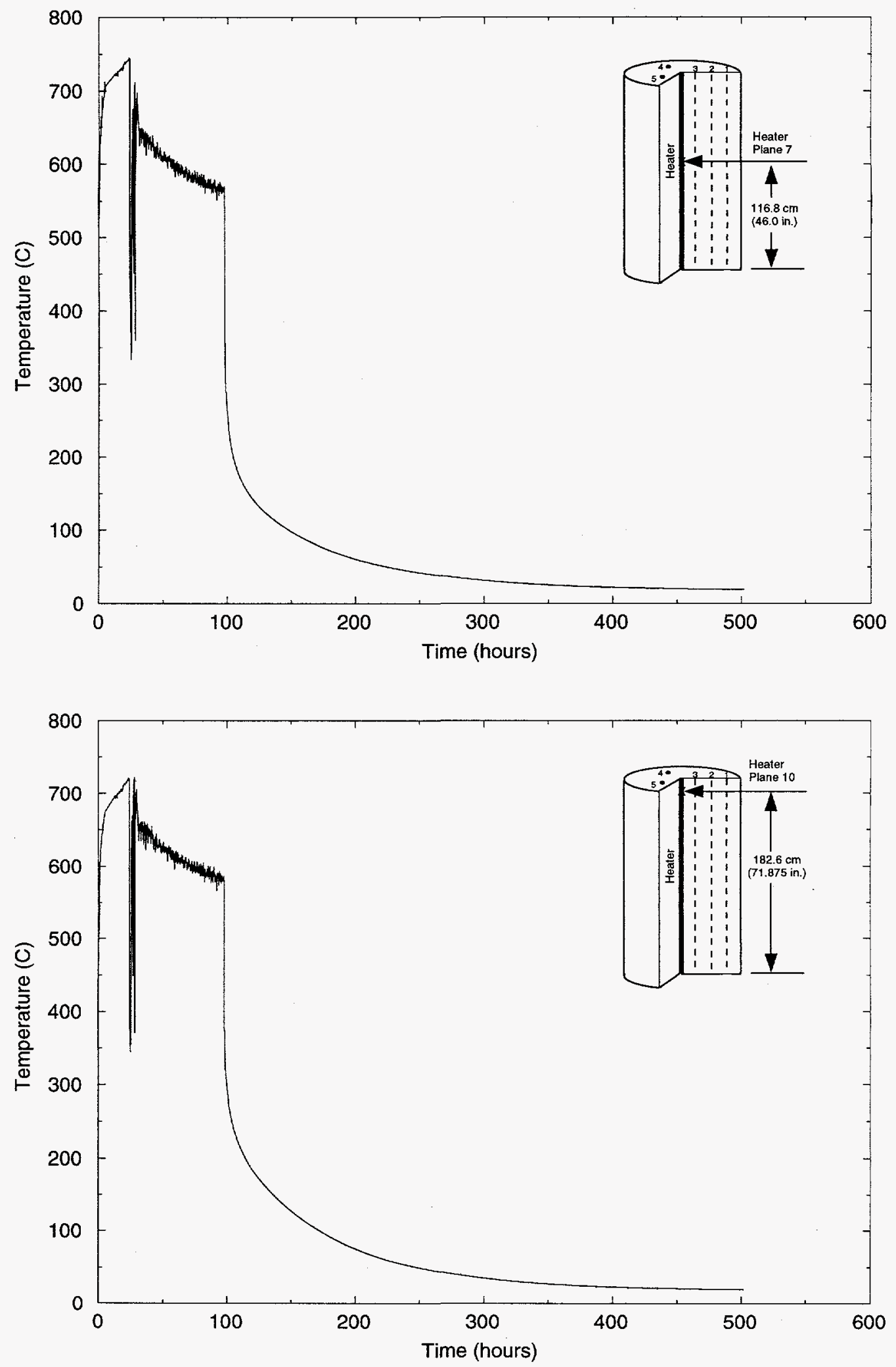

Figure A-7. Test 1 Temperature Data (continued) 

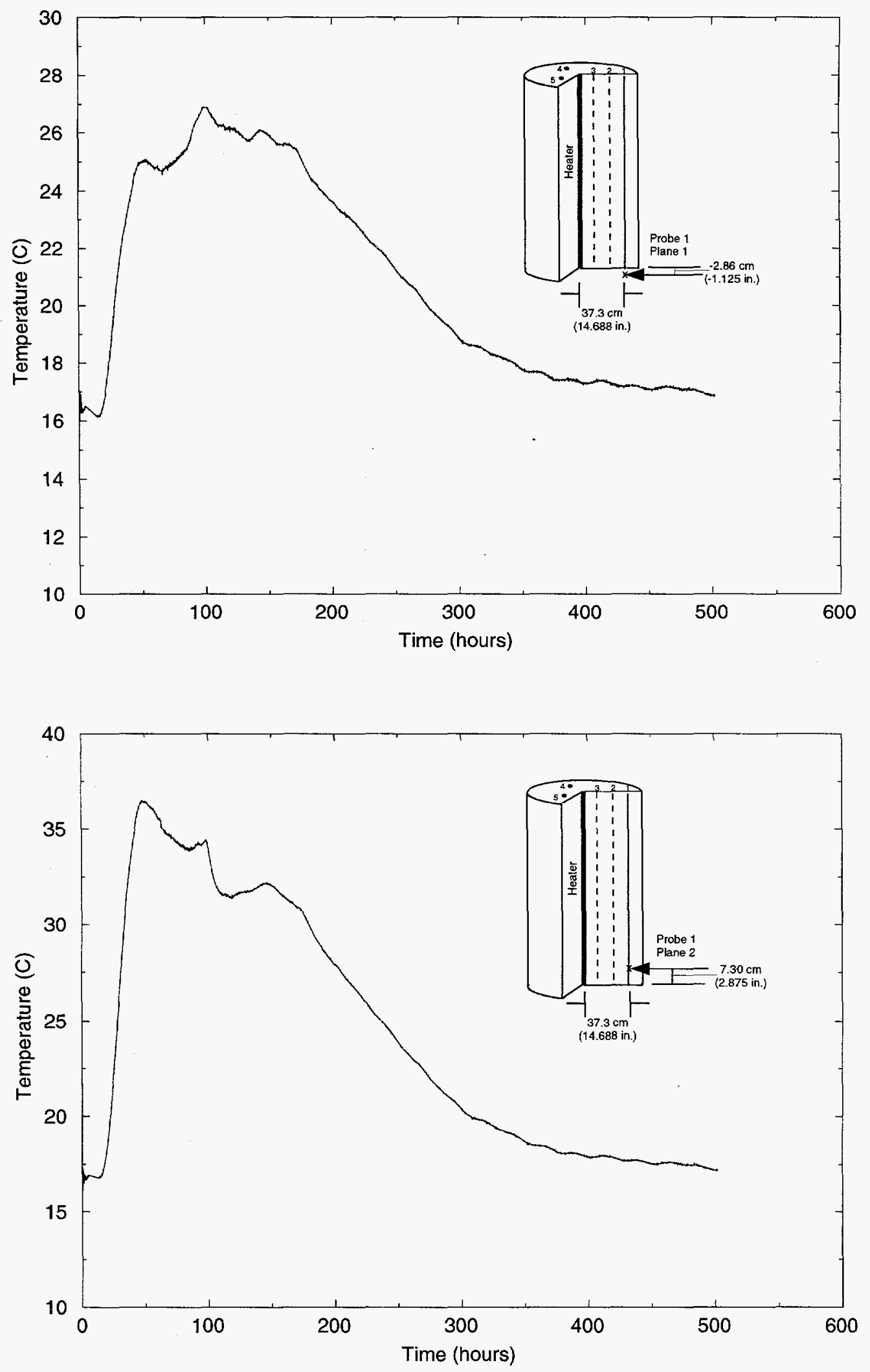

Figure A-7. Test 1 Temperature Data (continued) 

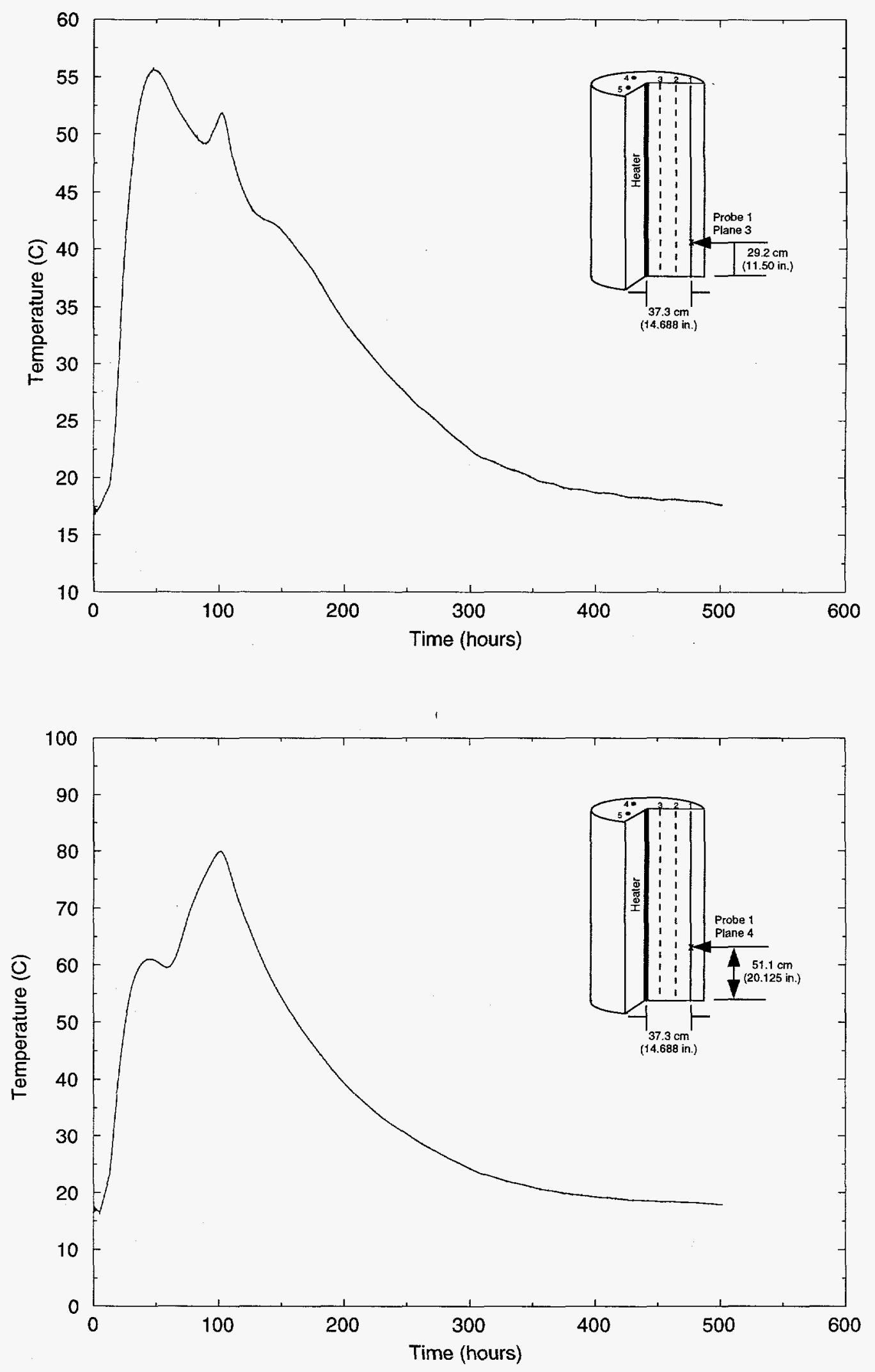

Figure A-7. Test 1 Temperature Data (continued) 

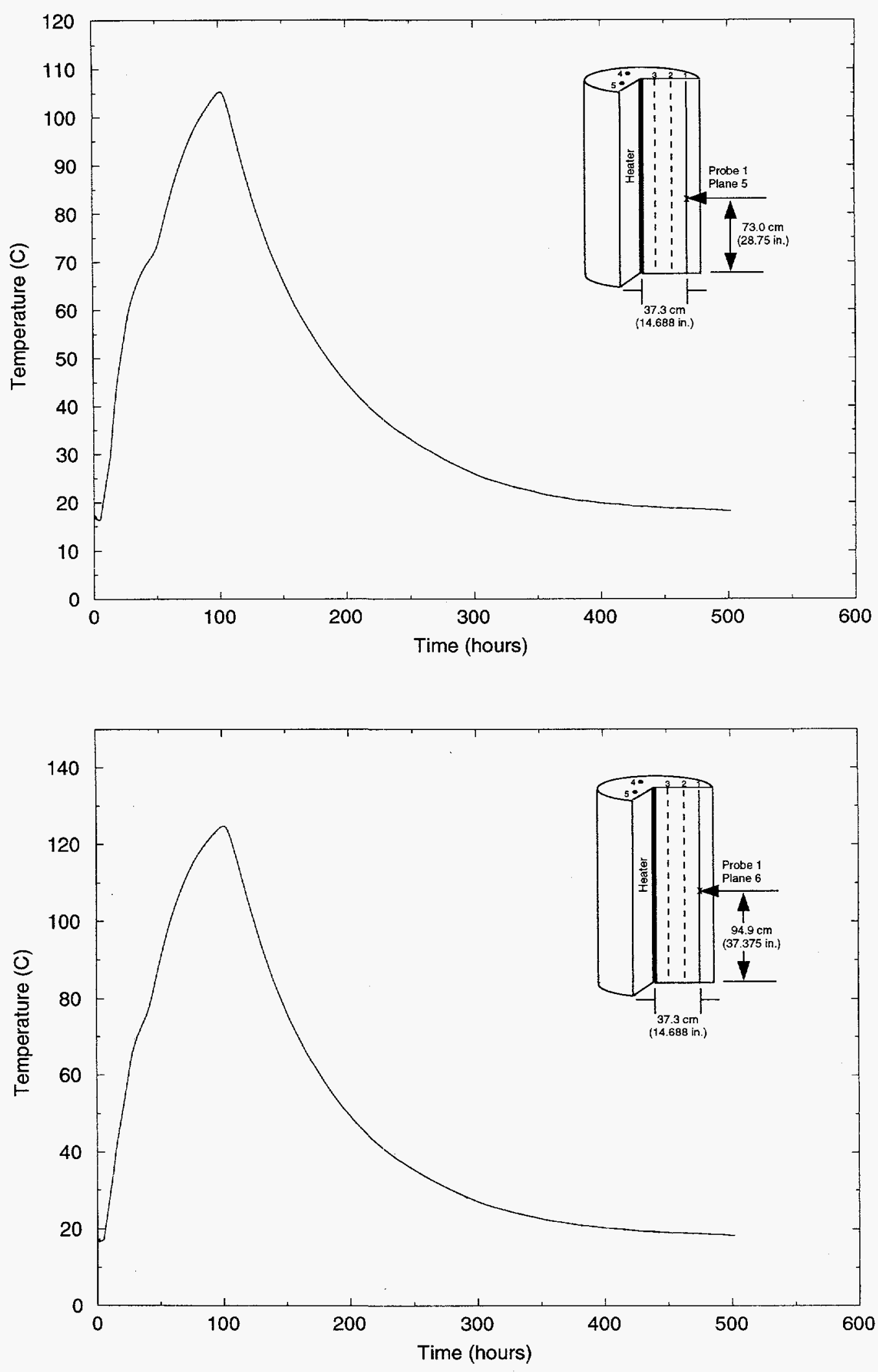

Figure A-7. Test 1 Temperature Data (continued) 

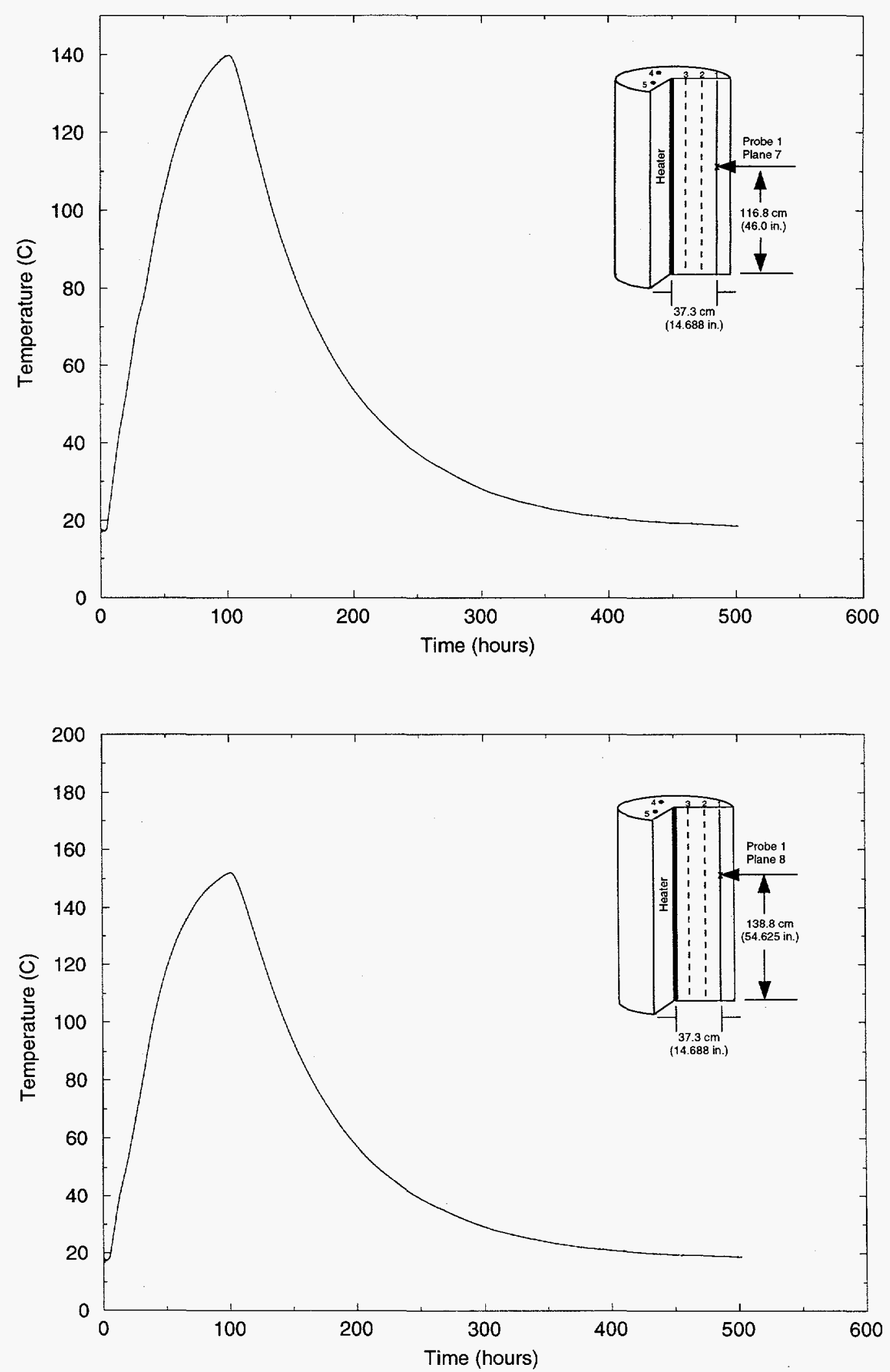

Figure A-7. Test 1 Temperature Data (continued) 

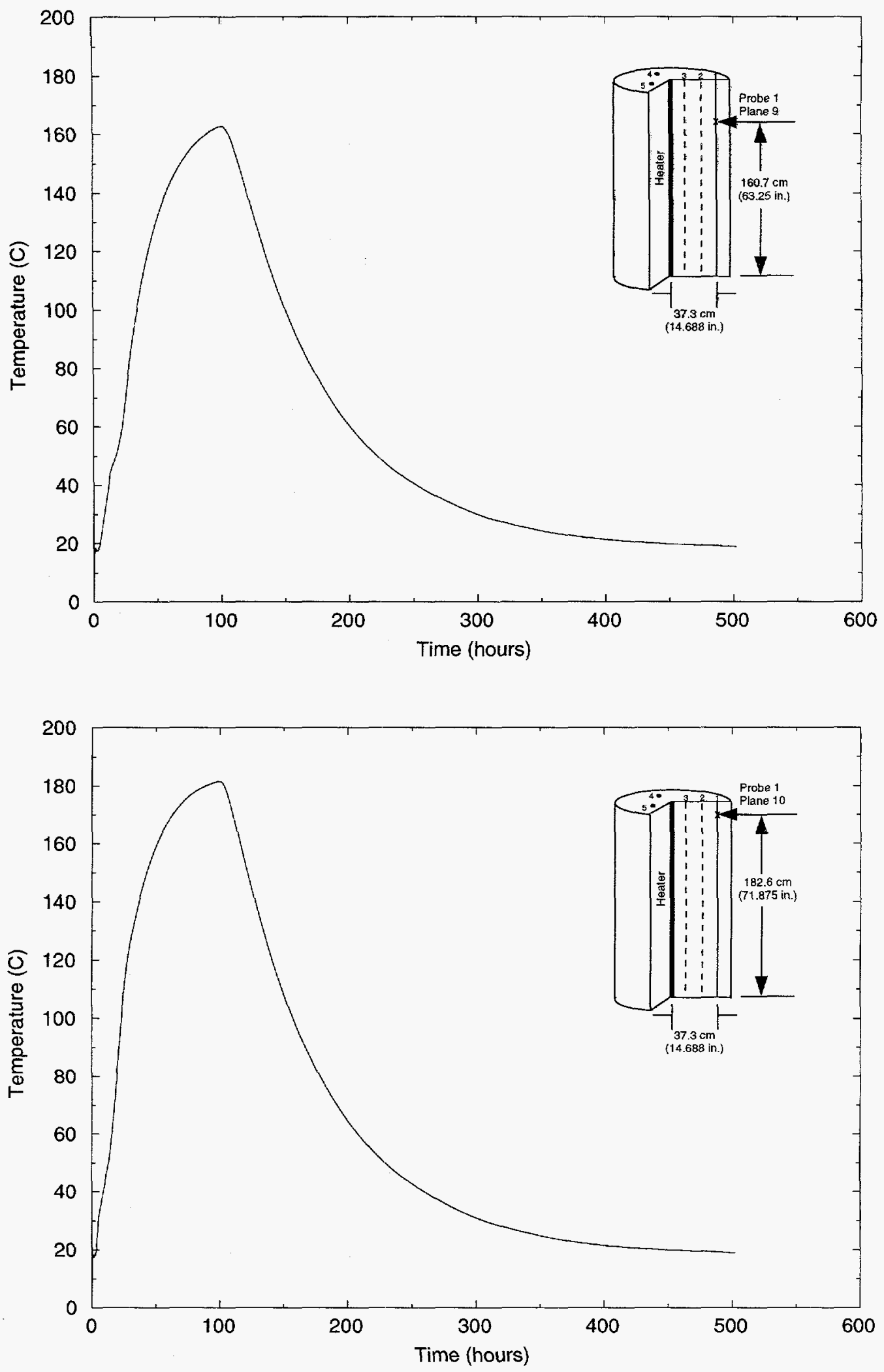

Figure A-7. Test 1 Temperature Data (continued) 

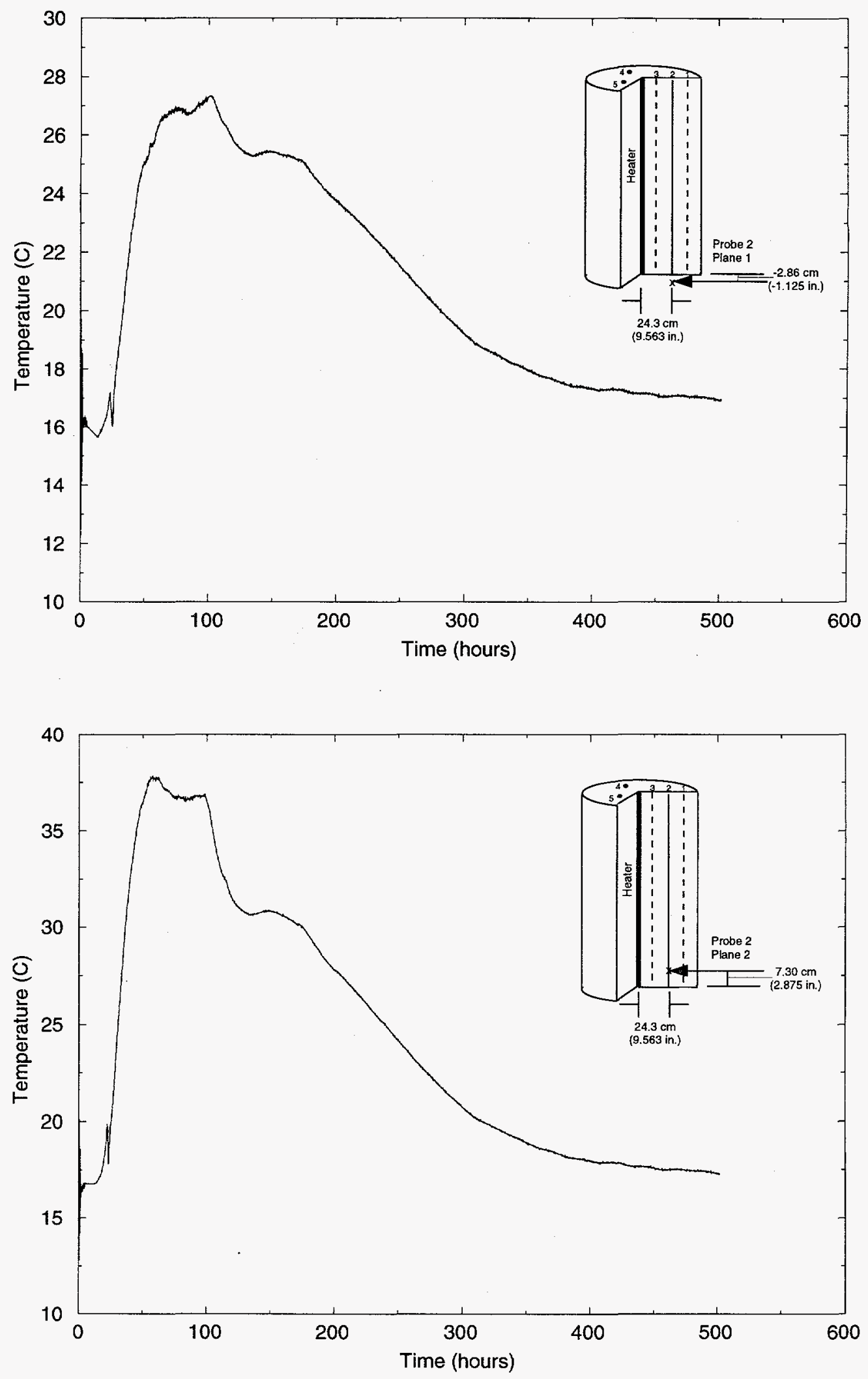

Figure A-7. Test 1 Temperature Data (continued) 

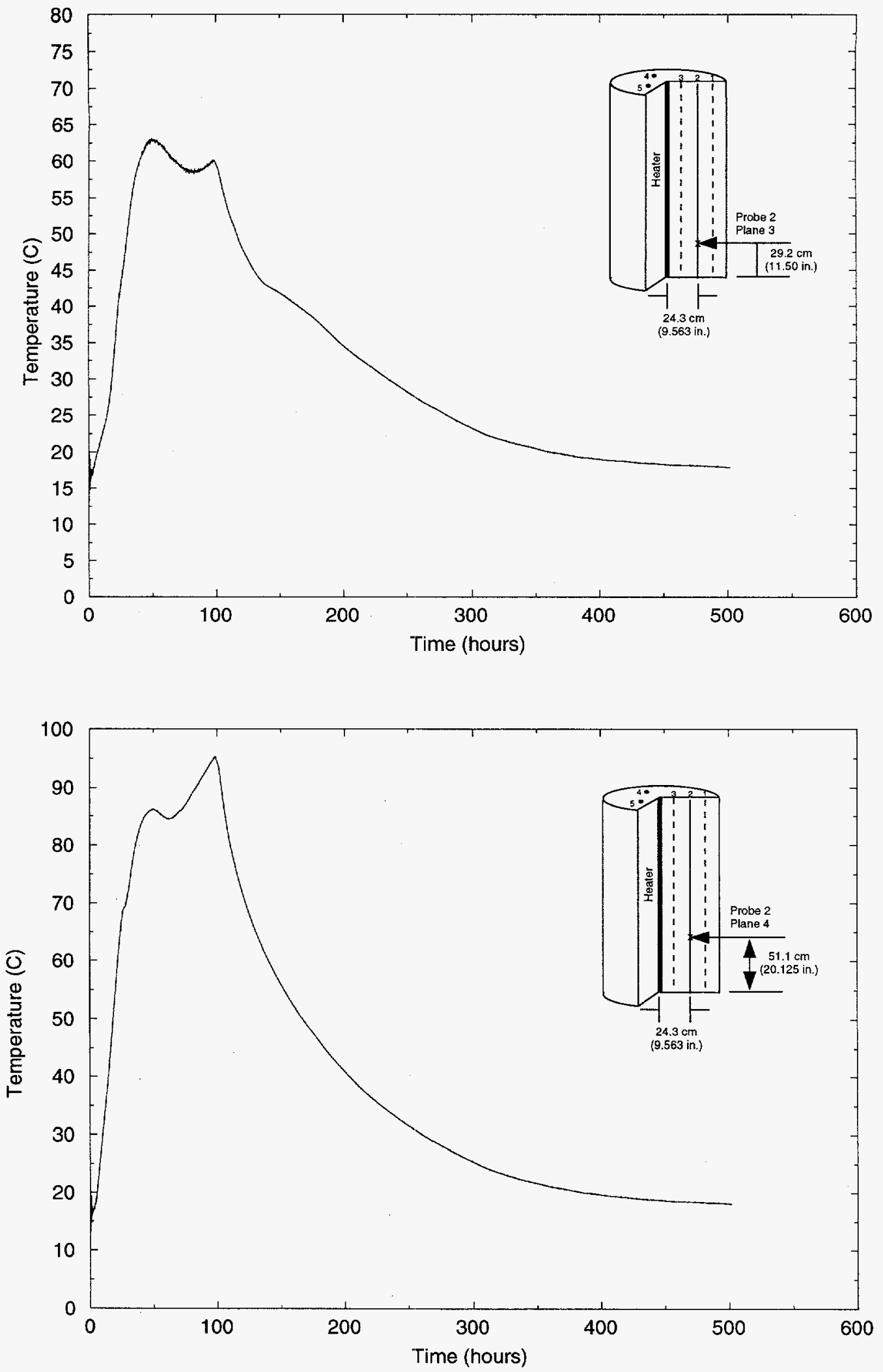

Figure A-7. Test 1 Temperature Data (continued) 

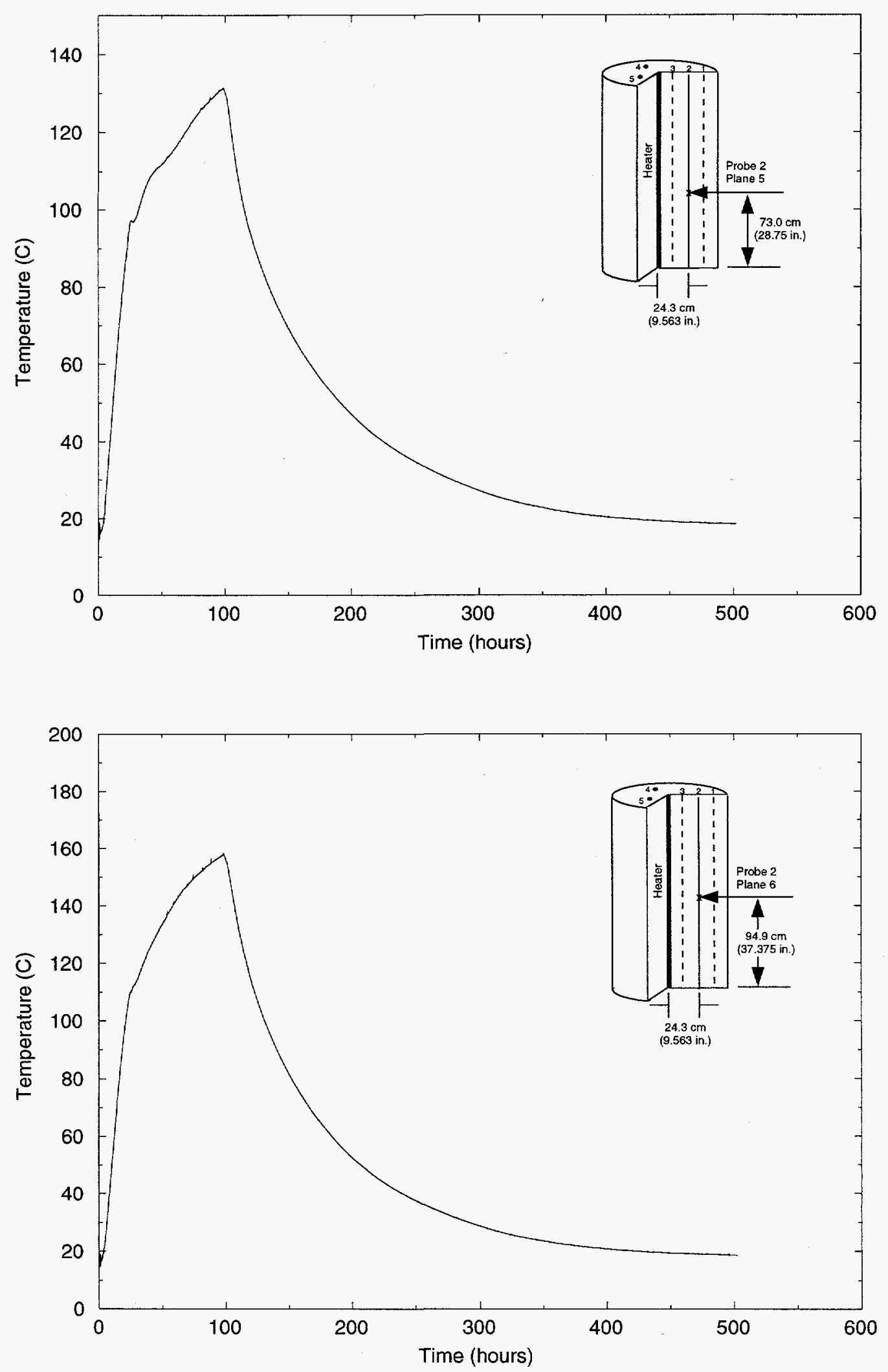

Figure A-7. Test 1 Temperature Data (continued) 

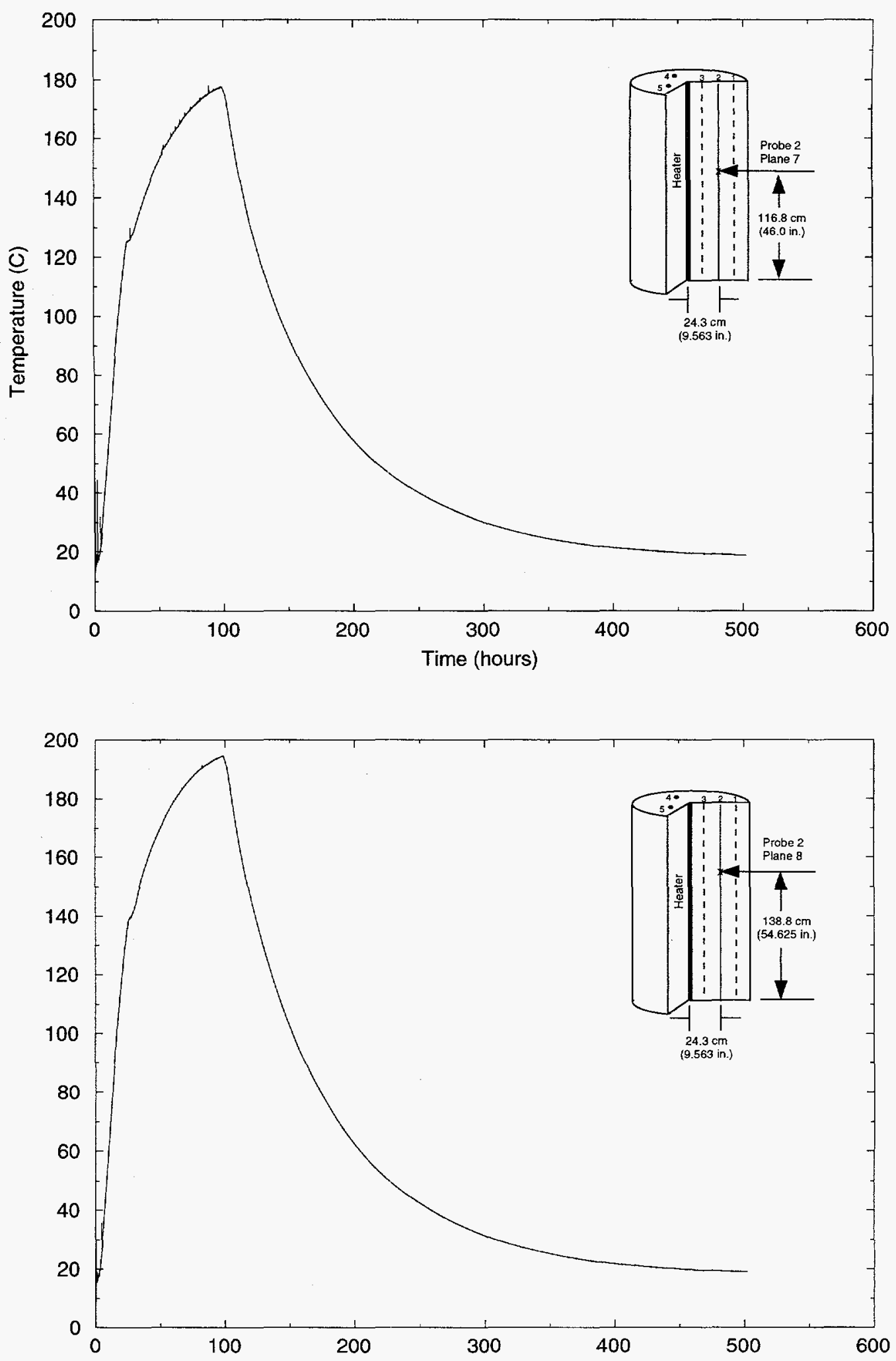

Figure A-7. Test 1 Temperature Data (continued) 

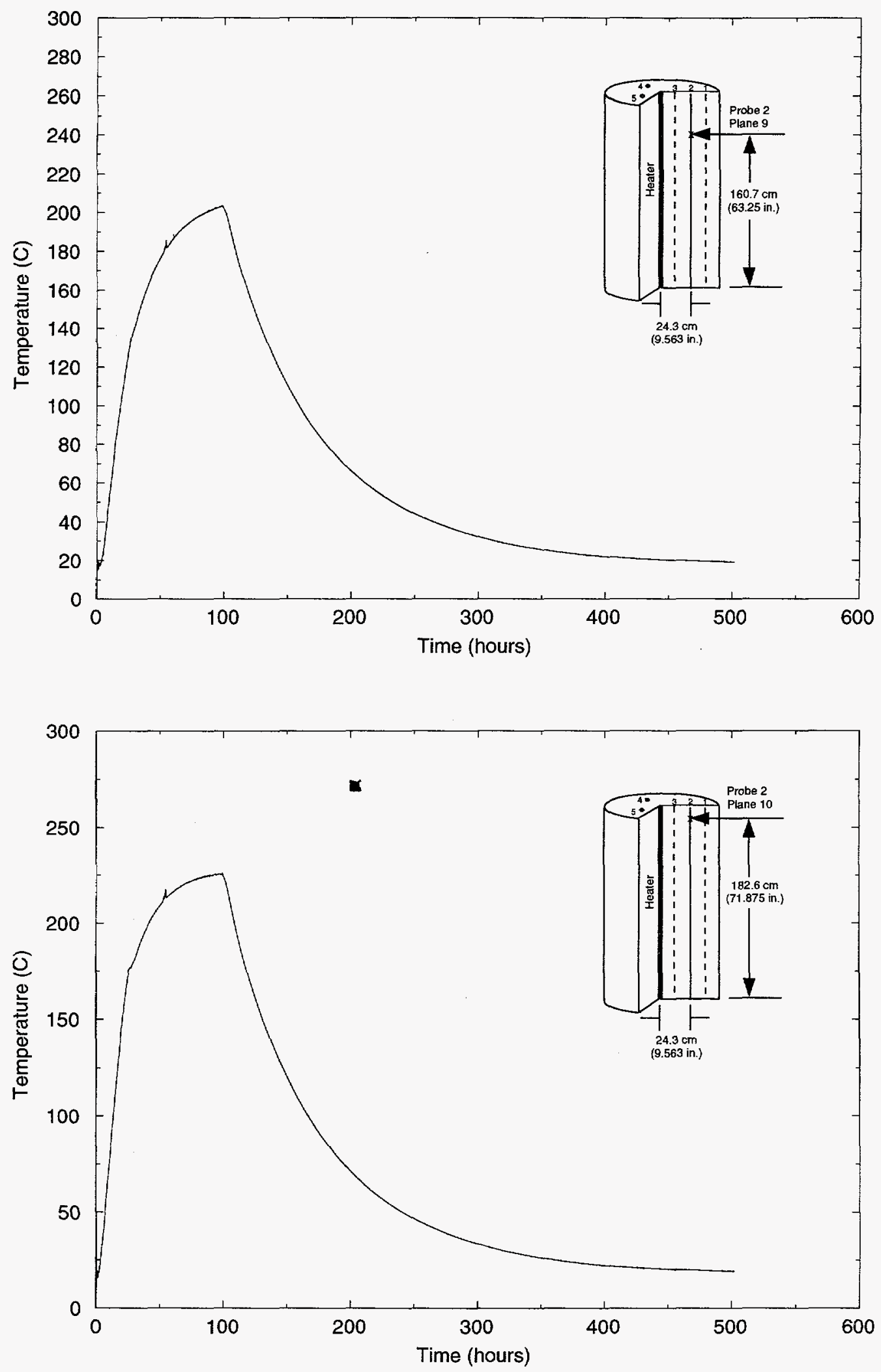

Figure A-7. Test 1 Temperature Data (continued) 

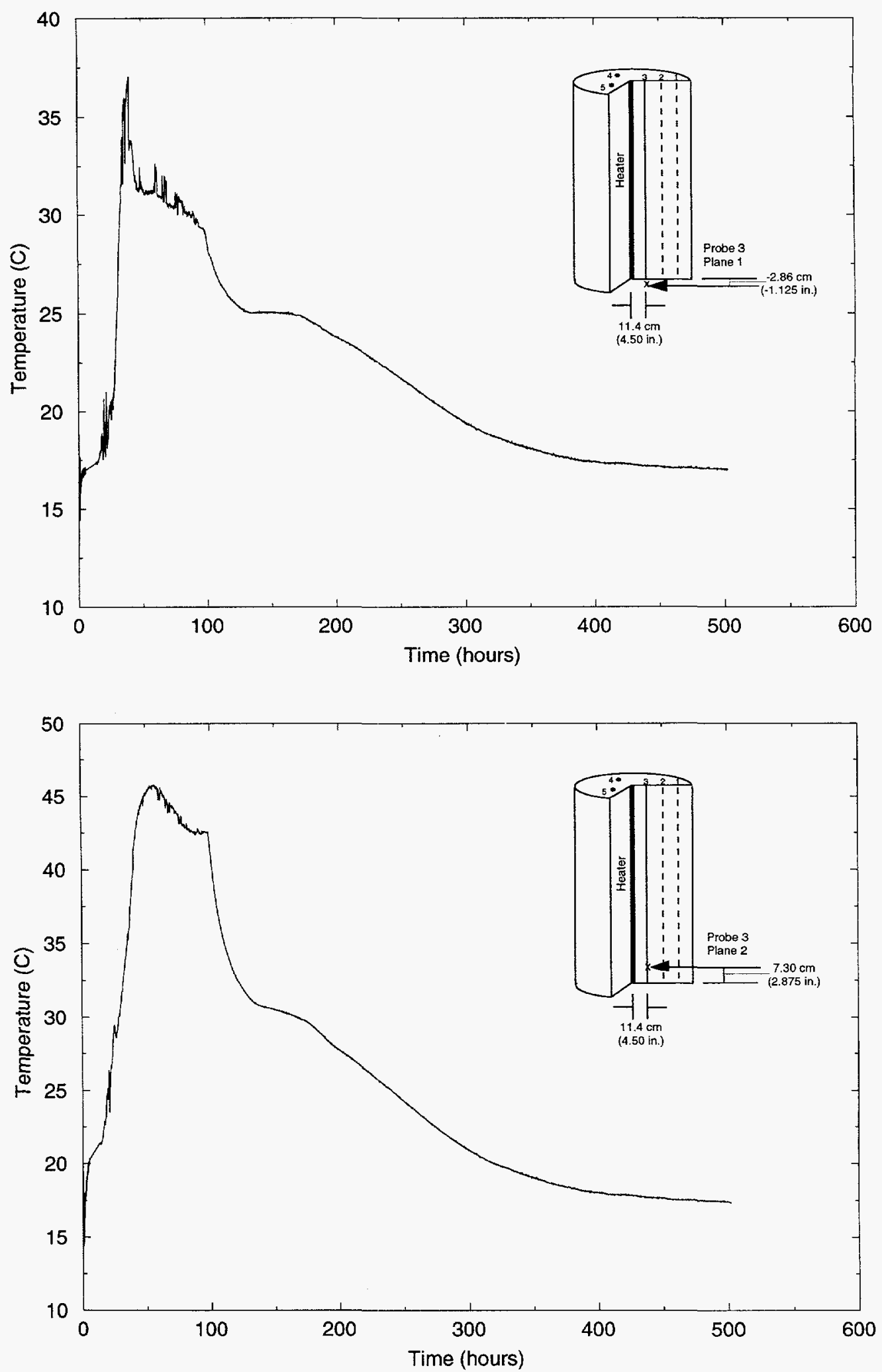

Figure A-7. Test 1 Temperature Data (continued) 

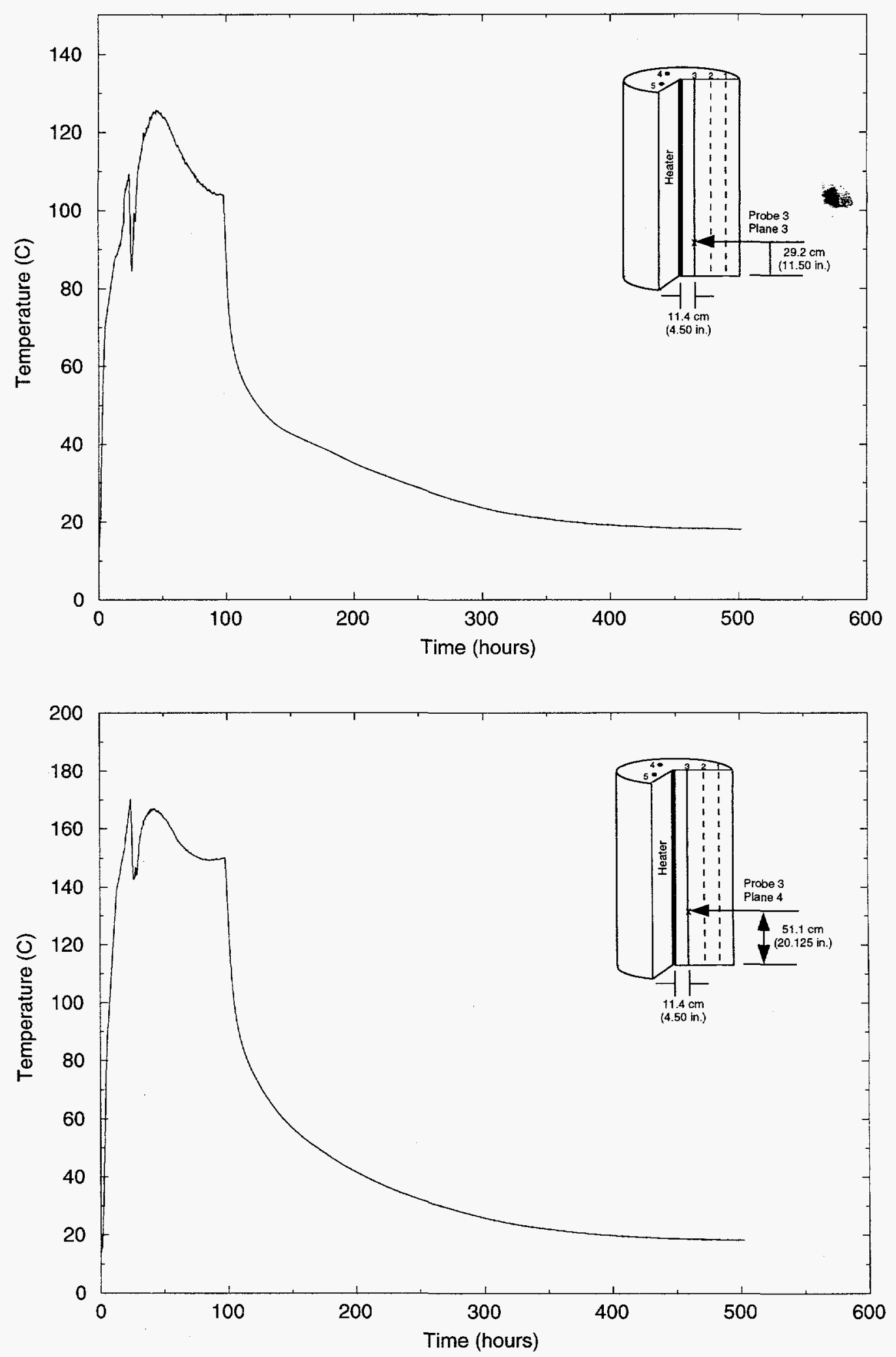

Figure A-7. Test 1 Temperature Data (continued) 

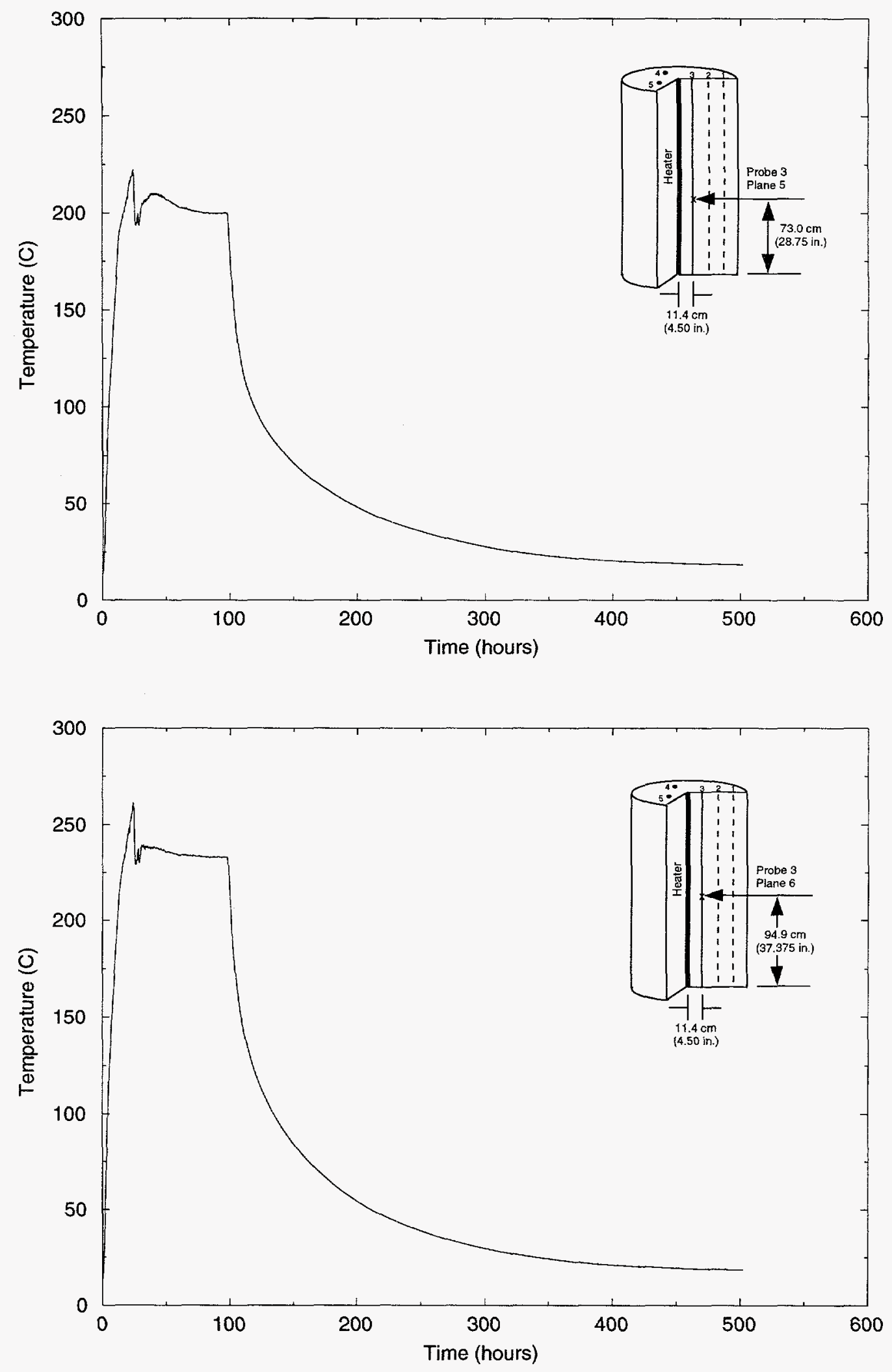

Figure A-7. Test 1 Temperature Data (continued) 

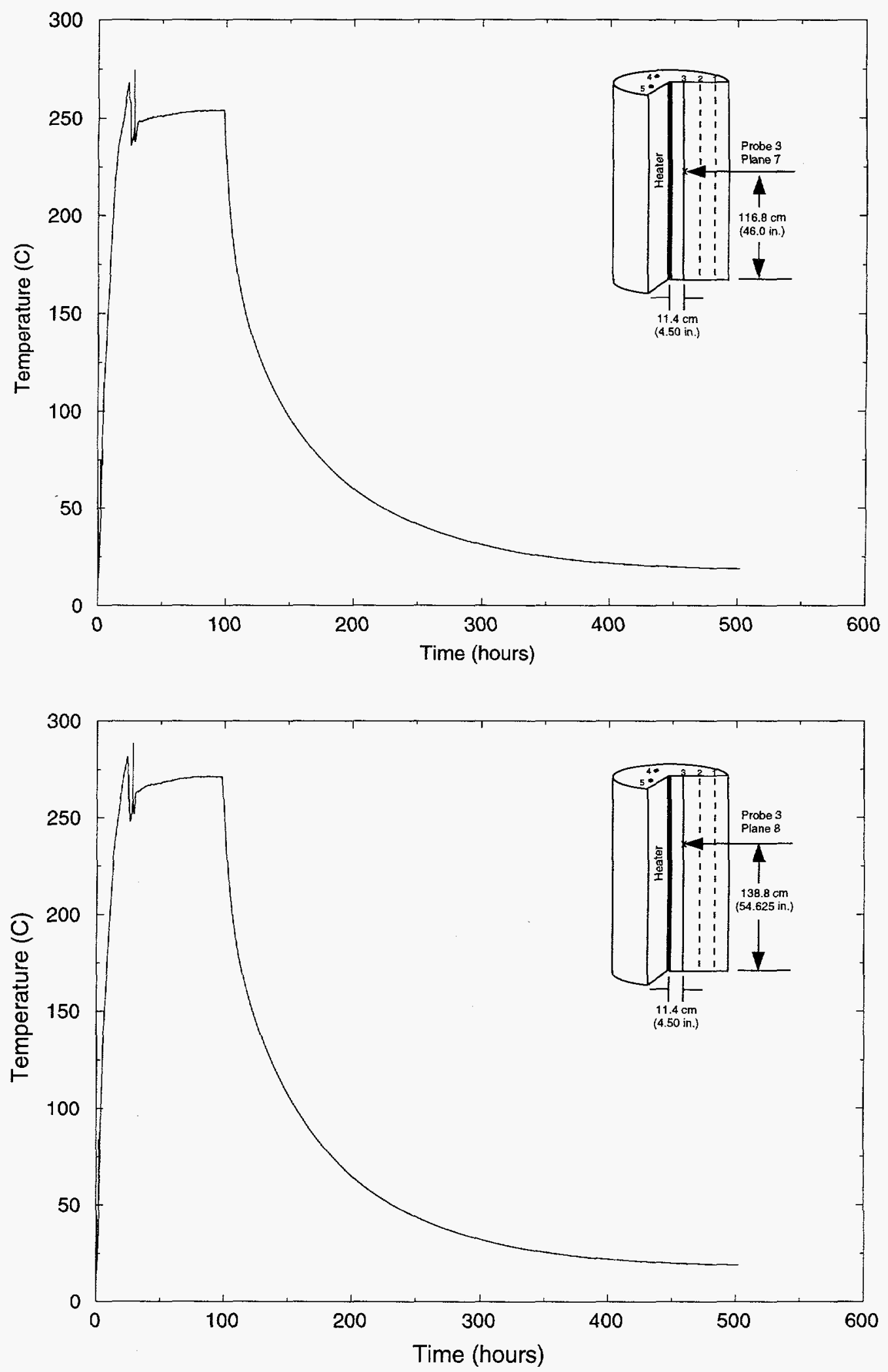

Figure A-7. Test 1 Temperature Data (continued) 

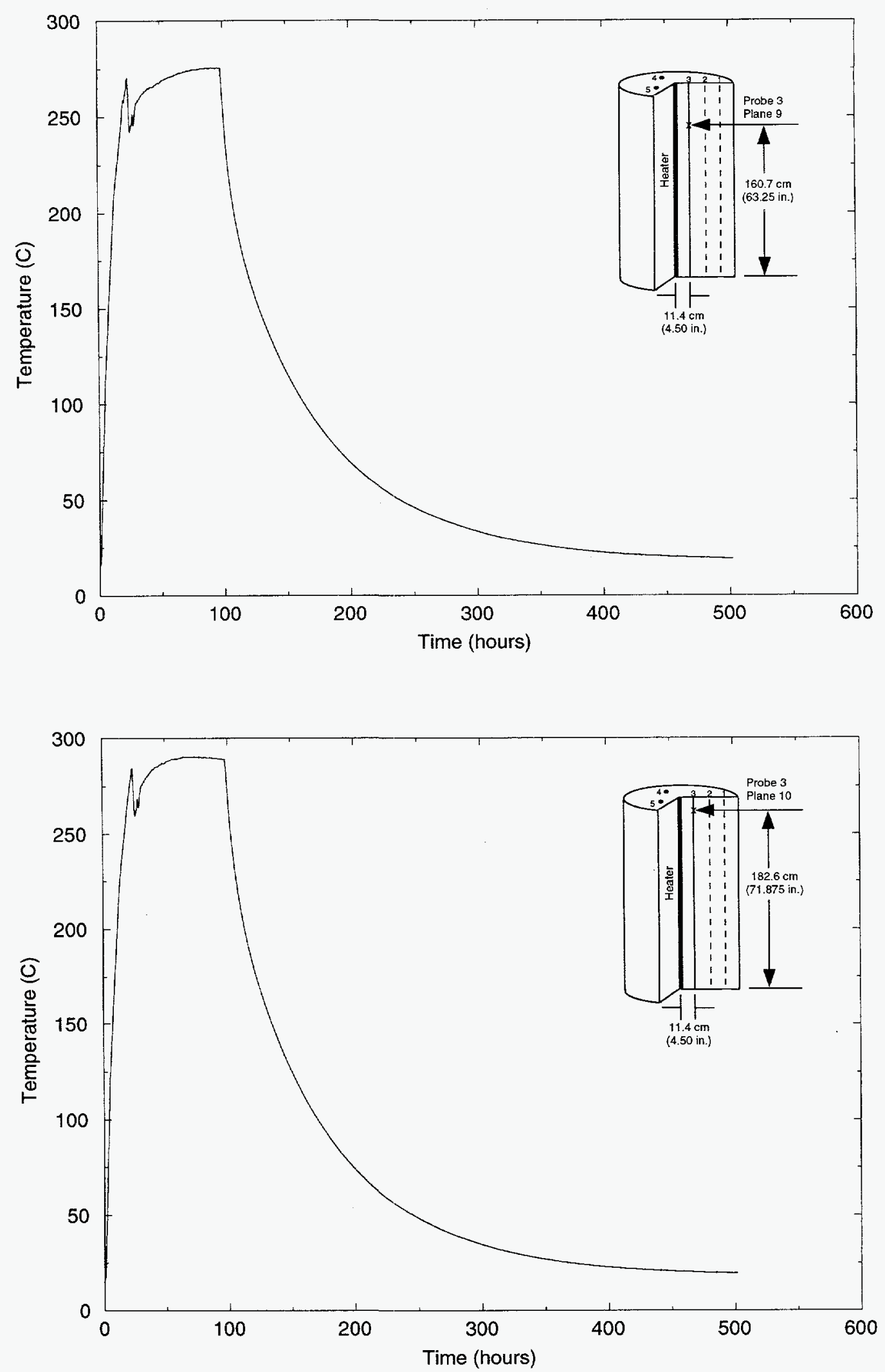

Figure A-7. Test 1 Temperature Data (continued) 

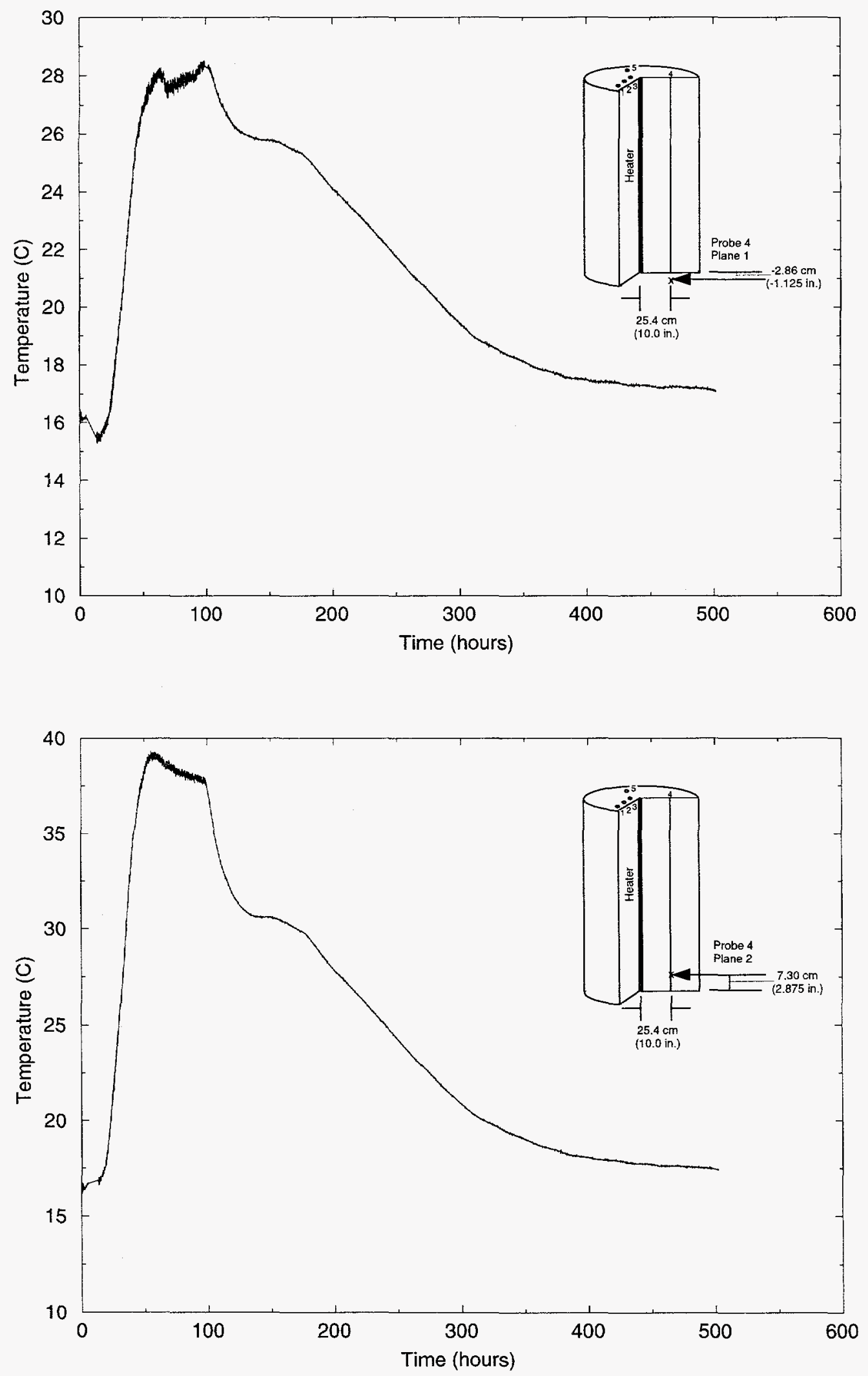

Figure A-7. Test 1 Temperature Data (continued) 

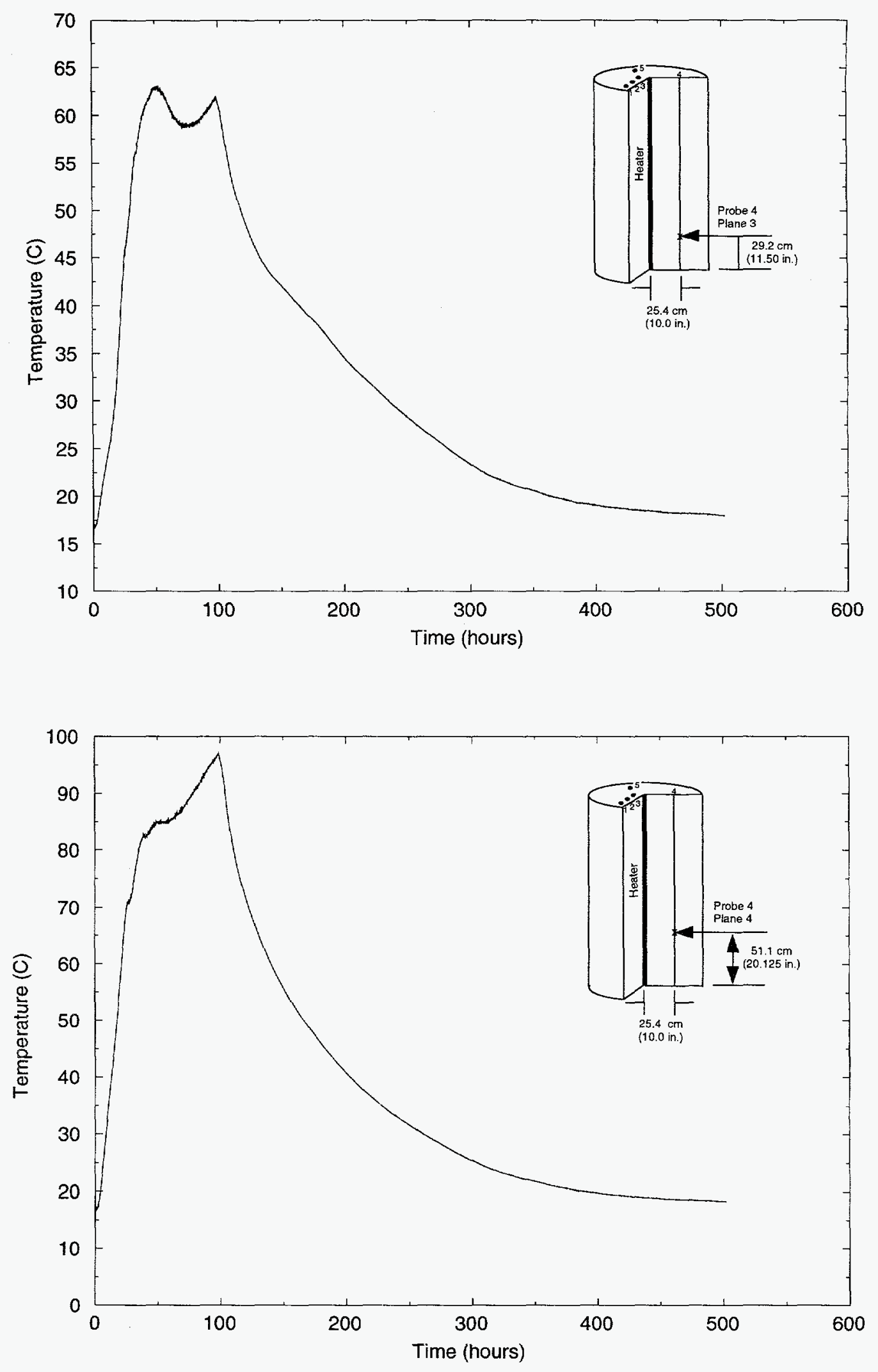

Figure A-7. Test 1 Temperature Data (continued) 

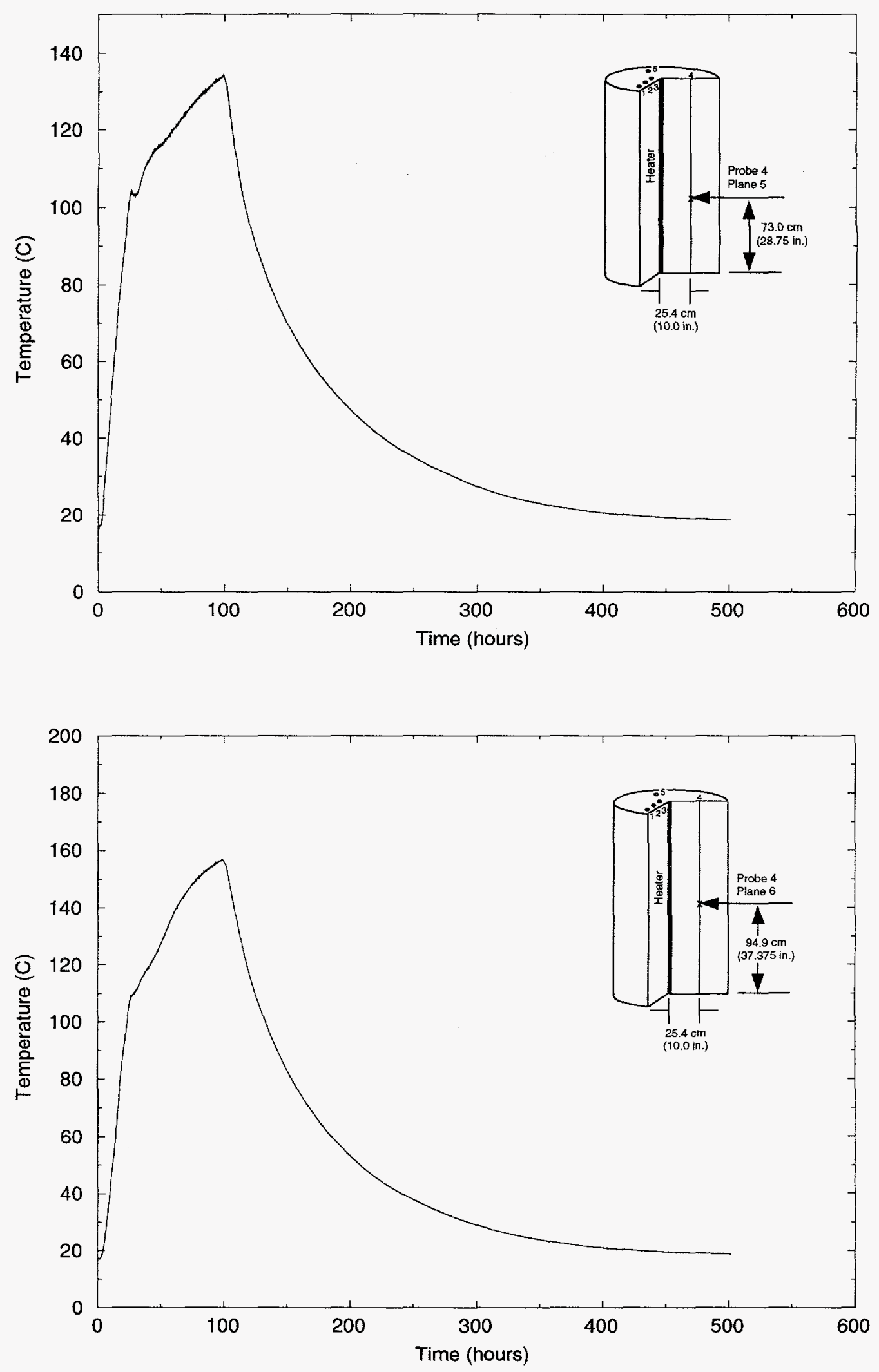

Figure A-7. Test 1 Temperature Data (continued) 

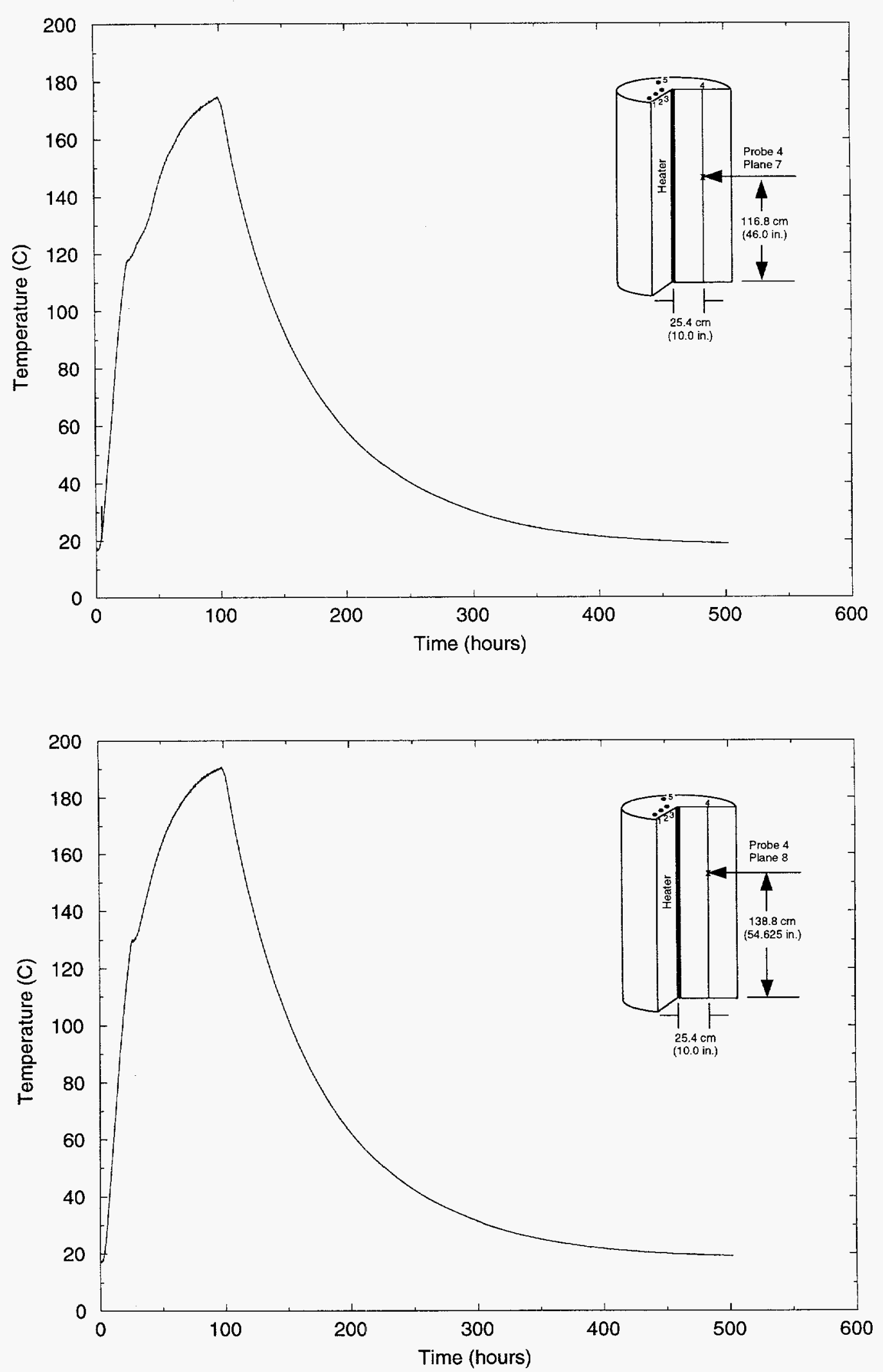

Figure A-7. Test 1 Temperature Data (continued) 

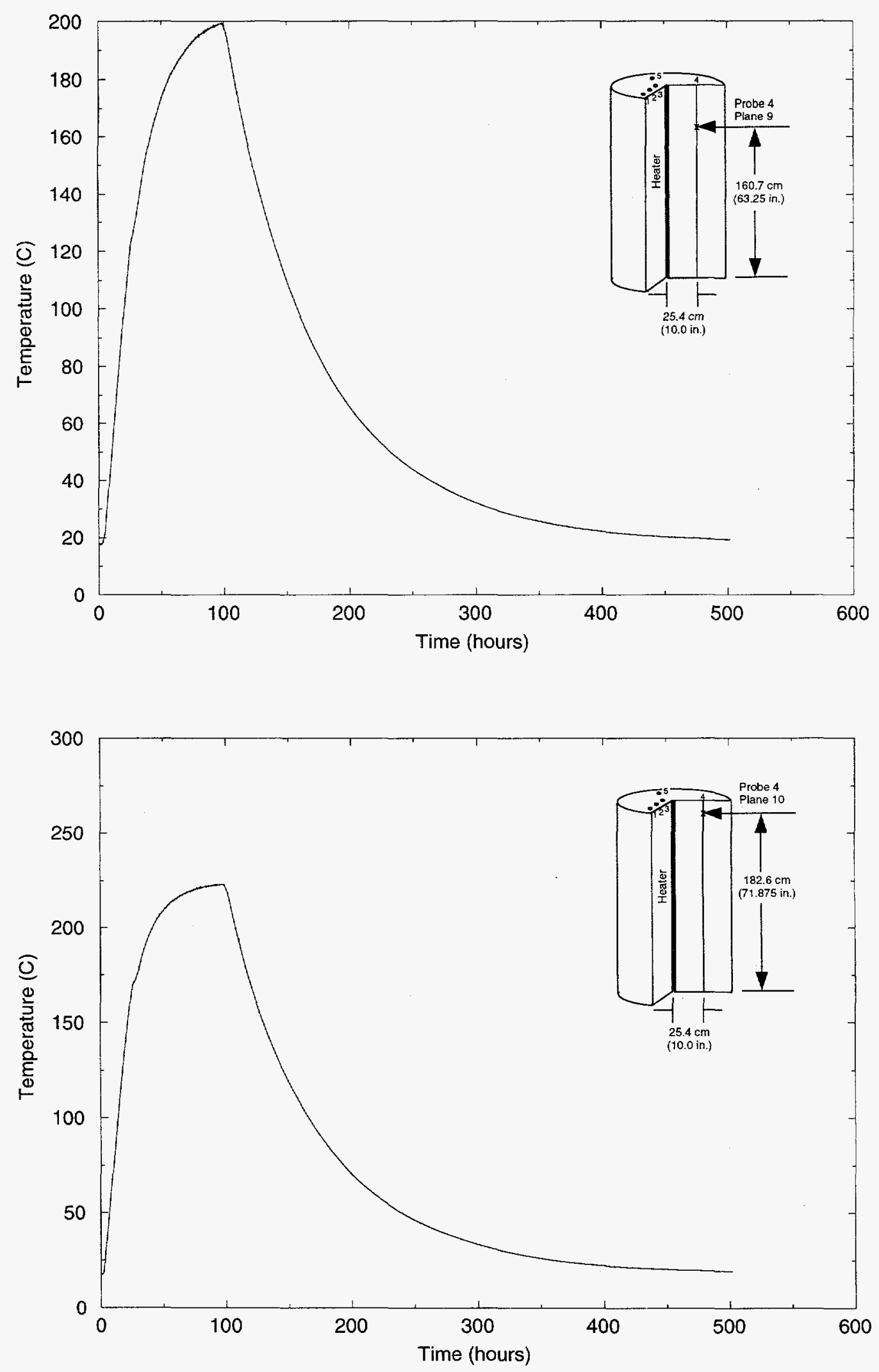

Figure A-7. Test 1 Temperature Data (continued) 

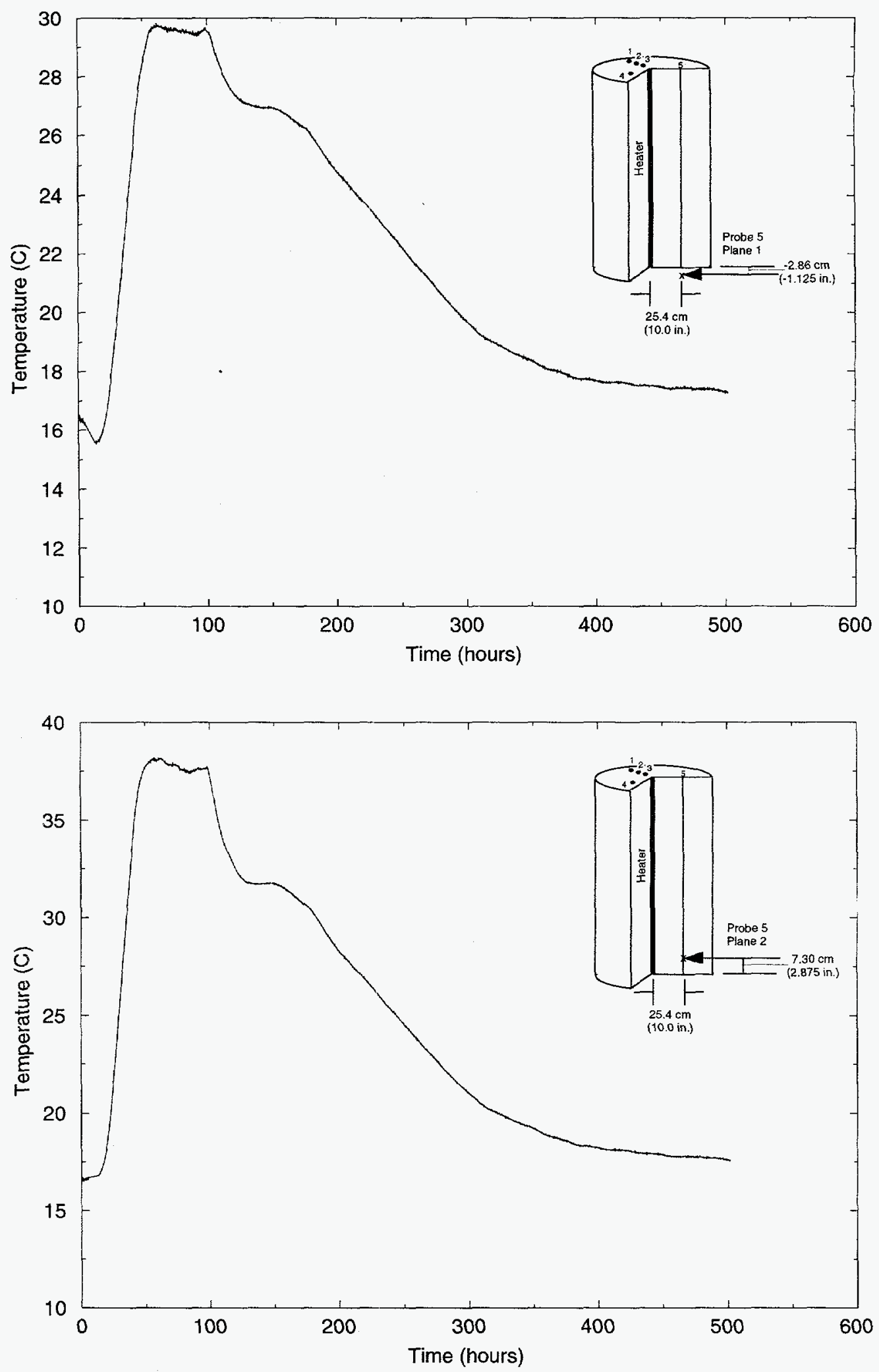

Figure A-7. Test 1 Temperature Data (continued) 

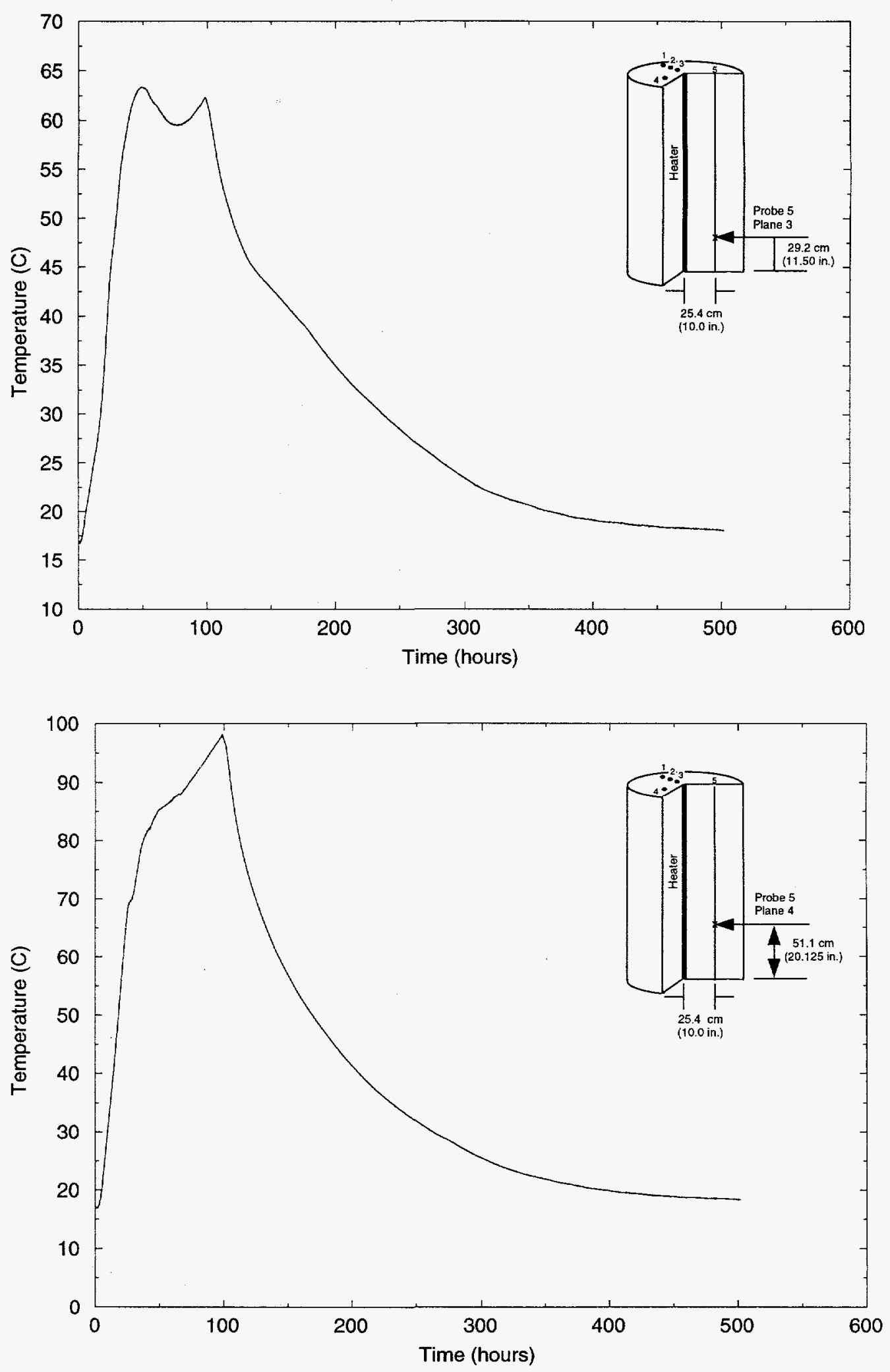

Figure A-7. Test 1 Temperature Data (continued) 

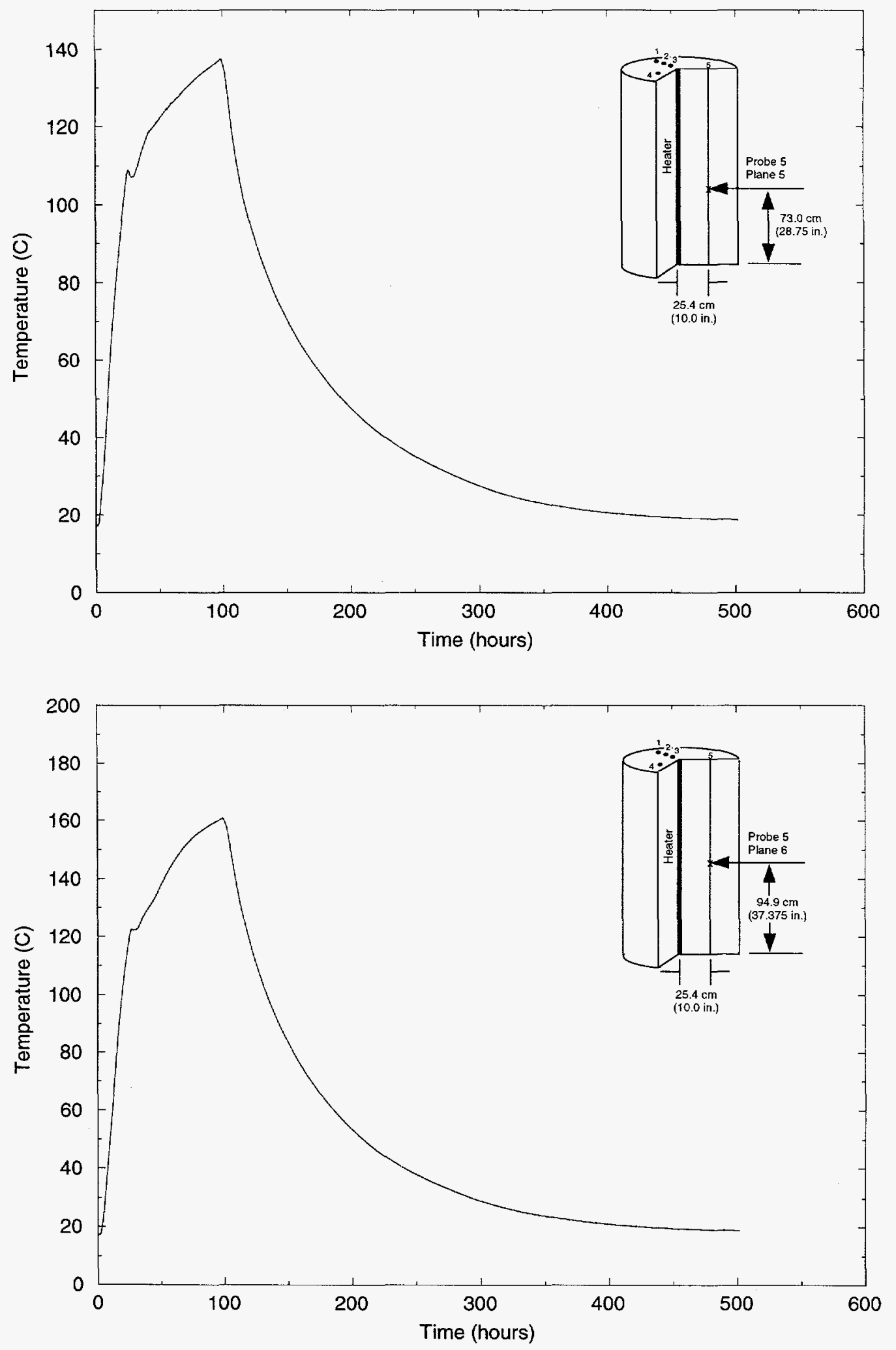

Figure A-7. Test 1 Temperature Data (continued) 

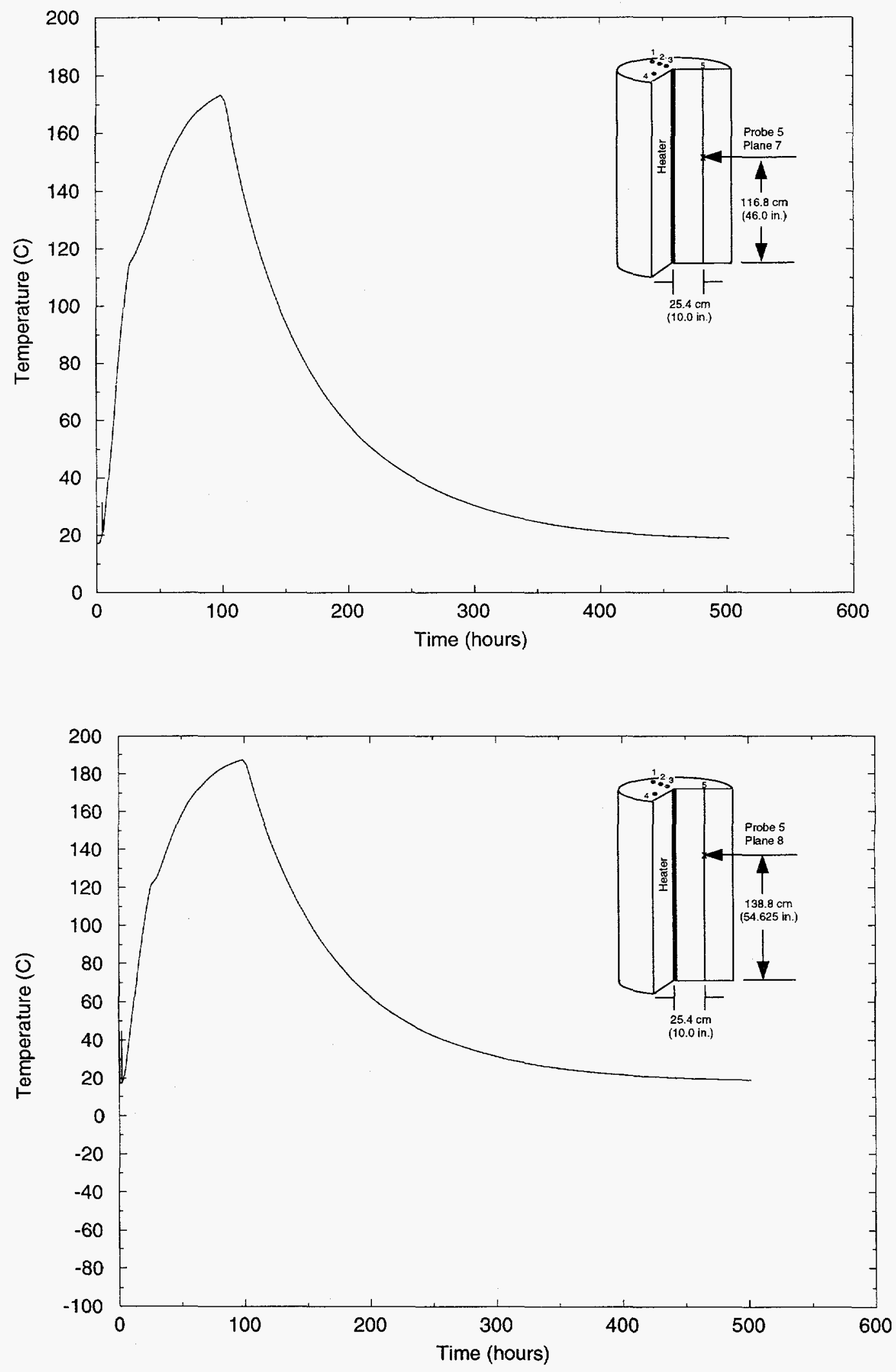

Figure A-7. Test 1 Temperature Data (continued) 

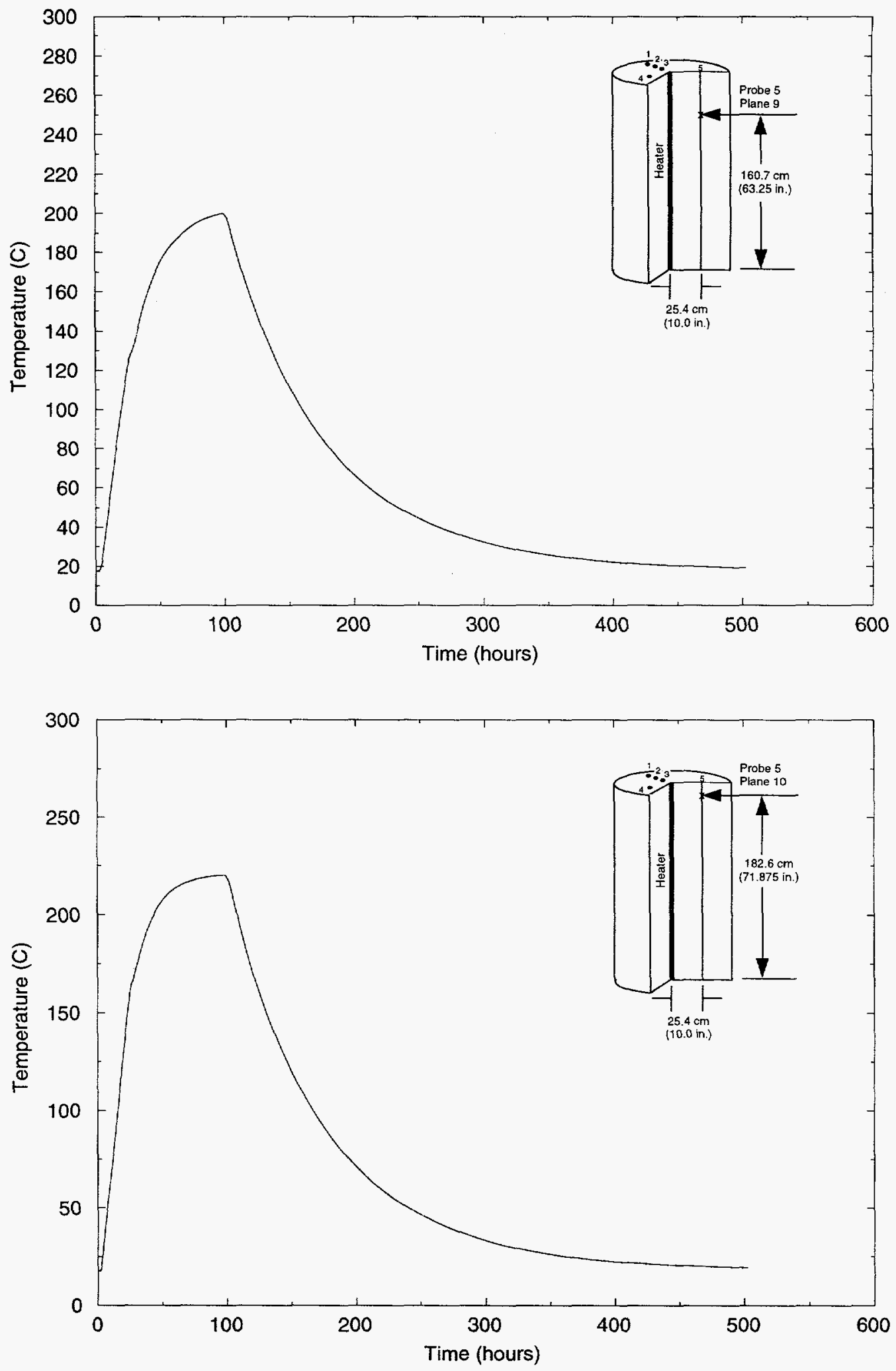

Figure A-7. Test 1 Temperature Data (continued) 

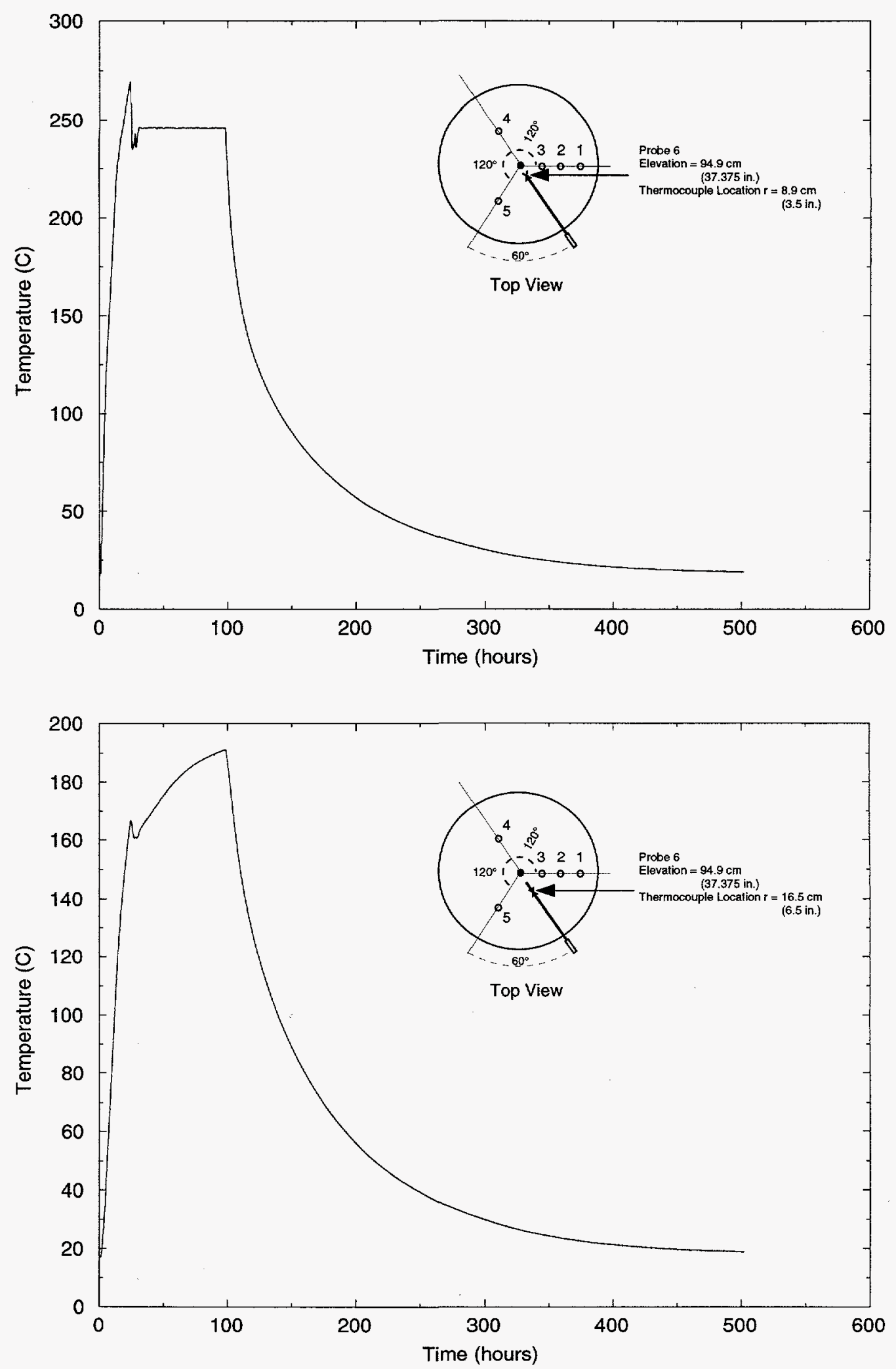

Figure A-7. Test 1 Temperature Data (continued) 

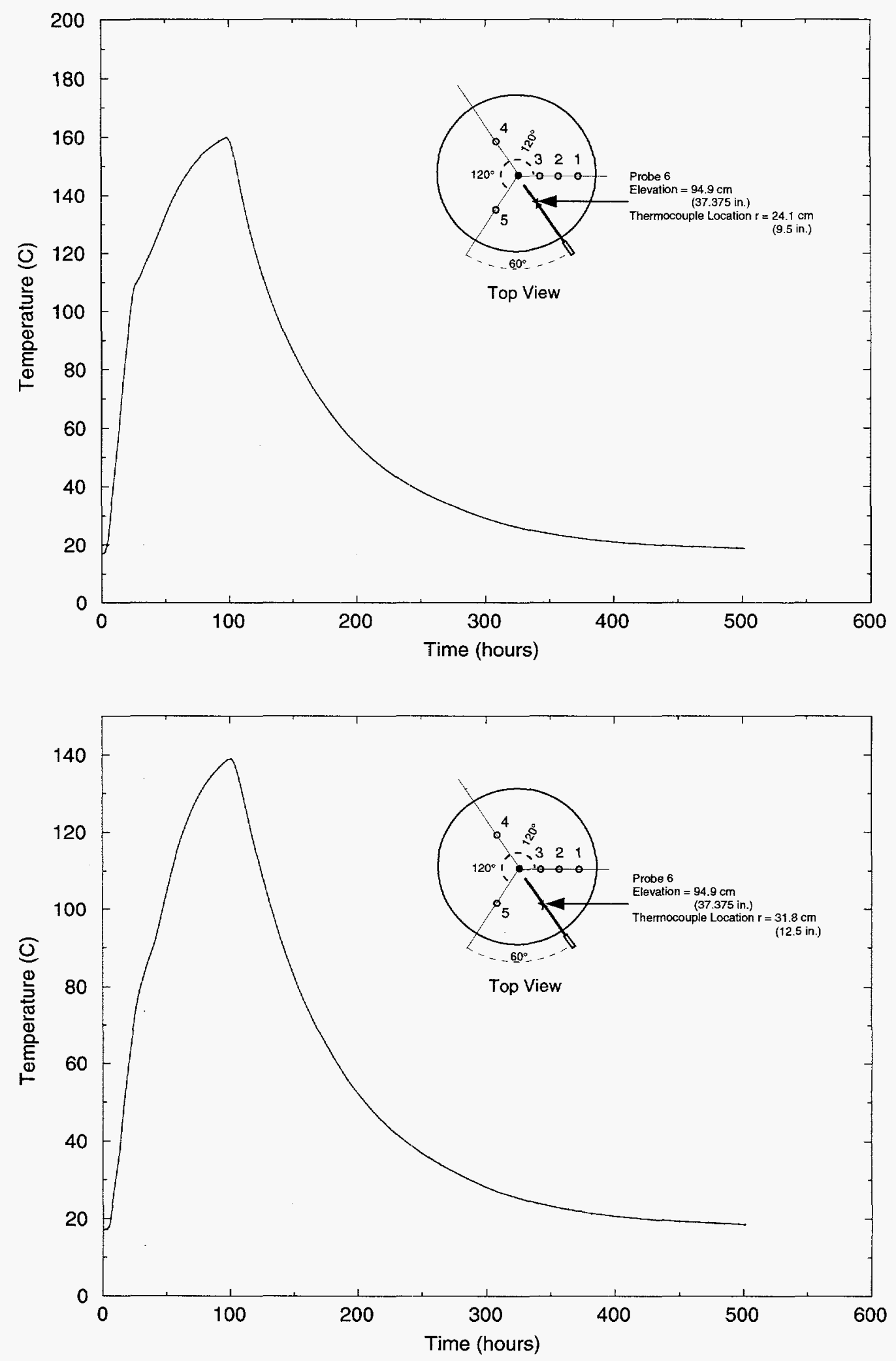

Figure A-7. Test 1 Temperature Data (continued) 

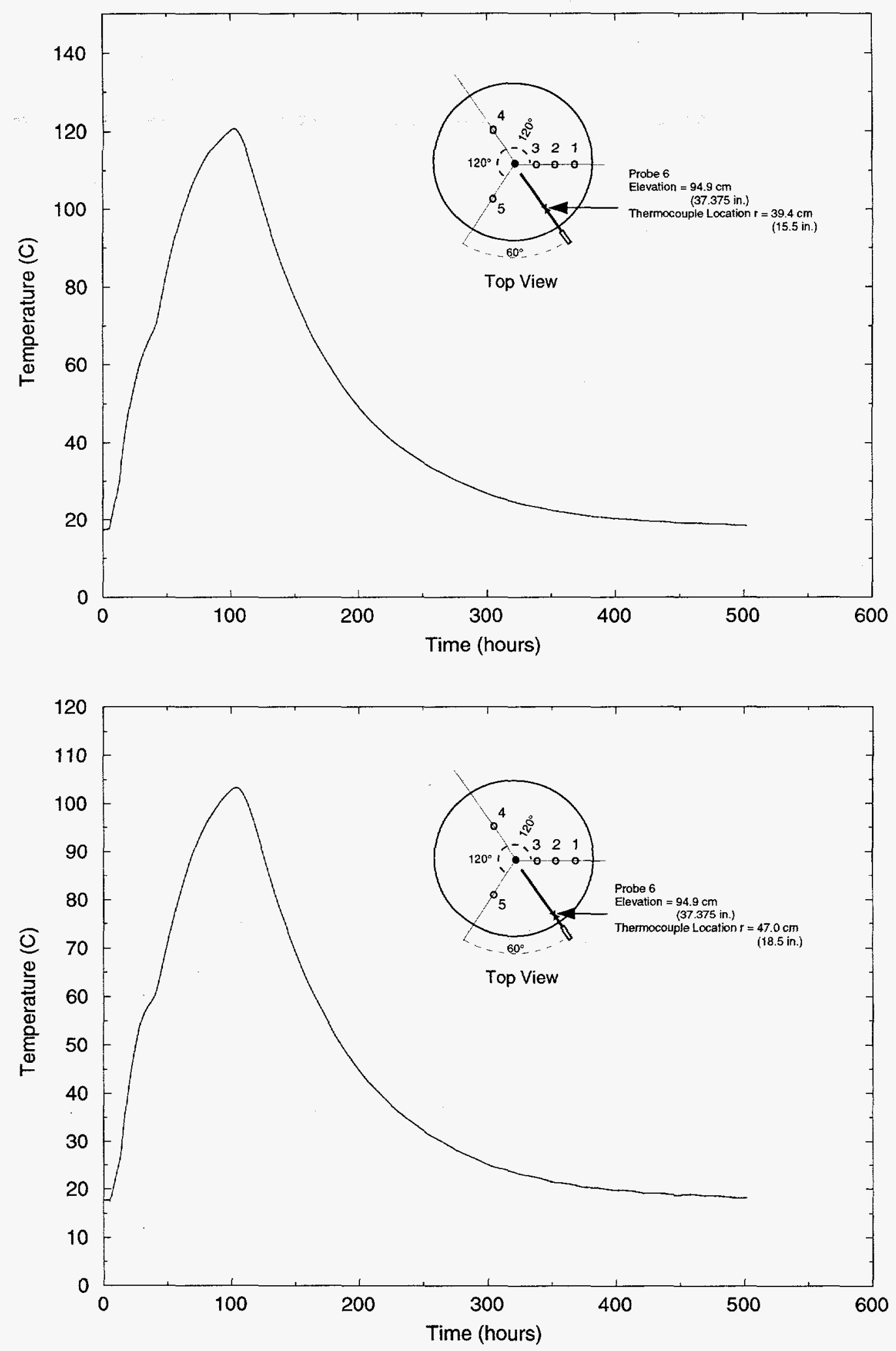

Figure A-7. Test 1 Temperature Data (continued) 

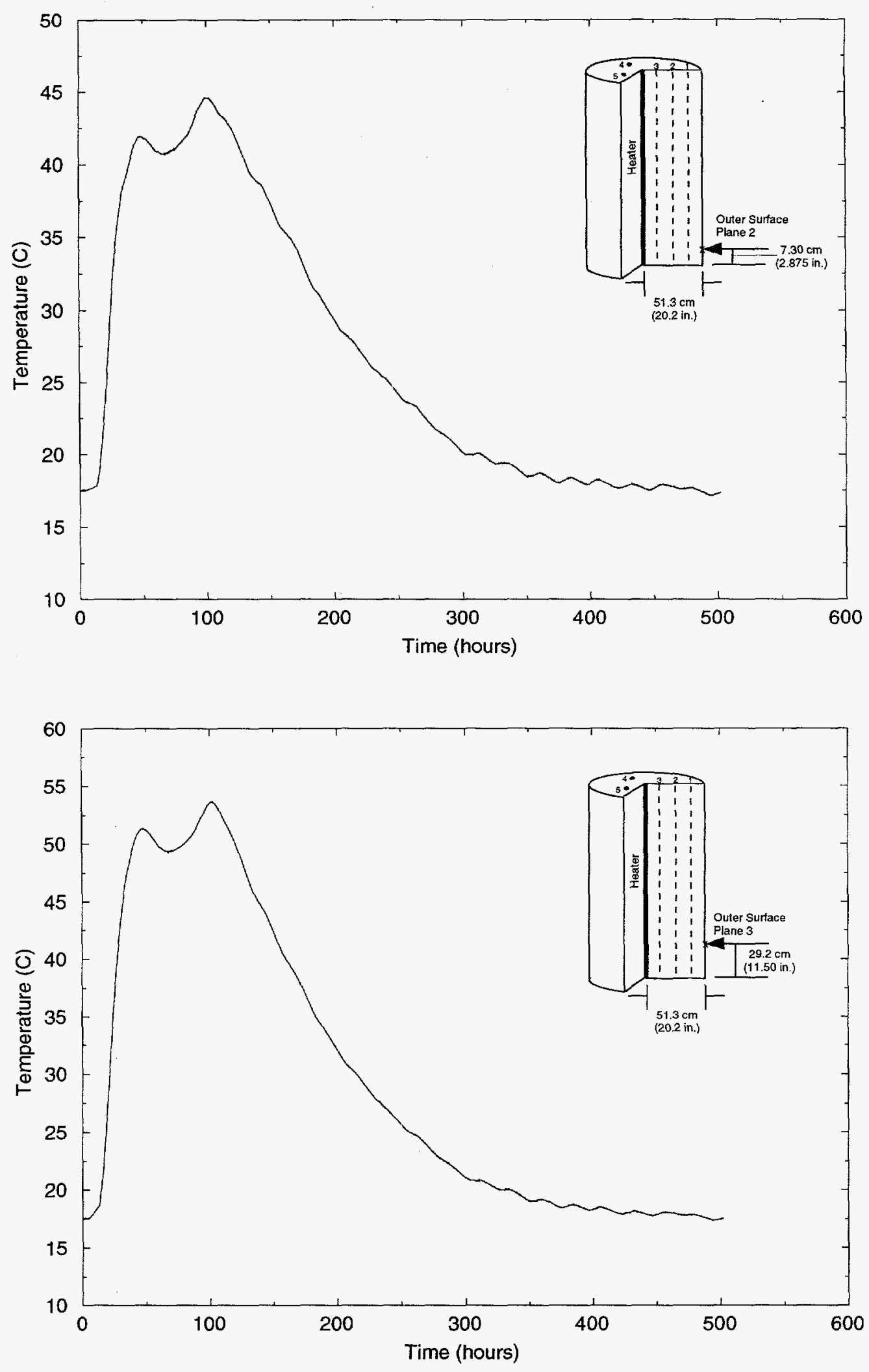

Figure A-7. Test 1 Temperature Data (continued) 

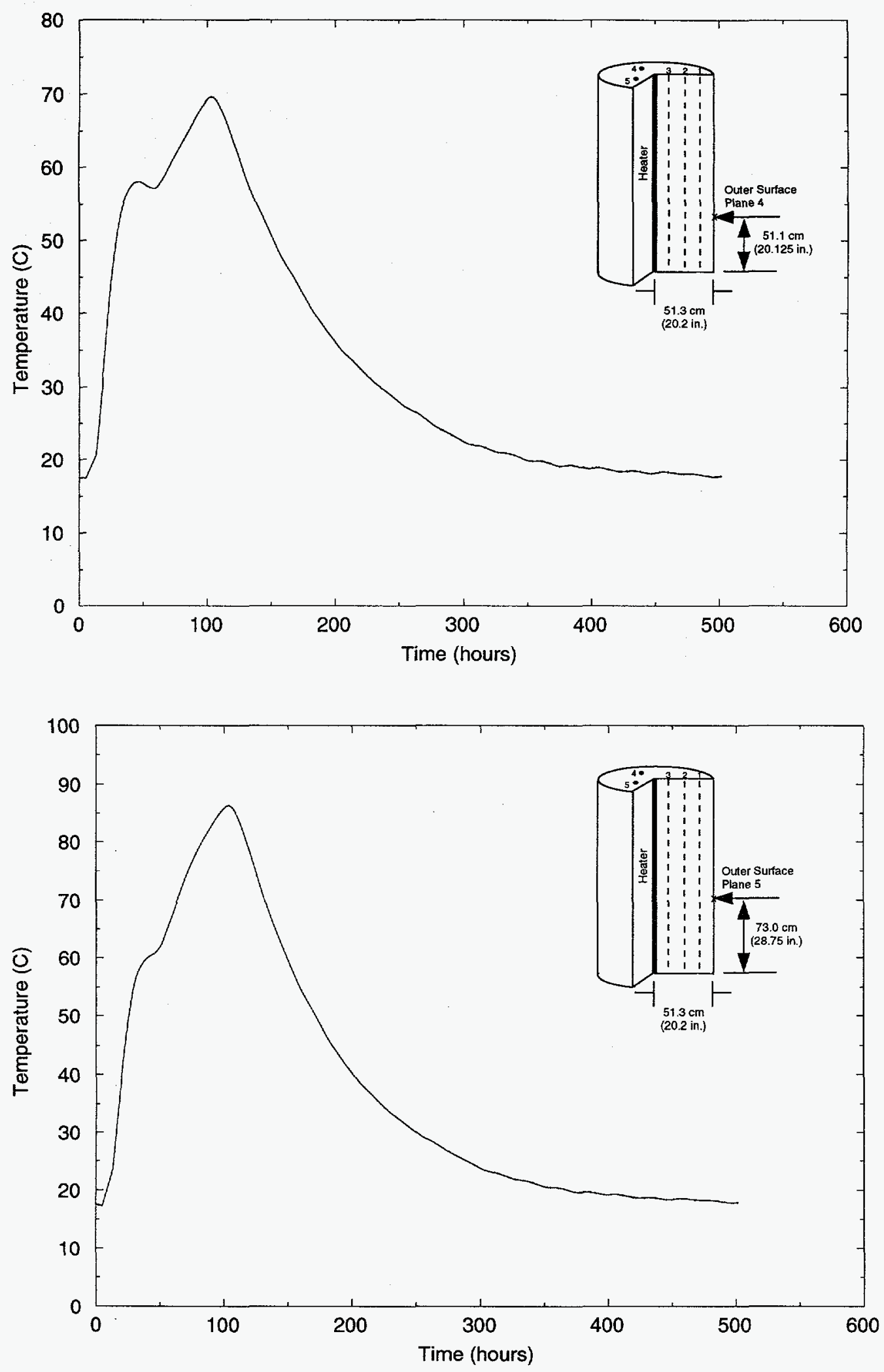

Figure A-7. Test 1 Temperature Data (continued) 

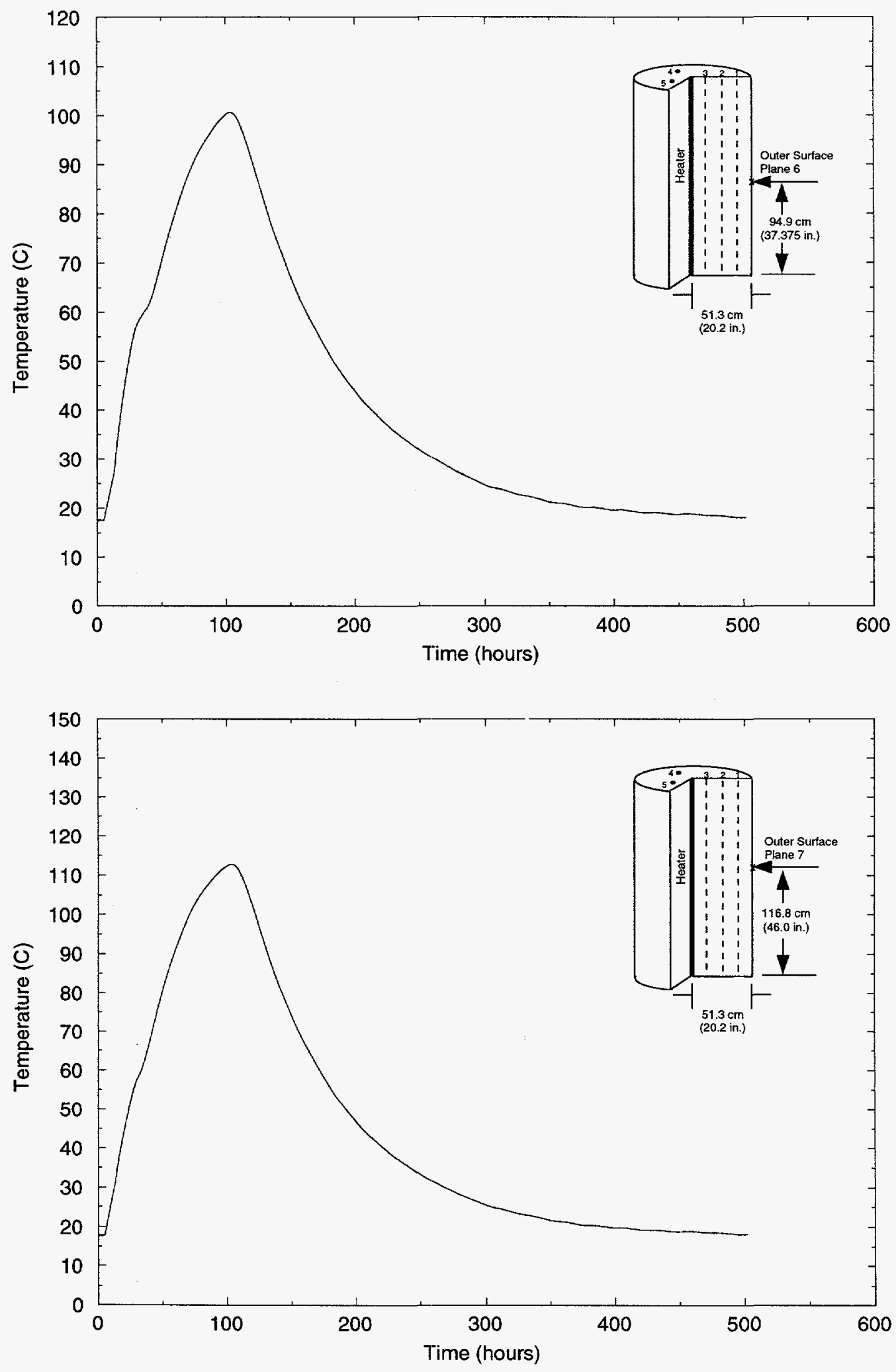

Figure A-7. Test 1 Temperature Data (continued) 

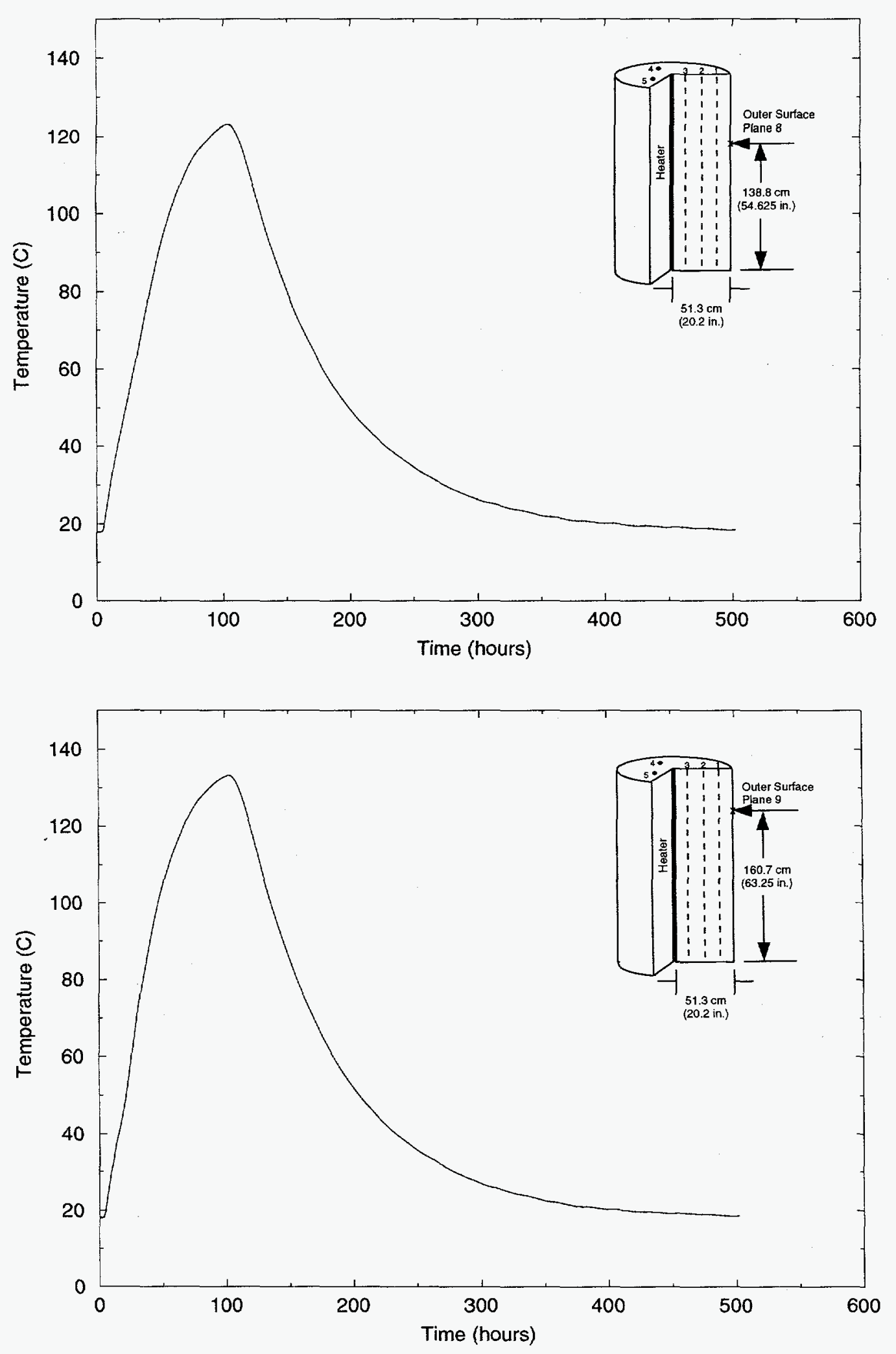

Figure A-7. Test 1 Temperature Data (continued) 

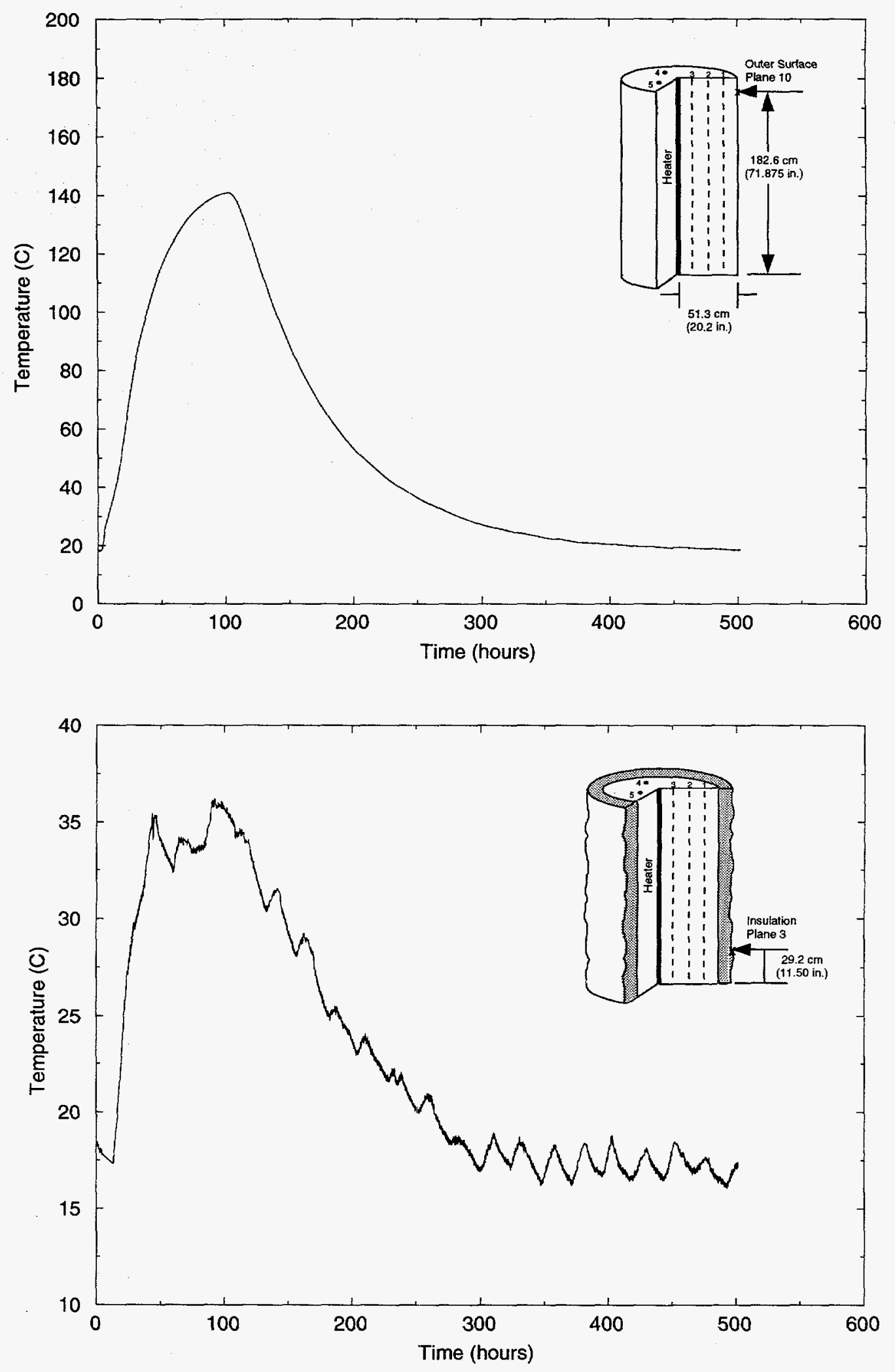

Figure A-7. Test 1 Temperature Data (continued) 

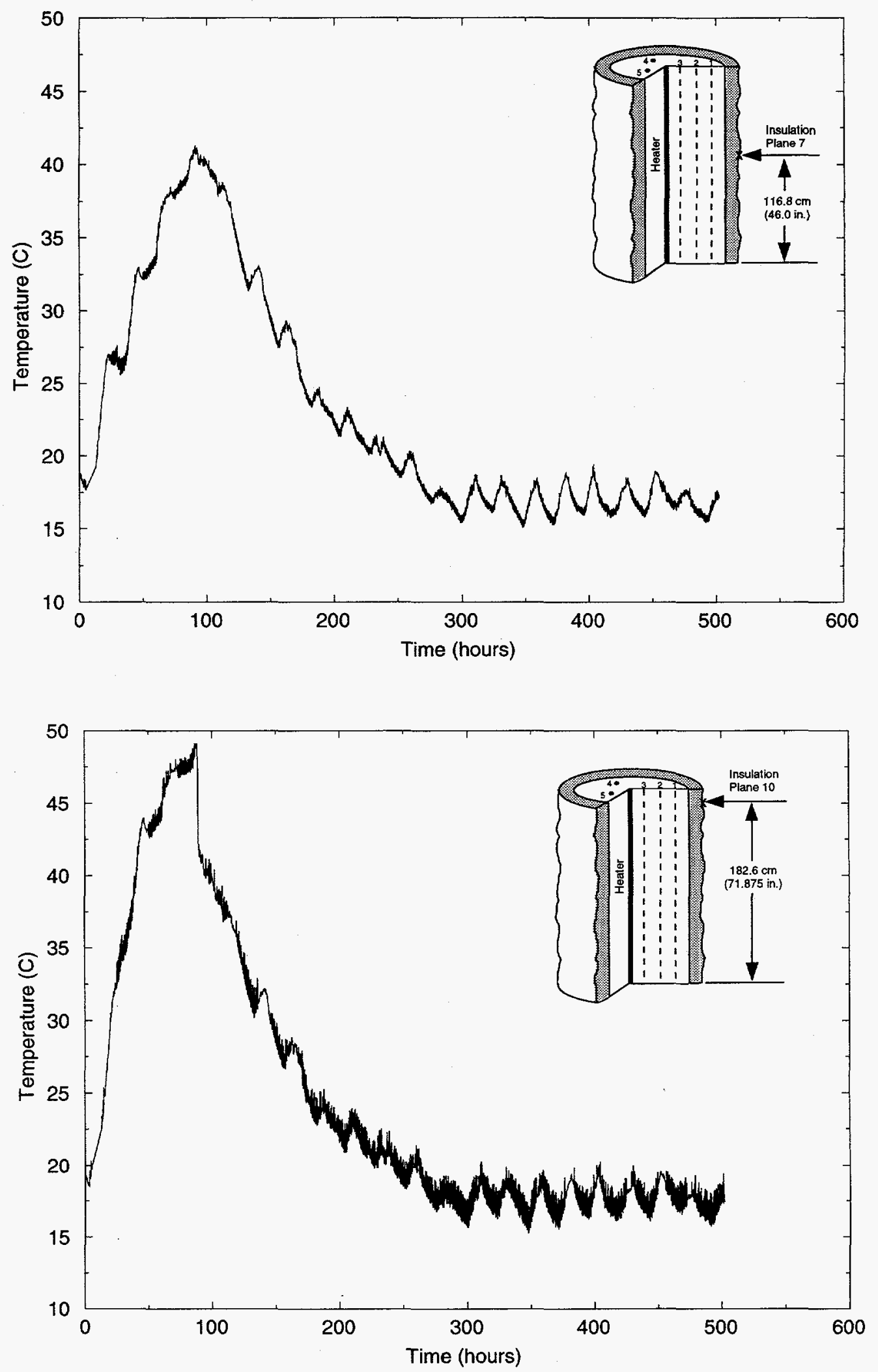

Figure A-7. Test 1 Temperature Data (continued) 


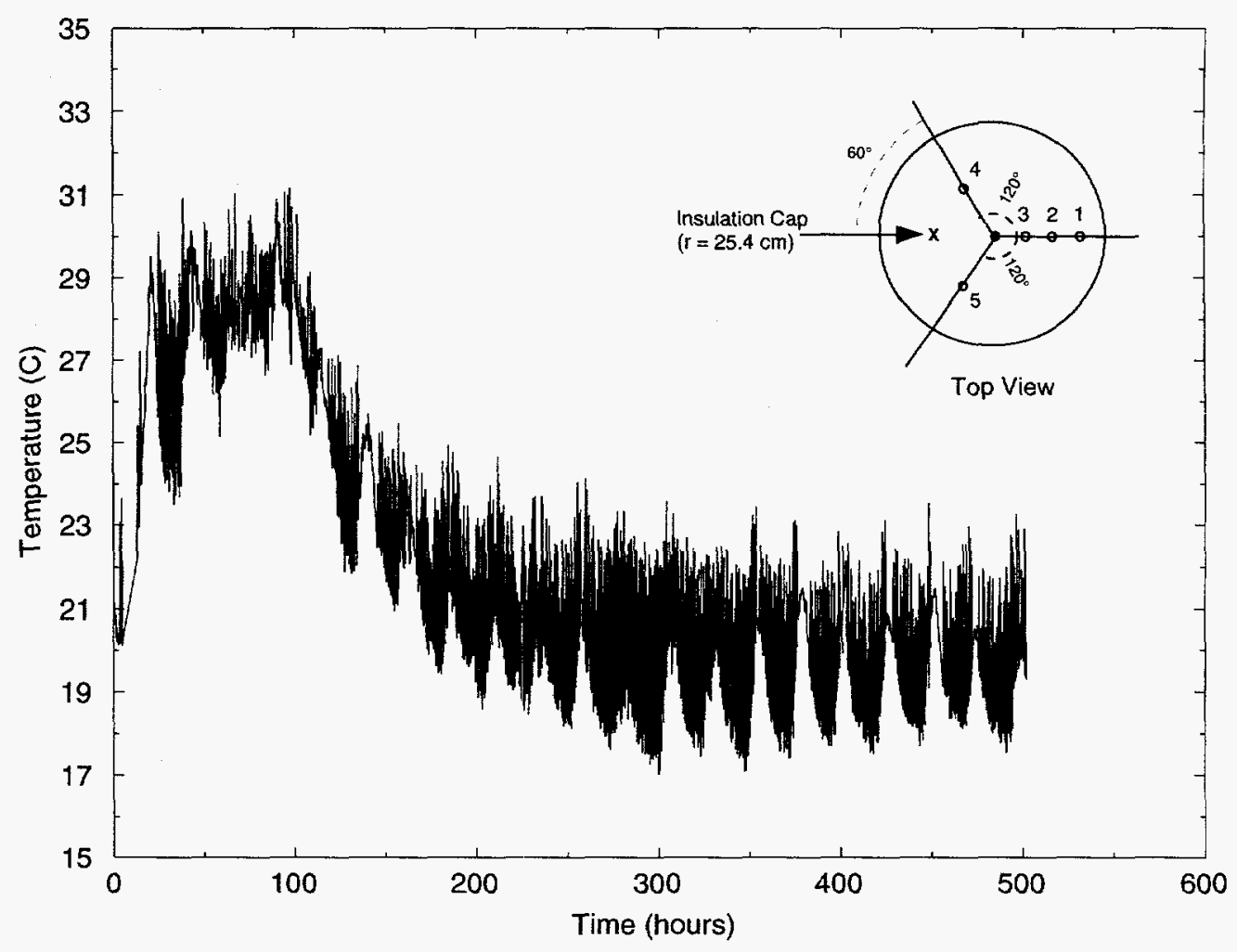

Figure A-7. Test 1 Temperature Data (concluded) 


\section{APPENDIX B}

\section{Test 2 Data}

Included in this appendix are data obtained during Test 2. Test 2 was initiated on April 5, 1994 and terminated April 15, 1994. The total duration of Test 2 was 237 hours and 24 minutes. Prior to a presentation of the complete power and temperature data for Test 2, data which directly support modeling assumptions are presented.

\section{B.1 AXISYMMETRIC CONDITIONS}

One of the fundamental assumptions in all of the post-test analyses presented in Chapter 4 is that axisymmetric thermal response existed within the test apparatus. As indicated in Chapter 3, Probes 4 and 5 were installed to confirm the validity of this assumption. Probes 4 and 5 were installed at the same radial distance from the heater, $120^{\circ}$ apart. Figure B-1 presents comparisons of the Probe 4 and Probe 5 responses for the ten measurement planes defined in Figure 3-5. Table B-1 documents the maximum and average differences in temperature readings between Probes 4 and 5. Based on the data from Probes 4 and 5, it appears that axisymmetric conditions did exist within the test apparatus during Test 2 .

\section{B.2 LOWER BOUNDARY CONDITION}

The TOUGH2 simulations presented in Chapter 4 assume that the lower boundary of the test apparatus is adequately represented by a constant temperature of $17^{\circ} \mathrm{C}$. Figure B-2 is a plot of the first 20 hours of data obtained from plane $1(2.90 \mathrm{~cm}$ into the refractory brick base) for all of the axial thermocouple probes. Linear regression of the data results in a lower boundary temperature of $17.1 \pm 0.4^{\circ} \mathrm{C}$. This is consistent with the assumed TOUGH2 boundary condition. 


\section{B.3 HEATER POWER}

The TOUGH 2 post-test analyses of Test 2 assumed a heater power output of 1840 $\mathrm{W}$ for the first 20 hours of the experiment. Figure B-3 presents the heater power data for the first 20 hours of Test 2 . For Test 2 , full power was applied for the first 11 hours and 34 minutes. Linear regression of the data results in a mean power output of $1839 \mathrm{~W}$ with a standard deviation of $24.4 \mathrm{~W}$. This is consistent with the modeling assumption.

For the remaining power-on period of Test 2 , the silicon controlled rectifier (SCR) modified the current applied to the heater at a rate of 8 times per second. Power data could only be recorded on the order of every 5 seconds. Consequently, much of the power data is not available during the period when the SCR was modifying the current input. Linear regression of the data recorded between 11 hours 34 minutes and 20 hours results in a mean value of $1576 \mathrm{~W}$ with a standard deviation of $576 \mathrm{~W}$. Given that much of the power data is unavailable during the SCR controlled period of the test, it is difficult to make any firm conclusions regarding the potential impact of the TOUGH2 assumption of a constant $1840 \mathrm{~W}$ from the heater. It is likely that the assumption overestimates the actual conditions during the period between 11 hours 34 minutes and 20 hours.

\section{B.4 TEST 2 DATA}

Figures B-4 and B-5 present the complete power and temperature data traces for Test 2 . 
Table B-1. Maximum and Average Temperature Differences Between Probes 4 and 5 for Test 2

\begin{tabular}{|c|c|c|c|c|}
\hline \multirow{2}{*}{ Plane } & \multicolumn{2}{|c|}{$\begin{array}{c}\text { Thermocouple Location } \\
\text { (Probe 4 and Probe 5) }\end{array}$} & Average \\
\cline { 2 - 3 } & $\begin{array}{c}\text { Radial Distance } \\
\text { from Heater } \\
(\mathbf{c m})\end{array}$ & $\begin{array}{c}\text { Elevation from } \\
\text { Brick Base } \\
(\mathbf{c m})\end{array}$ & $\begin{array}{c}\text { Maximum } \\
\text { Temperature } \\
\left.\text { Difference } \text { ( }^{\circ} \mathbf{C}\right)\end{array}$ & $\begin{array}{c}\text { Avemperature } \\
\text { Temference ( }\end{array}$ \\
\hline \hline 1 & 25.4 & -2.90 & 0.66 & 0.34 \\
\hline 2 & 25.4 & 7.30 & 0.49 & 0.19 \\
\hline 3 & 25.4 & 29.2 & 0.44 & 0.16 \\
\hline 4 & 25.4 & 51.1 & 4.32 & 0.54 \\
\hline 5 & 25.4 & 73.0 & 5.44 & 0.92 \\
\hline 6 & 25.4 & 94.9 & 17.7 & 2.17 \\
\hline 7 & 25.4 & 116.8 & 3.61 & 0.54 \\
\hline 8 & 25.4 & 138.8 & 8.64 & 1.22 \\
\hline 9 & 25.4 & 160.7 & 2.67 & 0.50 \\
\hline 10 & 25.4 & 182.6 & 11.5 & 1.54 \\
\hline
\end{tabular}



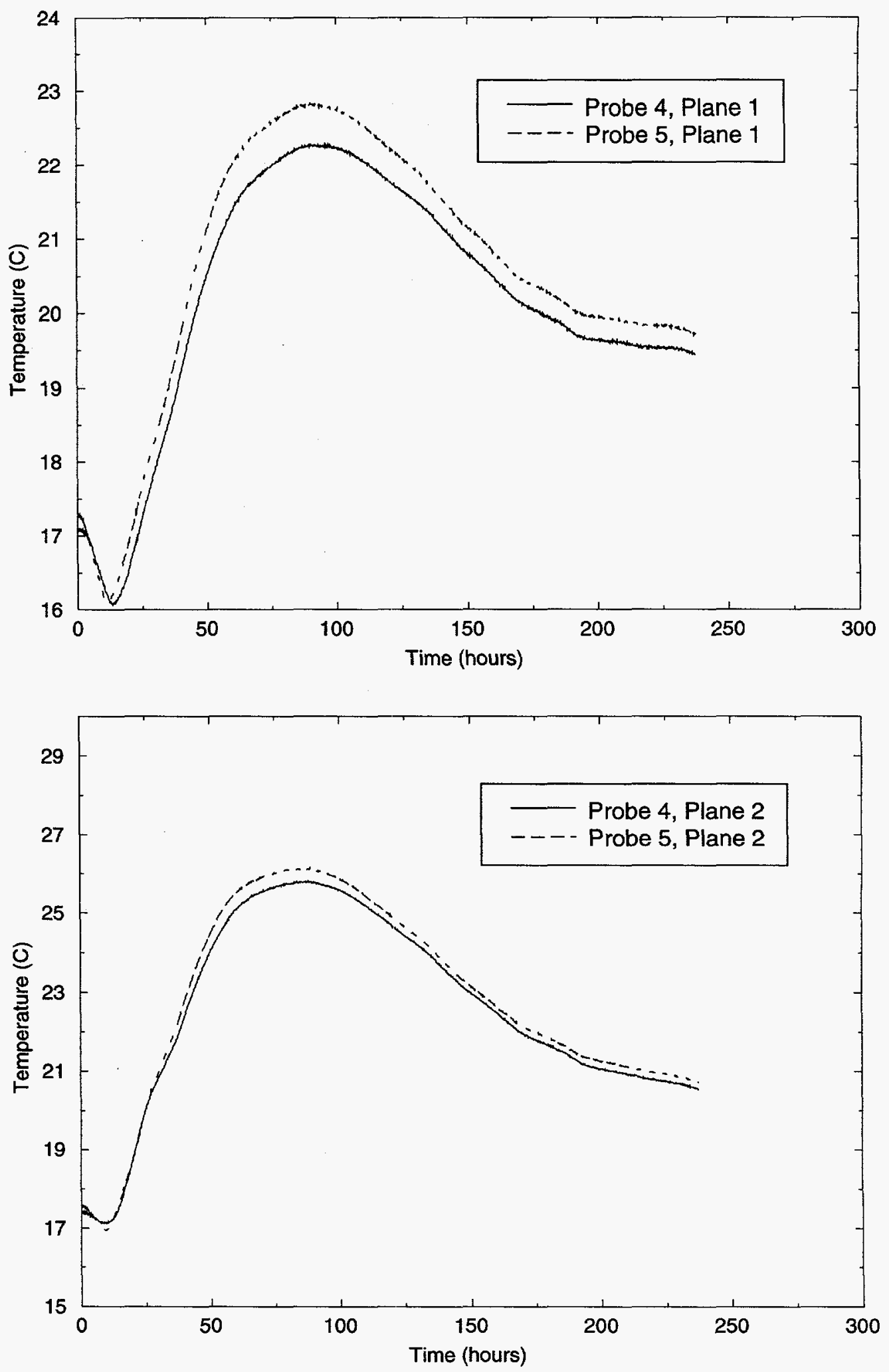

Figure B-1. Comparison of Data from Probes 4 and 5 for Test 2 

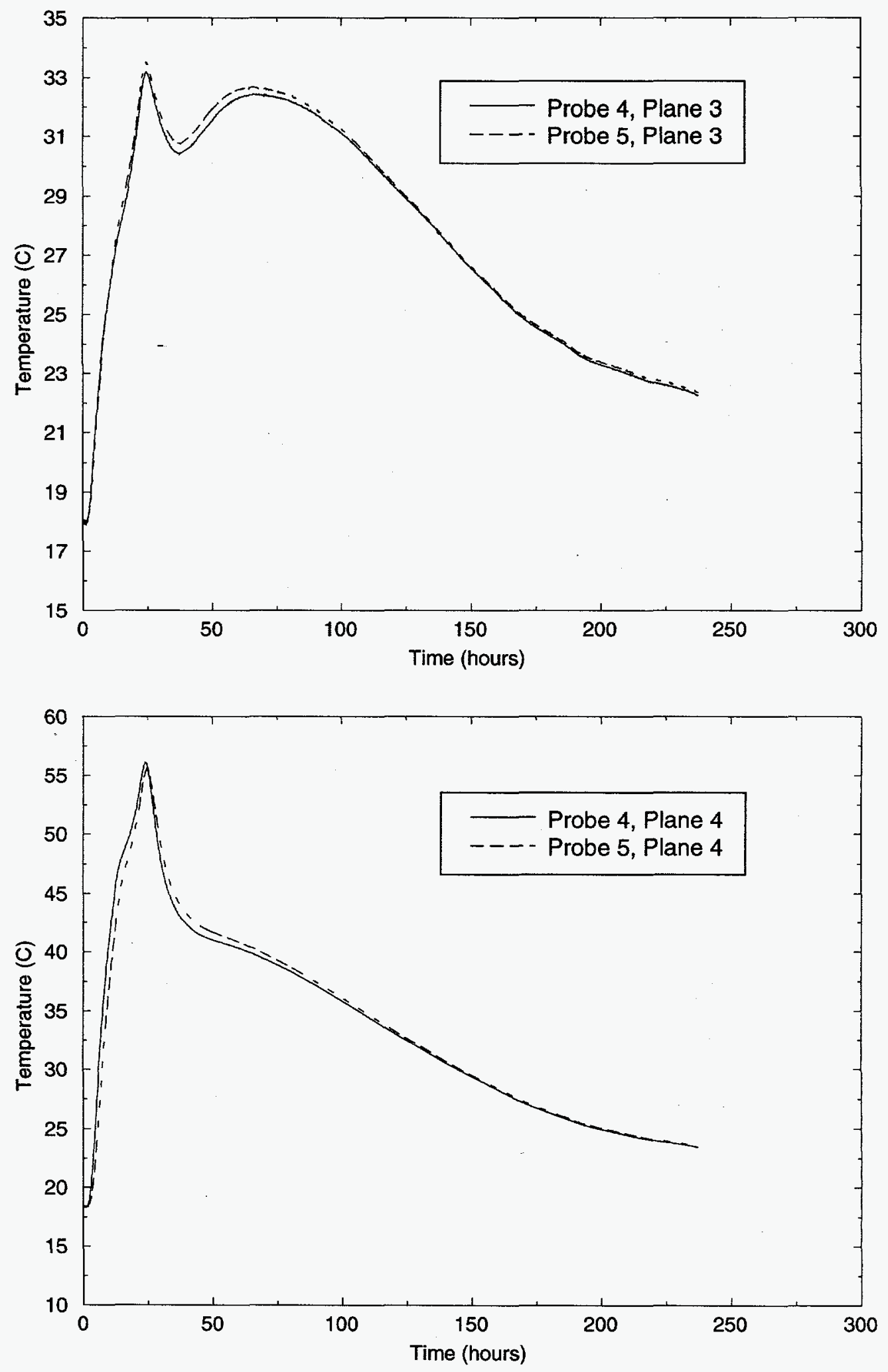

Figure B-1. Comparison of Data from Probes 4 and 5 for Test 2 (continued) 

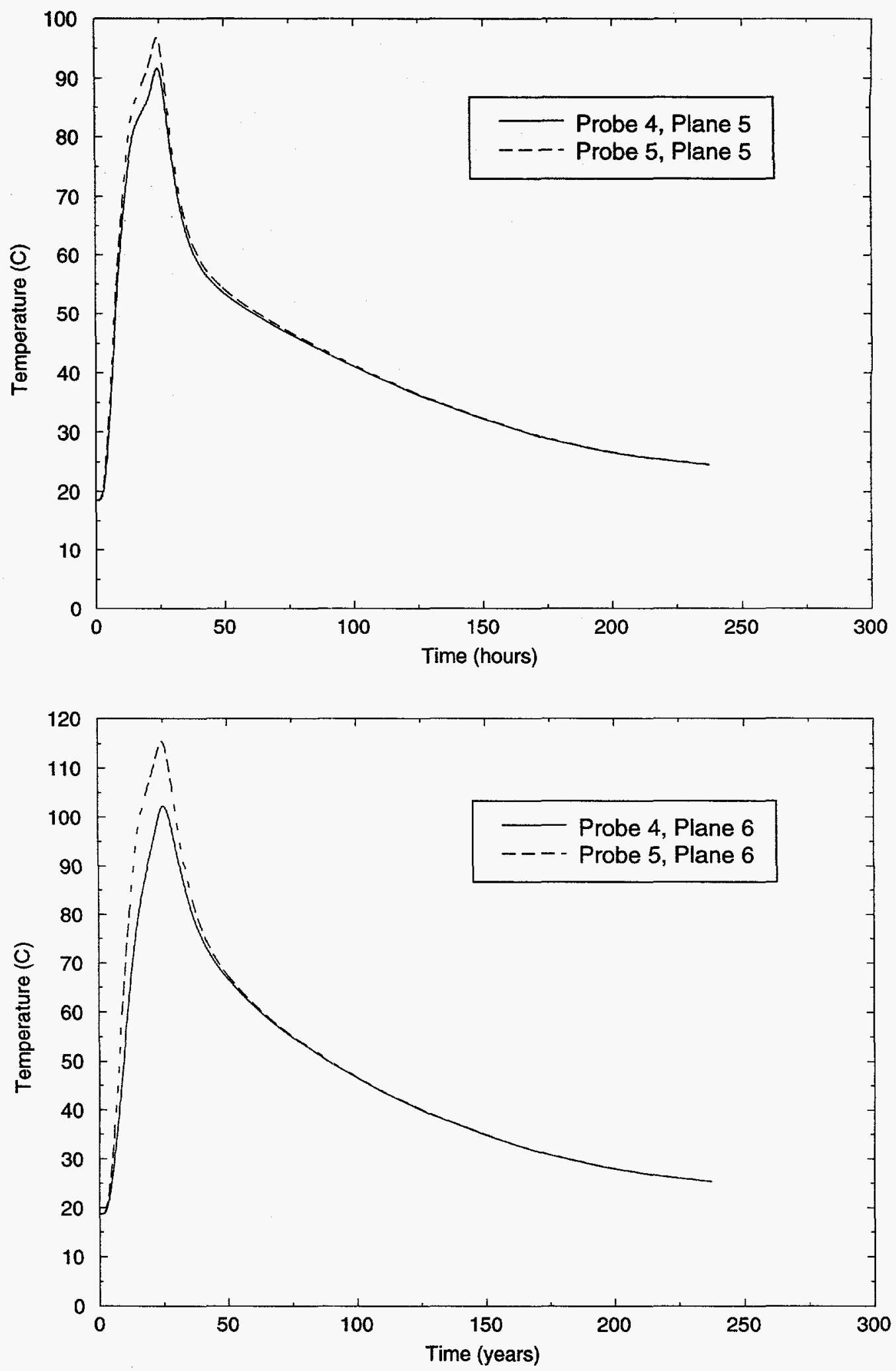

Figure B-1. Comparison of Data from Probes 4 and 5 for Test 2 (continued) 

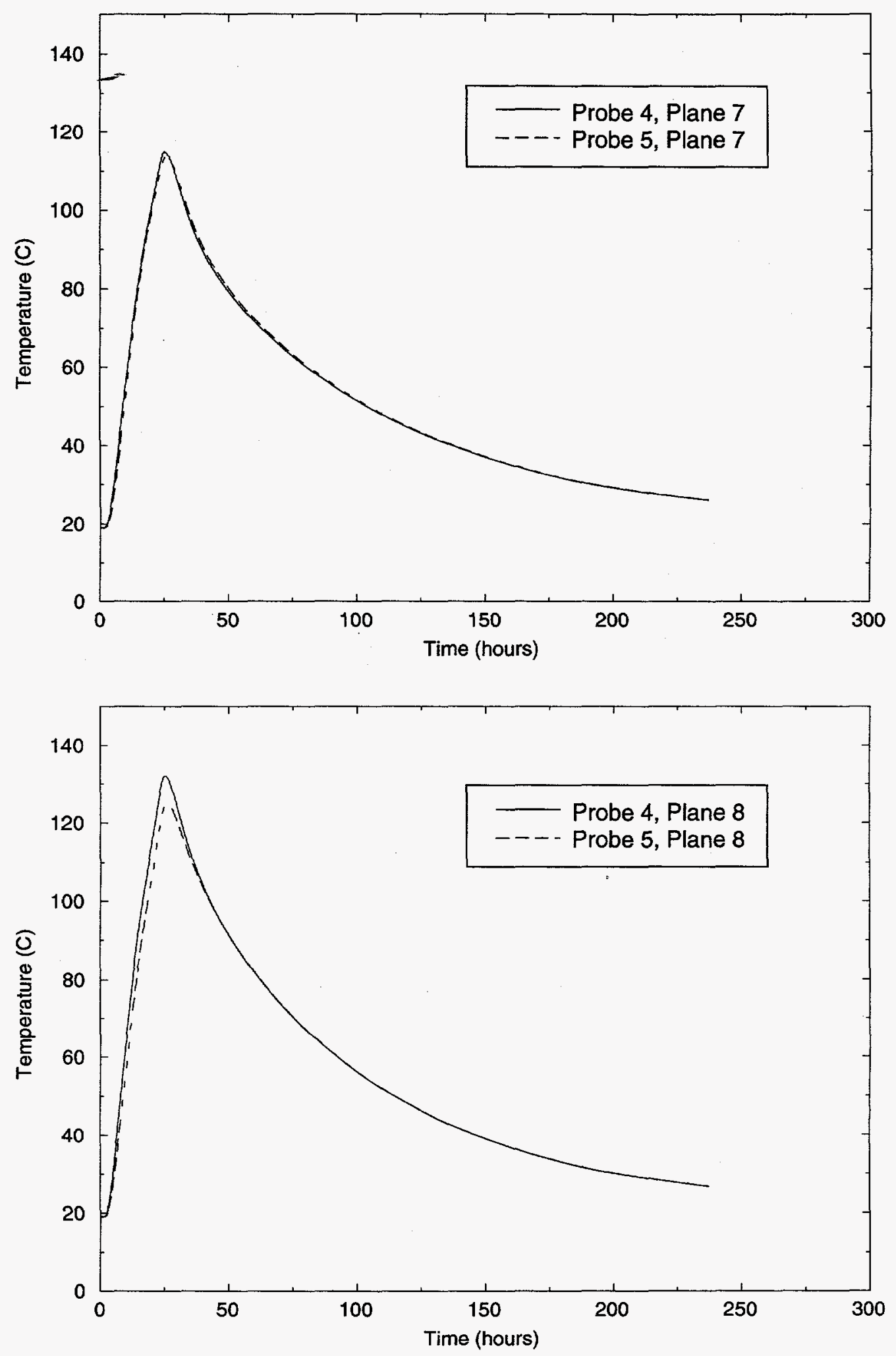

Figure B-1. Comparison of Data from Probes 4 and 5 for Test 2 (continued) 

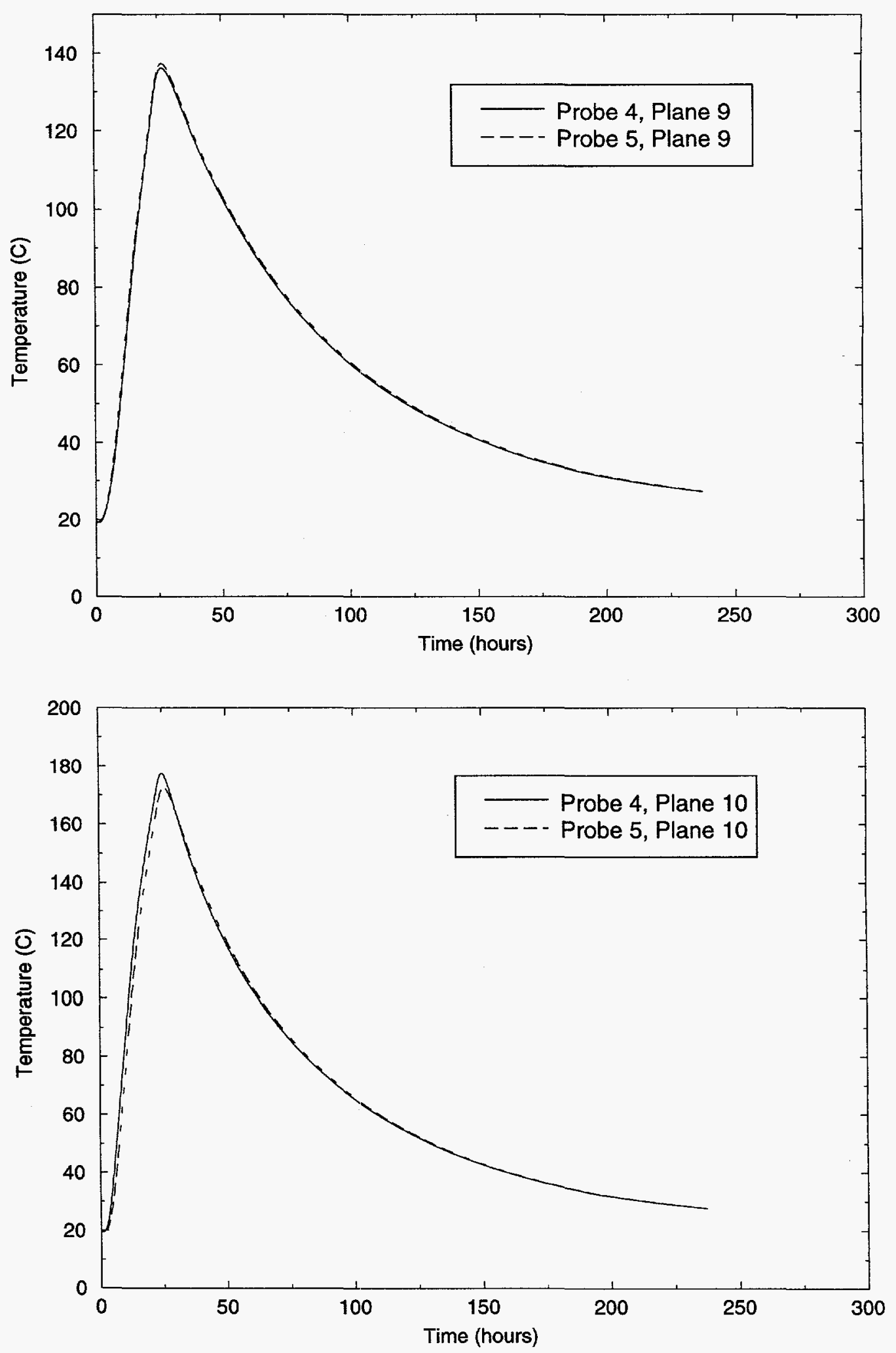

Figure B-1. Comparison of Data from Probes 4 and 5 for Test 2 (concluded) 


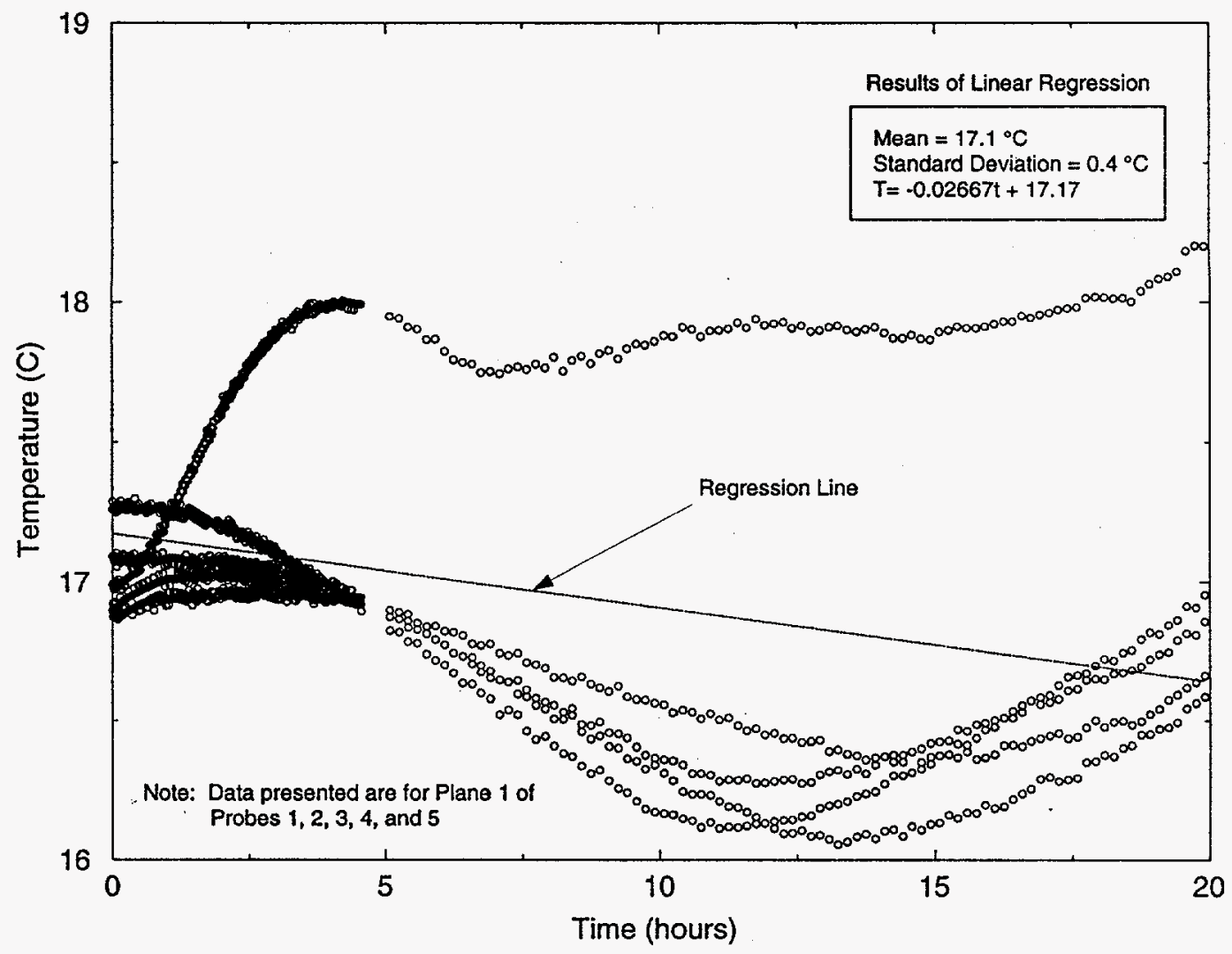

Figure B-2. Data Related to Lower Boundary Condition Modeled in TOUGH2 Analyses

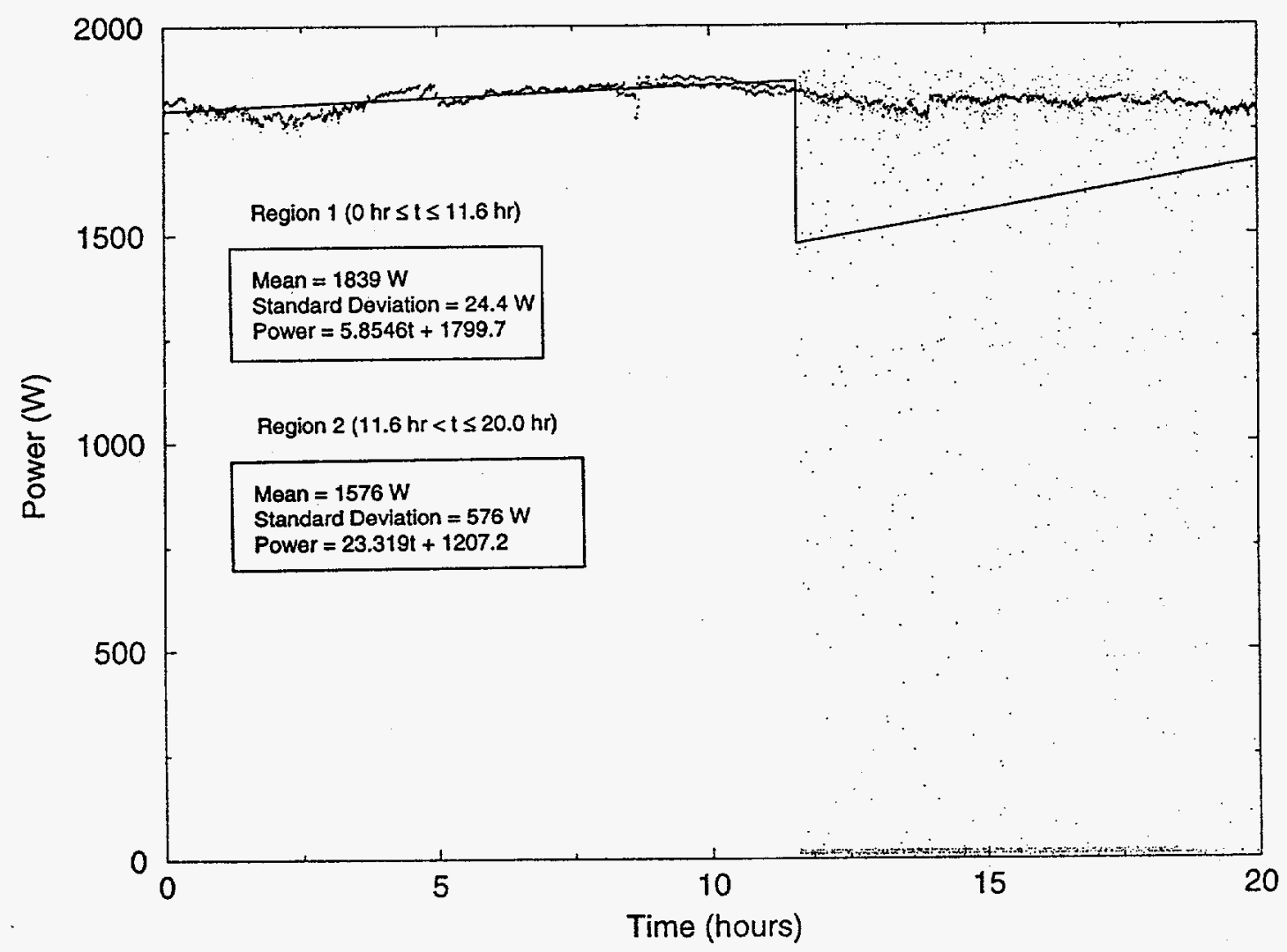

Figure B-3. Power Data for First 20 Hours of Test 2 


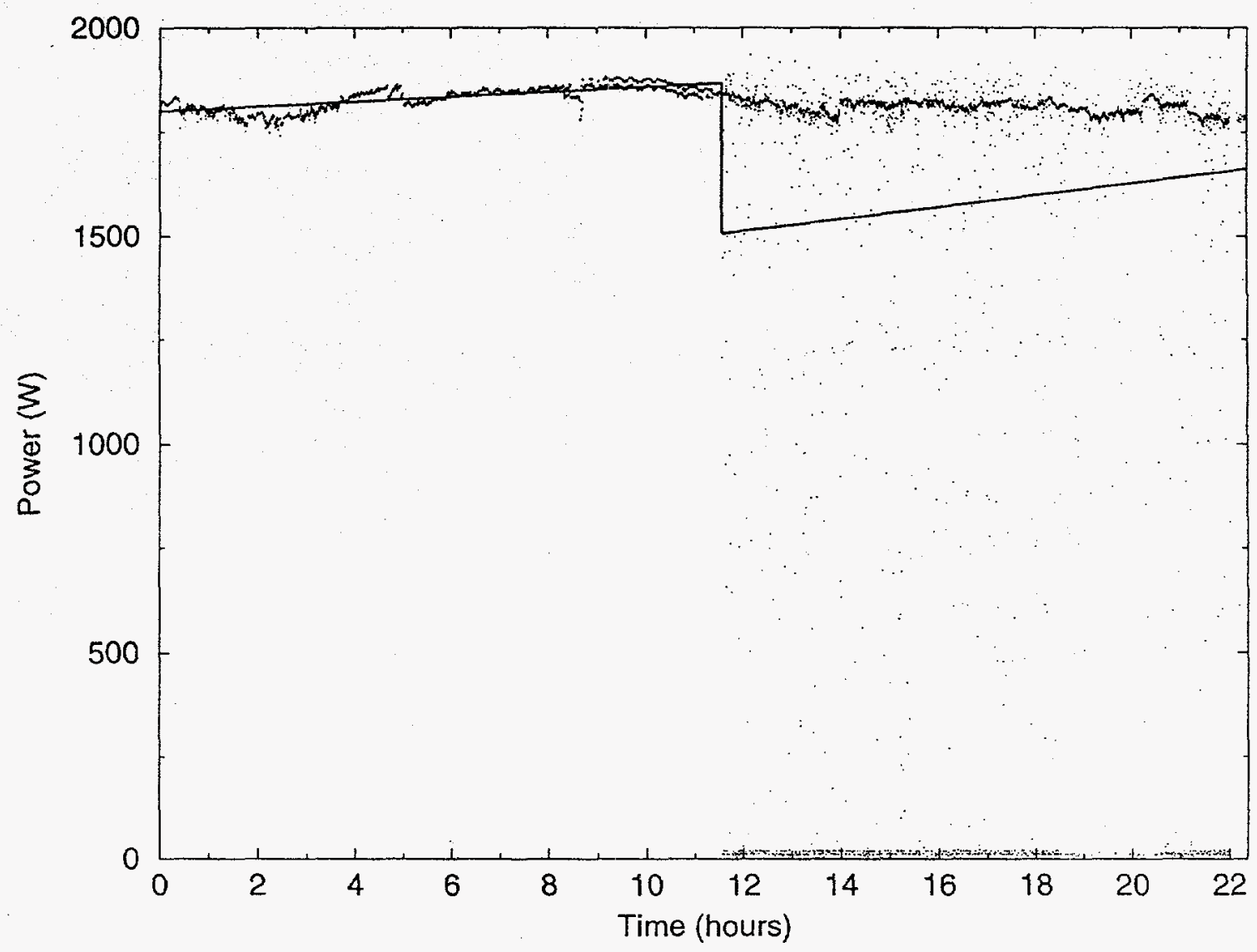

Region $\mathrm{f}(\mathrm{ohr} \leq \mathrm{t} \leq 11.6 \mathrm{hr})$

Region $2(11.6 \mathrm{hr}<\mathrm{t} \leq 22.4 \mathrm{hr})$

Mean $=1839 \mathrm{~W}$

Standard Deviation $=24.4 \mathrm{~W}$

Mean $=1582 \mathrm{~W}$

Standard Deviation $=568 \mathrm{~W}$

Power $=5.8546 t+1799.7$

Power $=14.352 t+1341.0$

Figure B-4. Complete Power Data for Test 2 

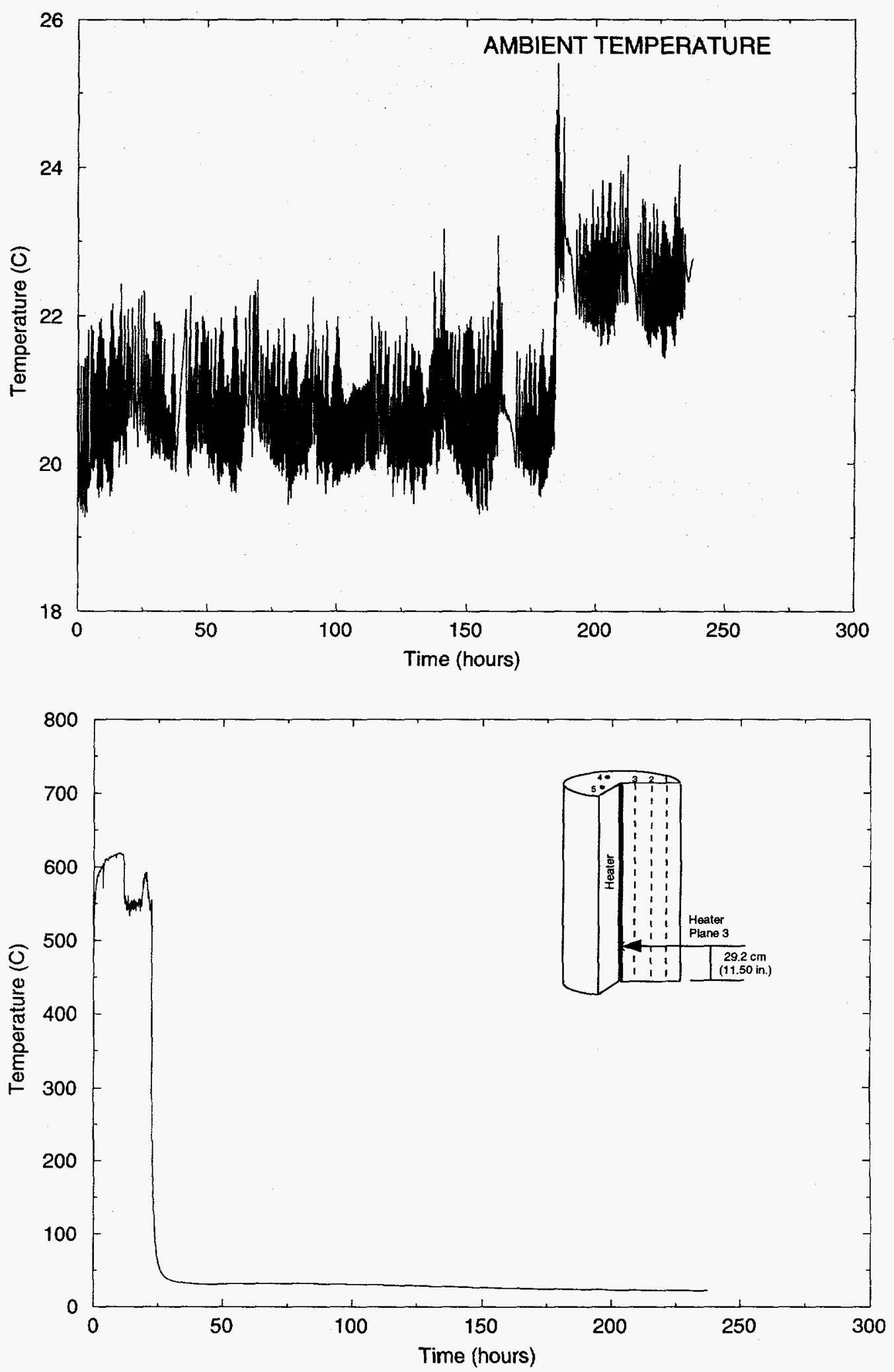

Figure B-5. Test 2 Temperature Data

B-11 

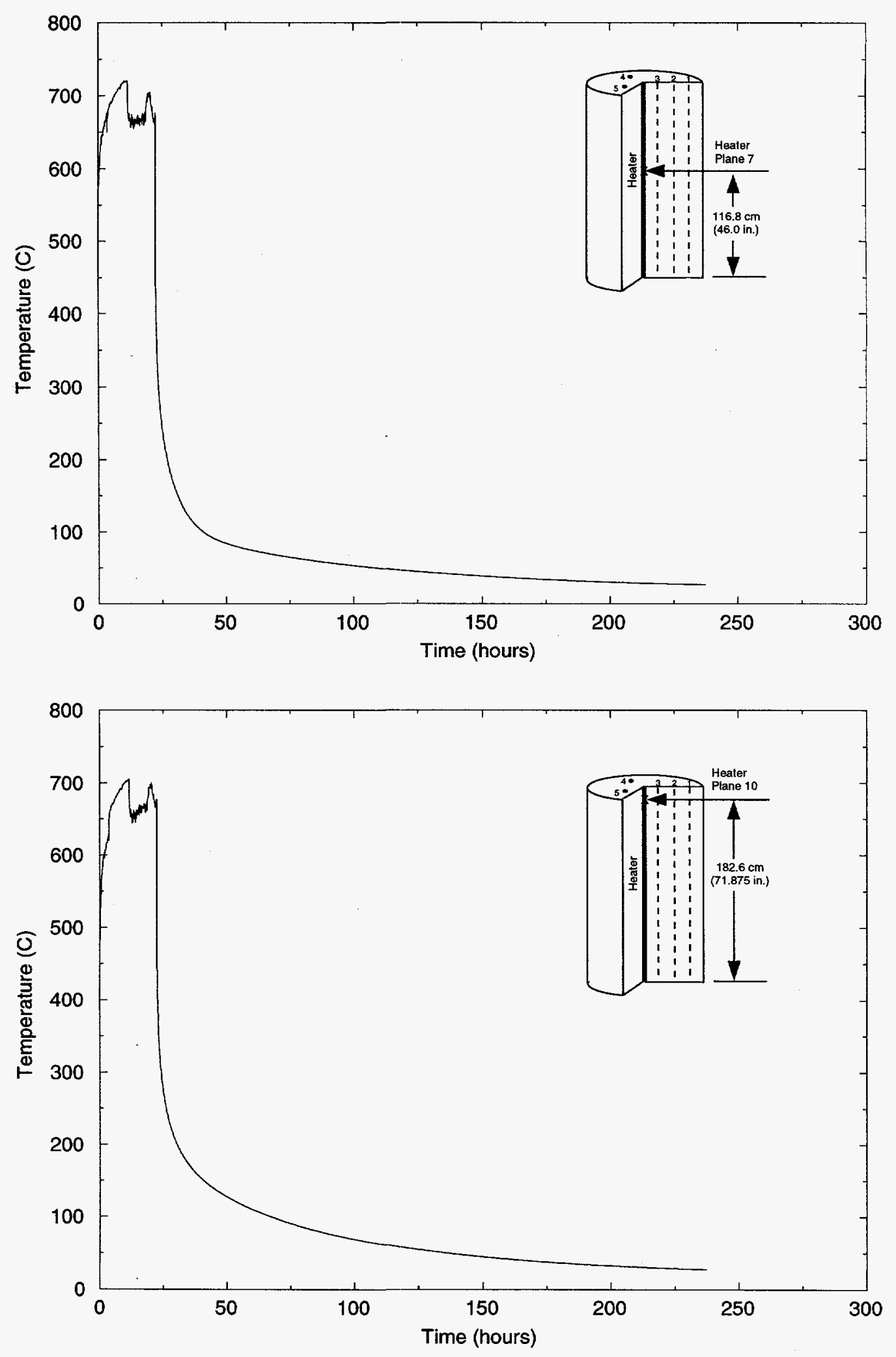

Figure B-5. Test 2. Temperature Data (continued) 

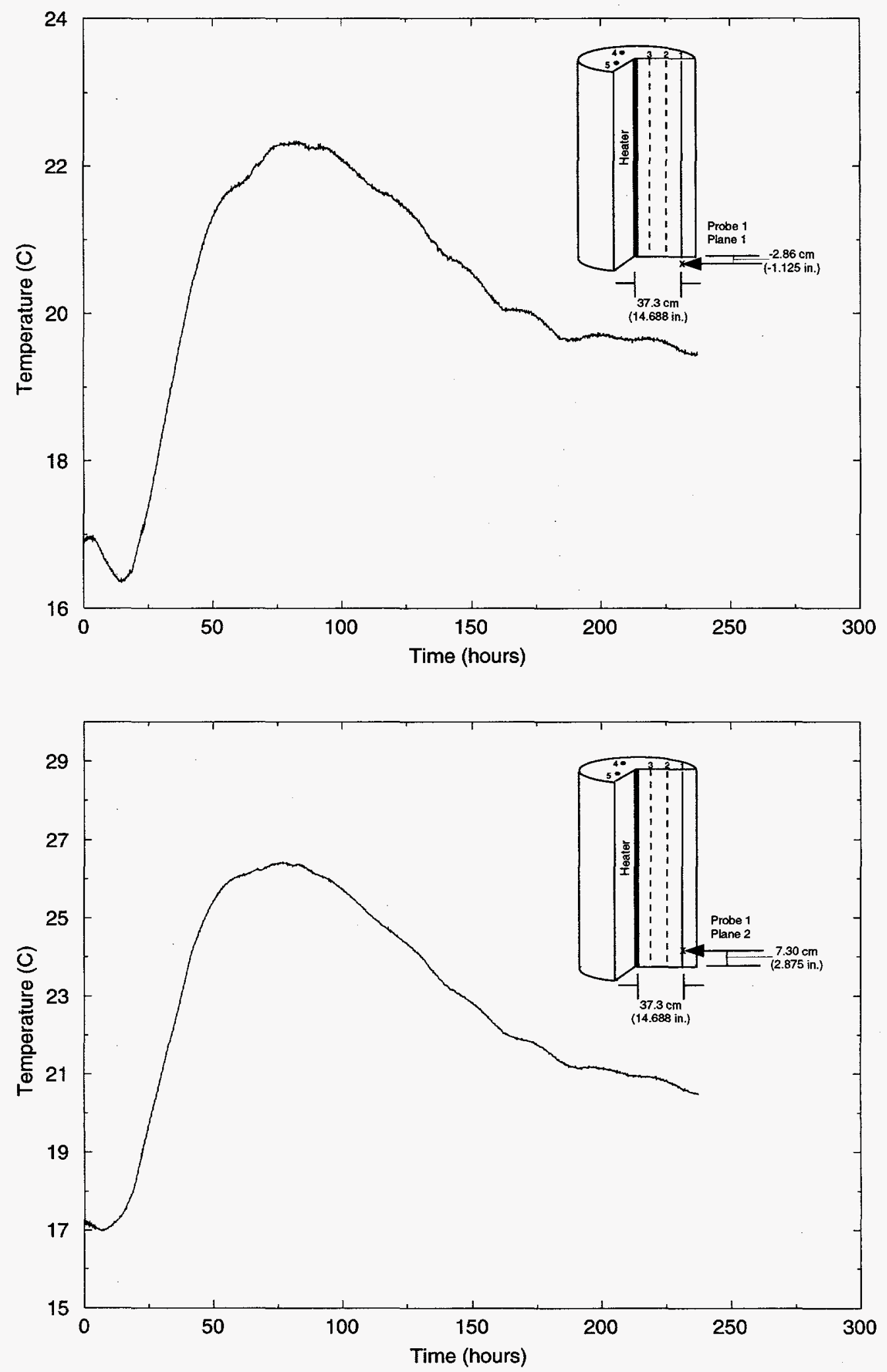

Figure B-5. Test 2 Temperature Data (continued) 

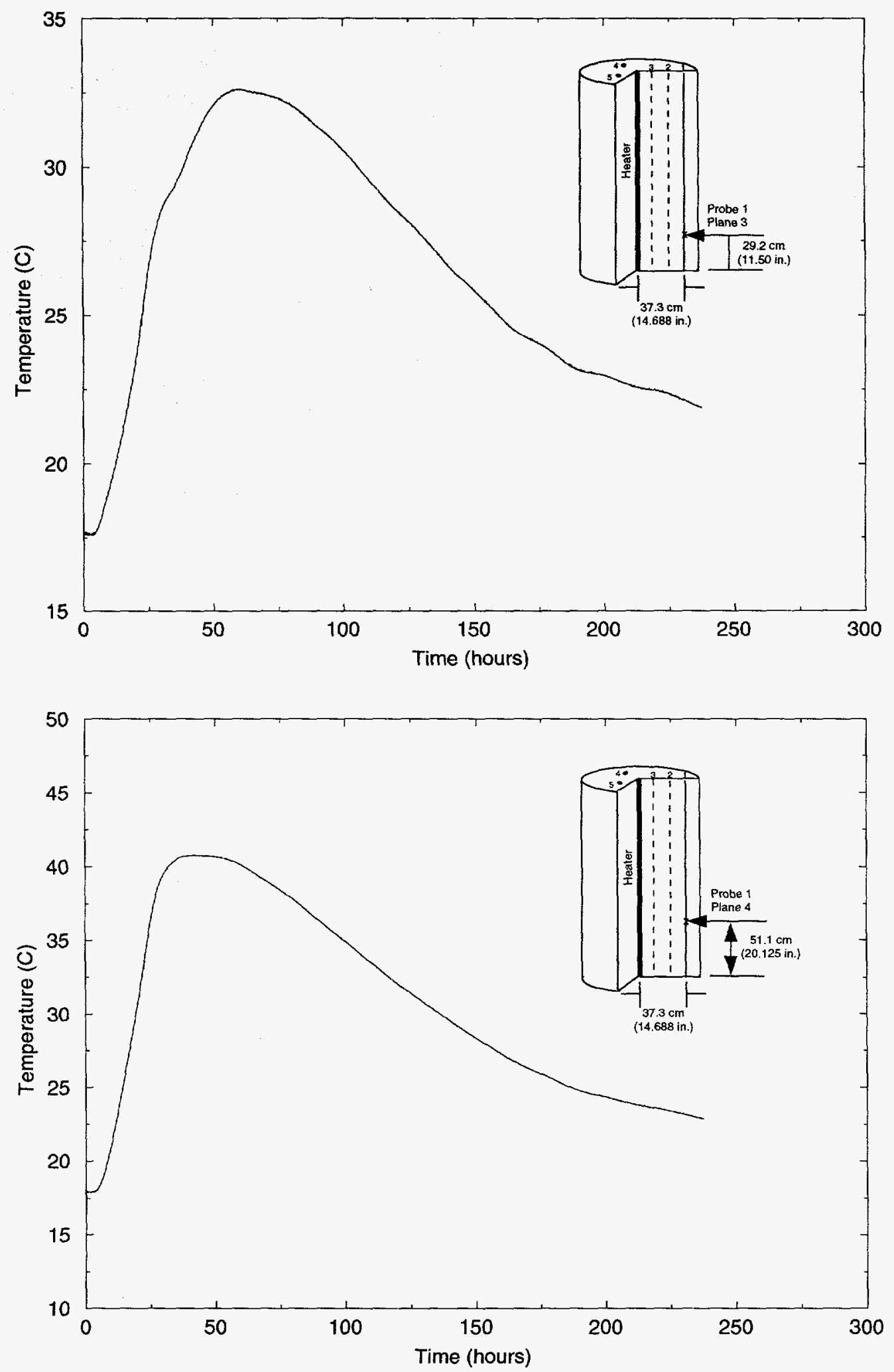

Figure B-5. Test 2 Temperature Data (continued) 

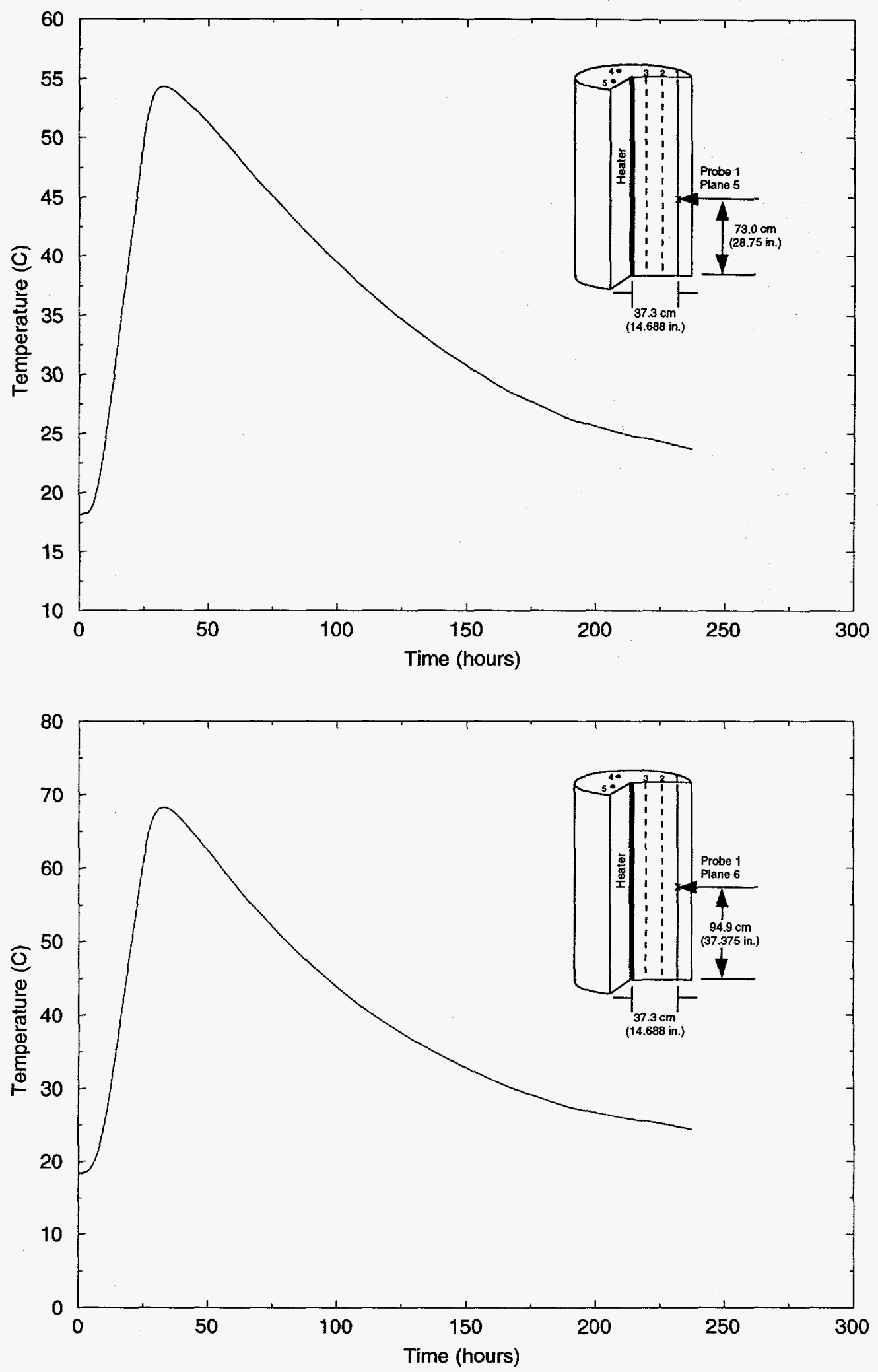

Figure B-5. Test 2 Temperature Data (continued) 

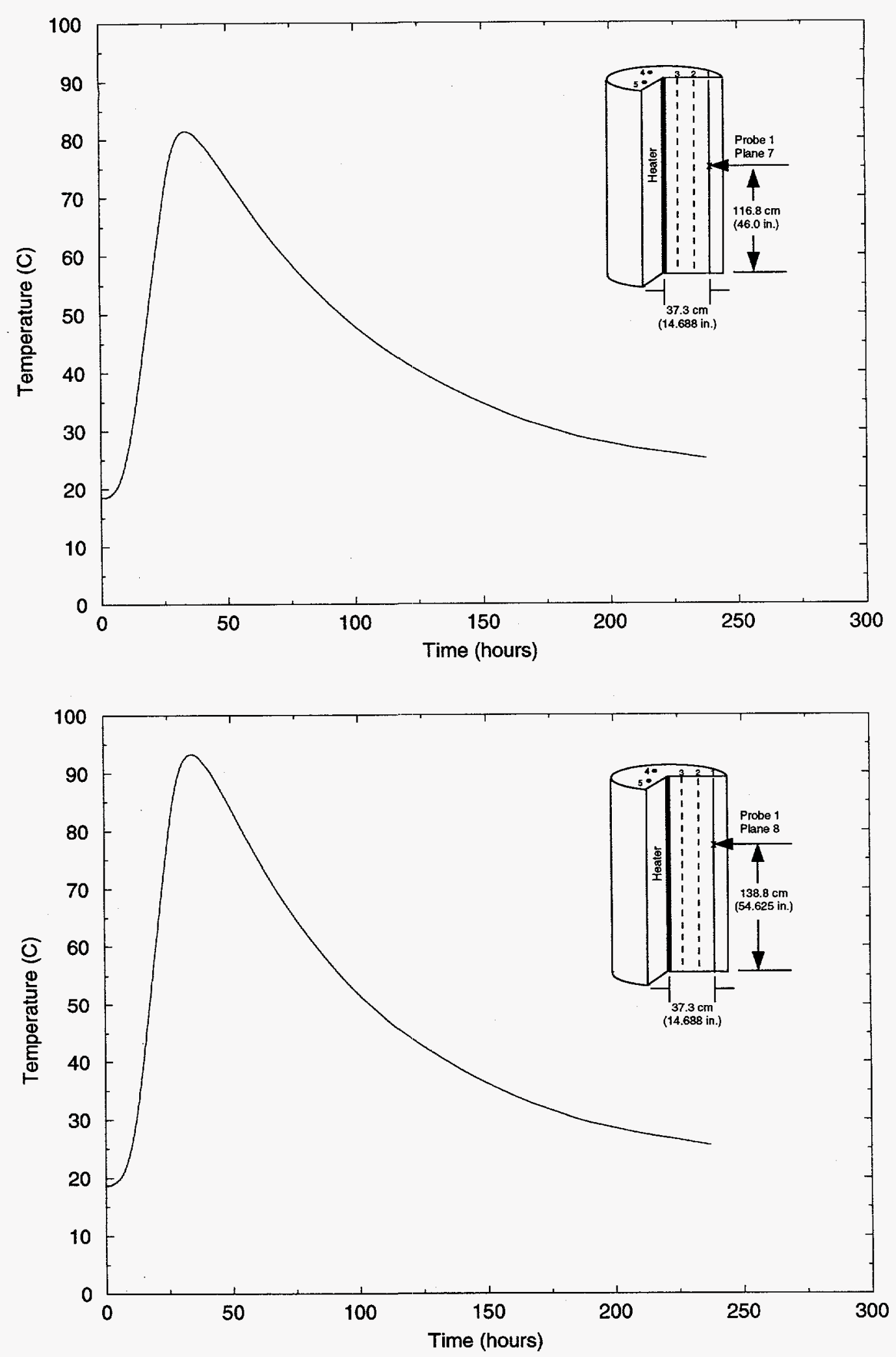

Figure B-5. Test 2 Temperature Data (continued) 

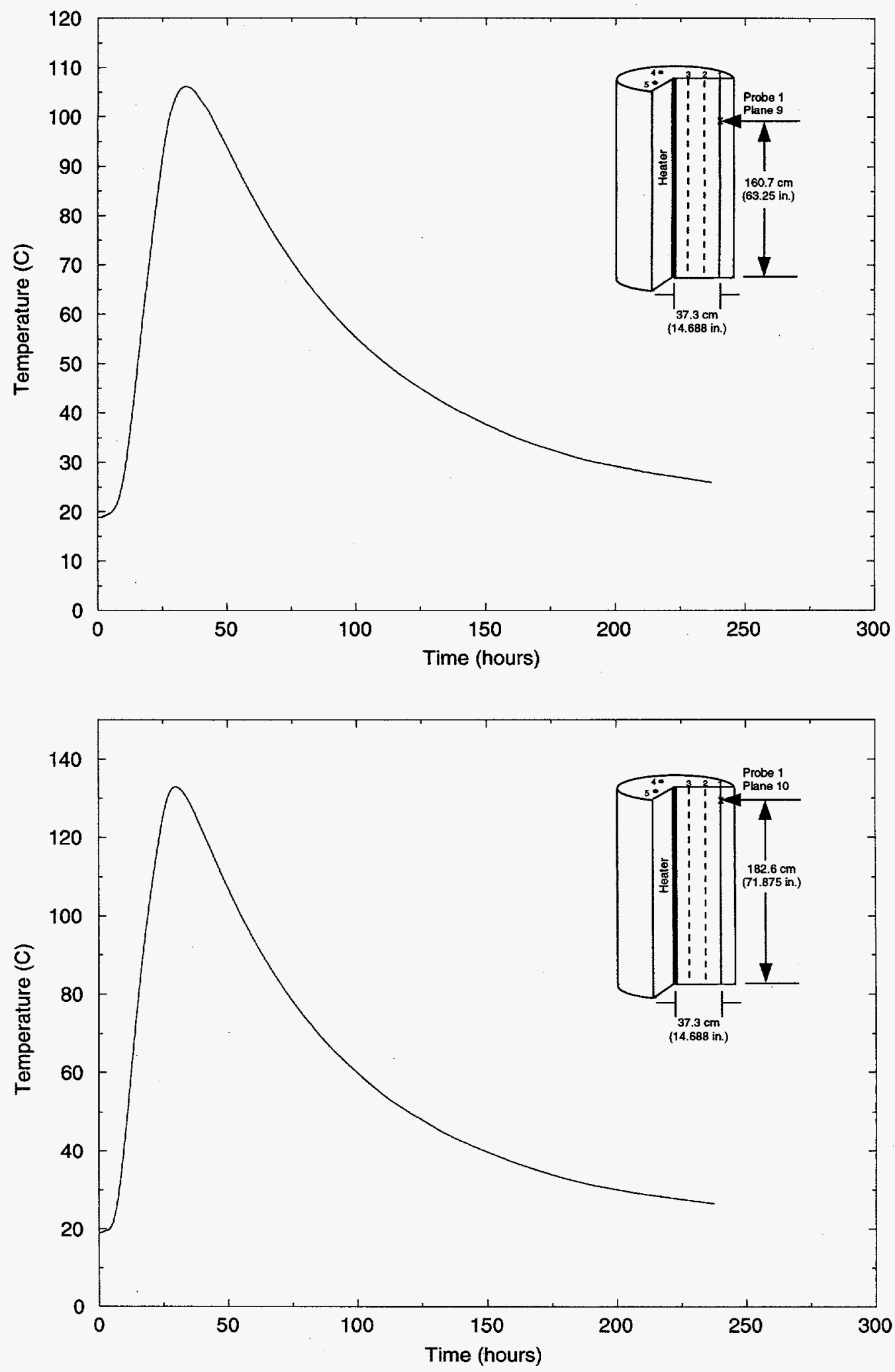

Figure B-5. Test 2 Temperature Data (continued) 

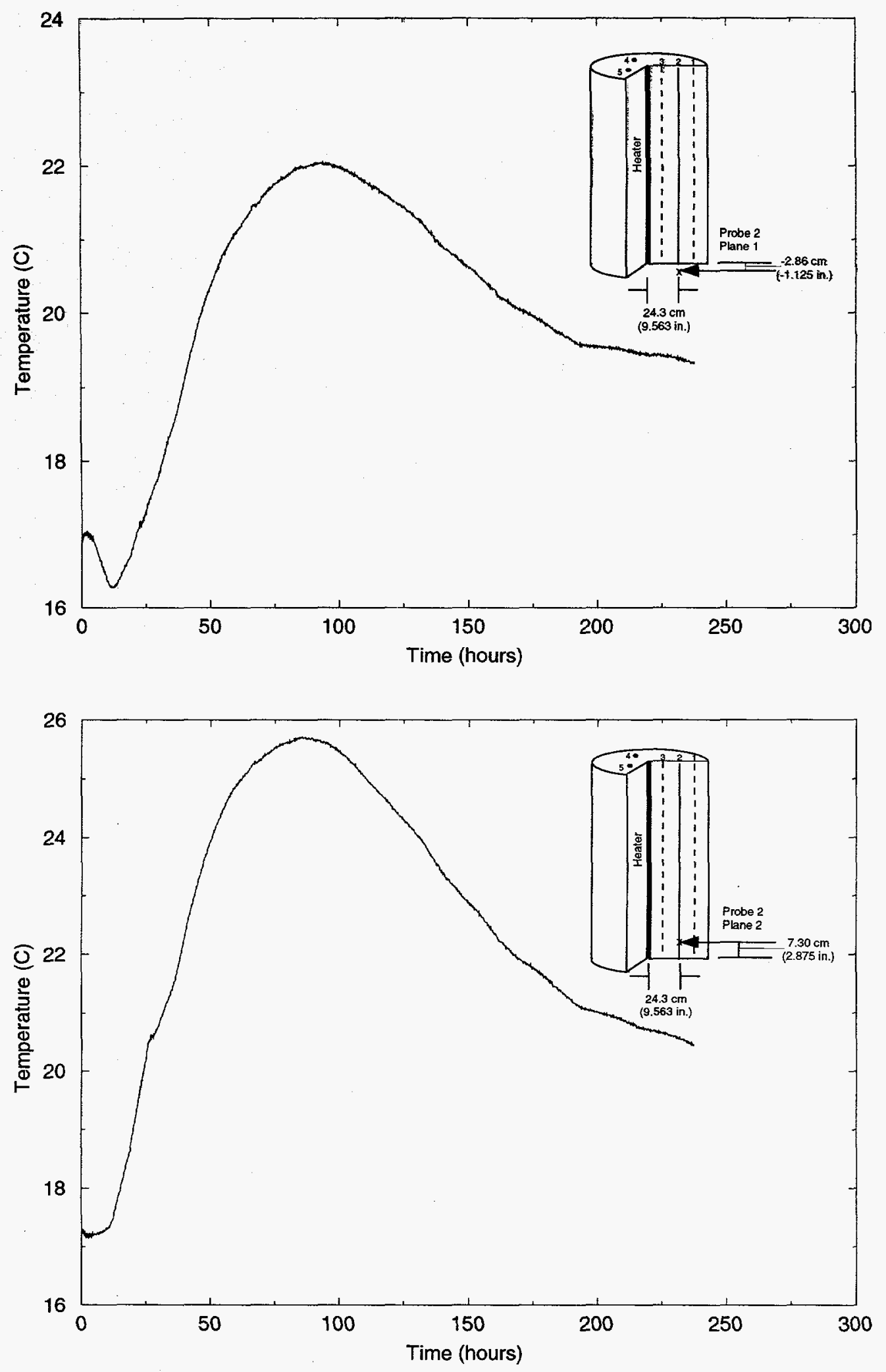

Figure B-5. Test 2 Temperature Data (continued) 

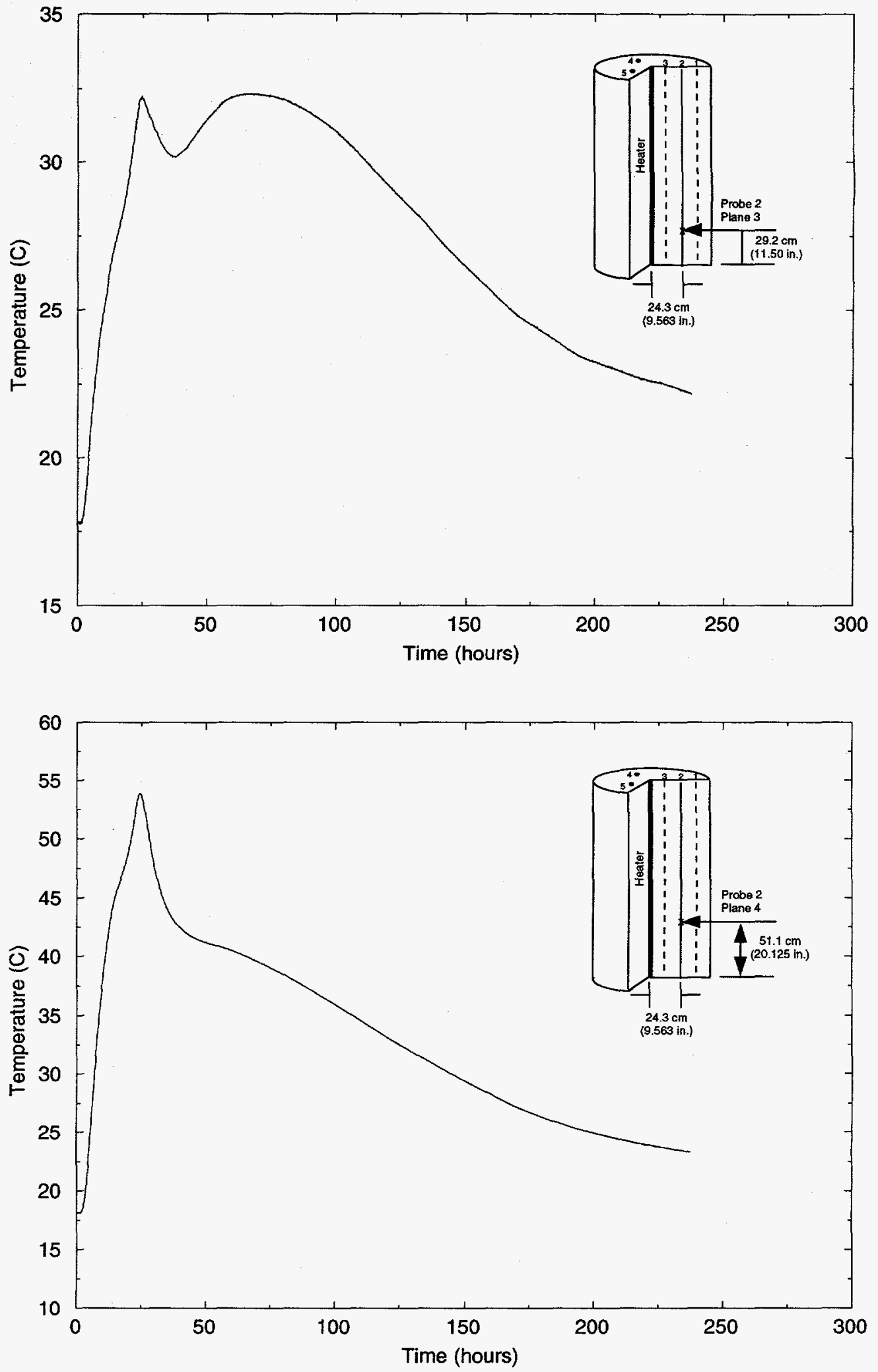

Figure B-5. Test 2 Temperature Data (continued) 

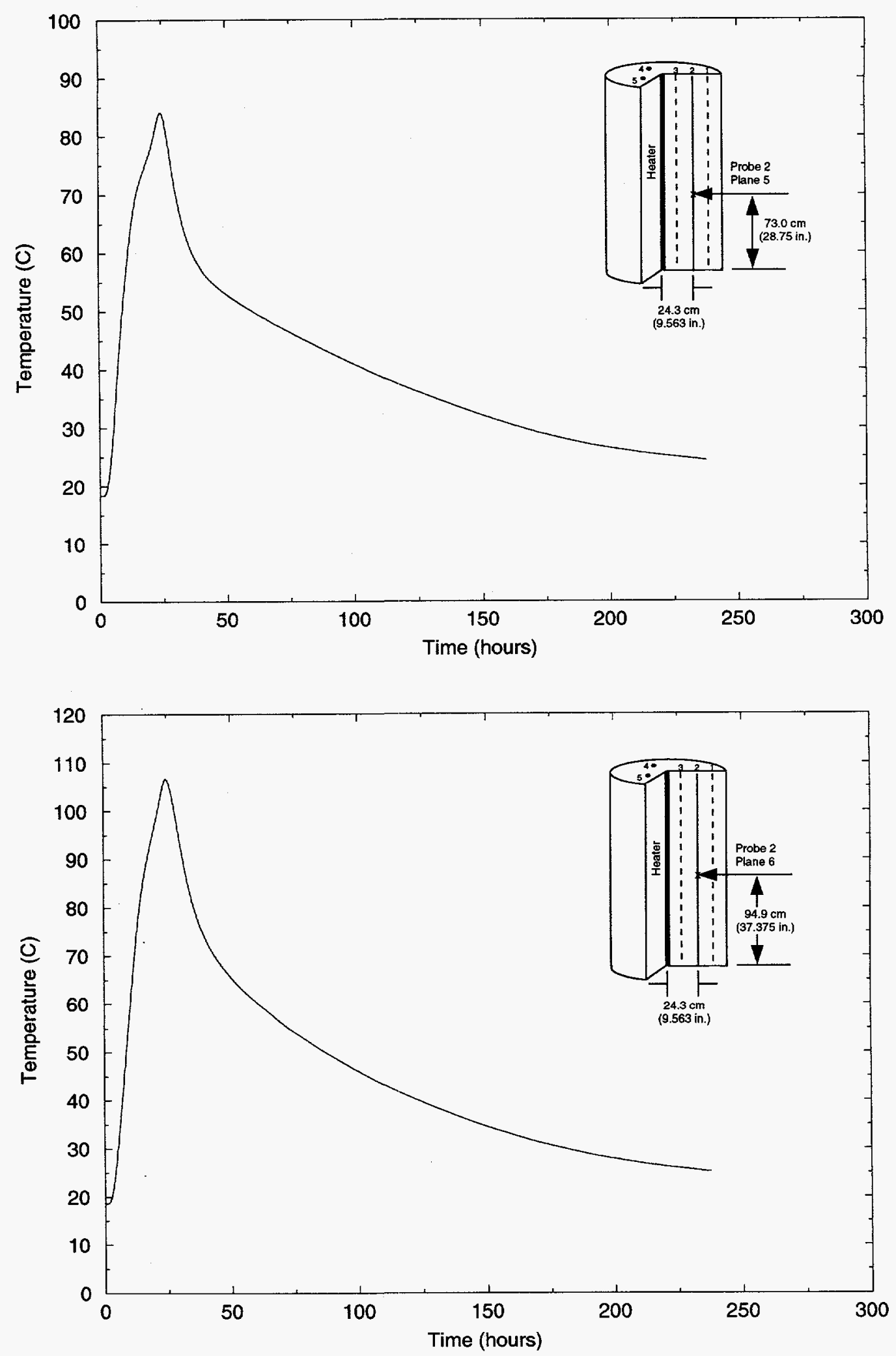

Figure B-5. Test 2 Temperature Data (continued) 

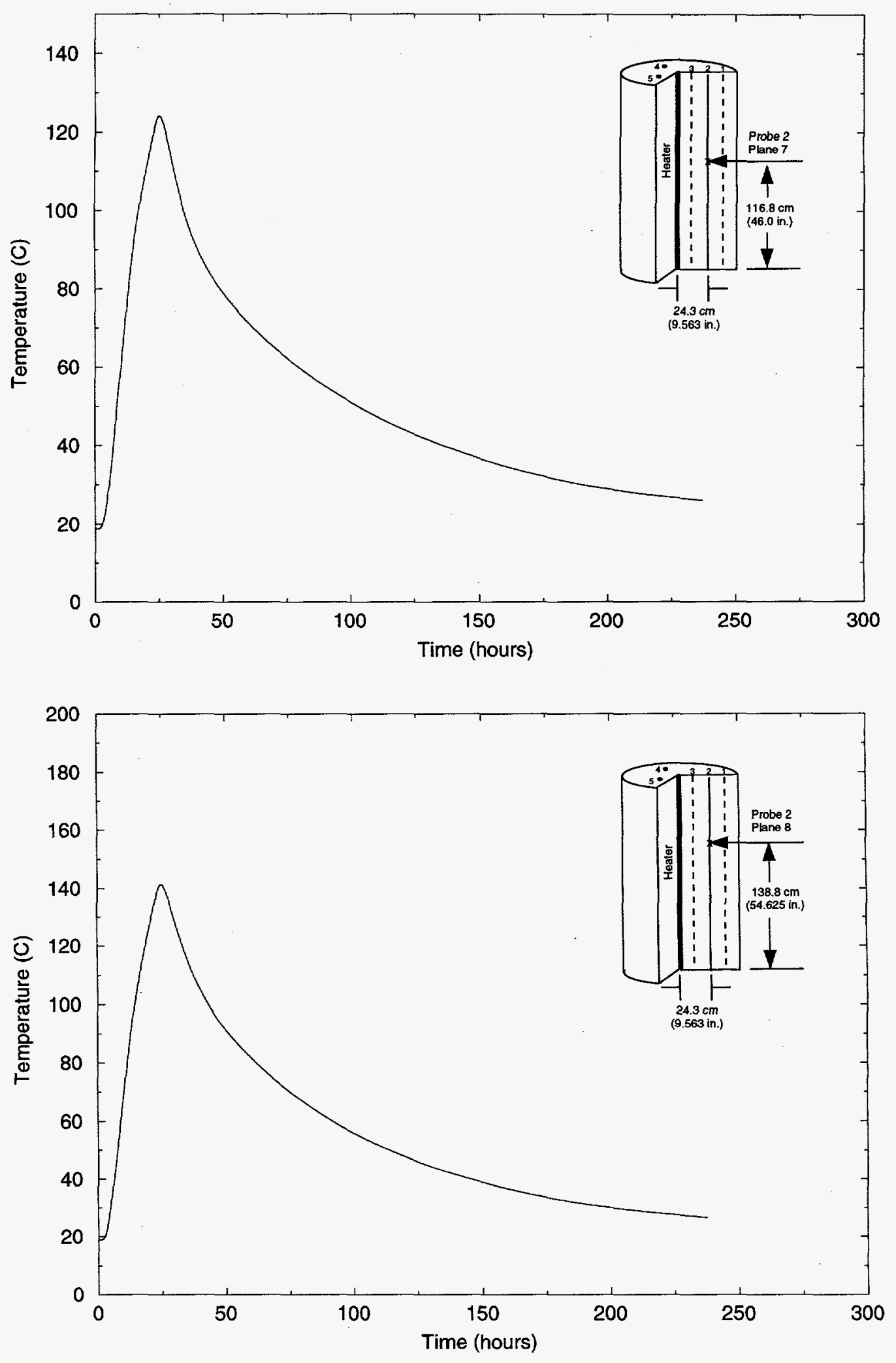

Figure B-5. Test 2 Temperature Data (continued) 

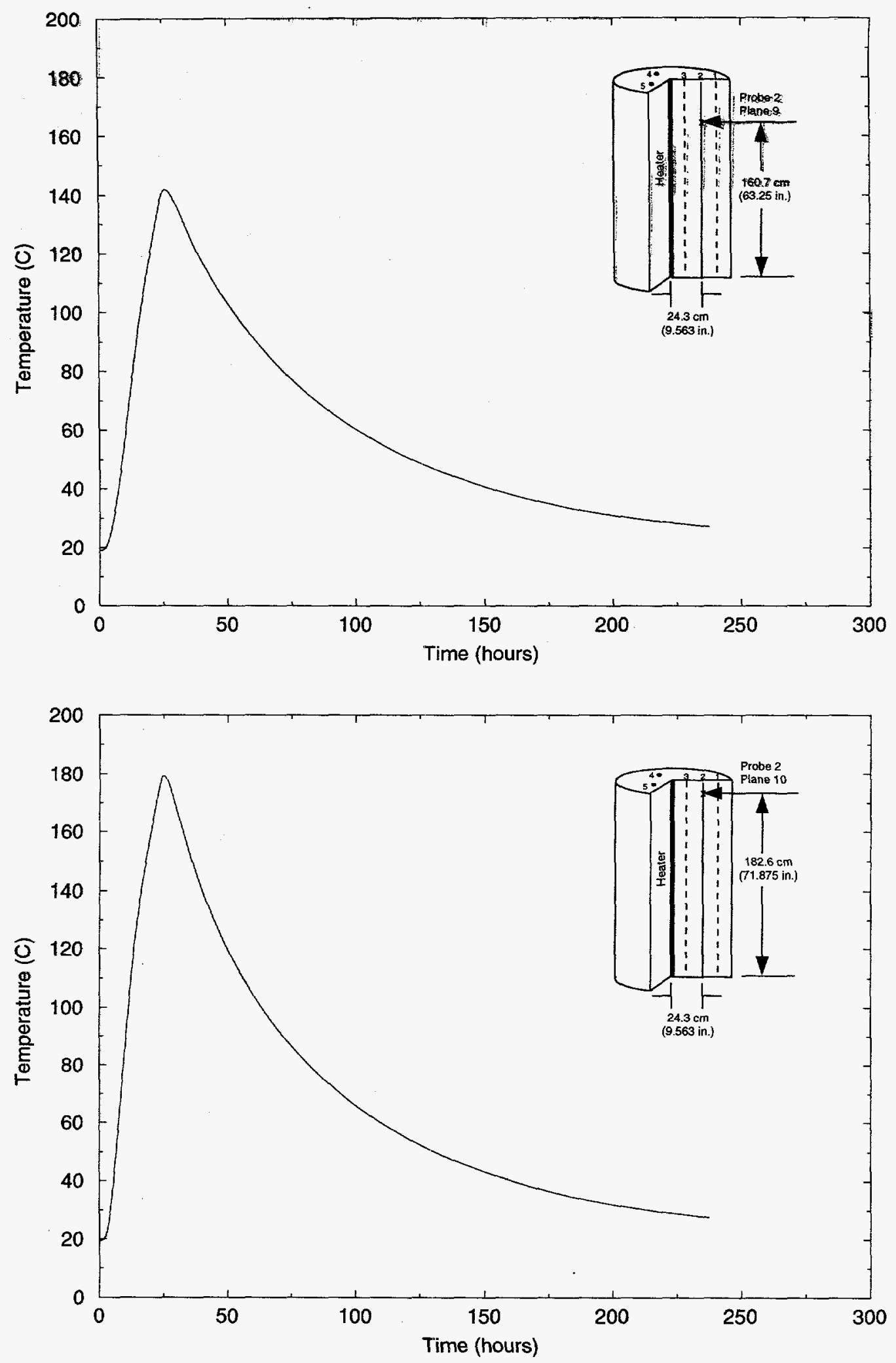

Figure B-5. Test 2 Temperature Data (continued) 

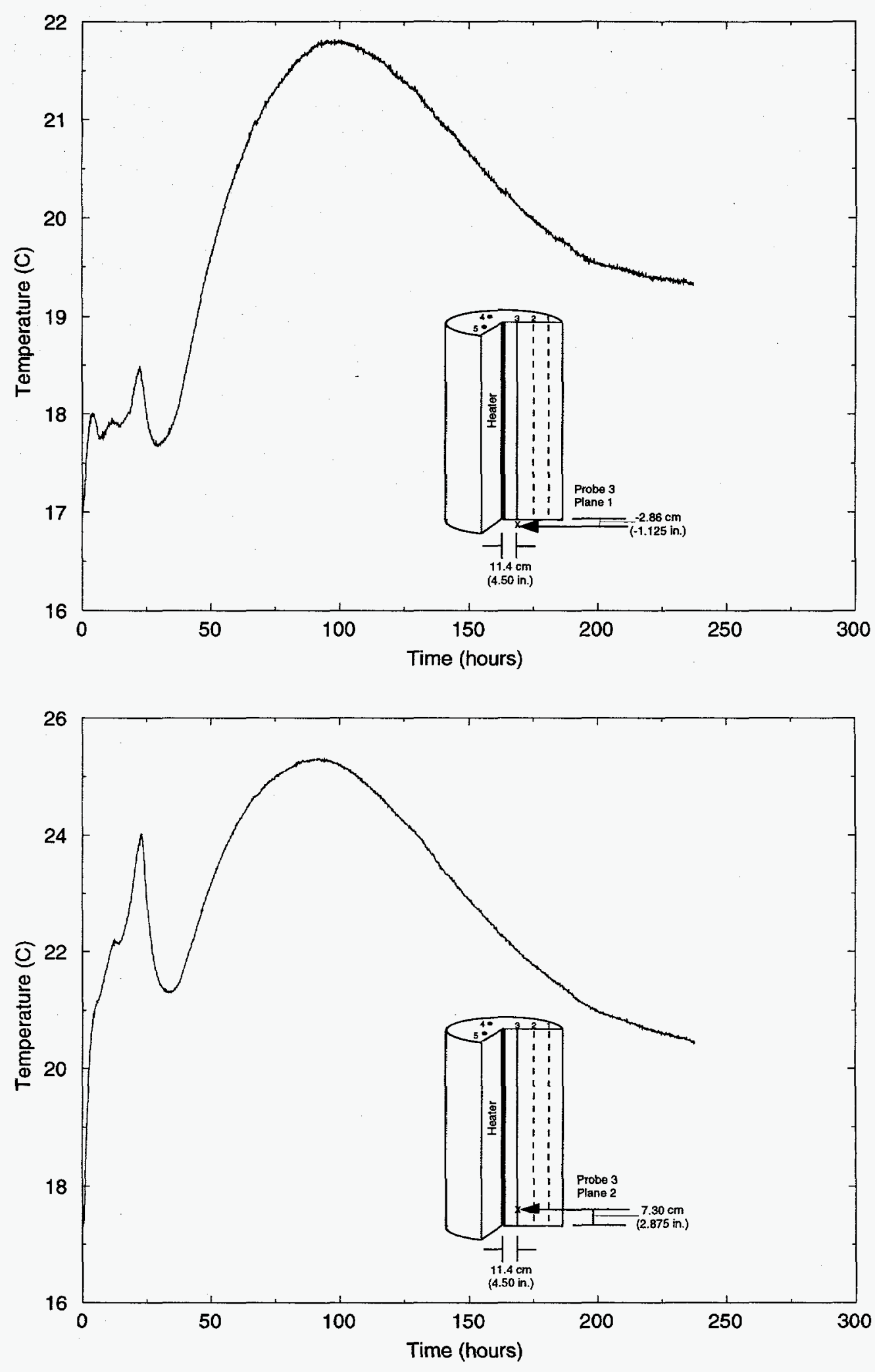

Figure B-5. Test 2 Temperature Data (continued) 

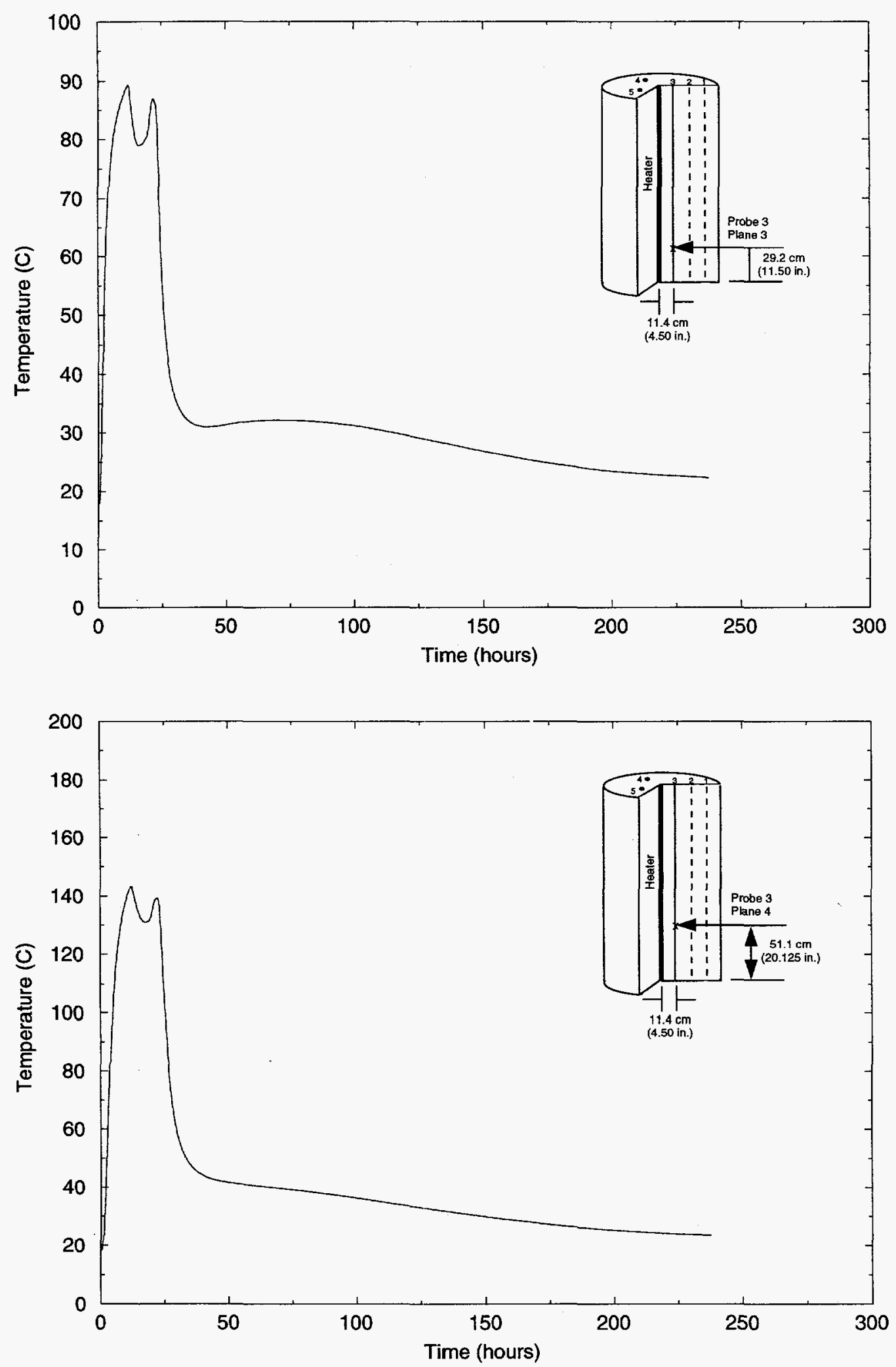

Figure B-5. Test 2 Temperature Data (continued) 

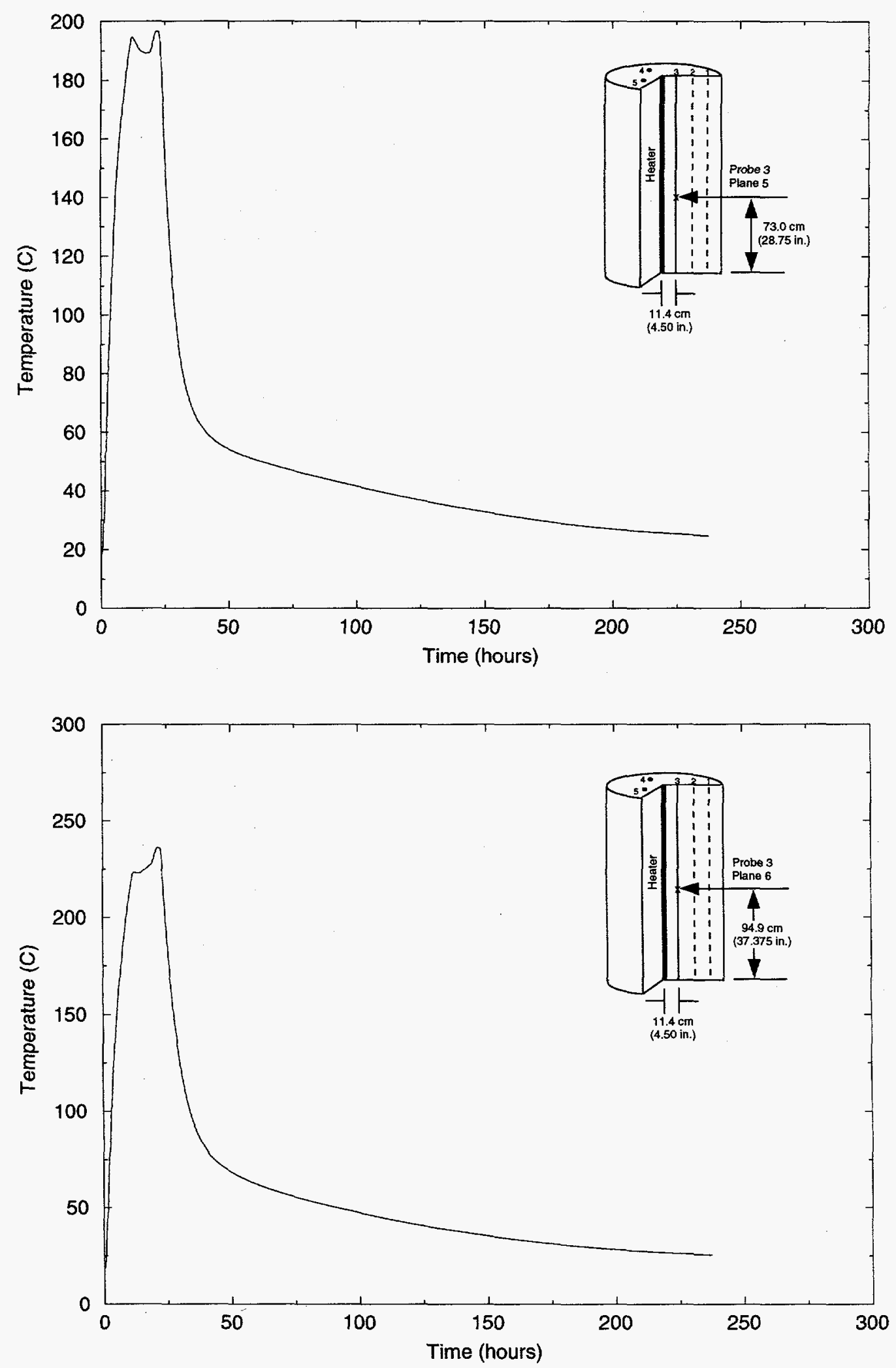

Figure B-5. Test 2 Temperature Data (continued) 

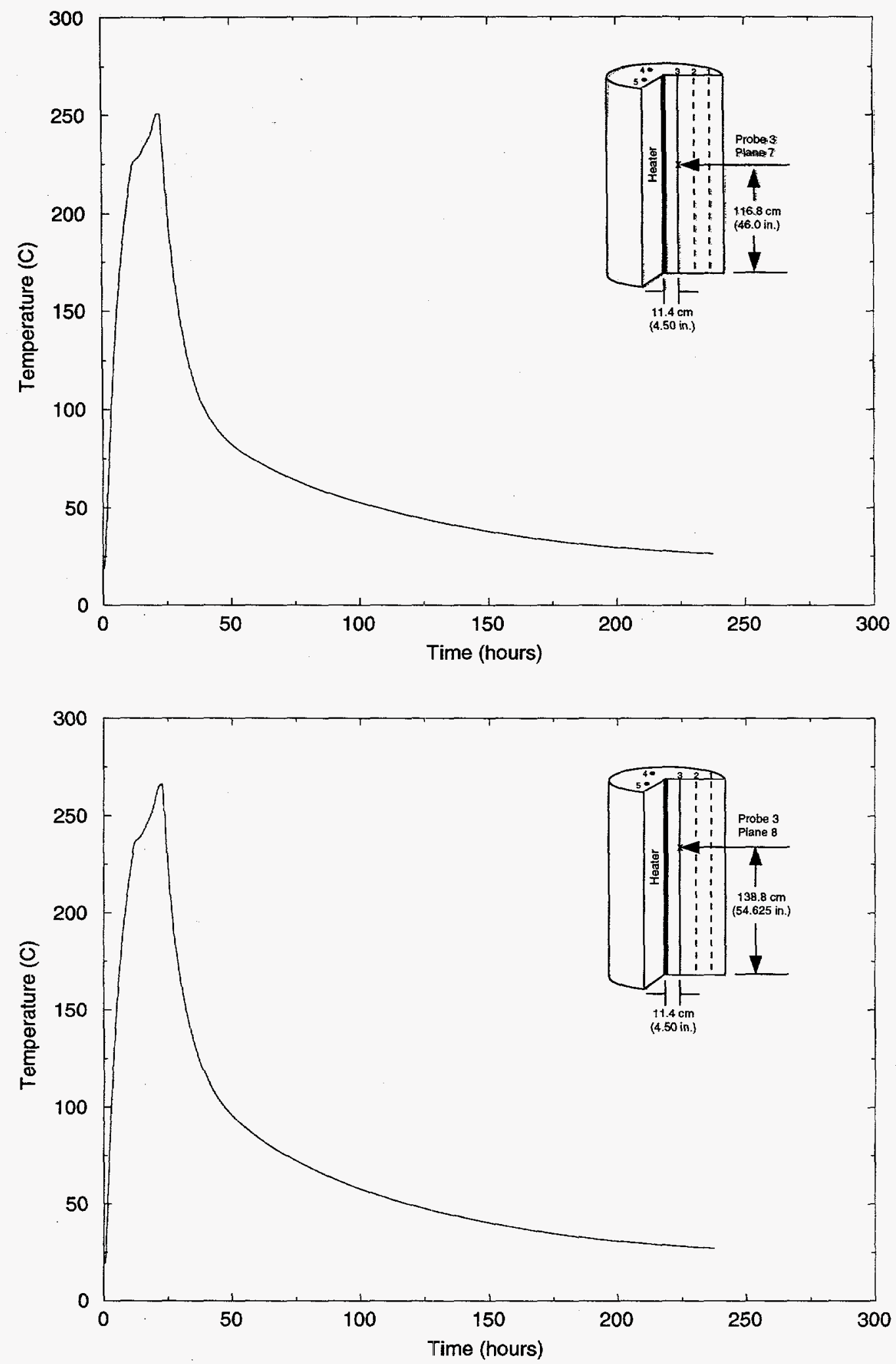

Figure B-5. Test 2 Temperature Data (continued) 

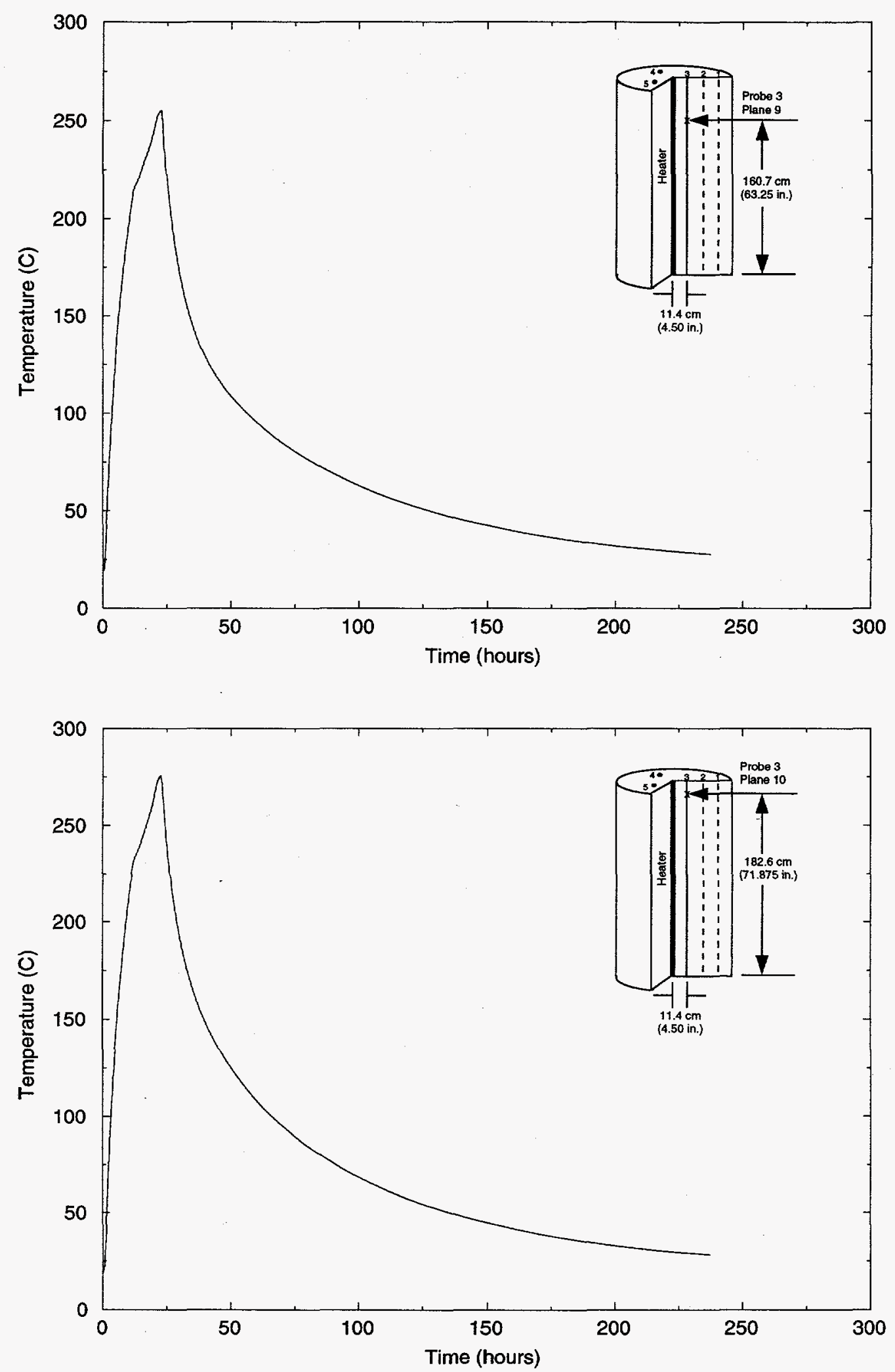

Figure B-5. Test 2 Temperature Data (continued) 

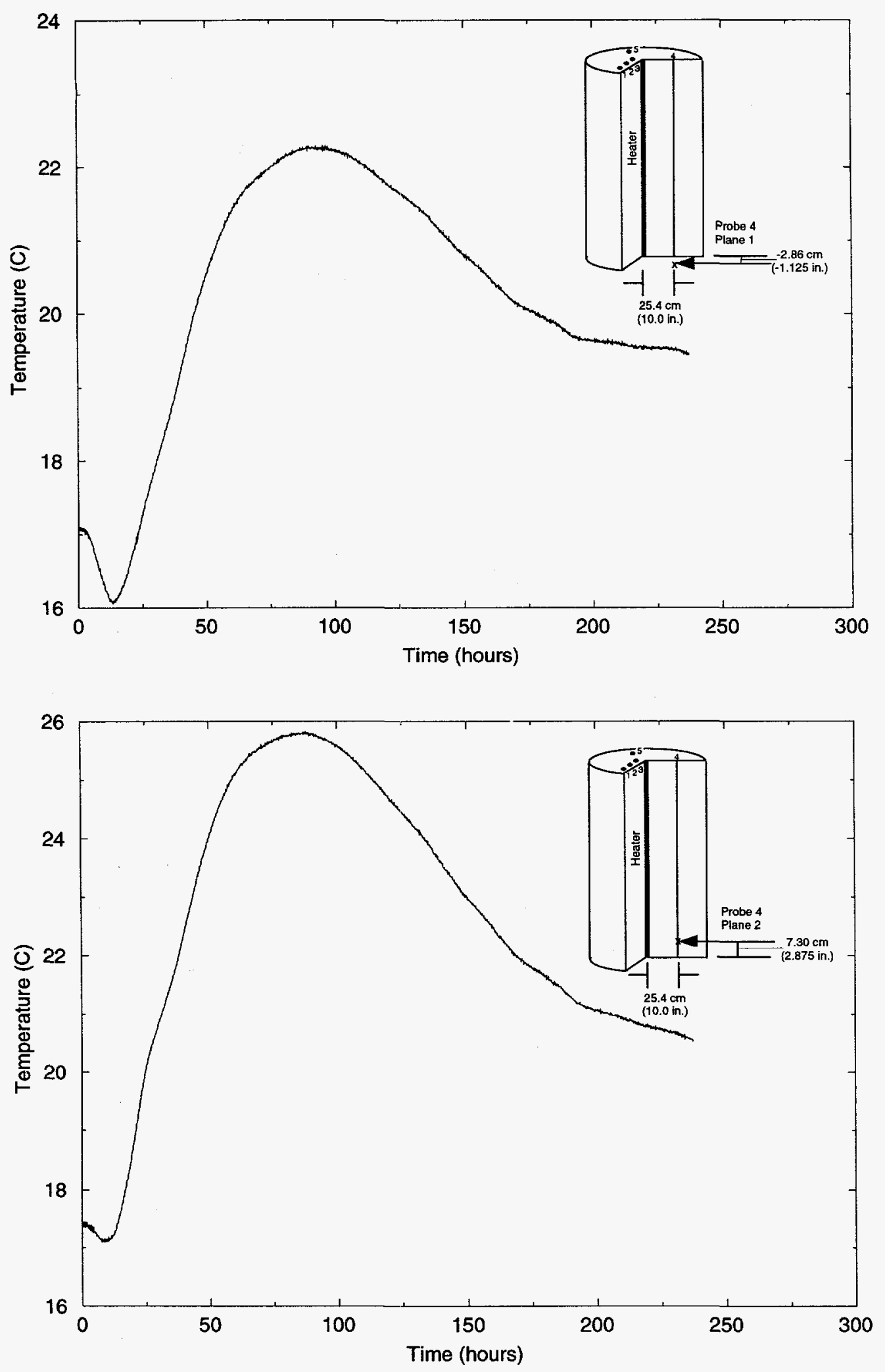

Figure B-5. Test 2 Temperature Data (continued) 

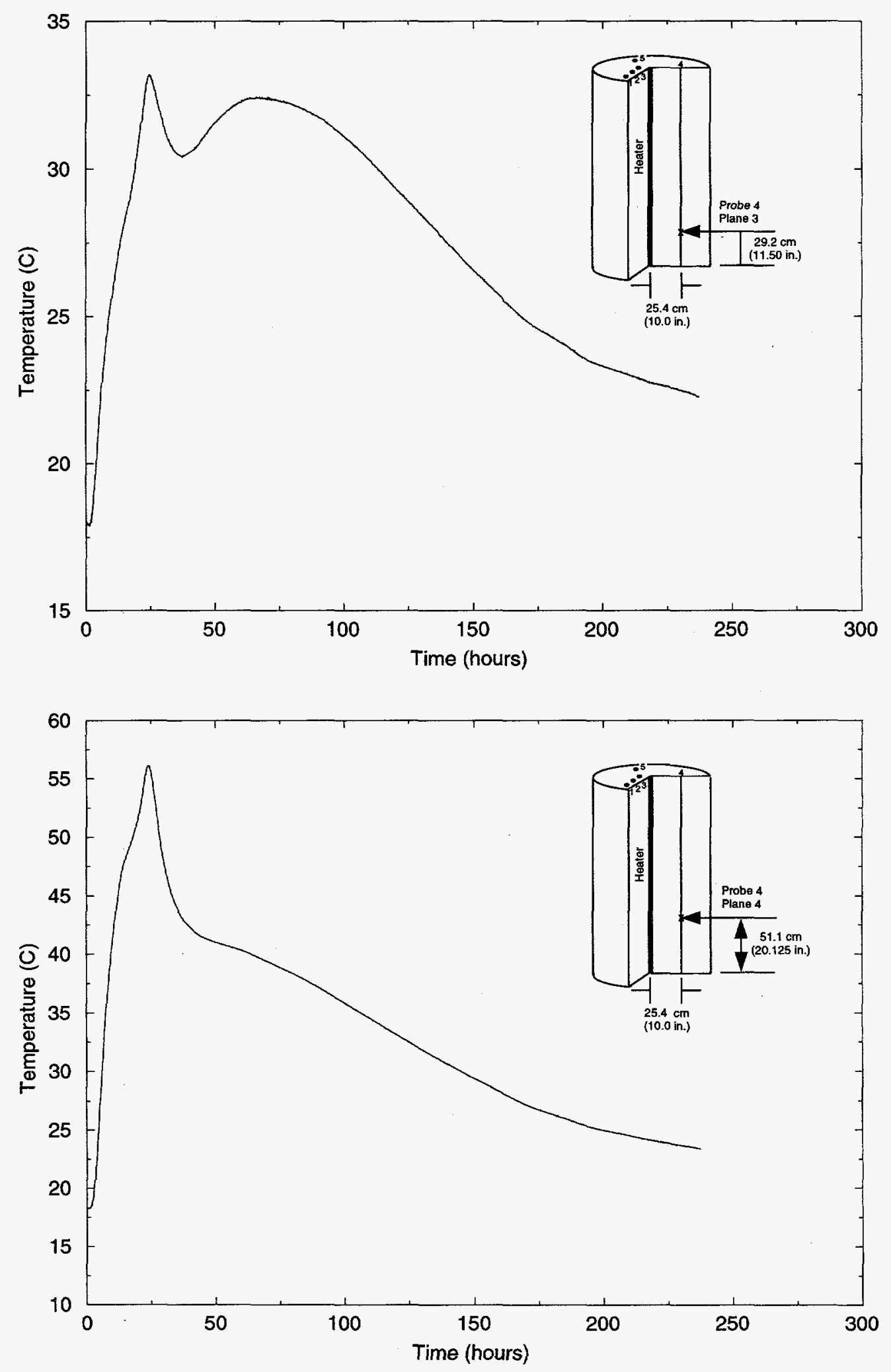

Figure B-5. Test 2 Temperature Data (continued) 

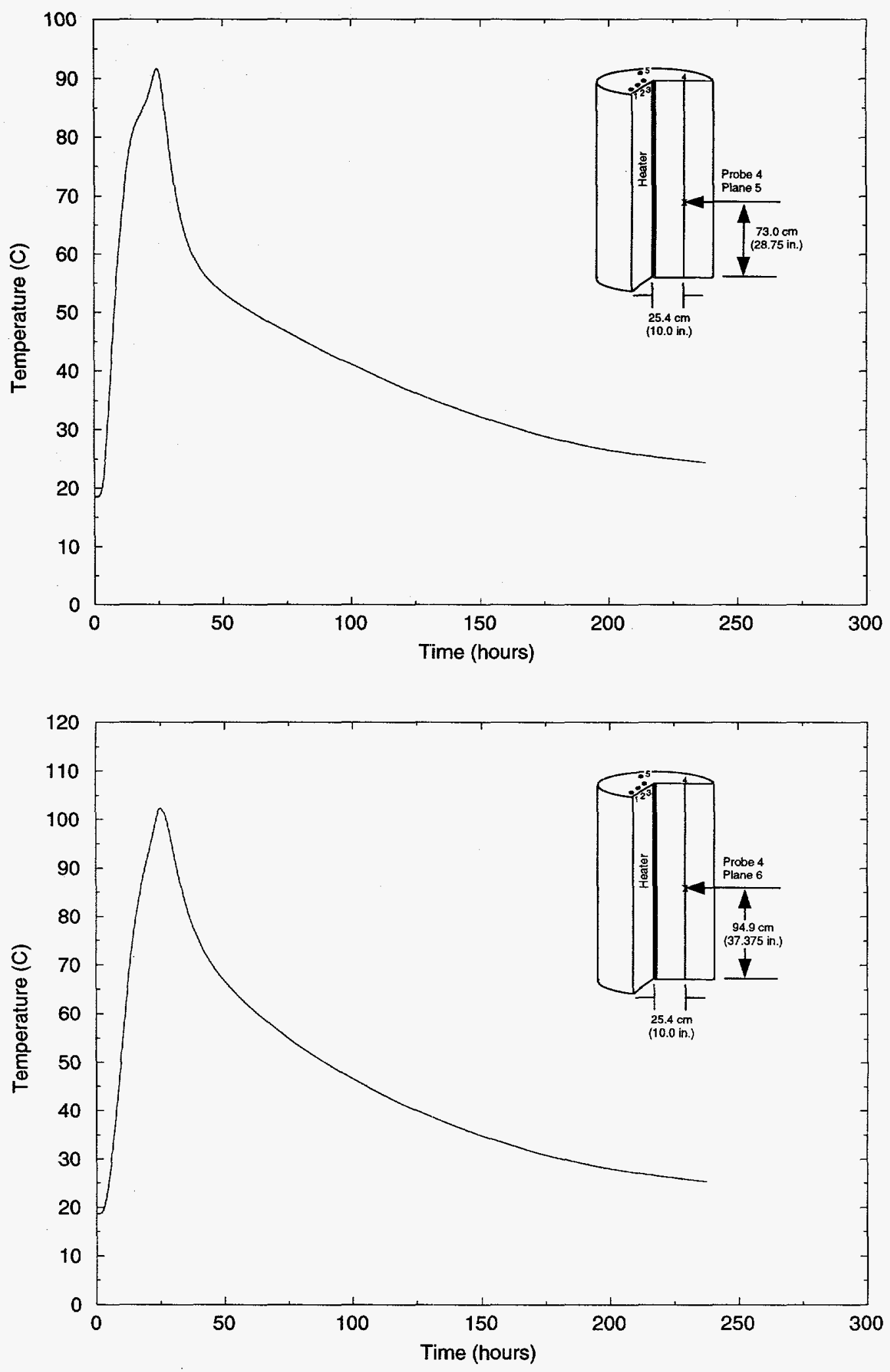

Figure B-5. Test 2 Temperature Data (continued) 

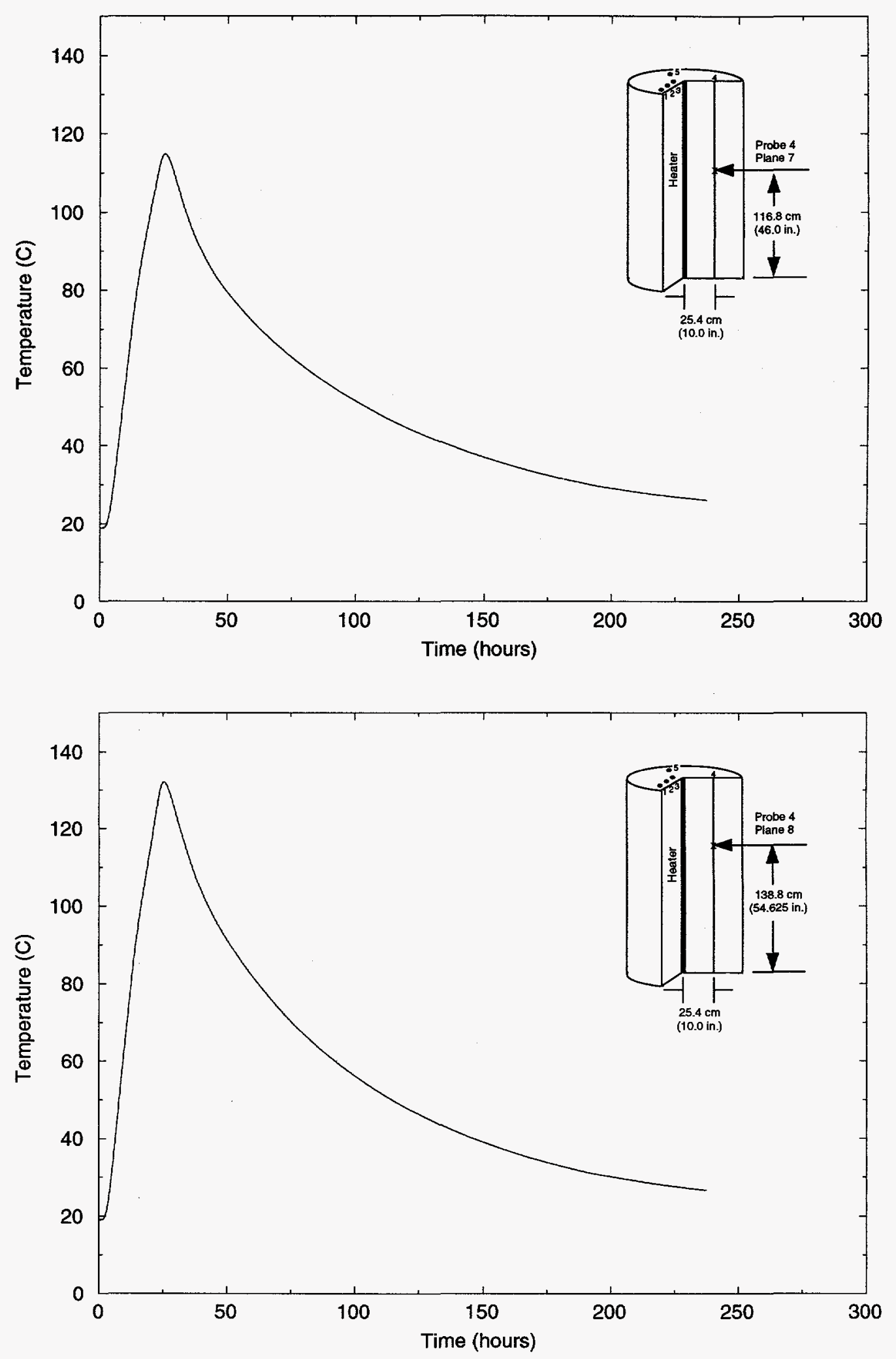

Figure B-5. Test 2 Temperature Data (continued) 

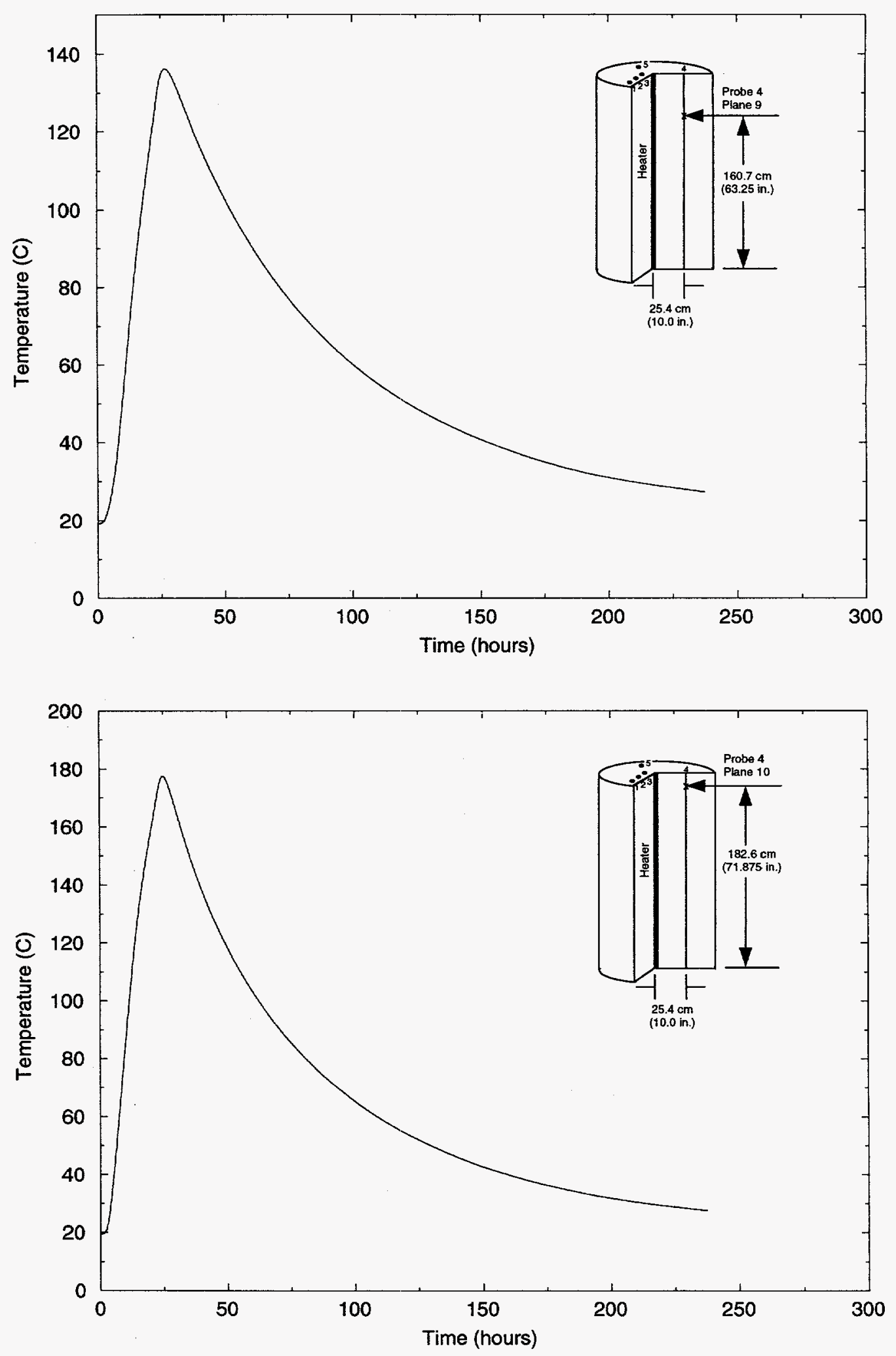

Figure B-5. Test 2 Temperature Data (continued) 

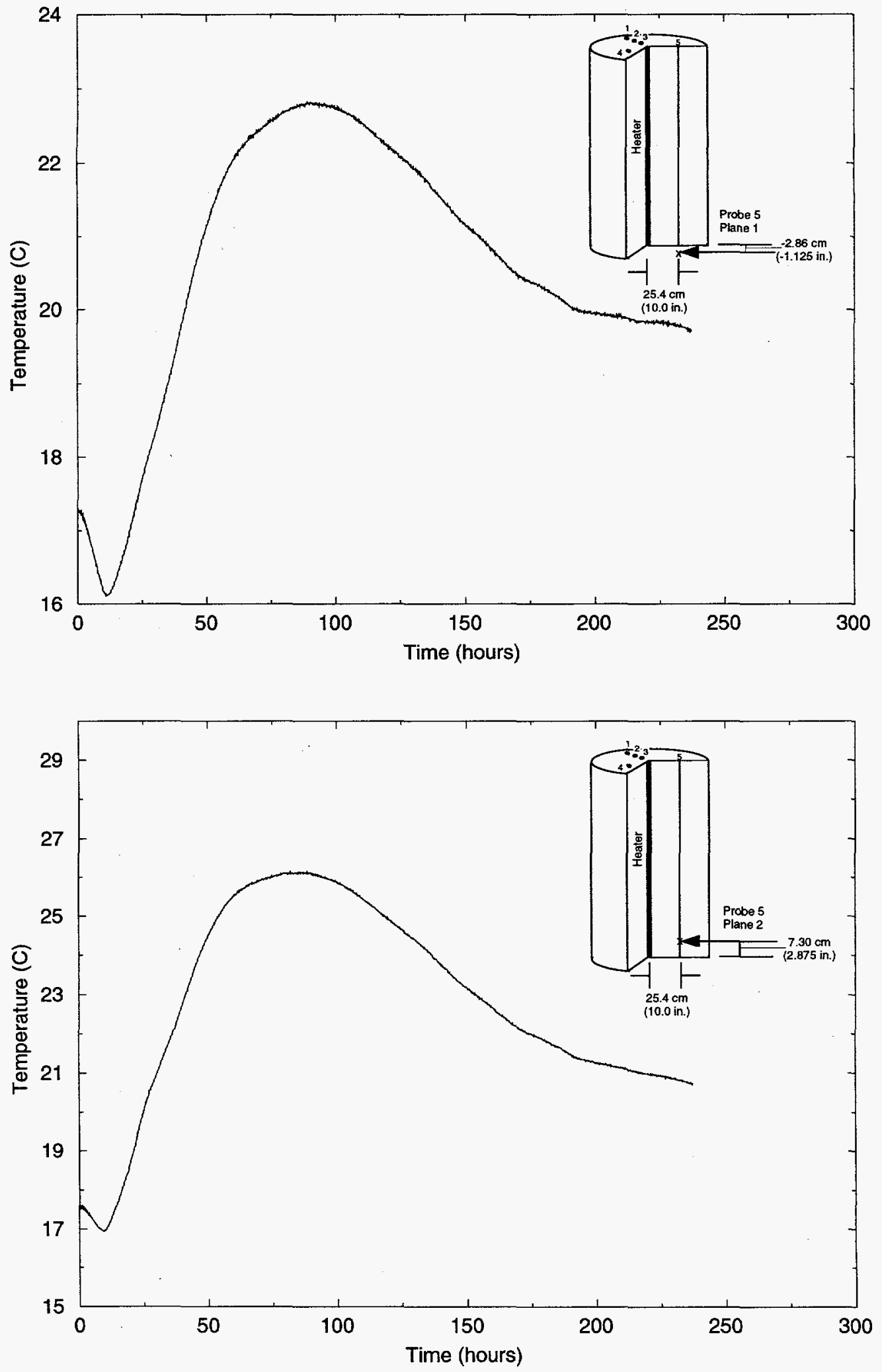

Figure B-5. Test 2 Temperature Data (continued) 

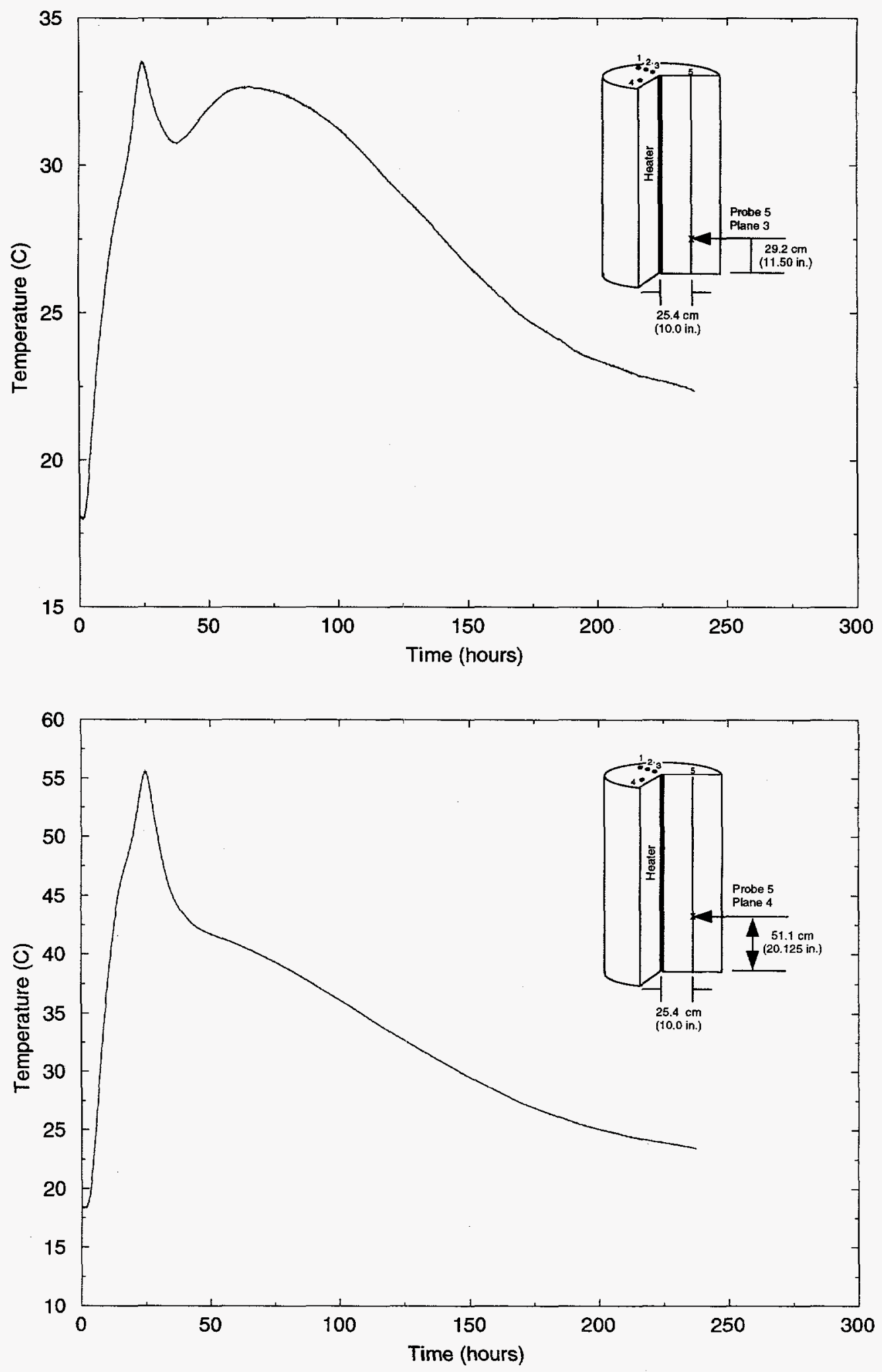

Figure B-5. Test 2 Temperature Data (continued) 

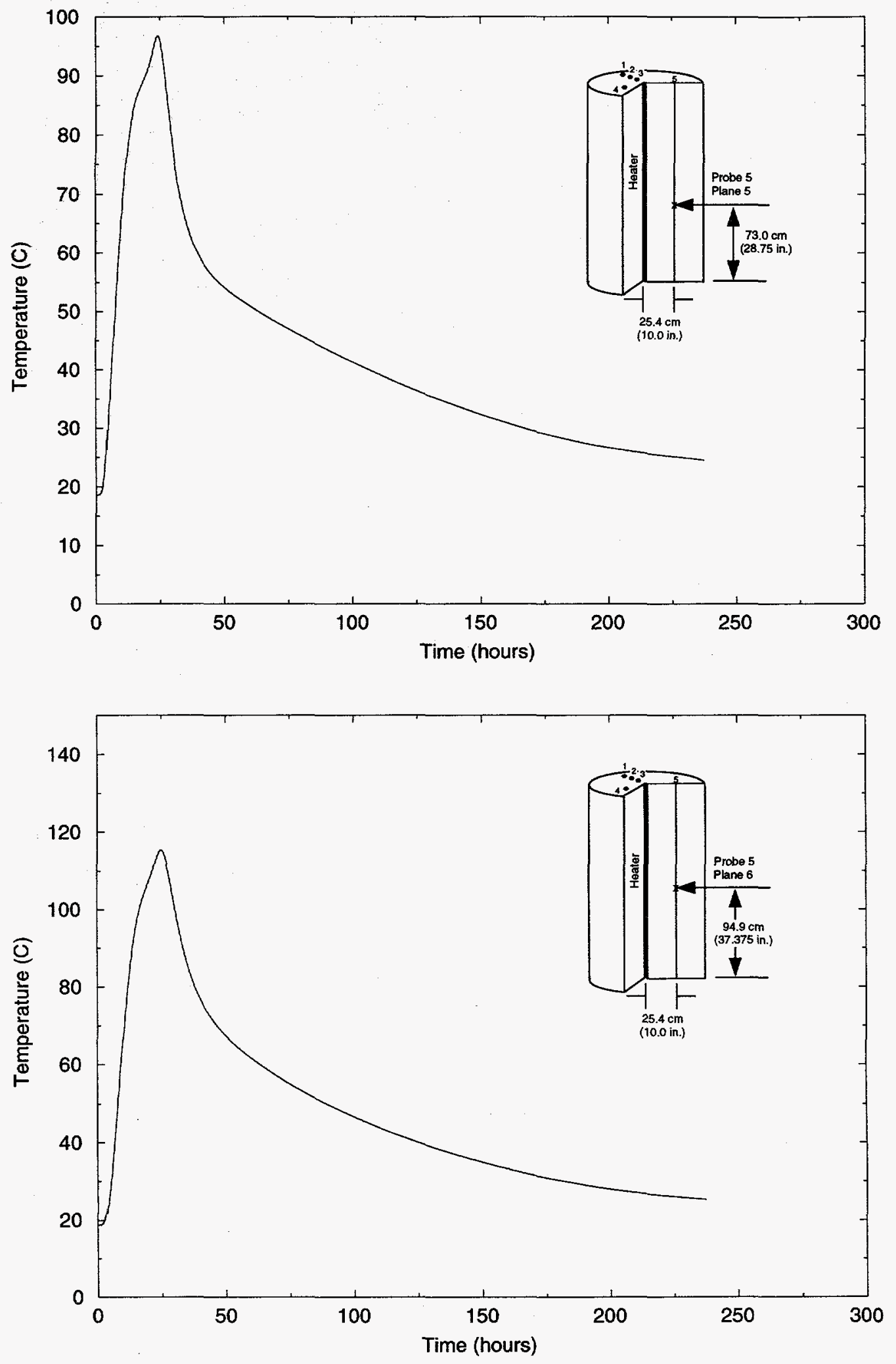

Figure B-5. Test 2 Temperature Data (continued) 

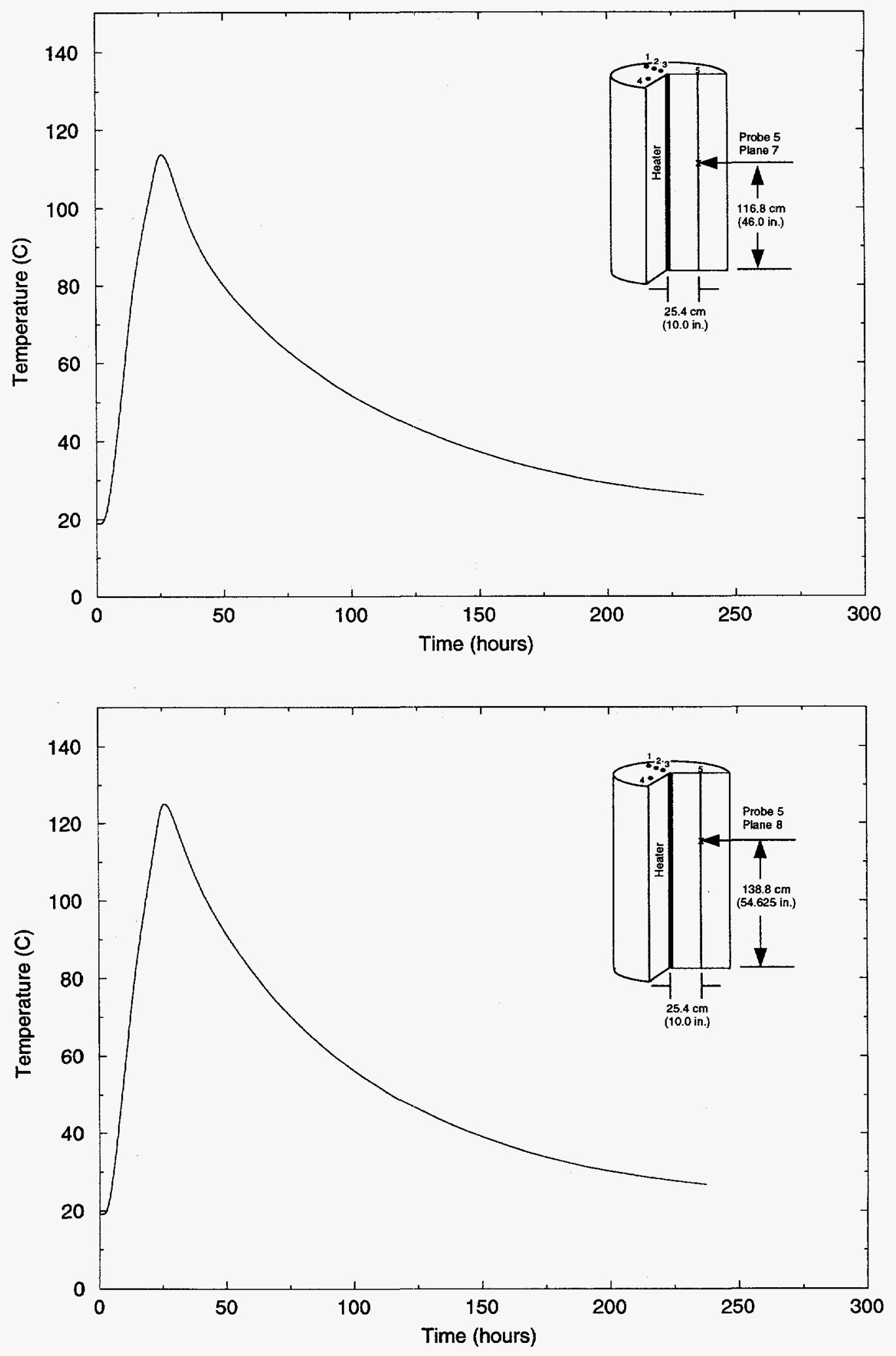

Figure B-5. Test 2 Temperature Data (continued) 

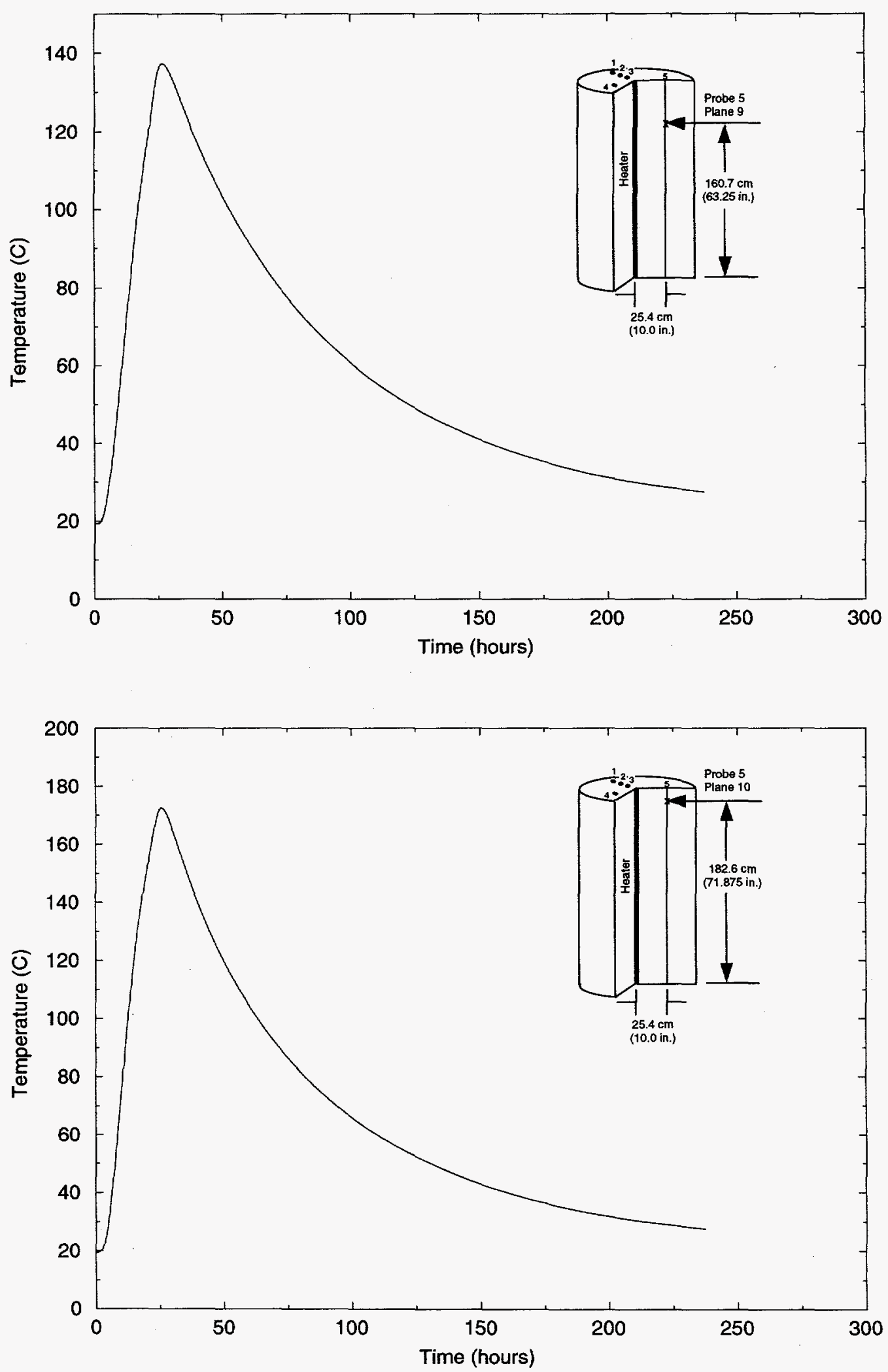

Figure B-5. Test 2 Temperature Data (continued) 

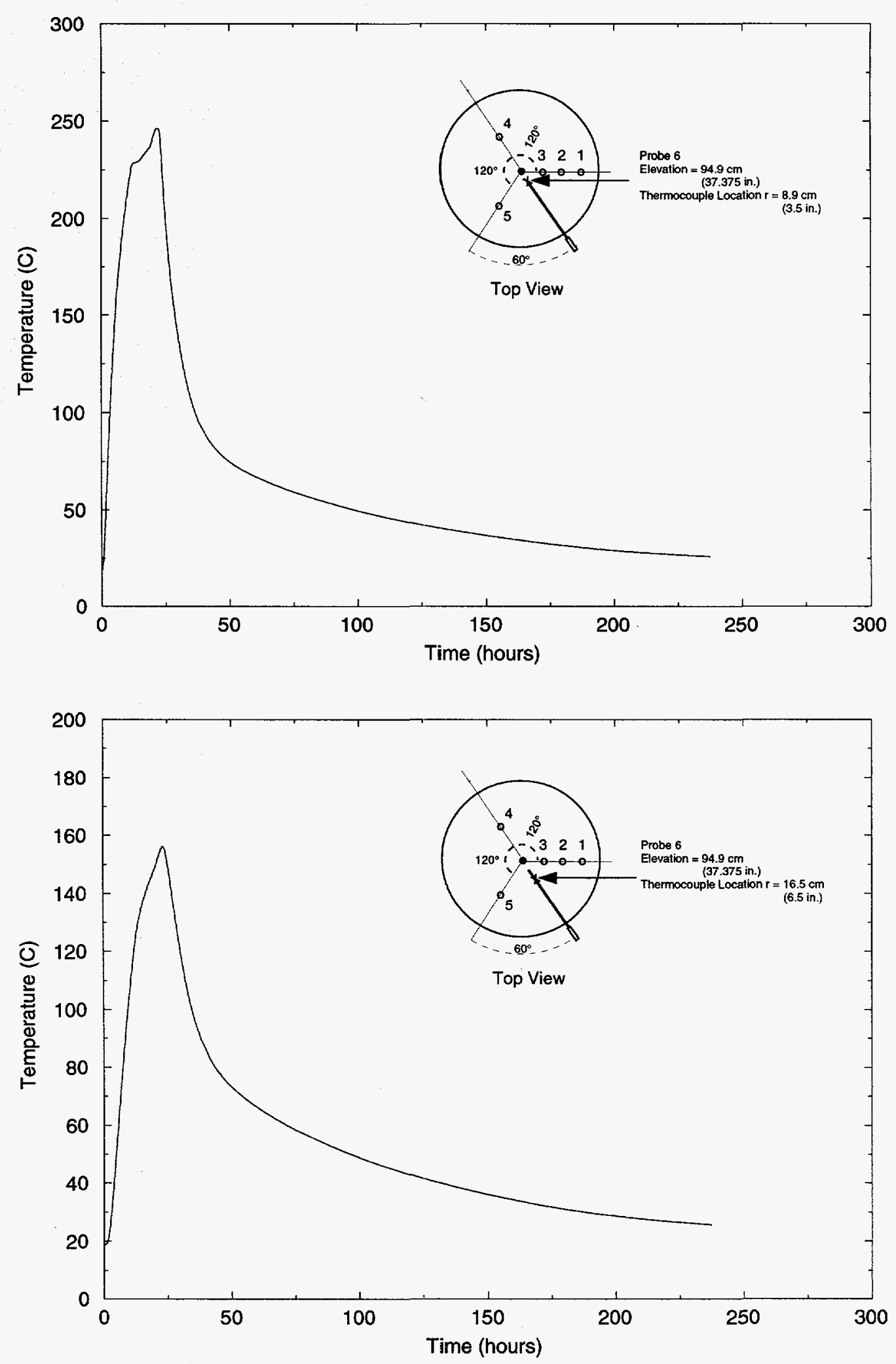

Figure B-5. Test 2 Temperature Data (continued) 

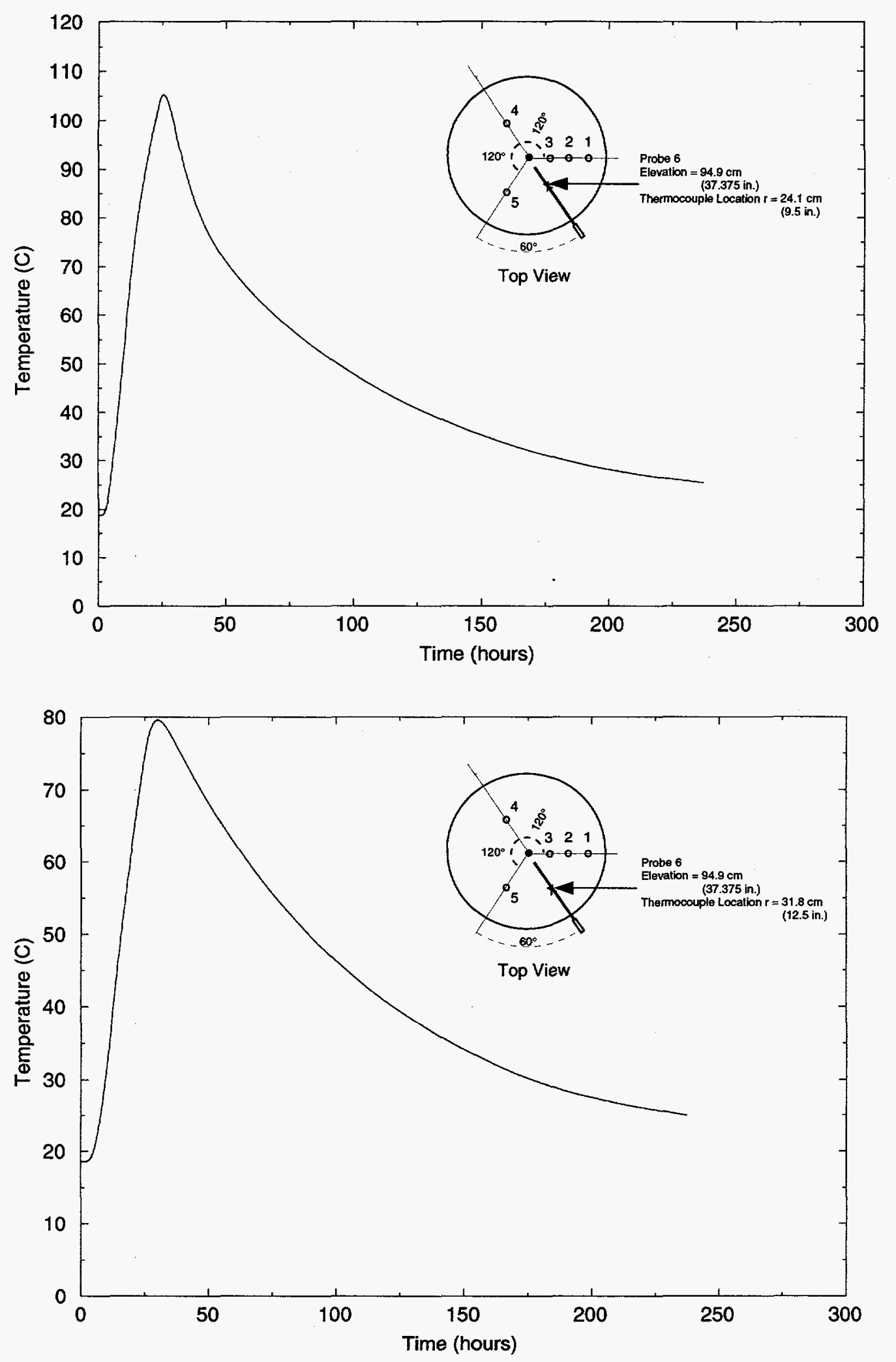

Figure B-5. Test 2 Temperature Data (continued) 

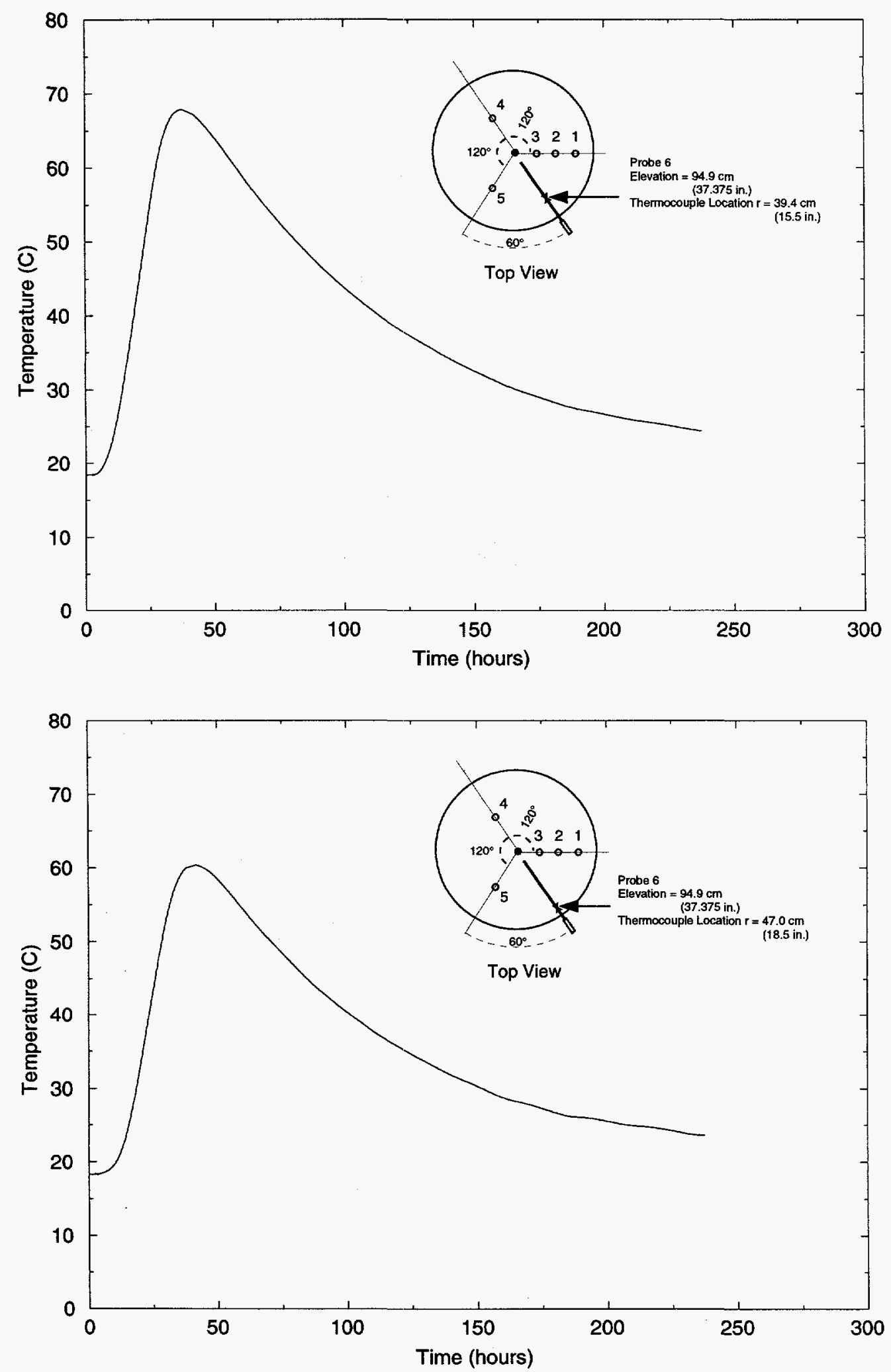

Figure B-5. Test 2 Temperature Data (continued) 

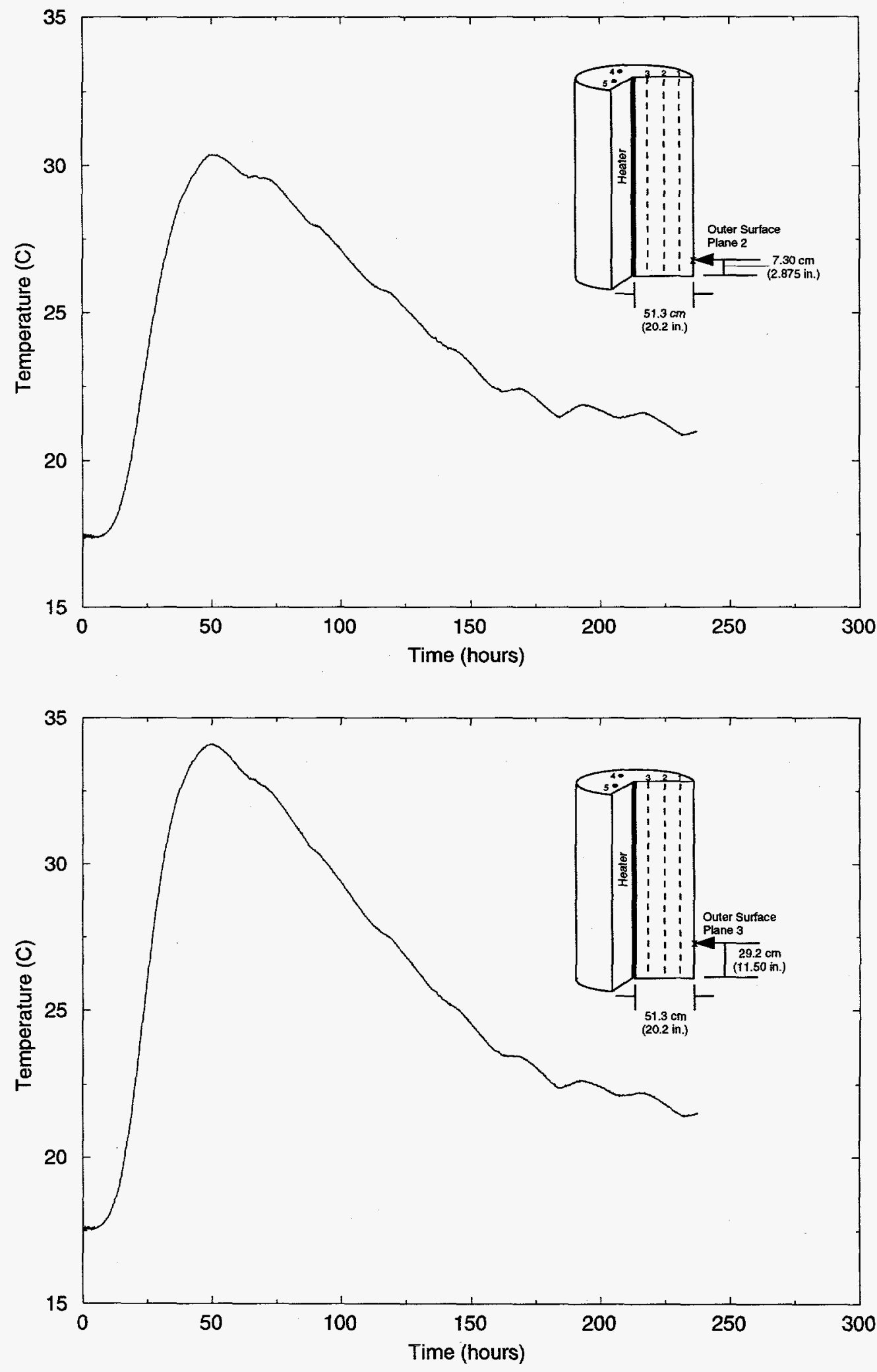

Figure B-5. Test 2 Temperature Data (continued) 

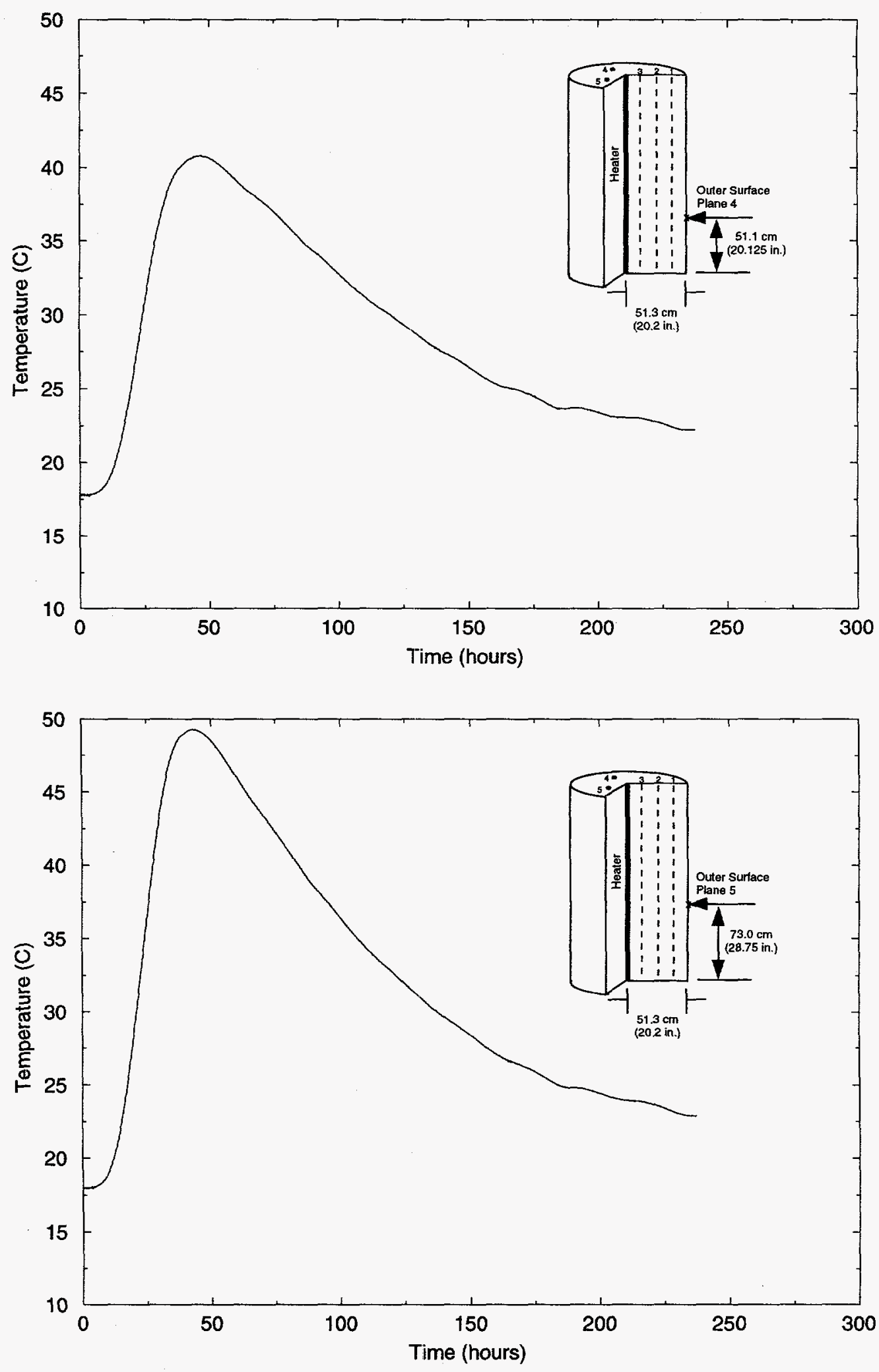

Figure B-5. Test 2 Temperature Data (continued) 

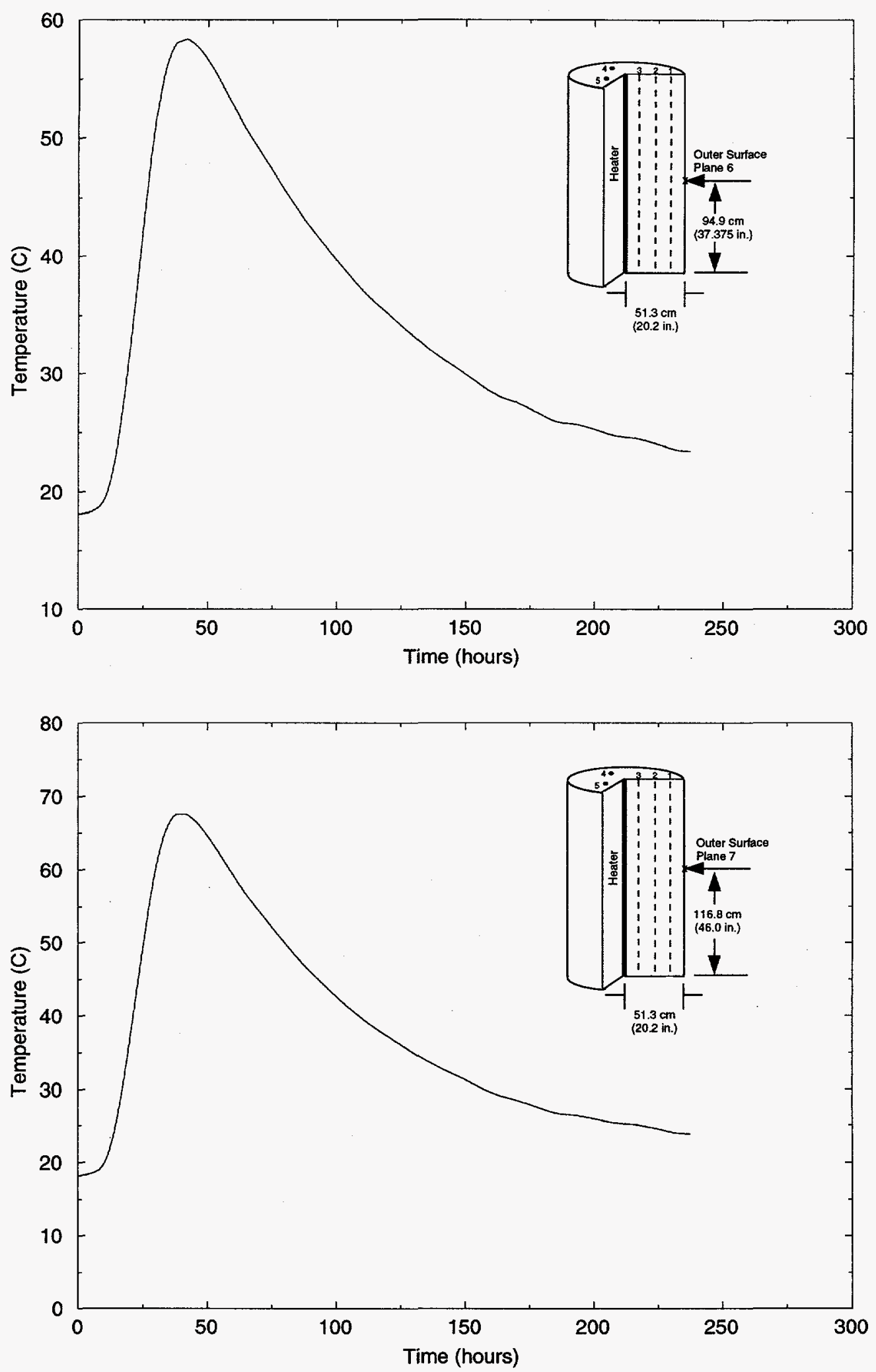

Figure B-5. Test 2 Temperature Data (continued) 

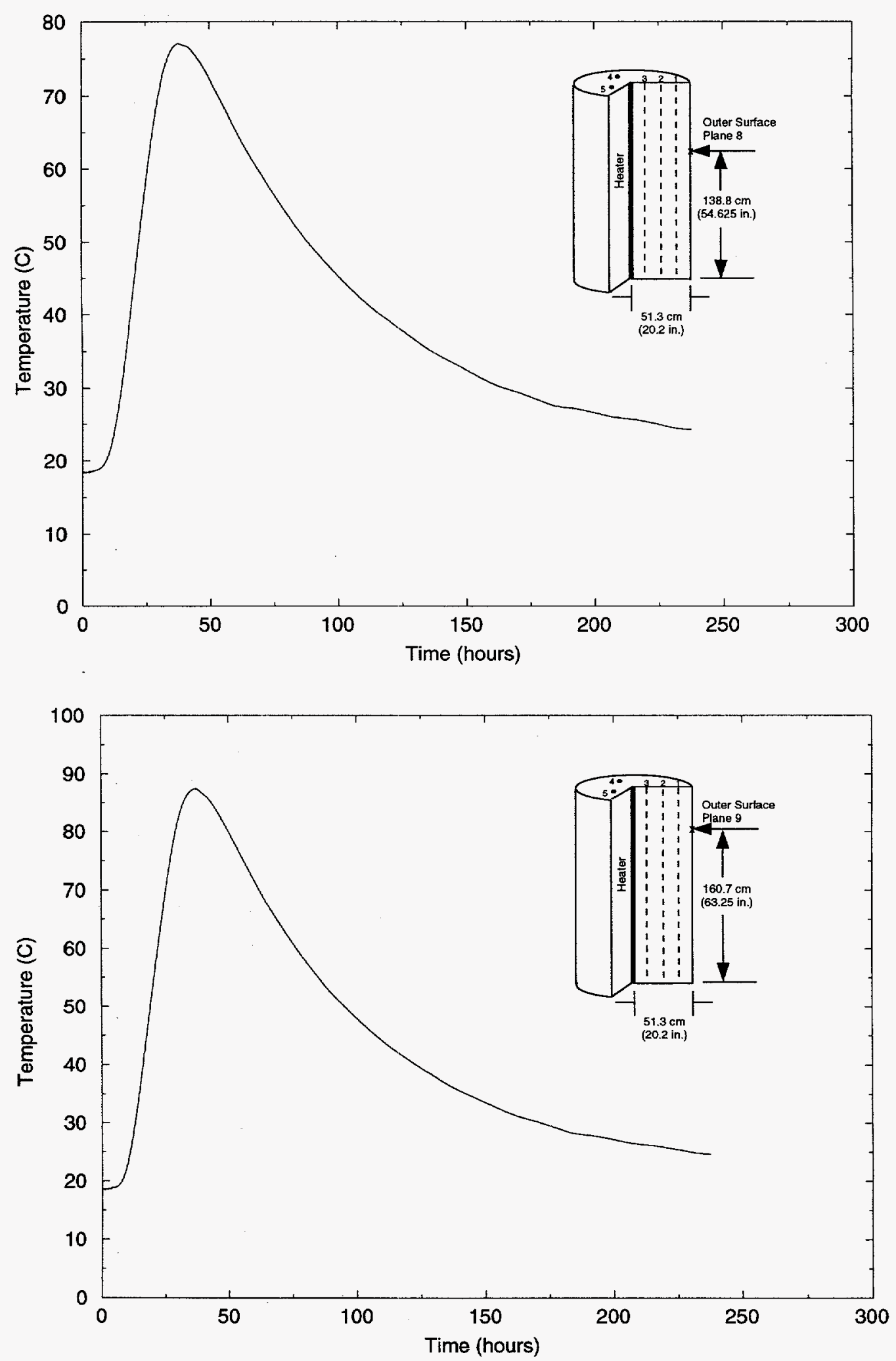

Figure B-5. Test 2 Temperature Data (continued) 

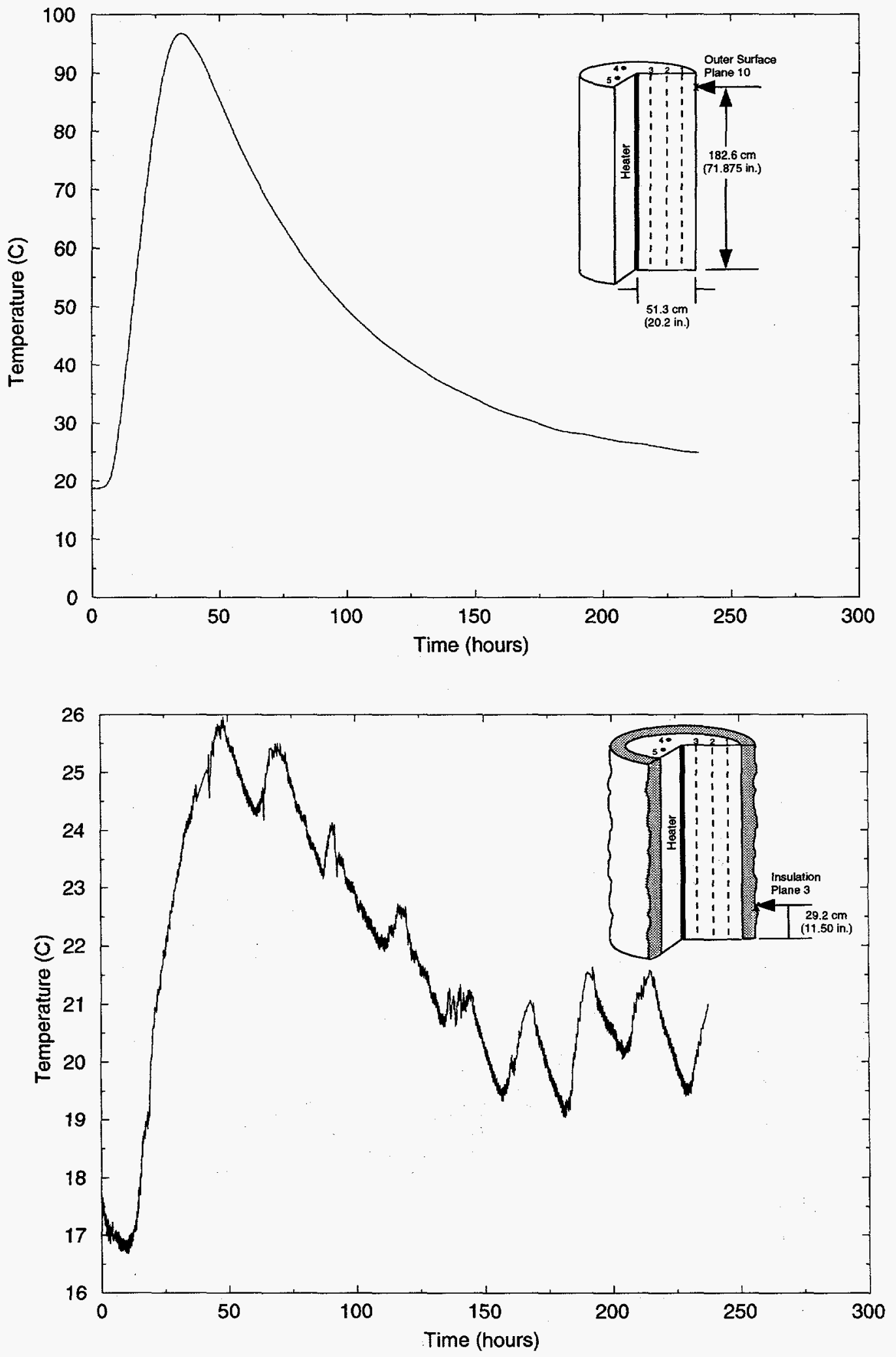

Figure B-5. Test 2 Temperature Data (continued) 

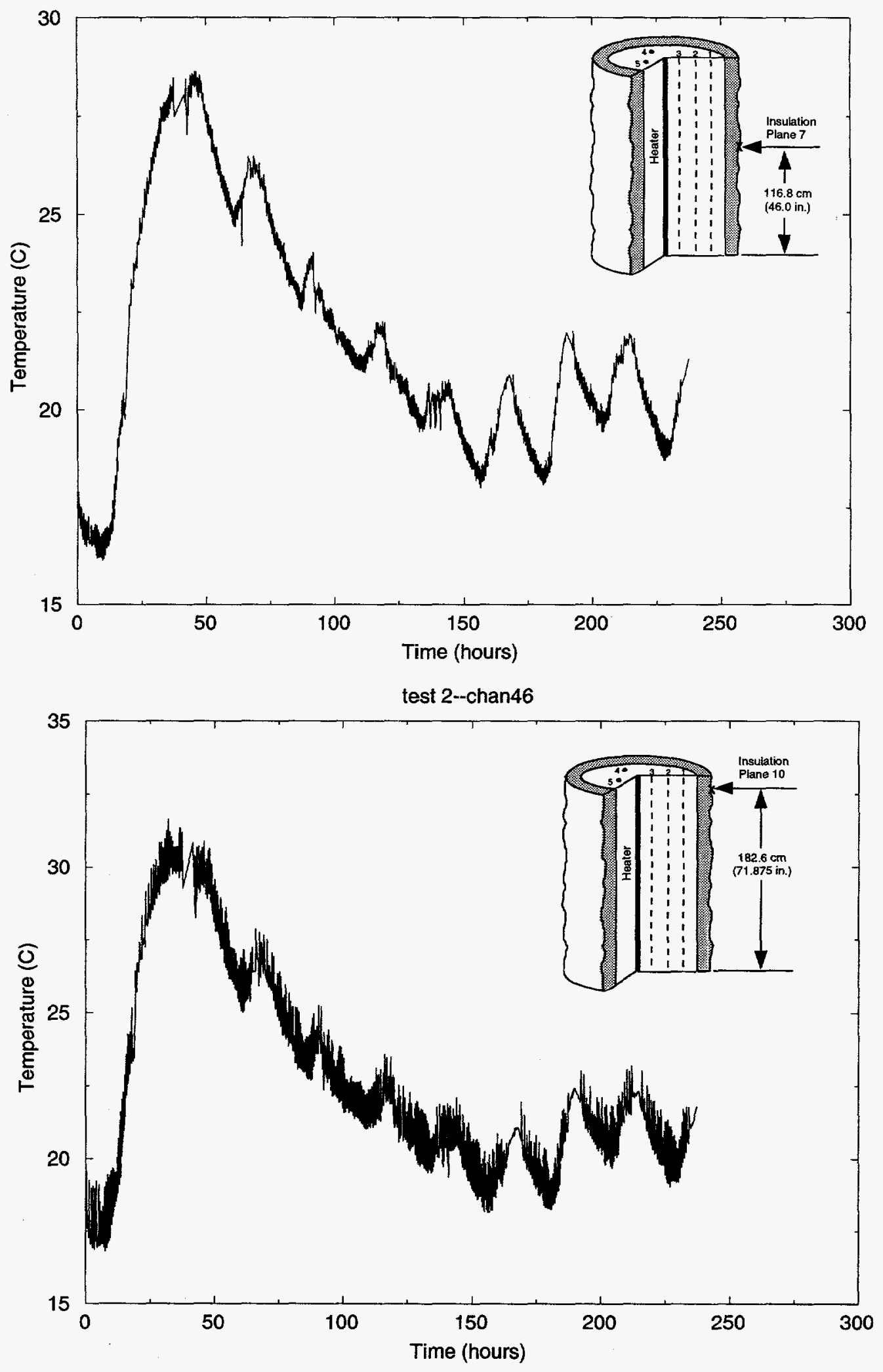

Figure B-5. Test 2 Temperature Data (continued) 


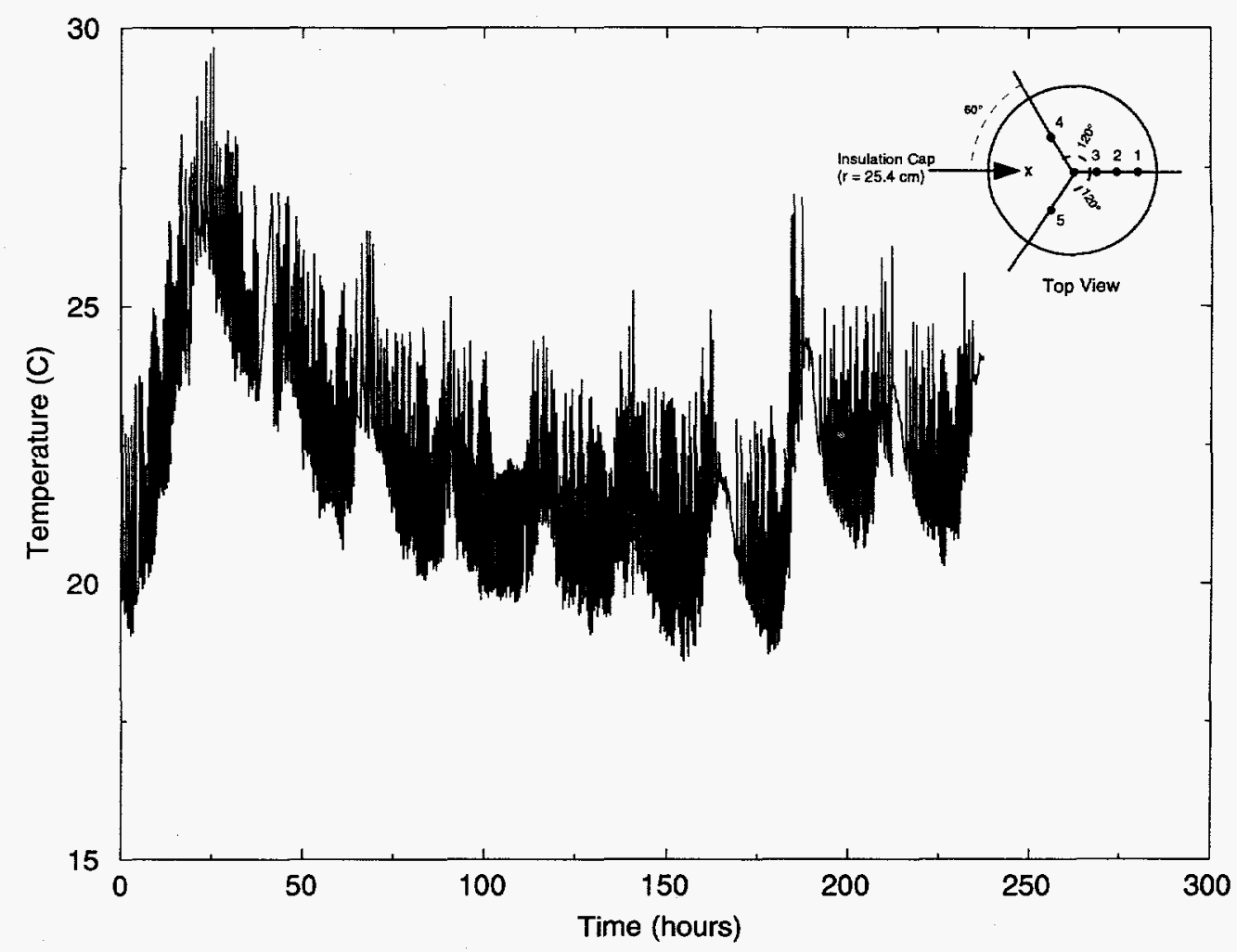

Figure B-5. Test 2 Temperature Data (concluded) 
This page has been intentionally left blank. 


\section{APPENDIX C}

RIB Appendix

Information from the Reference Information Base Used in this Report:

This report contains no information from the Reference Information Base.

Candidate Information for the Reference Information Base:

This report contains no candidate information for the Reference Information Base.

Candidate Information for the Geographic Nodal Information Study and Evaluation System:

This report contains no candidate information for the Geographic Nodal Information Study and Evaluation System. 
This page has been intentionally left blank. 


\section{YUCCA MOUNTAIN SITE CHARACTERIZATION PROJECT SAND 94-2320 DISTRIBUTION LIST}

D. A. Dreyfus (RW-1)

Director

OCRWM

US Department of Energy

1000 Independence Avenue SW

Washington, DC 20585

L. H. Barrett (RW-2)

Acting Deputy Director

OCRWM

US Department of Energy

1000 Independence Avenue SW

Washington, DC 20585

1

S. Rousso (RW-40)

Office of Storage and Transportation

OCRWM

US Department of Energy

1000 Independence Avenue SW

Washington, DC 20585

1

R. A. Milner (RW-30)

Office of Program Management

and Integration

OCRWM

US Department of Energy

1000 Independence Avenue SW

Washington, DC 20585

D. R. Elle, Director

Environmental Protection Division

DOE Nevada Field Office

US Department of Energy

P.O. Box 98518

Las Vegas, NV 89193-8518

1

T. Wood (RW-14)

Contract Management Division

OCRWM

US Department of Energy

1000 Independence Avenue SW

Washington, DC 20585

4

Victoria F. Reich, Librarian

Nuclear Waste Technical Review Board

1100 Wilson Blvd., Suite 910

Arlington, VA 22209

1 Wesley Barnes, Project Manager

Yucca Mountain Site Characterization

Office

US Department of Energy

P.O. Box 98608-MS 523

Las Vegas, NV 89193-8608
1

Director, Public Affairs Office

c/o Technical Information Resource Center

DOE Nevada Operations Office

US Department of Energy

P.O. Box 98518

Las Vegas, NV 89193-8518

8

Technical Information Officer

DOE Nevada Operations Office

US Department of Energy

P.O. Box 98518

Las Vegas, NV 89193-8518

1

J. R. Dyer, Deputy Project Manager

Yucca Mountain Site Characterization Office

US Department of Energy

P.O. Box 98608 - MS 523

Las Vegas, NV 89193-88608

M. C. Brady

Laboratory Lead for YMP

M\&O/Sandia National Laboratories

1261 Town Center Drive

Bldg. 4, Room 421A

Las Vegas, NV 89134

1

J. A. Canepa

Laboratory Lead for YMP

EES-13, Mail Stop J521

M\&O/Los Alamos National Laboratory

P.O. Box 1663

Los Alamos, NM 87545

1

Repository Licensing \& Quality

Assurance

Project Directorate

Division of Waste Management, MS T7J-9

US NRC

Washington, DC 20555

1 Senior Project Manager for Yucca

Mountain

Repository Project Branch

Division of Waste Management, MS T7J-9

US NRC

Washington, DC 20555

$1 \quad$ NRC Document Control Desk

Division of Waste Management, MS T7J-9

US NRC

Washington, DC 20555 
Chad Glenn

NRC Site Representative

301 E Stewart Avenue, Room 203

Las Vegas, NV 89101

1 Center for Nuclear Waste

Regulatory Analyses

Southwest Research Institute

6220 Culebra Road

Drawer 28510

San Antonio, TX 78284

W. L. Clarke

Laboratory Lead for YMP

M\&O/ Lawrence Livermore Nat'l Lab

P.O. Box 808 (L-51)

Livermore, CA 94550

1 Robert W. Craig

Acting Technical Project Officer/YMP

US Geological Survey

101 Convention Center Drive, Suite P-110

Las Vegas, NV 89109

1 J. S. Stuckless, Chief

Geologic Studies Program

MS 425

Yucca Mountain Project Branch

US Geological Survey

P.O. Box 25046

Denver, CO 80225

1 L. D. Foust

Technical Project Officer for YMP

TRW Environmental Safety Systems

101 Convention Center Drive

Suite P-110

Las Vegas, NV 89109

1 A. L. Flint

U. S. Geological Survey

MS 721

P. O. Box 327

Mercury, NV 89023

Robert L. Strickler

Vice President \& General Manager

TRW Environmental Safety Systems, Inc.

2650 Park Tower Dr.

Vienna, VA 22180

1
1

Records Specialist

US Geological Survey

MS 421

P.O. Box 25046

Denver, CO 80225

1

M. D. Voegele

Deputy of Technical Operations

M\&O/SAIC

101 Convention Center Drive

Suite P-110

Las Vegas, NV 89109

2

A. T. Tamura

Science and Technology Division

OSTI

US Department of Energy

P.O. Box 62

Oak Ridge, TN 37831

1 P. J. Weeden, Acting Director

Nuclear Radiation Assessment Div. US EPA

Environmental Monitoring Sys. Lab P.O. Box 93478

Las Vegas, NV 89193-3478

1 John Fordham, Deputy Director

Water Resources Center

Desert Research Institute

P.O. Box 60220

Reno, NV 89506

The Honorable Jim Regan

Chairman

Churchill County Board of

Commissioners

$10 \mathrm{~W}$. Williams Avenue

Fallon, NV 89406

R. R. Loux

Executive Director

Agency for Nuclear Projects

State of Nevada

Evergreen Center, Suite 252

1802 N. Carson Street

Carson City, NV 89710

Brad R. Mettam

Inyo County Yucca Mountain Repository Assessment Office P. O. Drawer L

Independence, CA 93526

US Bureau of Reclamation

Code D-8322

P.O. Box 25007

Denver, CO 80225-0007
Vernon E. Poe

Office of Nuclear Projects

Mineral County

P.O. Box 1600

Hawthome, NV 89415 
Les W. Bradshaw

Program Manager

Nye County Nuclear Waste Repository

Project Office

P.O. Box 1767

Tonopah, NV 89049

$1 \quad$ Florindo Mariani

White Pine County Coordinator

P. O. Box 135

Ely, NV 89301

1 Tammy Manzini

Lander County Yucca Mountain Information Officer

P.O. Box 10

Austin, NV 89310

1 Jason Pitts

Lincoln County Nuclear Waste

Program Manager

P. O. Box 158

Pioche, NV 89043

1 Dennis Bechtel, Coordinator

Nuclear Waste Division

Clark County Dept. of Comprehensive Planning

P.O. Box 55171

Las Vegas, NV 89155-1751

1 Juanita D. Hoffman

Nuclear Waste Repository

Oversight Program

Esmeralda County

P.O. Box 490

Goldfield, NV 89013

$1 \quad$ Sandy Green

Yucca Mountain Information Office

Eureka County

P.O. Box 714

Eureka, NV 89316

1 Economic Development Dept.

City of Las Vegas

400 E. Stewart Avenue

Las Vegas, NV 89101

1 Community Planning \& Development

City of North Las Vegas

P.O. Box 4086

North Las Vegas, NV 89030

$2 \quad$ Librarian

YMP Research \& Study Center

101 Convention Center Drive, Suite P-110

Las Vegas, NV 89109
1 Library Acquisitions

Argonne National Laboratory

Building 203, Room CE-111

9700 S. Cass Avenue

Argonne, IL 60439

$1 \quad$ Glenn Van Roekel

Manager, City of Caliente

P.O. Box 158

Caliente, NV 89008

G. S. Bodvarsson

Head, Nuclear Waste Department

Lawrence Berkeley National Laboratory

1 Cyclotron Road, MS 50E

Berkeley, CA 94720

1 Steve Hanauer (RW-2)

OCRWM

U. S. Department of Energy

1000 Independence Ave.

Washington, DC 20585

$1 \quad$ Victor Palciauskas

U.S. Nuclear Waste Technical Review Board

1100 Wilson Boulevard, Suite 910

Arlington, VA 22209

Randy Manteufel

Center for Nuclear Waste Regulatory Analysis

Southwest Research Instate

6220 Culebra Road

San Antonio, TX 78238-5166

1

Mark Balady

M\&O/TRW

101 Convention Center Drive

Las Vegas, NV 89109

1 Steven Saterlie

M\&O/TRW

101 Convention Drive

Las Vegas, NV 89109

Thomas Doering

M\&O/Framatome Cogema Fuels

101 Convention Center Drive

Las Vegas, NV 89109

MS

0977

1324

1325

1325

1325

1325

1325

1326

1326

1326

R. S. Longenbaugh, 9421

C. K. Ho, 6115

L. S. Costin, 6852

R. E. Finley, 6852

J. T. George, 6852

E. E. Ryder, 6852

S. R. Sobolik, 6852

G. E. Barr, 6851

N. D. Francis, 6851

J. H. Gauthier, 6851 
1326

$1 \quad 1395$

2

1330

20

1330

9018

0899

0619
M. L. Wilson, 6851

L. E. Shephard, 6800

B. Pierson, 6811

100/1215/SAND94-2320/QA

WMT Library, 6752

Central Technical Files, 8523-2

Technical Library, 4414

Review and Approval Desk, 12630 , For DOE/OSTI 